Márcio Dalla Valle Martino

TRANSISTORES DE TUNELAMENTO INDUZIDO POR EFEITO DE CAMPO APLICADOS A CIRCUITOS BÁSICOS 
Márcio Dalla Valle Martino

\section{TRANSISTORES DE TUNELAMENTO INDUZIDO POR EFEITO DE CAMPO APLICADOS A CIRCUITOS BÁSICOS}

Tese de Doutorado apresentada à Escola Politécnica da Universidade de São Paulo para a obtenção do título de Doutor em Ciências. 
Márcio Dalla Valle Martino

\section{TRANSISTORES DE TUNELAMENTO INDUZIDO POR EFEITO DE CAMPO APLICADOS A CIRCUITOS BÁSICOS}

Tese de Doutorado apresentada à Escola Politécnica da Universidade de São Paulo para a obtenção do título de Doutor em Ciências.

Área de Concentração:

Engenharia Elétrica / Microeletrônica.

Orientadora:

Profa. Dra. Paula Ghedini Der Agopian

\section{São Paulo}


Este exemplar foi revisado e corrigido em relação à versão original, sob responsabilidade única do autor e com a anuência de seu orientador.

São Paulo de de

Assinatura do autor:

Assinatura do orientador:

\section{Catalogação-na-publicação}

Martino, Márcio Dalla Valle

Transistores de tunelamento induzido por efeito de campo aplicados a circuitos básicos / M. D. V. Martino -- versão corr. -- São Paulo, 2018. $146 \mathrm{p}$.

Tese (Doutorado) - Escola Politécnica da Universidade de São Paulo. Departamento de Engenharia de Sistemas Eletrônicos.

1.Microeletrônica 2.Transistores 3.Circuitos analógicos 4.Tunelamento 5.Dispositivos novos I.Universidade de São Paulo. Escola Politécnica. Departamento de Engenharia de Sistemas Eletrônicos II.t. 


\section{DEDICATÓRIA}

Dedico este trabalho

Aos meus pais,

João Antonio Martino

Marinês Dalla Valle Martino

À minha irmã,

Fernanda Dalla Valle Martino

Aos meus avós,

Nicola Martino (in memorian)

Ottilia Coti Martino

Ivo Rubens Dalla Valle (in memorian)

Maria de Lourdes Bonazza Dalla Valle 
"Em algum lugar, alguma coisa incrível está esperando para ser descoberta."

Carl Sagan 


\section{AGRADECIMENTOS}

À professora e orientadora Paula Ghedini Der Agopian, pela dedicação, amizade e confiança depositada.

Aos meus pais, Marinês e João, à minha irmã, Fernanda, e à minha namorada, Silvia, pelo constante incentivo e pelos diários ensinamentos em mais esta etapa da minha vida.

Aos colegas do grupo SOI, pelas enriquecedoras discussões e pelo compartilhamento da experiência de cada membro.

Ao professor Cor Claeys, à professora Rita Rooyackers e ao IMEC pela disponibilidade da infraestrutura necessária para esta atividade de pesquisa.

Aos meus familiares e amigos, por todos os momentos especiais proporcionados e pelas alegrias compartilhadas.

A todos que de alguma forma colaboraram para a realização deste trabalho e que, de forma involuntária, foram aqui omitidos. 


\section{RESUMO}

Este trabalho apresenta o estudo de transistores de tunelamento controlados por efeito de campo, denominados TFETs. Foram realizadas análises com base em explicações teóricas, simulações numéricas e medidas experimentais para demonstrar a viabilidade do uso desta tecnologia em blocos de circuitos fundamentais, atuando como alternativa para permitir o contínuo escalamento de dispositivos.

A motivação para o uso de transistores com corrente principal resultante do tunelamento de banda para banda consiste na proposta de superar o limite físico de inclinação de sublimiar da tecnologia CMOS convencional de $60 \mathrm{mV} /$ década sob temperatura ambiente. Afinal, esta limitação impede a redução na tensão de alimentação de circuitos e, consequentemente, apresenta crescentes problemas quanto à dissipação de potência.

Com este objetivo, foram realizadas simulações numéricas de diversas geometrias alternativas visando atenuar as características indesejáveis dos TFETs, como a corrente ambipolar e a relativamente baixa relação lon/loff. Inicialmente foram definidos os modelos necessários para representar adequadamente os fenômenos relevantes sob variação de temperatura e é definida uma estrutura capaz de minimizar os efeitos da ambipolaridade. Posteriormente, medidas experimentais foram utilizadas para calibrar as simulações e estudar o efeito da temperatura e do dimensionamento no funcionamento de dispositivos desta tecnologia.

Comparando resultados práticos e simulados, nota-se como uma redução no comprimento de porta, com a consequente inserção de uma subposição (underlap) em relação à junção canal/dreno, e uma diminuição na temperatura permitem a obtenção de valores promissores de inclinação de sublimiar e de relação lon/loff.

Com base nestes resultados individuais, foram projetados circuitos básicos de aplicações analógicas, notadamente espelho de corrente e par diferencial, para a avaliação da viabilidade de duas diferentes estruturas de transistores de tunelamento. Foram realizadas medidas experimentais e simulações numéricas de ambos os circuitos com variações nas condições de polarização, na situação de descasamento entre os dispositivos e na temperatura de operação. O impacto em 
parâmetros fundamentais dos circuitos estudados, como a tensão de conformidade, a razão de espelhamento de corrente e o ganho de tensão diferencial, foi comparado para estruturas de tunelamento pontual (Point TFET), de tunelamento em linha (Line TFET) e de FinFETs.

Em relação aos circuitos de espelhos de corrente, observou-se alta tensão de conformidade e baixa dependência com a temperatura para os circuitos com transistores de tunelamento. O Point TFET ainda apresentava a vantagem adicional da baixa susceptibilidade ao descasamento do comprimento de canal, porém com a desvantagem da baixa magnitude da corrente de referência quando comparado ao espelho com Line TFETs ou FinFETs.

Já no caso de pares diferenciais, a maior tensão de conformidade foi obtida com FinFETs, enquanto os transistores de tunelamento apresentaram em comum a não degradação do ganho com a temperatura. Novamente o circuito com Point TFETs apresentou melhor resultado quando houve descasamento, enquanto que as outras duas tecnologias foram superiores quando ao ganho de tensão diferencial.

Dessa forma, foram propostas equações generalizadas para os parâmetros fundamentais de ambos os circuitos para as 3 tecnologias. De modo geral, foi possível validar, portanto, a viabilidade de transistores de tunelamento para a obtenção de dispositivos com bons parâmetros individuais e com bons impactos em circuitos analógicos fundamentais, reforçando a importância desta promissora tecnologia.

Palavras-chave: TFET, tunelamento de banda para banda, inclinação de sublimiar, impacto da temperatura, circuitos analógicos, FinFET, Point TFET, Line TFET. 


\section{ABSTRACT}

This works presents the study of tunneling field effect transistors, namely TFETs. Analyses have been performed based on theoretical explanations, numerical simulations and experimental data in order to show this technology suitability as part of basic circuit blocks, being an important alternative for the continuous devices scaling.

The basic idea of making use of band-to-band tunneling as the main current component comes from the possibility of reaching sub-60 mV/decade subthreshold slopes at room temperature, differently from conventional CMOS devices. After all, this physical limitation causes relevant power dissipation issues, since it requires relatively high power supply voltages.

Bearing this objective, numerical simulations of several alternative geometries have been performed in order to tackle TFETs disadvantages, such as the undesirable ambipolar currents and the low lon/loff ratio. At first, it was necessary to choose the most appropriate models to take into consideration the relevant phenomena under temperature variation and to define the physical structure in order to minimize ambipolar effects. After these analyses, experimental data have been used to calibrate simulation parameters and to study how temperature and physical dimensions affect the performance of devices based on this technology.

Comparing experimental and simulated results, it was possible to notice that when the structure is designed with gate underlap related to channel/drain junction and the temperature decreases, it was possible to obtain promising values for subthreshold slope and lon/loff ratio.

Based on the analyses of these individual results, basic analog circuits have been designed, namely current mirror and differential pair, so that two different tunneling devices structures have been highlighted. Experimental measurements and numeric simulations have been performed for both circuits, under different conditions in terms of bias voltages, channel length mismatch and operation temperature. The impact on fundamental circuit parameters, such as compliance voltage, current mirroring ratio and differential voltage gain, has been compared for circuits designed with Point TFETs, Line TFETs and FinFETs. 
Regarding current mirror circuits, the obtained results revealed higher values of compliance voltage and lower susceptibility to the temperature for circuits designed with tunneling transistors. In addition, Point TFETs provided the lowest susceptibility to channel length mismatch, but also the worst values of reference currents, when compared to circuits with Line TFETs and FinFETs.

Following the same procedure for differential pair, higher compliance voltage was obtained for FinFETs, while both tunneling transistors structures presented better behavior for differential voltage gain susceptibility to temperature variation. Once more, pairs with Point TFETs showed the best performance in terms of channel length mismatch, but the worst magnitude of differential voltage gain.

This way, general equations have been proposed to model relevant parameters for the circuits designed with each technology. From an overall point of view, it was possible to support the suitability of optimizing tunneling transistors in order to obtain devices with favorable individual parameters and positive impacts on essential analog circuits, reassuring the relevance of this promising technology.

Key-words: TFET, band-to-band tunneling, subthreshold slope, temperature impact, analog circuits, FinFET, Point TFET, Line TFET. 


\section{LISTA DE FIGURAS}

Figura 1 - Representação da Lei de Moore, onde o número de dispositivos no chip dobra aproximadamente a cada 18 meses.

Figura 2 - Esquema com as sucessivas propostas apresentadas para permitir contínuo escalamento de dispositivos.

Figura 3 - Evolução da tensão de alimentação e da tensão de limiar para tecnologias de $1,4 \mu \mathrm{m}$ a $65 \mathrm{~nm}$ com dispositivos CMOS convencionais

Figura 4 - Corrente de dreno em função da tensão de porta para três diferentes dispositivos, evidenciando o impacto da variação de $V_{\text {th }}$ em loff. 28

Figura 5 - Estimativa da evolução da potência estática e dinâmica para tecnologia MOS convencional.

Figura 6 - Comparação das inclinações de sublimiar previstas para uma chave ideal, um dispositivo MOS e um TFET. 34

Figura 7 - Seção transversal de um Point TFET do tipo $\mathrm{N}$ de porta dupla. 34

Figura 8 - Diagrama de bandas de energia para um n-Point TFET desligado. .35

Figura 9 - Diagrama de bandas de energia para um n-Point TFET ligado. .36

Figura 10 - Diagrama de bandas de energia representando predomínio de corrente $\mathrm{SRH}$.

Figura 11 - Diagrama de bandas de energia representando predomínio de corrente TAT. .38

Figura 12 - Diagrama de bandas de energia representando predomínio de corrente BTBT.

Figura 13 - Representação da variação do mecanismo de transporte predominante à medida que é alterada a tensão em uma determinada junção. 40

Figura 14 -Seção transversal de um Line TFET do tipo N. 42

Figura 15 -Diagrama de bandas de energia para um dispositivo Line TFET. 43

Figura 16 - Representação dos blocos de entrada e saída do programa Atlas. 46

Figura 17 - Largura da faixa proibida do silício em função da temperatura. .48

Figura 18 - Estrutura esquemática de um pTFET com alinhamento entre porta e fonte e subposição entre porta e dreno. A concentração de dopagem $\mathrm{N}+$ e P+é de $10^{20} \mathrm{~cm}^{-3}$ 
Figura 19 - Seção transversal de um NW-TFET obtida com microscopia eletrônica de transmissão.

Figura 20 - Estrutura esquemática de um NW-TFET.

Figura 21 - Corrente de dreno em função da tensão de porta para perfil de dopagem abrupto, com $V_{D S}=-1,5 \mathrm{~V}, \mathrm{~L}_{\mathrm{ch}}-\mathrm{LG}_{\mathrm{G}}=10 \mathrm{~nm}$ e $\mathrm{L}_{\mathrm{ch}}$ variando de 20 a 100nm.

Figura 22 - Corrente de dreno em função da tensão de porta para perfil de dopagem abrupto, $L_{c h}-L_{G}=10 \mathrm{~nm}, V_{D S}$ de $-1,5 \mathrm{~V}$ e $-0,05 \mathrm{~V}$ e $L_{c h}$ de $20 \mathrm{~nm}$ e $60 \mathrm{~nm}$. .58

Figura 23 - Diagrama de bandas de energia para perfil de dopagem abrupto, $L_{c h}-$ $L_{G}=10 n m$, $V_{D S}$ de $-1,5 \mathrm{~V}$ e $-0,05 \mathrm{~V}$ e $L_{c h}$ de $20 \mathrm{~nm}$ e $60 \mathrm{~nm}$ e $\mathrm{IDS}_{\mathrm{DS}}=10^{-7} \mathrm{~A} / \mu \mathrm{m} . . .59$ Figura 24 - Corrente de dreno em função da tensão de porta para $L_{c h}-L_{G}=10 \mathrm{~nm}$, $\mathrm{L}_{c h}=30 \mathrm{~nm}, \mathrm{~V}_{\mathrm{DS}}$ de $-1,5 \mathrm{~V}$ e -0,05V e perfis de dopagem abrupto e gaussiano. 60 Figura 25 - DIBT em função do comprimento de canal para $L_{c h}-L_{G}=10 \mathrm{~nm}$, $L_{c h}$ variando de 20 a 100nm e perfis de dopagem abrupto e gaussiano.

Figura 26 - DIBT em função do comprimento de canal para perfil de dopagem abrupto, $L_{c h}-L_{G}$ de $10 \mathrm{~nm}$ e $20 \mathrm{~nm}$ e $L_{c h}$ variando de 30 a $100 \mathrm{~nm}$.

Figura 27 - Corrente de dreno em função da tensão de porta para fontes com diferentes composições.

Figura 28 - Corrente de dreno experimental para temperatura variando de 25 a $150^{\circ} \mathrm{C}$. Duas diferentes estruturas de fonte foram analisadas: $\mathrm{Si}_{0,73 \mathrm{Ge}_{0,27} \mathrm{e}}$ Si $0,54 \mathrm{Ge}_{0,46 \text {. }}$

Figura 29 - Corrente de dreno experimental para temperatura variando de 25 a $150^{\circ} \mathrm{C}$. Duas diferentes técnicas de dopagem foram analisadas. .65

Figura 30 - Energia de ativação para diferentes composições de fonte. 66

Figura 31 - Corrente de dreno em função da tensão de dreno para diferentes composições de fonte.

Figura 32 - Eficiência do transistor $\left(g_{m} / l_{D S}\right)$ experimental em função da temperatura para diferentes composições de fonte. Gráfico inserido: Eficiência do transistor em função da corrente de dreno.

Figura 33 - Tensão de Early em função da temperatura para diferentes composições de fonte. .69

Figura 34 - Transcondutância para diferentes composições de fonte. 70

Figura 35 - Condutância de saída para diferentes composições de fonte. 71

Figura 36 - Ganho intrínseco de tensão em função da temperatura para diferentes composições de fonte. 
Figura 37 - Representação da estrutura dos dispositivos medidos Point TFETs e FinFETs.

Figura 38 - Vista superior da estrutura, com destaque às dopagens para o caso de

Point TFETS. .74

Figura 39 - Representação da estrutura dos dispositivos medidos Line TFETs......75

Figura 40 - Vista lateral da estrutura Line TFET ......................................... 76

Figura 41 - Circuitos básicos de espelho de corrente (a) com transistores do tipo P e (b) com transistores do tipo $\mathrm{N}$. .77

Figura 42 - Corrente de dreno em função da tensão de porta para Point TFETs e FinFETs com diferentes valores de comprimento de canal..... .78

Figura 43 - Corrente de dreno em função de $V_{D 2}$ para Point TFETs com diferentes larguras e comprimentos de canal. .79

Figura 44 - Corrente de dreno em função de $V_{D 2}$ para FinFETs com diferentes larguras e comprimentos de canal.

Figura 45 - Razão entre IDS2 e IDS1 em função de VD2 para espelhos de corrente de Point TFETs e FinFETs com largura de canal de $1 \mu \mathrm{m}$ e comprimento de canal de $10 \mu \mathrm{m}$.

Figura 46 - Resultados experimental e simulado da corrente de dreno em função da tensão de porta para Point TFET tipo P. 82

Figura 47 - Razão entre IDS2 e IDS1 em função de VD2 para espelhos de corrente de Point TFETs com comprimento de canal do transistor $T_{2}$ variando de 20 a $100 \mathrm{~nm}$.

Figura 48 - Razão entre IDS2 e IDS1 em função de $V_{D 2}$ para espelhos de corrente de FinFETs com comprimento de canal do transistor $\mathrm{T}_{2}$ variando de 20 a $100 \mathrm{~nm}$.

Figura 49 - Razão entre IDS2 e IDS1 em função de L2 para circuitos de espelho de corrente com Point TFETs e com FinFETs para $\mathrm{V}_{\mathrm{D} 2}$ variando de $-0,5 \mathrm{~V}$ a $+0,5 \mathrm{~V}$.

Figura 50 - Corrente de dreno em função de $V_{D 2}$ para Point TFETs com temperatura variando de 300 a $500 \mathrm{~K}$.

Figura 51 - Corrente de dreno em função de $V_{D 2}$ para FinFETs com temperatura variando de 300 a $500 \mathrm{~K}$. 86

Figura 52 - IDS2 $(T) / I_{D S 1}(300 K)$ em função da temperatura para espelhos de corrente de Point TFETs e de FinFETs com V Variando de $-0,5 \mathrm{~V}$ a $+0,5 \mathrm{~V}$ 
Figura 53 - $\operatorname{IDS} 2(T) / \operatorname{lDS}_{1}(300 \mathrm{~K})$ em função da temperatura para espelhos de corrente de Point TFETs e de FinFETs com L2 variando de $20 \mathrm{~nm}$ a $100 \mathrm{~nm}$.

Figura 54 - Corrente de dreno em função da tensão de porta para Line TFETs com diferentes valores de tensão de dreno e de comprimento e largura de canal. ...90 Figura 55 - Corrente de dreno em função da tensão de dreno para Line TFETs com diferentes valores de tensão de porta e de comprimento e largura de canal.....91

Figura 56 - Estrutura básica de um Line TFET com subposição da porta em relação ao canal... 92

Figura 57 - Razão de espelhamento de corrente em função de $V_{D 2}$ para diferentes valores de tensão de porta.

Figura 58 - Corrente de dreno em função da tensão de porta para Line TFETs com diferentes temperaturas e dimensões.

Figura 59 - Corrente de dreno em função da tensão de dreno para Line TFETs com diferentes temperaturas e dimensões.

Figura 60 - Energia de ativação em função da tensão de porta para Line TFETs com diferentes dimensões.

Figura 61 - Razão de espelhamento de corrente em função de $V_{D 2}$ para diferentes temperaturas.

Figura 62 - Razão de espelhamento de corrente em função da temperatura para diferentes dimensões do transistor $T_{1}$.

Figura 63 - Razão de espelhamento de corrente em função da razão entre as áreas de canal dos transistores $\mathrm{T}_{2}$ e $\mathrm{T}_{1}$ para diferentes temperaturas.

Figura 64 - Plano de corte de uma estrutura de nanofio vertical. .........................102

Figura 65 - Representação esquemática da estrutura de um Point TFET e um

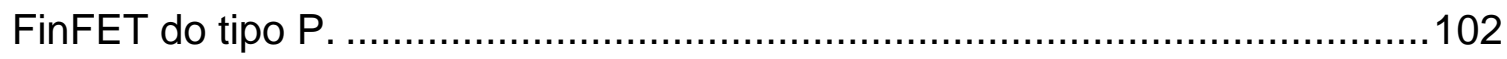

Figura 66 - Circuitos básicos de pares diferenciais (a) com carga passiva e (b) com carga ativa. 104

Figura 67 - IDS1/Iss e lDs2/Iss em função da tensão de entrada diferencial vid para um par diferencial balanceado com Point TFETs ou FinFETs. 106

Figura 68 - Variação do ganho diferencial $\left(A_{d}\left(L_{2}\right) / A_{d}(60 n m)\right)$ em função do comprimento de canal $\left(\mathrm{L}_{2}\right)$ do transistor $\mathrm{T}_{2}$. 108

Figura 69 - Variação do ganho de modo comum $\left(\mathrm{A}_{\mathrm{CM}}\left(\mathrm{L}_{2}\right) / \mathrm{Acm}_{\mathrm{c}}(60 \mathrm{~nm})\right)$ em função do comprimento de canal $\left(L_{2}\right)$ do transistor $T_{2}$. 109 
Figura 70 - Variação da taxa de rejeição de modo comum $\left(\mathrm{CMRR}\left(\mathrm{L}_{2}\right)\right.$ / CMRR(60nm)) em função do comprimento de canal ( $\left.L_{2}\right)$ do transistor $T_{2} \ldots . . .110$ Figura 71 - Tensões de dreno em função da tensão de entrada diferencial Vid para um par diferencial balanceado com Point TFETs ou FinFETs.

Figura 72 - IDS1/Iss e IDS2/Iss em função da tensão de entrada diferencial Vid para um par diferencial balanceado com Point TFETs ou FinFETs.

Figura 73 - Ganho de tensão diferencial para temperaturas de 300 a 450K. 114

Figura 74 - Ganho de tensão de modo comum para temperaturas de 300 a $450 \mathrm{~K}$.

Figura 75 - Taxa de rejeição de modo comum para temperaturas de 300 a 450K. 115 Figura 76 - Corrente de dreno em função da tensão de porta para Line TFETs com diferentes dimensões.

Figura 77 - Corrente de dreno em função da tensão de dreno para Line TFETs com diferentes dimensões.

Figura 78 - Transcondutância em função da tensão de porta para Line TFETs com diferentes dimensões.

Figura 79 - Corrente de dreno normalizada em função da tensão de entrada diferencial para Line TFETs com diferentes dimensões 119

Figura 80 - Ganho de tensão diferencial em função de Vss para pares de Line TFETs com diferentes dimensões. 120

Figura 81 - Corrente de dreno em função da tensão de porta para Line TFETs com diferentes dimensões, tensões de dreno e temperaturas. 122

Figura 82 - Corrente de dreno em função da tensão de dreno para Line TFETs com diferentes dimensões, tensões de porta e temperaturas.

Figura 83 - Transcondutância em função da tensão de porta para Line TFETs com diferentes dimensões, tensões de dreno e temperaturas. 123

Figura 84 - Corrente de dreno normalizada em função da tensão de entrada diferencial para pares de Line TFETs com diferentes temperaturas. 124

Figura 85 - Ganho de tensão diferencial em função da temperatura para pares de Line TFETs com diferentes dimensões. 


\section{LISTA DE TABELAS}

Tabela 1 - Modelos adotados para simulações dos dispositivos TFETs. .................51

Tabela 2 - Comparação das características de espelhos de corrente projetados com dispositivos FinfETs, Point TFETs e Line TFETs......................................100

Tabela 3 - Comparação das características de pares diferenciais projetados com dispositivos FinFETs, Point TFETs e Line TFETs.......................................127 


\section{LISTA DE ABREVIATURAS E SIGLAS}

BTBT Tunelamento de banda para banda

CMOS Estrutura metal-óxido-semicondutor complementar

CMRR Taxa de rejeição de modo comum

DIBT Estreitamento da barreira de tunelamento induzido pela tensão de dreno

FinFET Transistor de efeito de campo com estrutura em aletas (fins)

GaAs Arseneto de gálio

GND Nível de tensão de referência

$\mathrm{HfO}_{2} \quad$ Óxido de háfnio

InAs Arseneto de índio

i-Si Silício intrínseco

MOS Estrutura Metal-óxido-semicondutor

MOSFET Transistor de efeito de campo com estrutura metal-óxido-semicondutor

NW-TFET Transistor de tunelamento controlado por efeito de campo em estrutura de nanofio

Si Silício

SiGe Silício-germânio

$\mathrm{SiO}_{2} \quad$ Óxido de silício

SOI Silício sobre isolante

SPICE Programa de simulação com ênfase em circuitos integrados

SRH Schockley-Read-Hall

TAT Tunelamento induzido por armadilhas

TFET Transistor de tunelamento controlado por efeito de campo

TiN Nitreto de titânio 


\section{LISTA DE SÍMBOLOS}

Ad

$A_{c m}$

$A v$

BB.A

BB.B

BBT.GAMMA

BBT.A_KANE
Ganho de tensão diferencial [V/V]

Ganho de tensão de modo comum [V/V]

Ganho de tensão de malha aberta em baixa frequência [dB]

Parâmetro de ajuste da taxa de geração de tunelamento

Parâmetro de ajuste da taxa de geração de tunelamento [V/cm]

Parâmetro de ajuste da taxa de geração de tunelamento

Parâmetro de ajuste da taxa de geração de tunelamento $\left[\mathrm{eV}^{1 / 2} \cdot \mathrm{cm}^{-1} \cdot \mathrm{s}^{-1} \cdot \mathrm{V}^{-2}\right]$

BBT.B_KANE Parâmetro de ajuste da taxa de geração de tunelamento $\left[\mathrm{V} . \mathrm{cm}^{-1} \cdot \mathrm{eV}^{-3 / 2}\right]$

BBT.GAMMA Parâmetro de ajuste da taxa de geração de tunelamento

$\mathrm{C}_{\text {total }}$

Capacitância equivalente $[\mathrm{F}]$

D

Diâmetro do nanofio [nm]

$\mathrm{E}$

$E_{A}$

Ec

$\mathrm{E}_{\mathrm{g}}$

$\mathrm{E}_{\mathrm{i}}$

$E_{n}$

$E_{p}$

$E_{t}$

ETRAP

Ev

$\mathrm{F}$

$f$

GBBT

gD

$g_{m}$
Campo elétrico aplicado na estrutura [V/cm]

Energia de ativação [eV]

Nível energético de condução [V]

Largura de faixa proibida [V]

Nível energético intrínseco [V]

Nível energético dos elétrons [V]

Nível energético das lacunas [V]

Nível energético das armadilhas [V]

Diferença entre o nível de energia da armadilha e o nível de Fermi intrínseco [V]

Nível energético de valência [V]

Campo elétrico aplicado na estrutura [V/cm]

Frequência de chaveamento [Hz]

Taxa de geração de tunelamento

Condutância de saída do transistor [S]

Transcondutância do transistor [S] 


\begin{tabular}{|c|c|}
\hline$g_{m} / l_{D S}$ & $\begin{array}{l}\text { Relação entre a transcondutância e a corrente de dreno do } \\
\text { transistor MOS }\left[\mathrm{V}^{-1}\right]\end{array}$ \\
\hline h & Constante de Planck $\left(4,135667 \times 10^{-15}\right.$ eV.s $)$ \\
\hline$\hbar$ & Constante de Planck reduzida $\left(6,582119 \times 10^{-16} \mathrm{eV} . \mathrm{s}\right)$ \\
\hline IDS & Corrente entre dreno e fonte de dispositivos $[\mathrm{A}]$ \\
\hline lDS1 & Corrente entre dreno e fonte de dispositivos de entrada $[A]$ \\
\hline IDS2 & Corrente entre dreno e fonte de dispositivos de saída $[A]$ \\
\hline lofF & Corrente entre dreno e fonte de dispositivos desligados $[\mathrm{A}]$ \\
\hline lon & Corrente entre dreno e fonte de dispositivos acionados $[\mathrm{A}]$ \\
\hline IREF & Corrente de referência $[A]$ \\
\hline Iss & Corrente de referência $[A]$ \\
\hline k & Constante de Boltzmann $\left[1,38066 \times 10^{-23} \mathrm{~J} / \mathrm{K}\right]$ \\
\hline $\mathrm{K}_{\mathrm{n}}$ & $\begin{array}{l}\text { Componente para cálculo do incremento do campo dos elétrons } \\
\text { para poços de Dirac }\end{array}$ \\
\hline $\mathrm{K}_{\mathrm{p}}$ & $\begin{array}{l}\text { Componente para cálculo do incremento do campo das lacunas } \\
\text { para poços de Dirac }\end{array}$ \\
\hline $\mathrm{L}_{1}$ & Comprimento de canal de dispositivo de entrada [nm] \\
\hline $\mathrm{L}_{2}$ & Comprimento de canal de dispositivo de saída [nm] \\
\hline $\mathrm{L}_{3}$ & Comprimento de canal de dispositivo de carga $T_{3}[\mathrm{~nm}]$ \\
\hline $\mathrm{L}_{4}$ & Comprimento de canal de dispositivo de carga $\mathrm{T}_{4}[\mathrm{~nm}]$ \\
\hline Lef & Comprimento de canal efetivo [nm] \\
\hline Lef1 & Comprimento de canal efetivo do dispositivo de entrada [nm] \\
\hline Let2 & Comprimento de canal efetivo do dispositivo de saída [nm] \\
\hline$L_{G}$ & Comprimento de porta $[\mathrm{nm}]$ \\
\hline LGD & Comprimento de sobreposição de porta em relação ao dreno [nm] \\
\hline LGS & Comprimento de sobreposição de porta em relação à fonte [nm] \\
\hline Lch & Comprimento de canal $[\mathrm{nm}]$ \\
\hline $\mathrm{m}$ & Parâmetro de ajuste da susceptibilidade às dimensões \\
\hline mo & Massa do elétron em repouso $[\mathrm{kg}]$ \\
\hline MASS.TUNNEL & Massa efetiva do elétron $[\mathrm{kg}]$ \\
\hline $\mathrm{N}_{\mathrm{A}}$ & Concentração de impurezas aceitadoras $\left[\mathrm{cm}^{-3}\right]$ \\
\hline NW & Quantidade de nanofios em paralelo \\
\hline
\end{tabular}




\begin{tabular}{|c|c|}
\hline $\mathrm{n}$ & Concentração de elétrons $\left[\mathrm{cm}^{-3}\right]$ \\
\hline $\mathrm{n}_{\mathrm{i}}$ & Concentração intrínseca de portadores $\left[\mathrm{cm}^{-3}\right]$ \\
\hline $\mathrm{p}$ & Concentração de lacunas $\left[\mathrm{cm}^{-3}\right]$ \\
\hline$P_{\text {dinâmica }}$ & Potência dissipada por chaveamento [W] \\
\hline Pestática & Potência dissipada por correntes de fuga [W] \\
\hline q & Carga elementar do elétron $\left[1,6 \times 10^{-19} \mathrm{C}\right]$ \\
\hline ro & Resistência de saída do transistor $[\Omega]$ \\
\hline $\mathrm{RD}_{\mathrm{D}}$ & Resistência de carga $[\Omega]$ \\
\hline RsRH & Taxa de recombinação Schockley-Read-Hall \\
\hline $\mathrm{T}$ & Temperatura absoluta $[\mathrm{K}]$ \\
\hline $\mathrm{TL}_{\mathrm{L}}$ & Temperatura absoluta da estrutura simulada $[\mathrm{K}]$ \\
\hline TAUNO & Tempo de vida dos elétrons [s] \\
\hline TAUPO & Tempo de vida das lacunas [s] \\
\hline$T_{L}$ & Temperatura da estrutura do dispositivo $[\mathrm{K}]$ \\
\hline tox & Espessura do óxido de porta [nm] \\
\hline u & Variável de integração \\
\hline $\mathrm{V}_{\mathrm{CC}}$ & Tensão de alimentação [V] \\
\hline$V_{D}$ & Tensão de dreno do transistor [V] \\
\hline$V_{D 1}$ & Tensão de dreno do transistor de entrada [V] \\
\hline $\mathrm{V}_{\mathrm{D} 2}$ & Tensão de dreno do transistor de saída [V] \\
\hline$V_{D D}$ & Tensão de alimentação [V] \\
\hline$V_{D S}$ & Tensão entre dreno e fonte do transistor [V] \\
\hline VDS1 & Tensão entre dreno e fonte do transistor de entrada [V] \\
\hline VDS2 & Tensão entre dreno e fonte do transistor de saída [V] \\
\hline$V_{E A}$ & Tensão de Early [V] \\
\hline$V_{G}$ & Tensão de porta do transistor [V] \\
\hline$V_{G 1}$ & Tensão de porta do transistor de entrada [V] \\
\hline $\mathrm{V}_{\mathrm{G} 2}$ & Tensão de porta do transistor de saída [V] \\
\hline$V_{G S}$ & Tensão entre porta e fonte do transistor [V] \\
\hline $\mathrm{V}_{\mathrm{GS} 1}$ & Tensão entre porta e fonte do transistor de entrada [V] \\
\hline VGS2 & Tensão entre porta e fonte do transistor de saída [V] \\
\hline Vicm & Tensão de entrada de modo comum [V] \\
\hline
\end{tabular}




\begin{tabular}{|c|c|}
\hline Vid & Tensão de entrada diferencial [V] \\
\hline Vin1 & Tensão de entrada no transistor $\mathrm{T}_{1}[\mathrm{~V}]$ \\
\hline Vin2 & Tensão de entrada no transistor $\mathrm{T}_{2}[\mathrm{~V}]$ \\
\hline Vout & Tensão de saída do circuito [V] \\
\hline$V_{s}$ & Tensão de fonte do transistor [V] \\
\hline$V_{\text {S1 }}$ & Tensão de fonte do transistor de entrada [V] \\
\hline$V_{\mathrm{S} 2}$ & Tensão de fonte do transistor de saída [V] \\
\hline$V_{s s}$ & Tensão de alimentação [V] \\
\hline$V_{\text {th }}$ & Tensão de limiar do transistor [V] \\
\hline $\mathrm{W}_{1}$ & Largura de canal de dispositivo de entrada [nm] \\
\hline$W_{2}$ & Largura de canal de dispositivo de saída [nm] \\
\hline$W_{3}$ & Largura de canal de dispositivo de carga $T_{3}[\mathrm{~nm}]$ \\
\hline $\mathrm{W}_{4}$ & Largura de canal de dispositivo de carga $T_{4}[\mathrm{~nm}]$ \\
\hline$W_{\text {ef }}$ & Largura de canal efetiva $[\mathrm{nm}]$ \\
\hline$W_{\text {ef1 }}$ & Largura de canal efetiva do dispositivo de entrada [nm] \\
\hline$W_{\text {ef2 }}$ & Largura de canal efetiva do dispositivo de saída [nm] \\
\hline$\Gamma_{\mathrm{n}} \mathrm{DIRAC}$ & Incremento do campo dos elétrons para poços de Dirac \\
\hline$\Gamma_{\mathrm{p}} \mathrm{DIRAC}$ & Incremento do campo das lacunas para poços de Dirac \\
\hline
\end{tabular}




\section{SUMÁRIO}

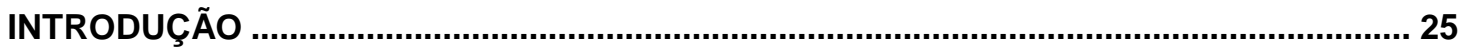

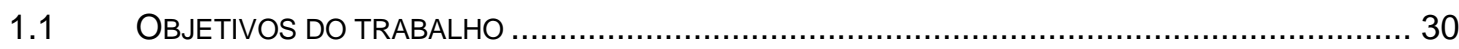

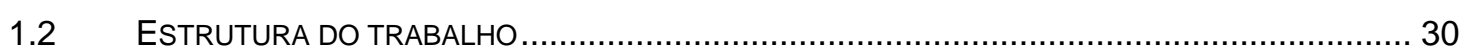

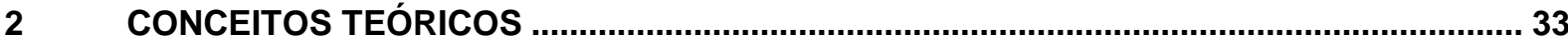

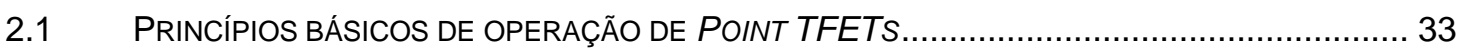

2.2 COMPONENTES DA CORRENTE DE TUNELAMENTO ……............................................. 36

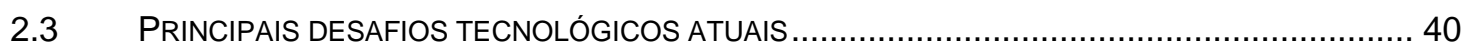

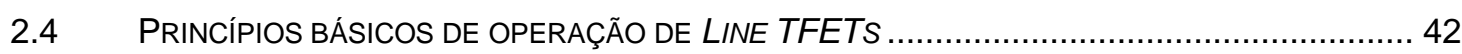

2.5 PROPOSTAS DE CIRCUITOS BÁSICOS COM TRANSISTORES DE TUNELAMENTO .................... 43

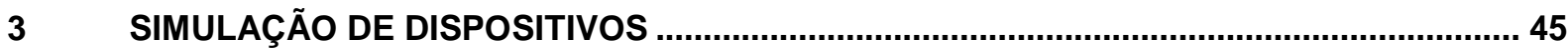

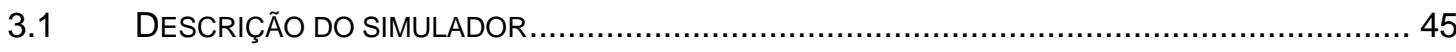

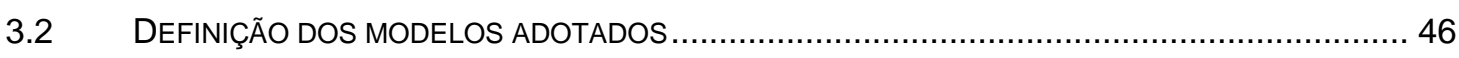

3.3 COMPARAÇÃO DO IMPACTO DA TEMPERATURA EM CADA MECANISMO DE TRANSPORTE .......51

4 PERFORMANCE DE DISPOSITIVOS TFETS IMPLEMENTADOS EM ESTRUTURA DE

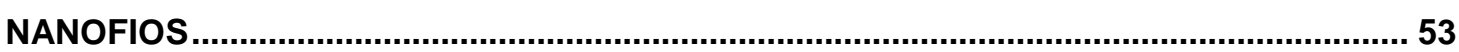

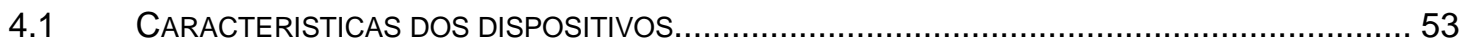

4.2 IMPACTO DA ESTRUTURA NO ESTREITAMENTO DA BARREIRA DE TUNELAMENTO INDUZIDO

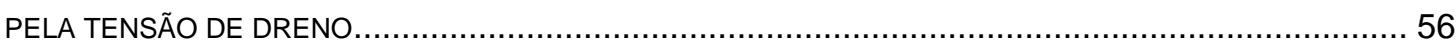

4.3 IMPACTO DA TEMPERATURA E DOS MECANISMOS DE TRANSPORTE NO COMPORTAMENTO

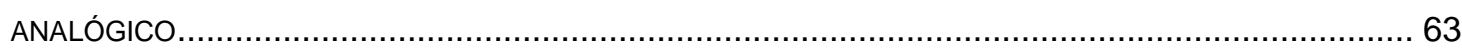

$5 \quad$ ANÁLISE DE CIRCUITOS DE ESPELHOS DE CORRENTE

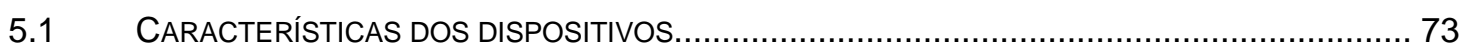

5.1.1 Especificação dos dispositivos com estrutura FinFET ............................................ 73

5.1.2 Especificação dos dispositivos com estrutura Line TFET ........................................ 75

5.2 CARACTERÍSTICAS DO CIRCUITO DE ESPELHO DE CORRENTE........................................... 76

5.3 RESULTADOS E ANÁLISES DE CIRCUITOS COM ESTRUTURAS FINFETS ............................ 77

5.3.1 Impacto das dimensões e da polarização ............................................................ 78

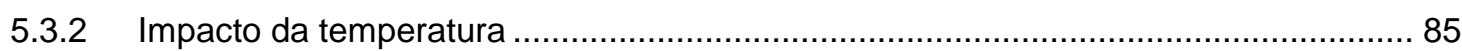

5.4 RESULTADOS E ANÁLISES DE CIRCUITOS COM ESTRUTURAS LINE TFETS........................ 89

5.4.1 Impacto das dimensões e da polarização ............................................................ 90

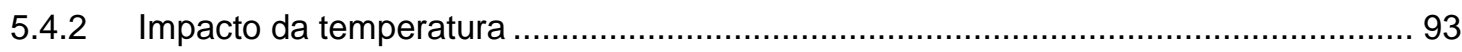

5.5 COMPARAÇÃO DE DESEMPENHO DE CIRCUITOS COM TRANSISTORES FINFETS, POINT TFETS

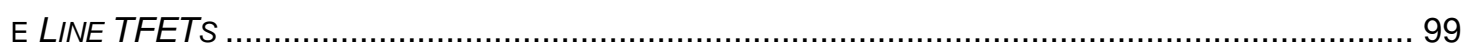




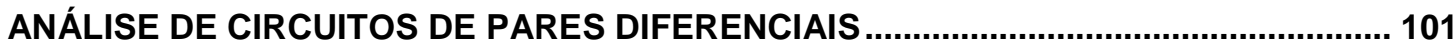

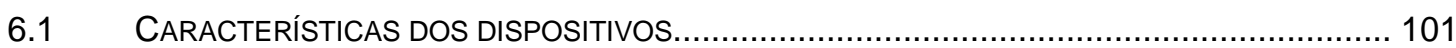

6.1.1 Especificação dos dispositivos com estrutura FinFET ........................................... 101

6.1.2 Especificação dos dispositivos com estrutura Line TFET ...................................... 103

6.2 CARACTERÍSTICAS DO CIRCUITO DE PAR DIFERENCIAL ............................................ 103

6.3 RESULTADOS E ANÁLISES DE CIRCUITOS COM ESTRUTURAS FINFETS .......................... 105

6.3.1 Impacto das dimensões e da polarização ................................................................ 105

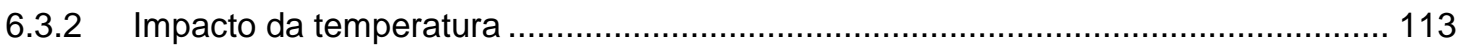

6.4 RESULTADOS E ANÁLISES DE CIRCUITOS COM ESTRUTURAS LINE TFETS........................116

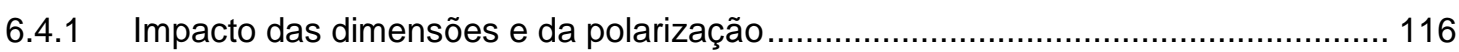

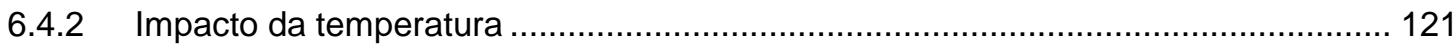

6.5 COMPARAÇÃO DE DESEMPENHO dE CIRCUITOS COM TRANSISTORES FINFETS, POINT TFETS

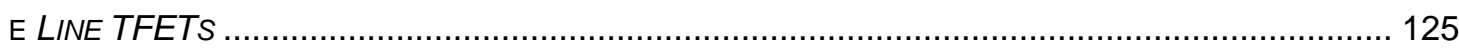

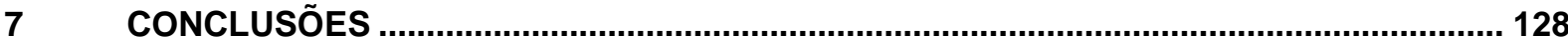

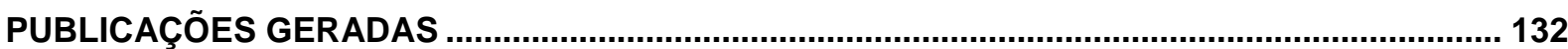

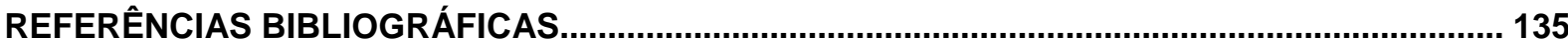

ANEXO 1: ARQUIVO DE SIMULAÇÃO DE UM TRANSISTOR DE TUNELAMENTO INDIVIDUAL141

ANEXO 2: ARQUIVO DE SIMULAÇÃO DE UM CIRCUITO DE ESPELHO DE CORRENTE.......... 144

ANEXO 3: ARQUIVO DE SIMULAÇÃO DE UM CIRCUITO DE PAR DIFERENCIAL ..................... 145 


\section{INTRODUÇÃO}

Nos nós tecnológicos mais recentes, dispositivos MOSFET têm apresentado dimensões bastante reduzidas, chegando à escala nanométrica. Deste modo, efeitos de canal curto e correntes de fuga, outrora irrelevantes, passam a prejudicar o desempenho dos transistores (1), o que exige novas propostas para que o ritmo de integração de componentes continue seguindo o previsto pela Lei de Moore (2), ilustrada na Figura 1.

Figura 1 - Representação da Lei de Moore, onde o número de dispositivos no chip dobra aproximadamente a cada 18 meses.

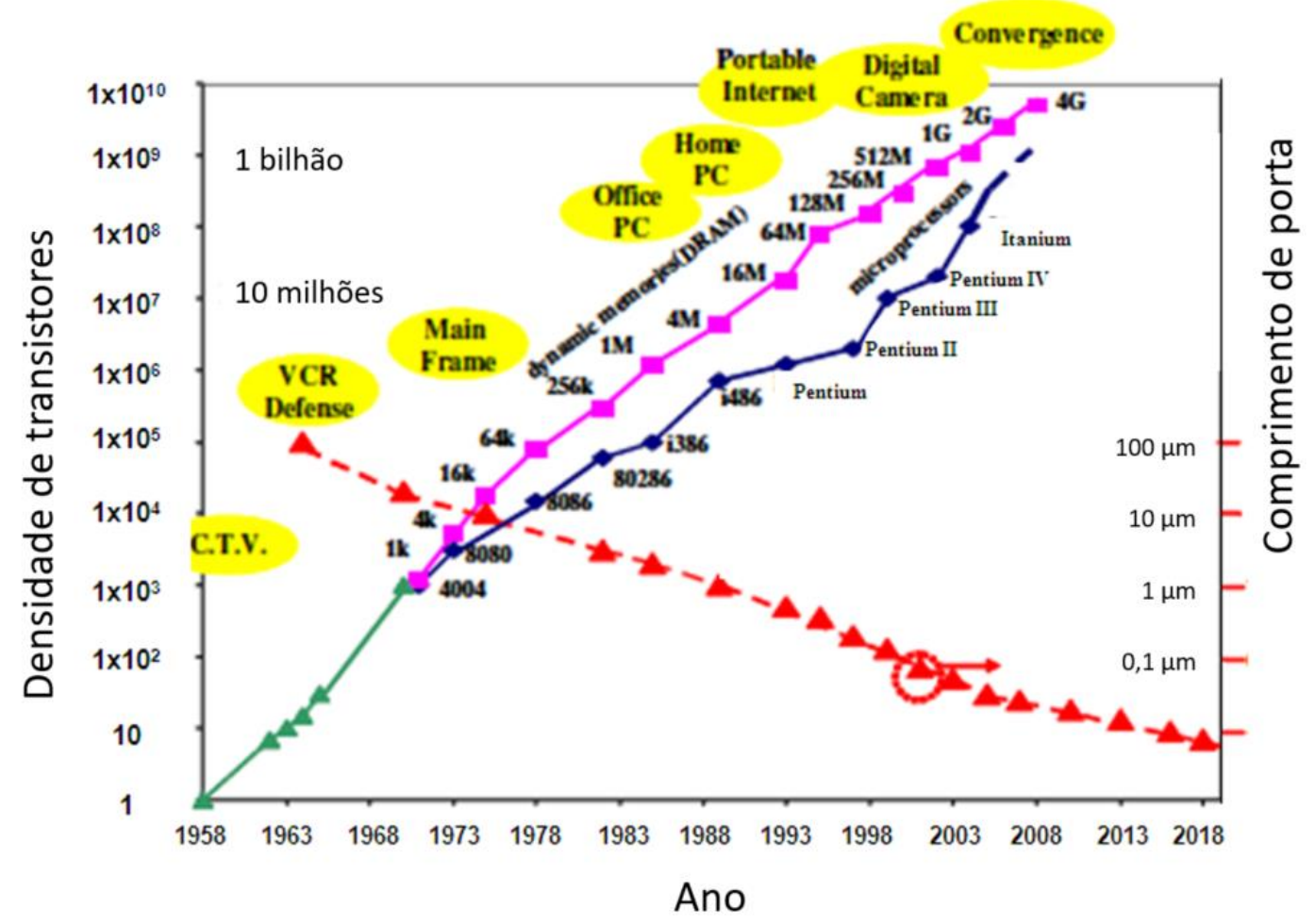

Fonte: Deleonibus (2009)

Diversas alternativas têm sido pesquisadas, abrangendo estratégias como o uso de novas estruturas e materiais (3). Assim, espera-se minimizar correntes de fuga com materiais de elevada constante dielétrica, bem como atenuar efeitos de canal curto com estruturas de múltiplas portas, nas quais as cargas do canal são mais bem controladas pela polarização de porta.

Com este objetivo, transistores verticais com portas laterais, tais quais os FinFETs, foram propostos e bem avaliados para dimensões inferiores a 100nm (4). 
Entretanto, para atingir dimensões abaixo do nó de $22 \mathrm{~nm}$, é necessário explorar novos princípios funcionais, como sugerido na Figura 2 (5).

Figura 2 - Esquema com as sucessivas propostas apresentadas para permitir contínuo escalamento de dispositivos.

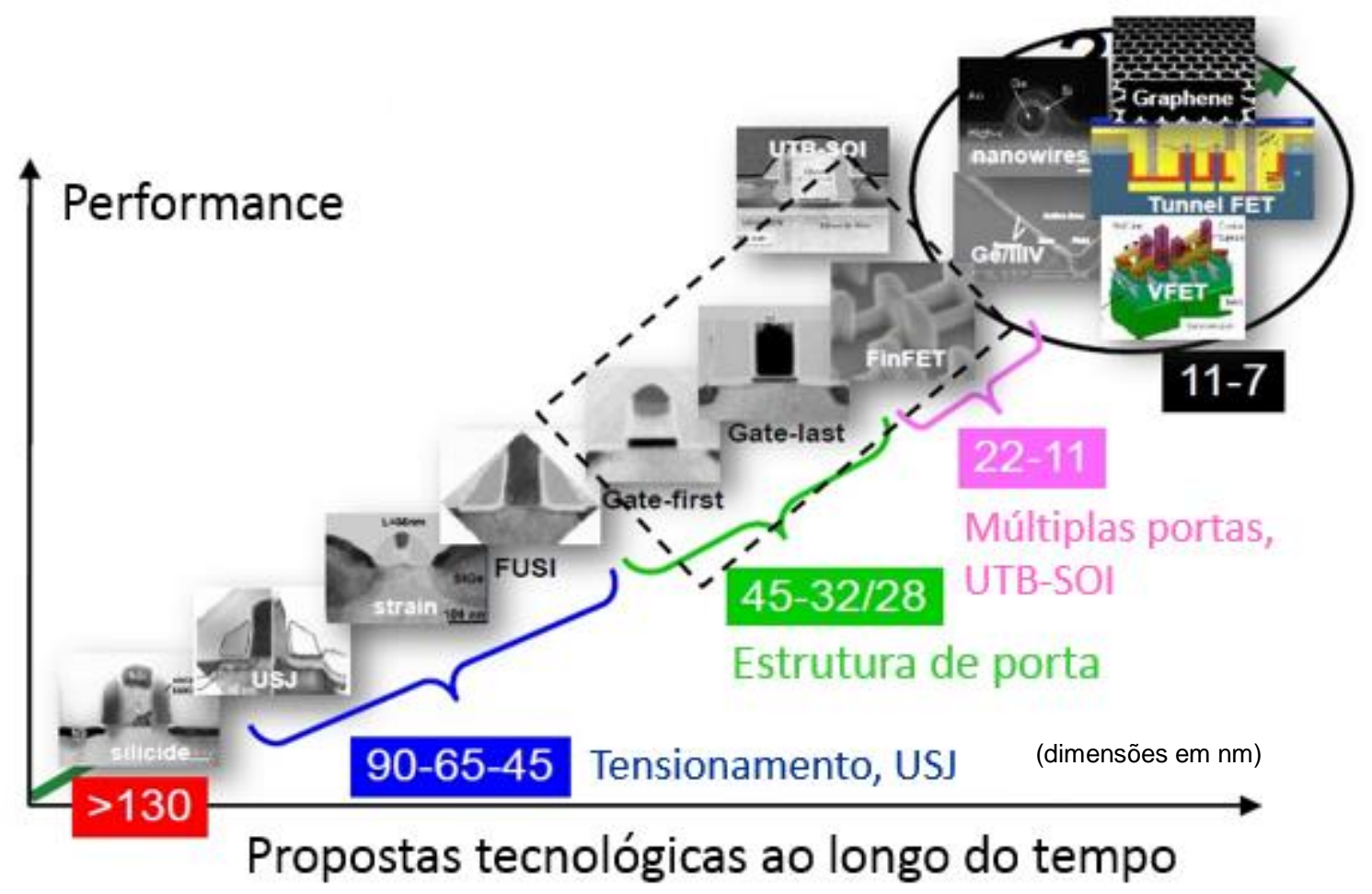

Fonte: Claeys (2009)

Tendo em mente o fator crítico da potência dissipada em circuitos com densidade de componentes cada vez maior, vale a pena observar os parâmetros que determinam as componentes dinâmica e estática do consumo de energia, conforme equações (1) e (2).

$$
\begin{gathered}
P_{\text {dinâmica }}=C_{\text {total }} \cdot V_{D D}^{2} \cdot f \\
P_{\text {estática }}=I_{O F F} \cdot V_{D D}
\end{gathered}
$$

onde Pdinâmica é a potência dissipada em virtude do chaveamento, Ctotal é a capacitância equivalente, $V_{D D}$ é a tensão de alimentação, $f$ é a frequência de chaveamento, Pestática é a potência dissipada em virtude das correntes de fuga e loff é a corrente quando o dispositivo está desligado (6). 
Nota-se, então, que ambas são dependentes da tensão de alimentação, o que sugere que a minimização deste parâmetro deve ser um ponto de atenção às alternativas tecnológicas estudadas.

Enquanto isso, do ponto de vista de aplicações digitais, outro requerimento bastante importante é a maximização da razão entre as correntes de dreno de um transistor acionado e de um desligado (lon/loff). Como este fator é diretamente dependente da diferença entre a tensão de alimentação e a tensão de limiar $\left(V_{D D}-V_{t h}\right)$, espera-se que a previamente comentada redução na tensão de alimentação seja acompanhada de uma adequada diminuição de $V_{\text {th. }}$.

A evolução destes dois parâmetros em função da geração tecnológica é exibida na Figura 3. Pode-se notar uma grave diminuição da diferença entre a tensão de alimentação e a tensão de limiar entre as tecnologias de $1,4 \mu \mathrm{m}$ e $65 \mathrm{~nm}$, variando de pouco mais de $4 \mathrm{~V}$ para apenas $0,7 \mathrm{~V}(7)$.

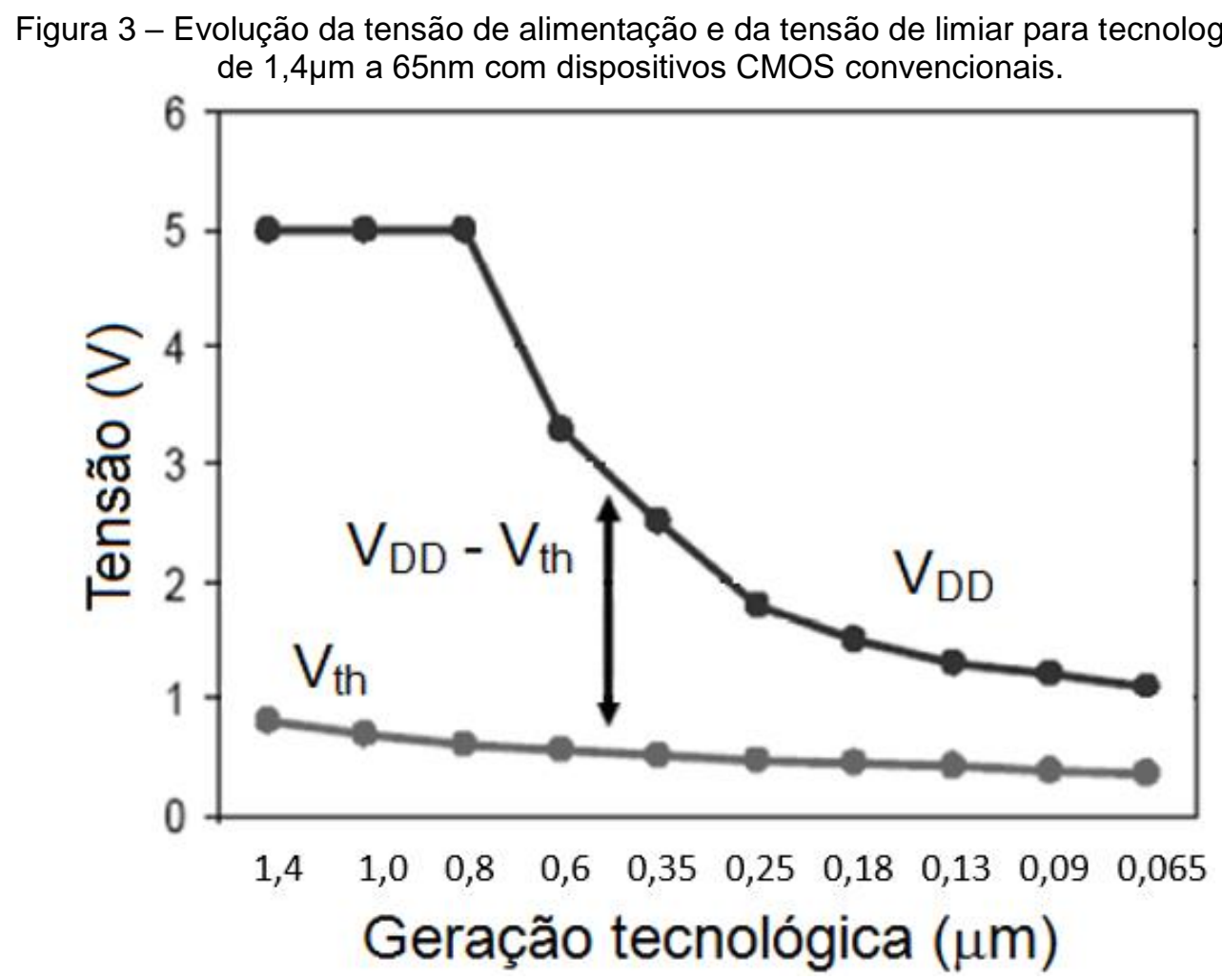

Fonte: Packan (2007)

Entretanto, é interessante compreender que a redução na tensão de limiar dos dispositivos convencionais esbarra no limite físico da variação da corrente por difusão térmica em função da variação de tensão. Este parâmetro é estimado em 
$\ln (10) . \mathrm{kT} / \mathrm{q}$, o que corresponde a cerca de $60 \mathrm{mV} /$ década à temperatura ambiente e resulta em curva característica similar ao ilustrado pela Figura 4 (8).

Figura 4 - Corrente de dreno em função da tensão de porta para três diferentes dispositivos, evidenciando o impacto da variação de $V_{\text {th }}$ em loff.

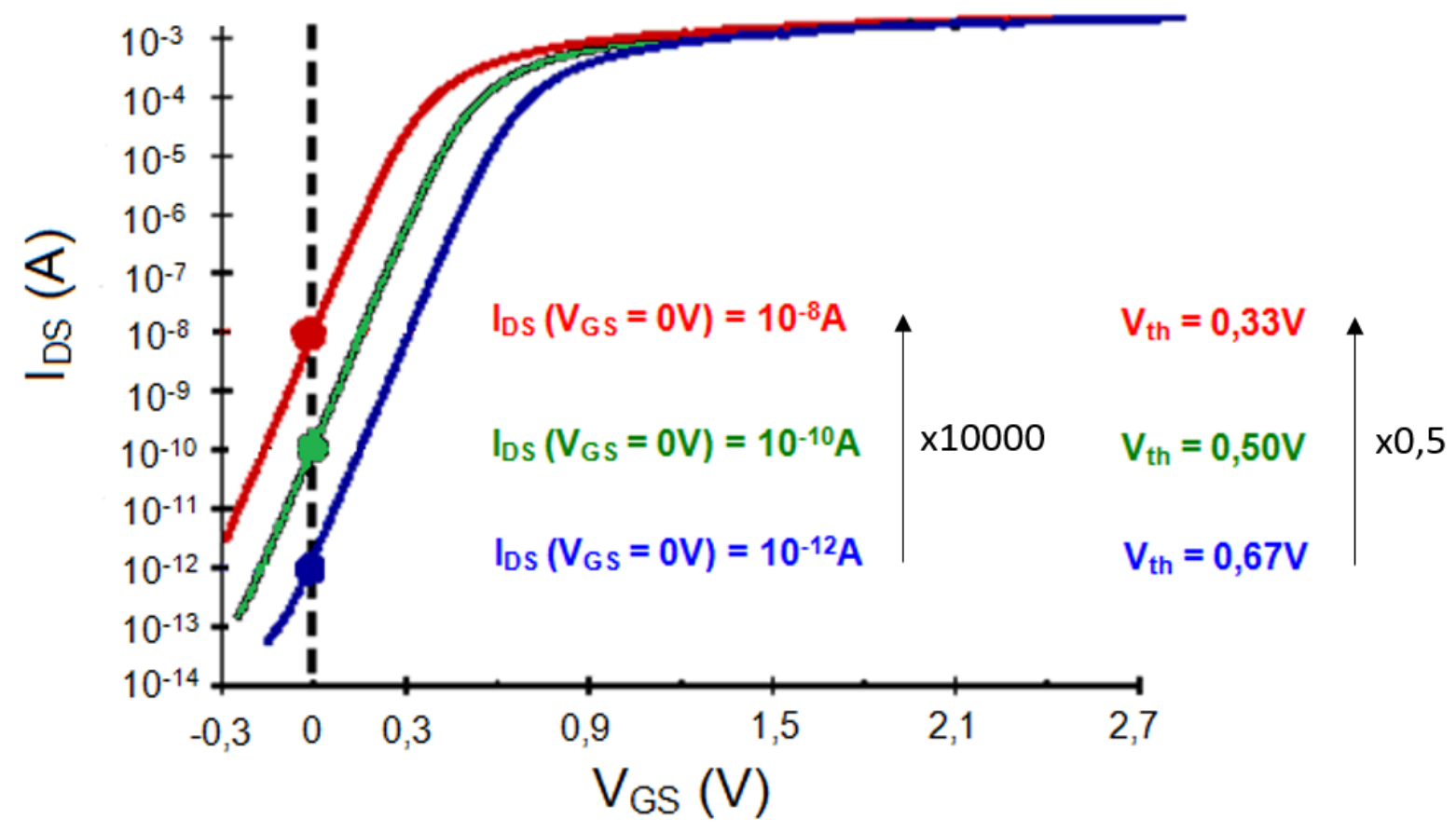

Fonte: Cox (2004)

Neste gráfico são apresentados três dispositivos, com suas respectivas curvas de corrente em função da tensão de porta à temperatura ambiente. Pode-se observar que, devido ao limite de $60 \mathrm{mV} /$ década da inclinação de sublimiar, a diminuição da tensão de limiar levou a um claro aumento na corrente de fuga lofF, extraída para $\mathrm{V}_{\mathrm{GS}}=0 \mathrm{~V}$. Analisando este exemplo em termos quantitativos, observase que uma redução da tensão de limiar pela metade causaria um aumento na corrente loff da ordem de 10 mil vezes. Lembrando da relação entre loff e potência estática mencionada na equação 2 , uma vez mais justifica-se a necessidade de procurar alternativas de componentes que operem com novos mecanismos de condução de corrente (9).

A mesma Figura 4 ainda nos permite extrair um objetivo quantitativo para a comentada razão lon/loff dos dispositivos. Partindo da geração tecnológica na qual se destaca a tecnologia CMOS convencional (Figura 2) e os valores adequados de 
tensão de alimentação e de tensão de limiar (Figura 3), pode-se calcular uma razão de nove ordens de grandeza quando $\mathrm{V}_{\text {th }}=0,67 \mathrm{~V}$.

Traçando um objetivo quantitativo também em termos de tensão de alimentação, são desejados dispositivos que apresentem um comportamento vantajoso para tensões inferiores a $0,5 \mathrm{~V}$ (10), o que seria suficiente para dar continuidade à evolução tecnológica que a Figura 3 ilustra.

Como justificativa adicional para a necessidade de estudar novas tecnologias que requeiram menor tensão de alimentação, menor tensão de limiar e menor dissipação de potência, é apresentada a Figura 5. Nela são representadas as previsões quanto à evolução das potências dinâmica e estática de dispositivos CMOS convencionais.

Figura 5 - Estimativa da evolução da potência estática e dinâmica para tecnologia MOS convencional.

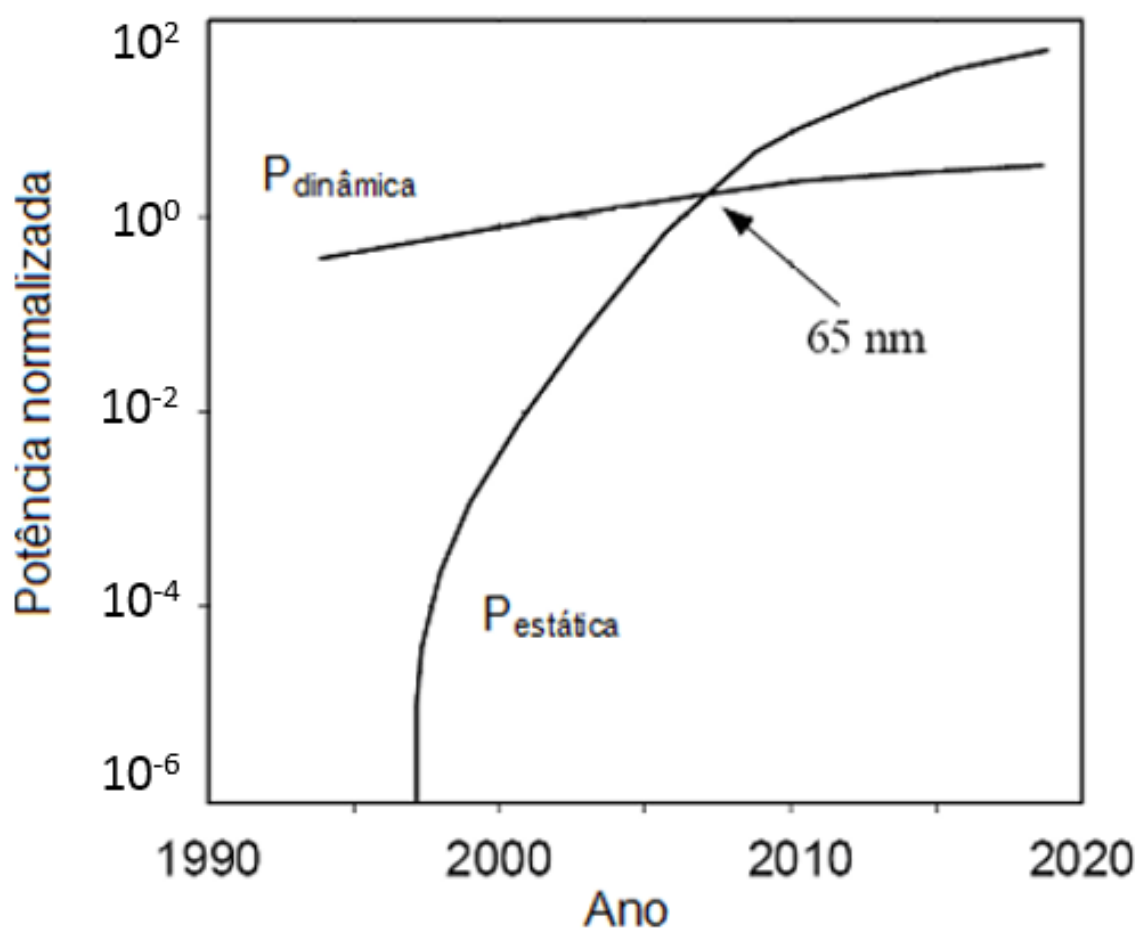

Fonte: Packan (2007)

Neste contexto tecnológico, é apresentada a proposta de utilização de transistores de tunelamento induzido por efeito de campo (TFETs). Baseados na estrutura de um diodo PIN ( $p+$ - intrínseco - $n+$ ) com modulação do canal controlada 
por uma porta (11), estes dispositivos têm corrente dependente principalmente de fenômenos de tunelamento quântico ao invés dos efeitos clássicos de difusão e deriva (12). Desta maneira, não há mais o limite de inclinação de sublimiar de $60 \mathrm{mV} /$ década à temperatura ambiente, abrindo possibilidade para desempenhos satisfatórios mesmo nas dimensões previstas pelas gerações mais recentes de dispositivos (13).

Além das claras vantagens em aplicações digitais, pode-se salientar ainda que esta tecnologia tem potencial não tão explorado em termos analógicos, como será detalhado ao longo deste trabalho.

Para concluir esta introdução, vale a pena frisar a semelhança estrutural com a tecnologia MOSFET convencional, o que permitiria a implementação através de técnicas de processamento já amplamente conhecidas e otimizadas. Isto permitiria aliar a performance vantajosa de transistores TFET com a confiabilidade do processo de fabricação dos transistores CMOS convencionais. Futuros dispositivos poderiam, inclusive, apresentar estruturas tridimensional tais quais as propostas de nanofios verticais (14).

\subsection{OBJETIVOS DO TRABALHO}

O objetivo deste trabalho é estudar teórica e experimentalmente diversas estruturas de dispositivos TFETs, avaliando o impacto de cada variação estrutural no desempenho dos transistores e em circuitos básicos utilizando dispositivos desta tecnologia. Serão abordados resultados obtidos de simulações numéricas e de medidas experimentais inicialmente avaliando transistores individuais e, em seguida, já como elementos de espelhos de corrente e de pares diferenciais.

Será analisada a influência no desempenho dos dispositivos causada por variação de dimensões, perfis de dopagem, condições de polarização e temperatura. Para fazer uma análise comparativa, dispositivos FinFETs com estrutura física similar foram utilizados como referência e duas diferentes implementações de transistores de tunelamento foram avaliadas.

\subsection{ESTRUTURA DO TRABALHO}

A estrutura do trabalho está dividida da seguinte forma: 
O primeiro capítulo resume o contexto tecnológico em que o trabalho se encaixa e a motivação técnica para que sejam realizados estudos de aprofundamento de conhecimentos sobre os transistores TFETs.

O capítulo 2 apresenta uma revisão teórica para justificar o princípio de funcionamento deste tipo de transistor e para listar as atuais dificuldades encontradas no seu desenvolvimento.

O terceiro capítulo apresenta detalhes das simulações de estruturas TFETs individualmente e dentro do contexto de circuitos básicos. Cada modelo selecionado é devidamente explicado com base nas justificativas teóricas do capítulo anterior.

O capítulo 4 destaca os resultados obtidos com a implementação de transistores de tecnologia TFET em estruturas de nanofios. Primeiramente é enfocado o efeito de estreitamento da barreira de tunelamento induzido pela tensão de dreno. Para isso, são comparadas estruturas com diferenças em aspectos como o comprimento de canal, o perfil de dopagem nas junções canal/fonte e canal/dreno e a dimensão da subposição de porta em relação à junção canal/dreno. A seguir, é estudado o comportamento analógico individual dos TFETs e a susceptibilidade à variação de temperatura e aos diferentes mecanismos de transporte dominantes. Com este objetivo, foram utilizados dados experimentais de estruturas com diferentes composições de fonte $\left(100 \%\right.$ Si e $\left.\mathrm{Si}_{1-x} \mathrm{Ge}_{\mathrm{x}}\right)$ e perfis de dopagem de junções.

Os dois capítulos 5 e 6 discutem a viabilidade de uso de dispositivos de tunelamento em circuitos básicos, como espelhos de corrente e pares diferenciais, respectivamente. Para isso, são comparados os resultados obtidos com duas diferentes estruturas de transistores de tunelamento, os quais são comparados entre si e também com dispositivos FinFET como referência.

Para isso, no quinto capítulo estuda-se o desempenho de circuitos espelhos de corrente, extraindo-se o impacto de variações nas dimensões, nas polarizações e na temperatura. Estuda-se através de resultados experimentais e simulados a aplicabilidade de cada tecnologia em relação a quesitos como tensão de conformidade e susceptibilidade ao descasamento de comprimento de canal e à variação da temperatura. Encerra-se o capítulo com a proposta de um modelo geral para a razão de espelhamento de correntes em circuitos desta natureza.

No capítulo seguinte segue-se abordagem análoga, porém com ênfase a pares diferenciais, em configuração de carga passiva e de carga ativa. Parâmetros 
característicos são extraídos e comparados para cada tecnologia, como ganho de tensão diferencial, ganho de tensão de modo comum e taxa de rejeição de modo comum. Novamente são comparadas as performances para variações de dimensões, polarizações e temperatura, sendo possível propor um modelo geral para o ganho obtido com cada tecnologia.

Finalmente, o último capítulo lista as conclusões deste trabalho, resumindo as observações do desempenho analógicos de transistores de tunelamento individuais, bem como a viabilidade em circuitos básicos. Ainda são indicadas propostas de futuros estudos para compreensão mais detalhada do potencial de aplicação desta tecnologia de transistores de tunelamento. 


\section{CONCEITOS TEÓRICOS}

Este capítulo explica o princípio de funcionamento e os principais mecanismos de transporte dos TFETs, bem como os desafios que ainda devem enfrentados para que o desempenho seja otimizado. São abordados os conceitos teóricos dos temas que serão detalhados ao longo do trabalho.

É importante mencionar que serão destacados dois tipos de estruturas de transistores de tunelamento. Uma delas, como tem o respectivo tunelamento ocorrendo pontualmente, é denominada na literatura de Point TFET, conforme explicações detalhadas em 2.1. Em virtude de limitações práticas discutidas em 2.3, outras estruturas também têm sido propostas, como a de transistores com tunelamento em linha, os Line TFETs, apresentados em detalhes em 2.4.

\subsection{PRINCÍPIOS BÁSICOS DE OPERAÇÃO DE POINT TFETS}

Os transistores de tunelamento controlados por efeito de campo permitem a obtenção de dispositivos com inclinação de sublimiar inferior a $60 \mathrm{mV} /$ década à temperatura ambiente, na medida em que os mecanismos clássicos de condução por difusão e deriva (15) são substituídos pelos efeitos de tunelamento quântico (16).

Diminuindo a inclinação de sublimiar em relação ao limite previsto para transistores MOSFET, obtém-se um comportamento mais próximo ao de uma chave ideal, o que permite a operação sob menor tensão de alimentação (17). A Figura 6 ilustra esta comparação entre o formato da curva característica de uma chave ideal, de um dispositivo MOS e de um TFET. 
Figura 6 - Comparação das inclinações de sublimiar previstas para uma chave ideal, um dispositivo MOS e um TFET.

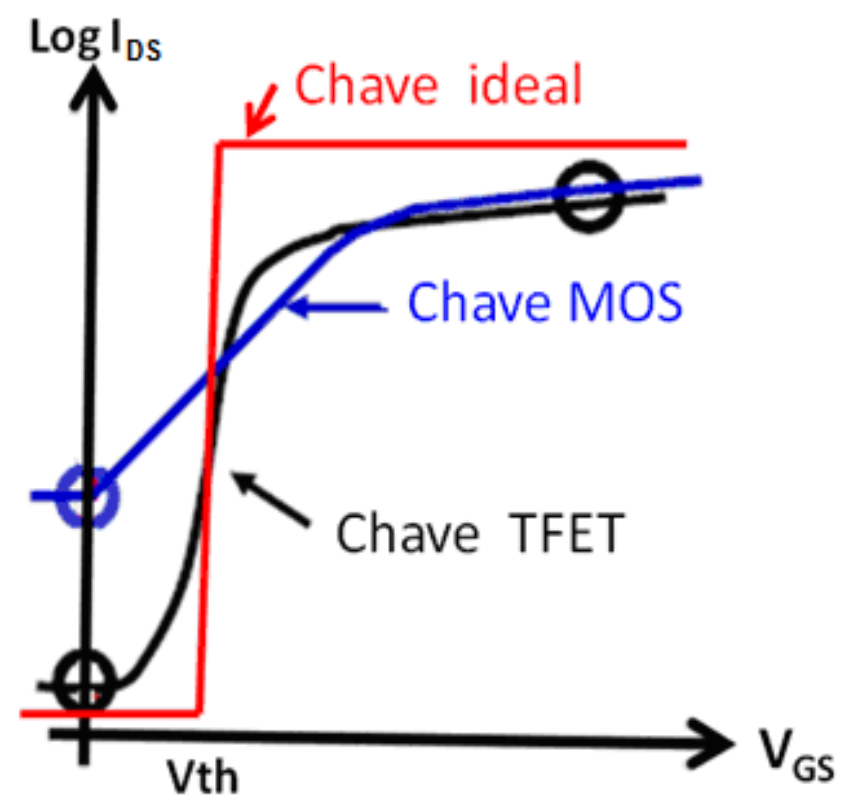

Fonte: Martino (2011)

Este efeito pode ser obtido através do uso de Point TFETs projetados com uma estrutura PIN ( $p+$ - intrínseco - $n+$ ) com controle de porta. Como exemplo, a Figura 7 esquematiza a estrutura típica de um transistor de tunelamento controlado por efeito de campo com implementação planar e porta dupla.

Figura 7 - Seção transversal de um Point TFET do tipo $\mathrm{N}$ de porta dupla.

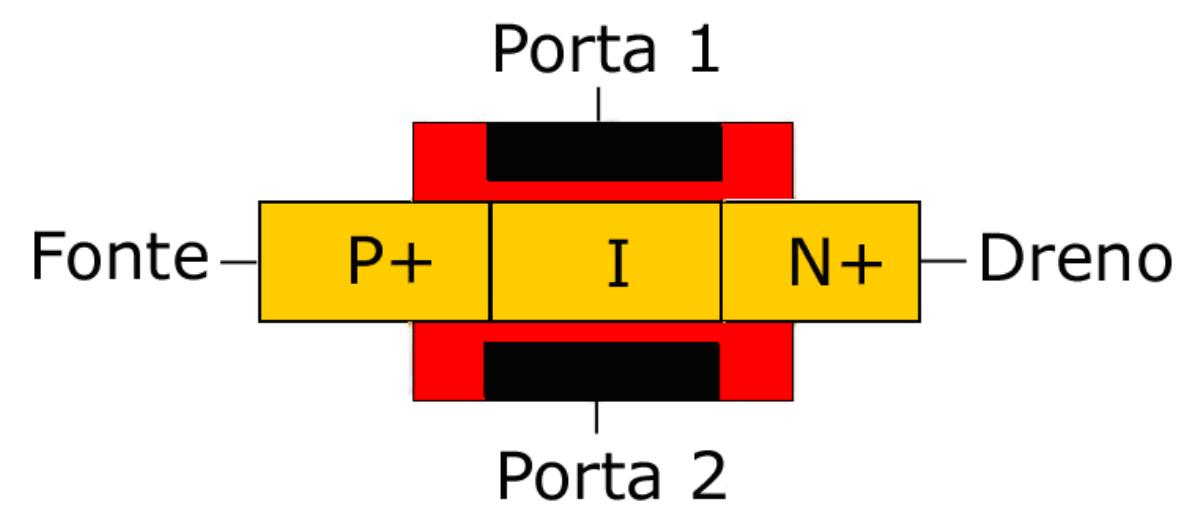

Fonte: Martino (2011)

É interessante lembrar inclusive que uma mesma estrutura pode funcionar tanto como tipo $\mathrm{N}$ quanto como tipo $\mathrm{P}$, dependendo da condição de polarização. Este fenômeno indesejado, denominado efeito ambipolar, também faz com que uma determinada região possa atuar como fonte ou como dreno. No caso da Figura 7, 
está representado um Point TFET do tipo $\mathrm{N}$, no qual a região $\mathrm{n}+$ é o dreno e a p+ é a fonte.

A melhor forma de compreender o funcionamento deste dispositivo é pela comparação dos diagramas de faixas de energia em duas situações distintas, sendo uma na condição de transistor ligado e outra na polarização de dispositivo desligado. Em ambos os casos, o terminal da fonte é aterrado e um potencial positivo é aplicado ao dreno.

Quando a tensão de porta é nula, não há passagem de nível significativo de corrente, conforme indicado pelos diagramas da Figura 8.

Entretanto, aumentando a tensão aplicada na porta, nota-se gradativa redução nos níveis de energia das bandas de condução e valência da região do canal. A Figura 9 mostra que o deslocamento nos níveis de energia pode levar a um forte tunelamento próximo à junção fonte-canal. Isto é, os elétrons da banda de valência da fonte tunelam para a banda de condução da região do canal.

Figura 8 - Diagrama de bandas de energia para um n-Point TFET desligado.

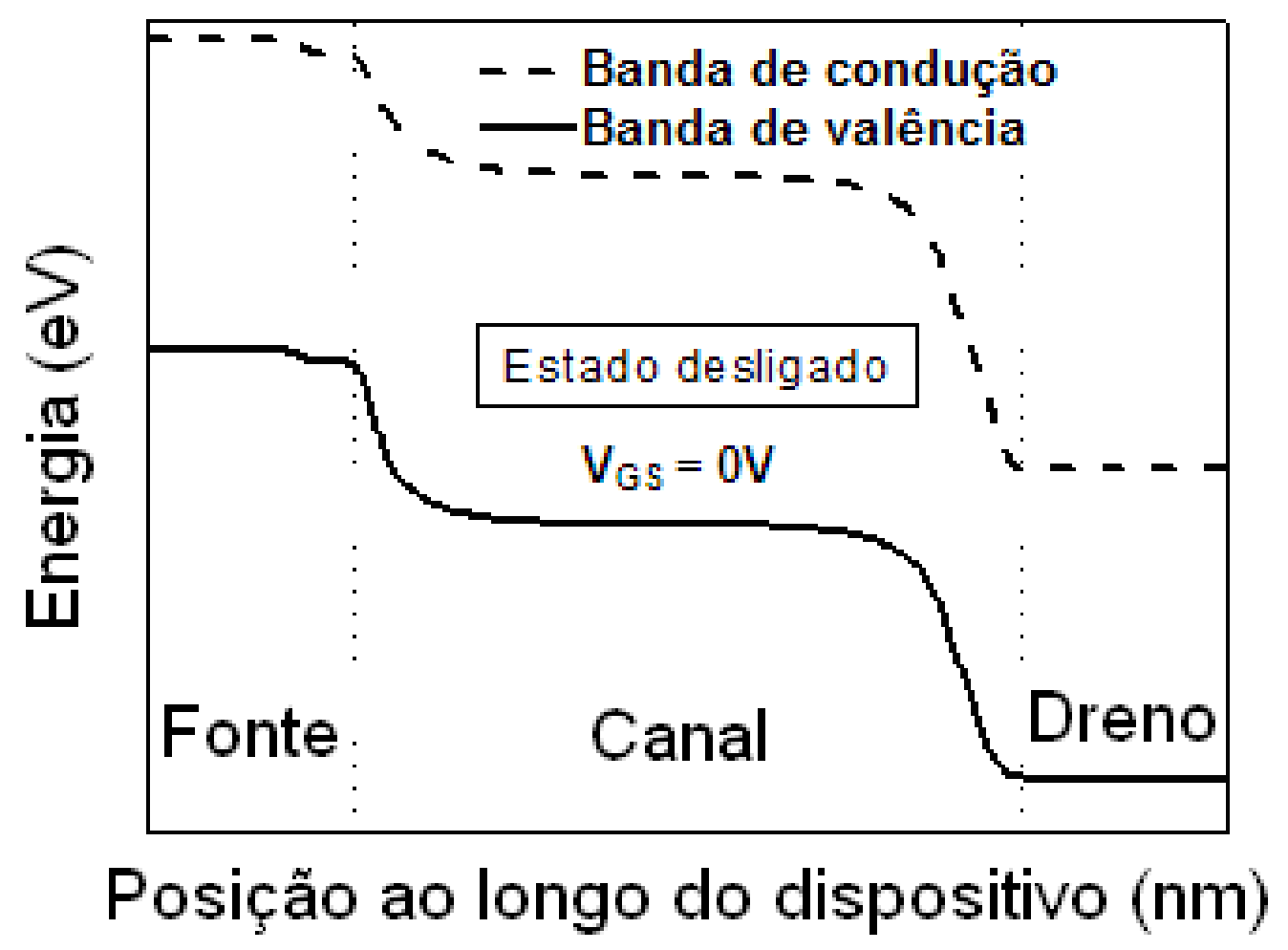

Fonte: Martino (2011) 
Figura 9 - Diagrama de bandas de energia para um n-Point TFET ligado.

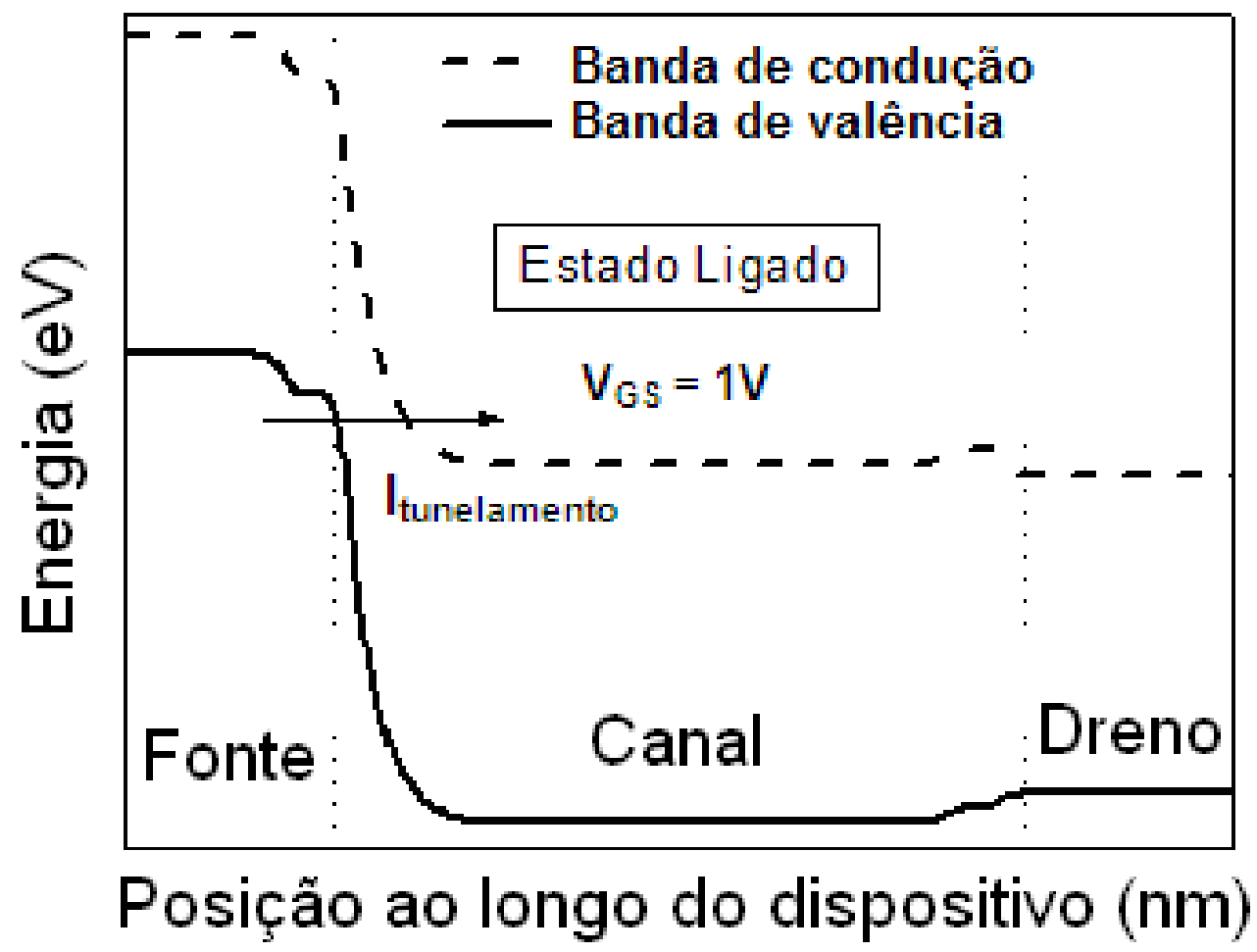

Fonte: Martino (2011)

Pode-se realizar análise semelhante para explicar a ocorrência do efeito ambipolar. Afinal, aplicando sobre a porta um potencial cada vez mais negativo, o efeito de tunelamento passaria a acontecer na área próxima à junção dreno-canal, gerando um indesejado aumento na corrente. $O$ item 2.3 resume este e outros desafios a serem superados por estes dispositivos, além de listar algumas das soluções avaliadas atualmente.

Para obter um p-Point TFET, poderia ser utilizada a mesma estrutura, porém aterrando o lado $n+$ (que passaria a atuar como fonte) e aplicando um potencial negativo no lado $p+$ (dreno). Desta forma, uma variação na polarização de porta para valores negativos resultaria em crescente tunelamento entre a região $n+e$ o canal, ativando o dispositivo.

\subsection{COMPONENTES DA CORRENTE DE TUNELAMENTO}

Para avaliar os resultados de simulações e de medidas experimentais ao longo deste trabalho, serão comentadas frequentemente as influências individuais das três principais componentes da corrente, notadamente BTBT (tunelamento de 
banda para banda), SRH (Schockley-Read-Hall) e TAT (tunelamento induzido por armadilhas).

A compreensão sobre as condições de polarização para que cada uma delas prevaleça ajuda a interpretar adequadamente a dependência dos resultados com fatores como temperatura, dimensões físicas, entre outros.

Iniciando a explicação pela condição de baixa tensão de porta (isto é, com o dispositivo desativado), há apenas uma pequena corrente fluindo entre fonte e canal em virtude da geração de Schockley-Read-Hall. Isto se deve à considerável barreira de energia que dificulta o tunelamento, de modo a permitir apenas a passagem de uma componente dependente exponencialmente da largura da faixa proibida e da temperatura (18). Esta condição é ilustrada pela Figura 10.

Figura 10 - Diagrama de bandas de energia representando predomínio de corrente SRH.

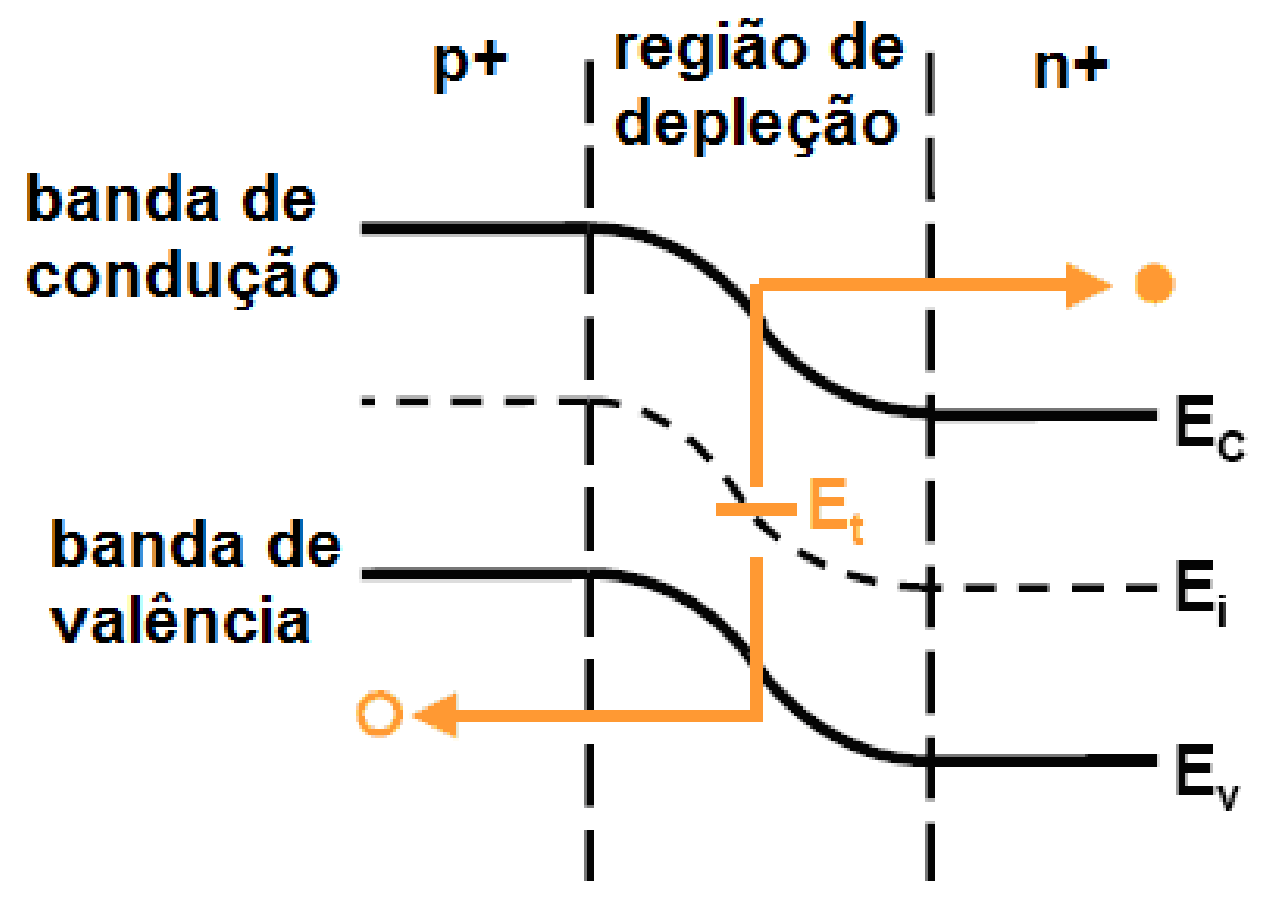

Fonte: Martino (2011)

Aumentando o potencial na porta, a barreira de energia vai sendo reduzida. Se a estrutura tiver poucas armadilhas, essa condição ainda não permite o pleno tunelamento, mas uma presença significativa de armadilhas atua de modo a dividir a barreira de energia em múltiplas partes. Em outras palavras, é como se houvesse 
alternativas de caminhos para sucessivos tunelamentos, cada um dos quais com uma barreira efetiva de potencial relativamente pequena.

Com isso, o aumento da corrente é potencializado, o que impacta a curva característica do transistor e gera uma região com menor inclinação de sublimiar. Esta componente também apresenta dependência exponencial da largura da faixa proibida e da temperatura. A

Figura 11 exibe um diagrama de bandas dessa corrente induzida por armadilhas (TAT).

Finalmente, para valores de tensão de porta continuamente crescentes, a barreira de potencial é fortemente reduzida, permitindo a passagem de corrente por tunelamento de banda para banda (BTBT). Nessa região, a inclinação de sublimiar torna-se ainda menor e, ao contrário das componentes mencionadas anteriormente, a susceptibilidade em relação à variação de temperatura é muito reduzida (19). Esta condição é indicada pela Figura 12.

Figura 11 - Diagrama de bandas de energia representando predomínio de corrente TAT.

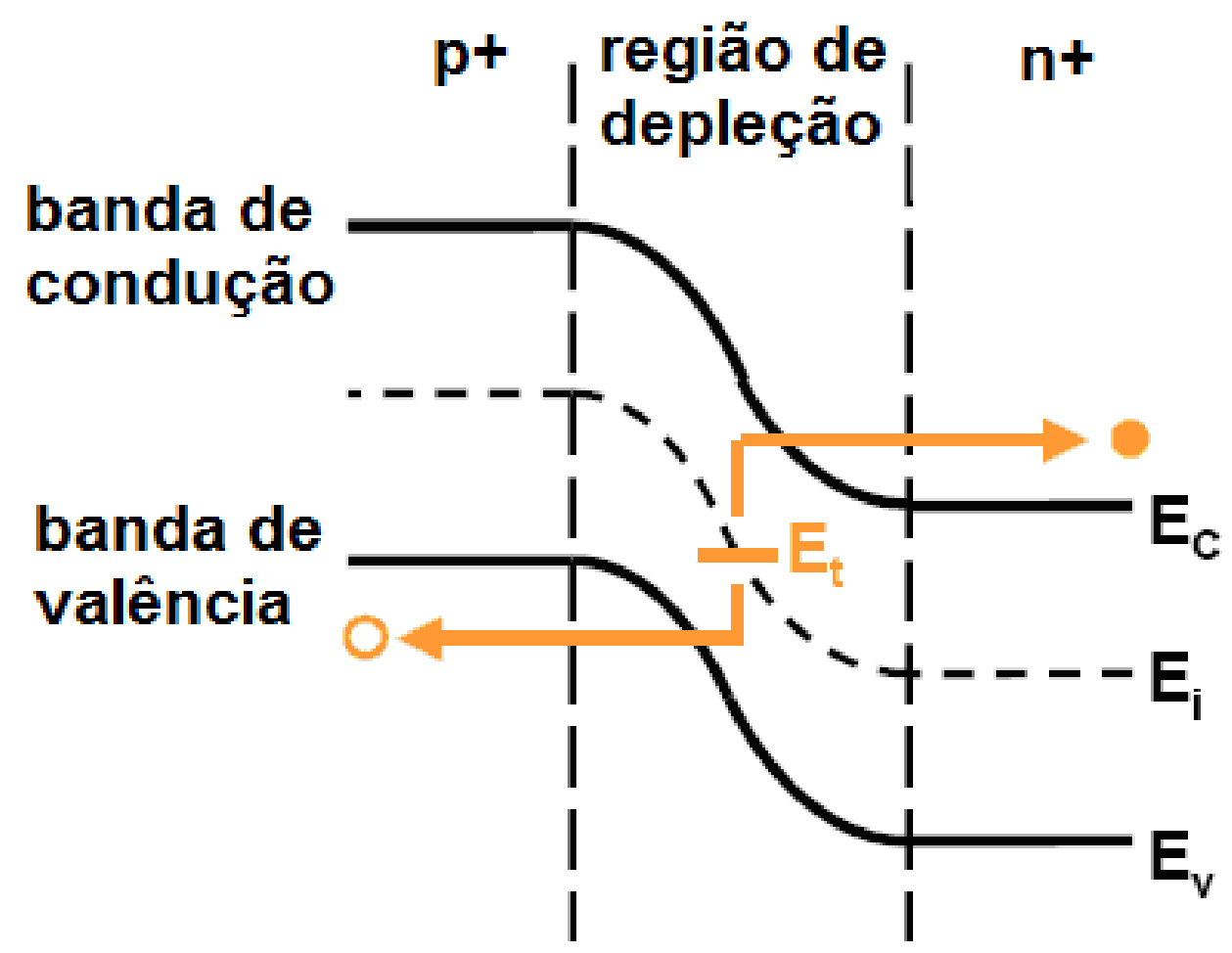

Fonte: Martino (2011) 
Figura 12 - Diagrama de bandas de energia representando predomínio de corrente BTBT.

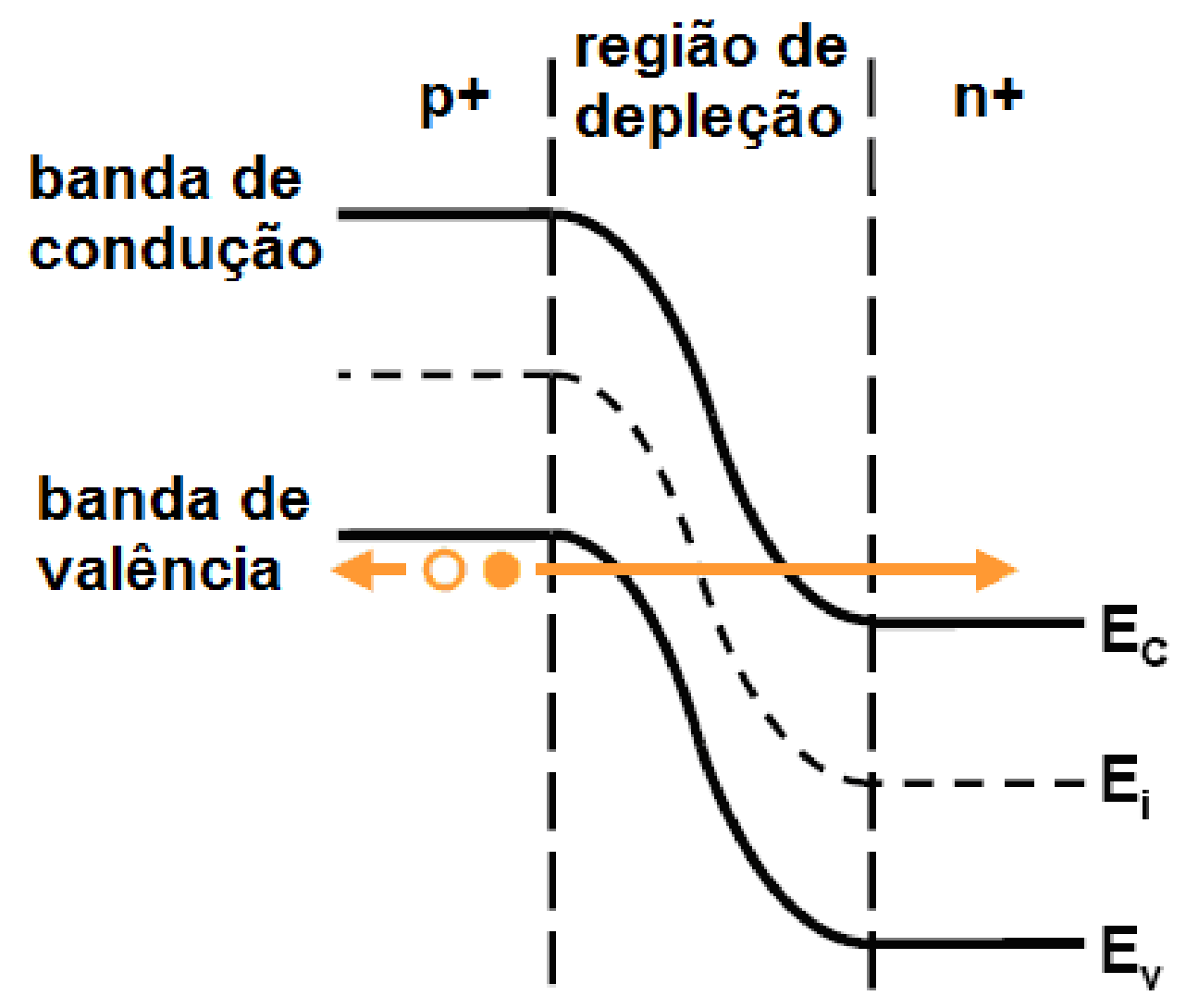

Fonte: Martino (2011)

As condições de polarização que resultam no predomínio de cada um dos três mecanismos de transporte mencionados podem ser resumidas na Figura 13, que esboça a variação de corrente numa junção em função da tensão aplicada. 
Figura 13 - Representação da variação do mecanismo de transporte predominante à medida que é alterada a tensão em uma determinada junção.

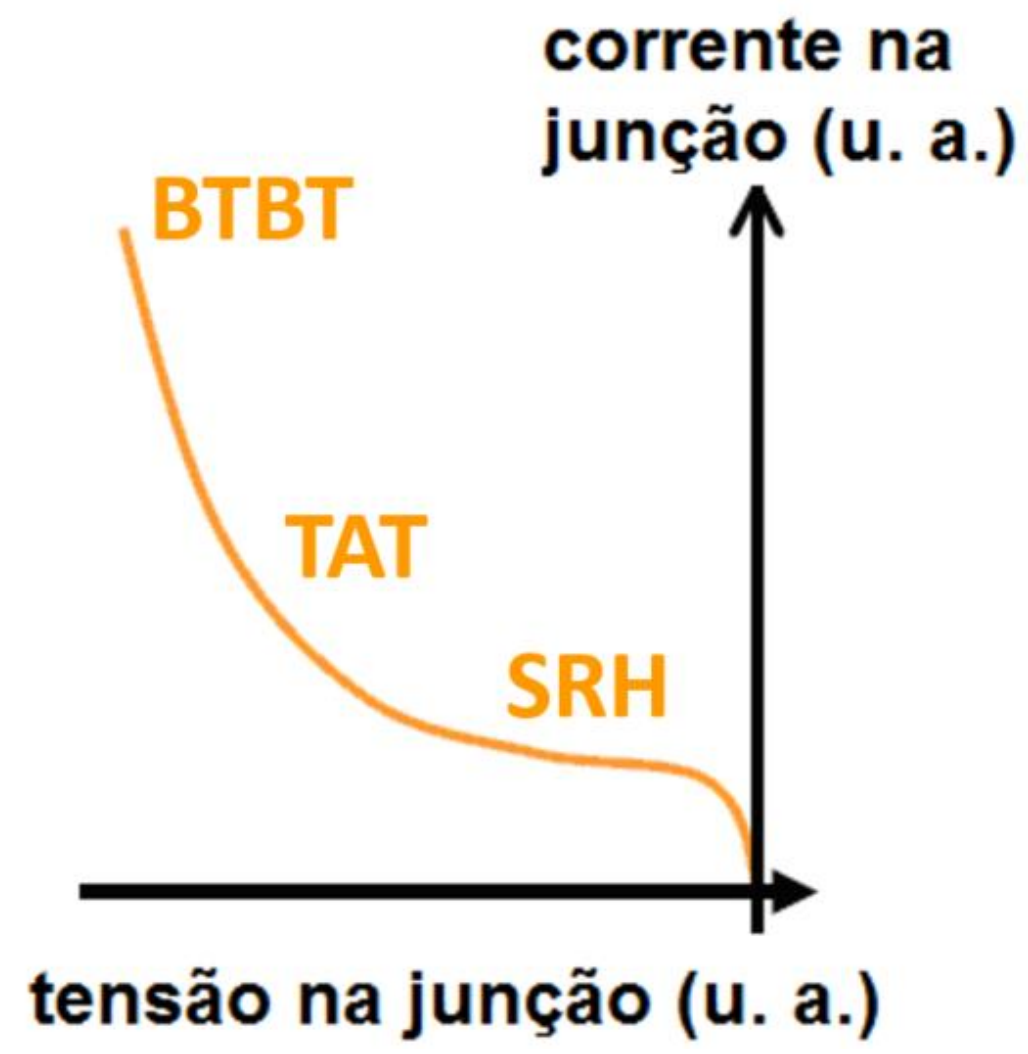

Fonte: Martino (2011)

No capítulo 3 são detalhadas as equações implementadas pelos modelos utilizados para as simulações de cada uma destas componentes e as escolhas são justificadas a partir dos parâmetros variáveis ao longo de todas as análises.

Já os capítulos 4, 5 e 6 utilizam por diversas vezes esta metodologia de avaliação da componente predominante na corrente para justificar o comportamento dos dispositivos TFETs.

\subsection{PRINCIPAIS DESAFIOS TECNOLÓGICOS ATUAIS}

Mesmo com todas as características promissoras da tecnologia TFET, há importantes desafios que devem ser enfrentados pela comunidade científica para maximizar o desempenho destes dispositivos, principalmente quanto ao efeito ambipolar e à baixa corrente de acionamento (Ion) (20).

Conforme previamente explicado na Figura 7, o efeito ambipolar ocorre pela simetria da estrutura básica dos Point TFETs, o que permite que um mesmo dispositivo funcione como transistor do tipo $\mathrm{N}$ e do tipo $\mathrm{P}$ dependendo da condição 
de polarização. Esta característica é bastante prejudicial e têm recebido numerosas sugestões de abordagem prática (21).

Uma das sugestões mais recorrentes para atenuar o tunelamento parasitário é baseada na utilização de estruturas forçadamente assimétricas, com subposição (underlap) de porta em relação à junção canal/dreno, onde não deve ocorrer tunelamento (22).

A questão da baixa corrente lon também é preocupante, visto que poderia limitar a velocidade de chaveamento e, consequentemente, toda a performance em aplicações digitais (23). Algumas soluções propõem o uso de técnicas tais quais tensionamento mecânico (strain) local, epitaxia seletiva, materiais com elevadas constantes dielétricas, entre outras (24).

No entanto, ainda há barreiras decorrentes da dificuldade de integração de óxidos com constantes dielétricas superiores a 100 na tecnologia CMOS e das limitações litográficas para estabelecer a precisão nanométrica no alinhamento da porta em relação à fonte com strain ou à heterojunção fonte/canal (25).

Outro ponto importante observado a partir das tomadas de dados experimentais de dispositivos Point TFETs refere-se ao impacto da utilização de um material na fonte com largura de faixa proibida reduzida para obter maior efetividade do BTBT, o que resulta, na prática, em valores de inclinação de sublimiar menores que $60 \mathrm{mV} /$ década (26).

Ainda assim, alguns resultados medidos para estruturas com fonte de silício são apresentados a título comparativo, apesar de não constituírem a solução final para transistores com inclinação de sublimiar inferior ao limite teórico da tecnologia CMOS convencional.

Em outras palavras, mesmo transistores com valores de inclinação de sublimiar, tensão de limiar e tensão de alimentação ainda fora do esperado para a operação final dos dispositivos de tunelamento podem ser utilizados para comparações dos benefícios e prejuízos de diferenças estruturais no desempenho dos dispositivos individualmente ou como elementos de circuitos maiores (27). 


\subsection{PRINCÍPIOS BÁSICOS DE OPERAÇÃO DE LINE TFETS}

Com o objetivo de enfrentar algumas características indesejáveis de transistores Point TFETs, como a baixa corrente de acionamento e a degradação observada experimental na inclinação de sublimiar, uma estrutura proposta mais recentemente é a de transistores com tunelamento em linha, denominadas na literatura de Line TFETs (28, 29, 30).

Nesta nova classe de dispositivos, a fonte é prolongada abaixo do canal, ao longo de toda a região controlada pela porta, conforme ilustrado pela Figura 14. Com isso, o tunelamento ocorre de modo alinhado ao campo elétrico da porta, ao contrário do que ocorre com Point TFETs $(31,32)$.

Figura 14 - Seção transversal de um Line TFET do tipo N.

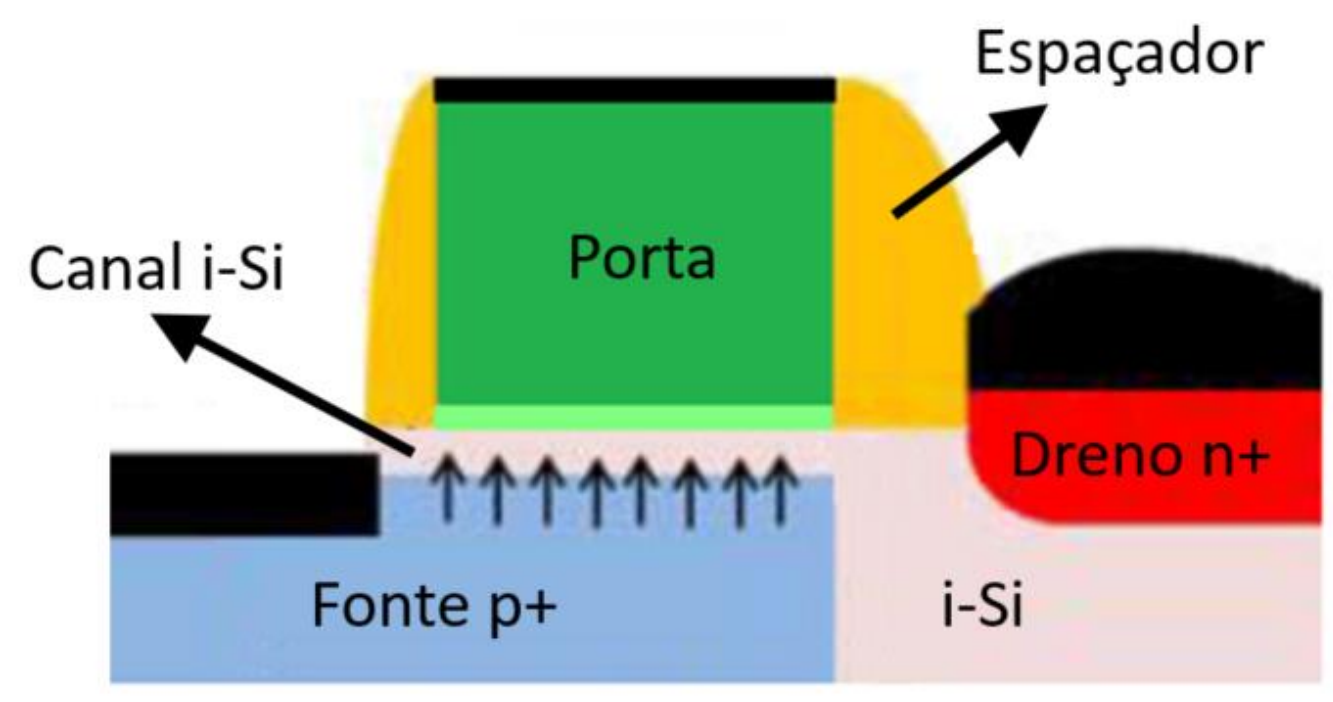

Fonte: Martino (2017)

A justificativa física para o funcionamento desta tecnologia pode ser baseada no diagrama de bandas de energia da Figura 15. É interessante compará-lo ao diagrama análogo de um Point TFET ligado, exibido previamente na Figura 9, atentando para a diferença quanto à direção do tunelamento (33). 
Figura 15 - Diagrama de bandas de energia para um dispositivo Line TFET.
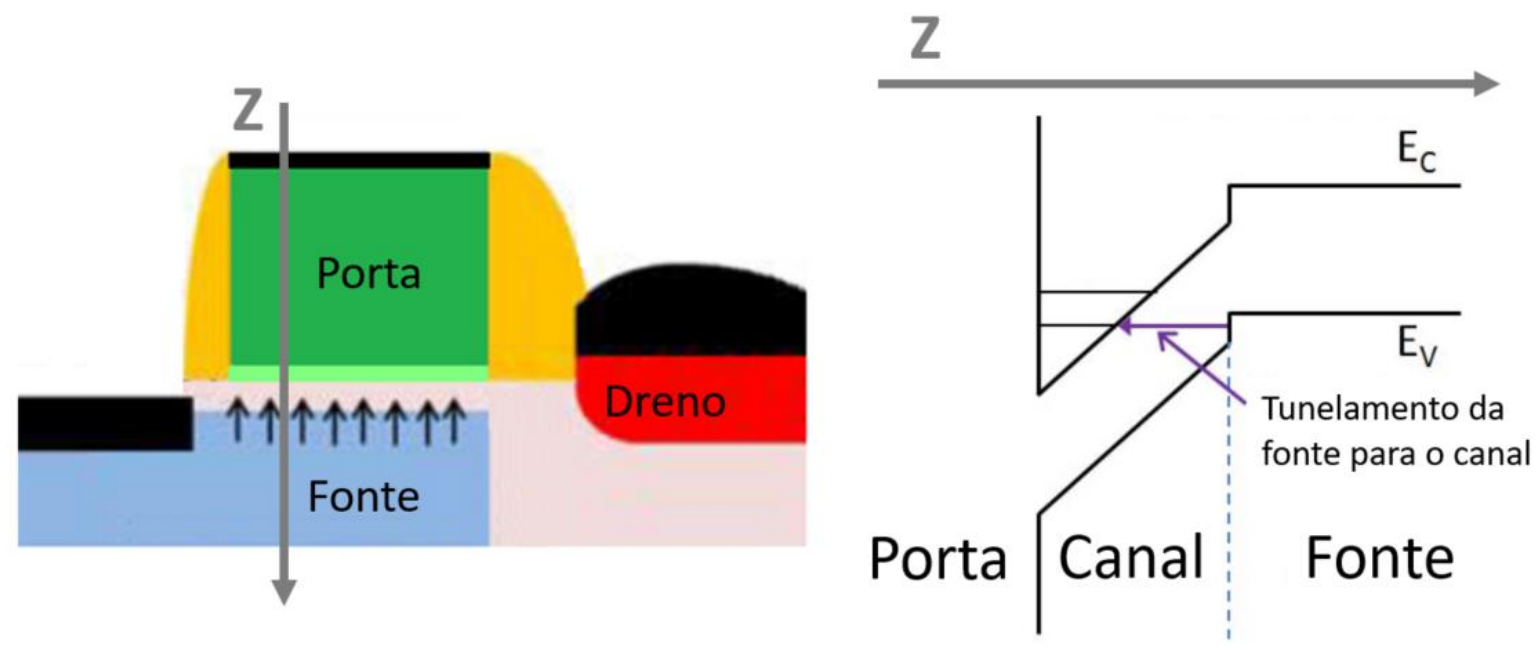

Fonte: Walke (2014)

Duas consequências muito importantes decorrem deste tipo de estrutura. A primeira é o aumento da corrente de acionamento (IoN). A segunda é que esta corrente passa a depender diretamente do comprimento efetivo de canal (Lef). Esta dependência é diferente da observada na tecnologia MOS convencional, cuja corrente é inversamente proporcional a Lef, e ao já comentado efeito da pouca dependência da corrente de Point TFETs em relação ao comprimento de canal (12, $34)$.

Desta forma, as semelhanças (mecanismos de transporte, pouca susceptibilidade à temperatura) e diferenças (magnitude de lon, dependência do comprimento de canal) entre transistores Point TFETs e Line TFETS serão diretamente relacionadas às diferenças de performance observadas em circuitos projetados com cada uma destas tecnologias nos capítulos 5 (espelhos de corrente) 6 (pares diferenciais).

\subsection{PROPOSTAS DE CIRCUITOS BÁSICOS COM TRANSISTORES DE TUNELAMENTO}

Em virtude das características promissoras de transistores de tunelamento justificadas pelos princípios de operação detalhados em 2.1 e 2.4, é interessante não apenas o aprofundamento quanto às otimizações estruturais que melhoram os parâmetros de transistores individuais, mas também a avaliação da performance 
destes dispositivos como partes de circuitos fundamentais. Nesta seção, são apresentadas algumas referências que têm destacado recentemente propostas de otimização de transistores já com foco em impactos em circuitos $(35,36,37)$.

Configurações digitais, como inversores e multiplexores, são as mais frequentemente analisadas na literatura, sendo a maioria dos trabalhos baseada em simulações $(38,39)$, porém também com algumas ocorrências de dados experimentais $(40,41)$.

Circuitos analógicos com transistores de tunelamento também têm sido propostos, basicamente com análise de simulações (42, 43, 44, 45). É neste contexto que se insere a contribuição deste trabalho, que apresenta dados experimentais de circuitos básicos para embasar as comparações entre FinFETs, Point TFETs e Line TFETs.

Os circuitos de espelho de corrente e pares diferenciais foram escolhidos por serem estágios fundamentais de inúmeros circuitos mais complexos, atuando em aplicações que requeiram corrente constante ou ainda como estágio de entrada de amplificadores operacionais, respectivamente. São blocos tipicamente implementados como circuitos integrados, o que facilita o casamento entre os dispositivos, ao qual muitas vezes o desempenho global é bastante sensível. 


\section{SIMULAÇÃO DE DISPOSITIVOS}

A simulação de dispositivos ao longo deste trabalho foi baseada no programa Atlas da Silvaco, um simulador numérico $2 D$ e $3 D$ que utiliza equacionamentos físicos do comportamento de dispositivos semicondutores. Desta forma, podem ser aproveitadas importantes vantagens de um simulador físico, notadamente a possibilidade de previsão do desempenho de dispositivos sem a necessidade da inclusão de dados experimentais e a alternativa de estudar o impacto de fenômenos individualmente, inseparáveis na prática.

É importante salientar que os resultados apresentados correspondem a simulações bidimensionais, uma vez que os modelos de tunelamento implementados pelo Atlas apenas podem ser habilitados para esta condição.

Para a etapa de simulação de circuitos, também foi utilizado um modo híbrido denominado Mixed Mode, que permite uma simulação de circuitos (aos moldes do SPICE) utilizando estruturas com o equacionamento físico do Atlas.

Neste capítulo serão apresentados e comparados modelos físicos referentes aos mecanismos de tunelamento adotados, bem com seus respectivos equacionamentos. No final, é apresentada uma lista resumindo os modelos escolhidos para simular cada efeito.

\subsection{DESCRIÇÃO DO SIMULADOR}

Os trabalhos com o programa Atlas podem se basear no conjunto com outras aplicações focadas em simulação de processos e estruturas, como ilustrado na Figura 16. Especificamente neste trabalho, as simulações ocorreram a partir dos arquivos de comandos de entrada e os resultados gerados foram analisados e comparados para cada estrutura e condições de polarização (46). 
Figura 16 - Representação dos blocos de entrada e saída do programa Atlas.

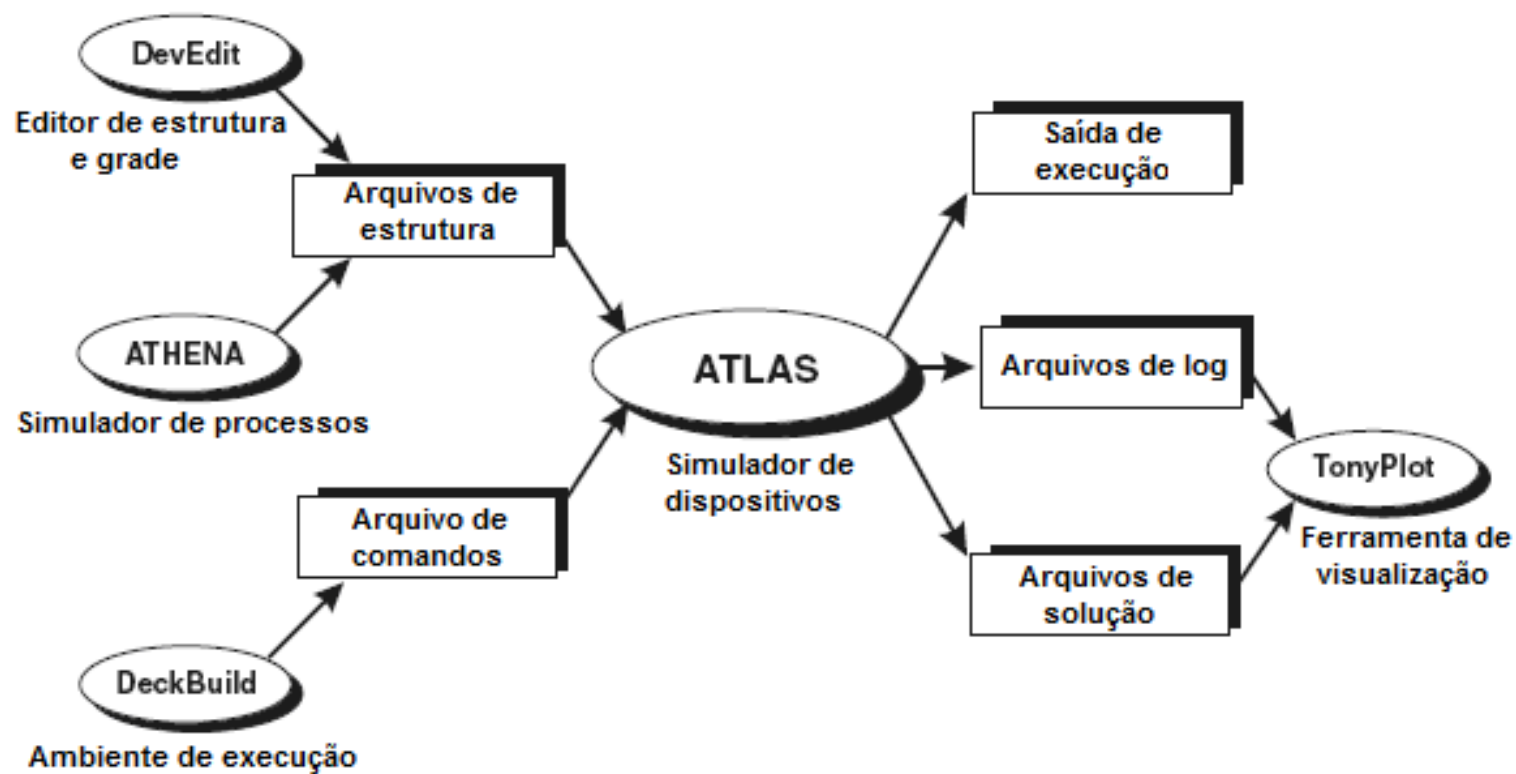

Fonte: Martino (2011)

\subsection{DEFINIÇÃO DOS MODELOS ADOTADOS}

Este item explica os principais modelos disponíveis para os fenômenos mais importantes em dispositivos TFETs, bem como suas vantagens e limitações. Para cada um dos modelos analisados é apresentado o respectivo equacionamento. Nota-se que as entradas do programa aparecem sempre codificadas por letras maiúsculas seguidas.

Pode-se começar destacando os diferentes modelos físicos disponíveis para o fenômeno fundamental da corrente de tunelamento de banda para banda (BTBT). De modo geral, o mecanismo de geração de portadores na banda de condução por tunelamento é dado pela equação (3) (47).

$$
G_{B B T}=(\text { BВ.A }) F^{\text {BВ.GАMмА }} \exp \left(-\frac{\text { BВ.B }}{F}\right)
$$

onde $\mathrm{F}$ é a magnitude do campo elétrico e BB.A, BB.B e BB.GAMMA são parâmetros definidos pelo usuário. 
O programa prevê dois modelos com este equacionamento, porém com diferentes trios de parâmetros de entrada, com base em diferentes aplicações.

O modelo padrão (BBT.STD) é adequado para semicondutores com transição direta como GaAs. Neste caso, os valores utilizados por padrão são BB. $A=9,6615 \times 10^{18}$, BB.B $=3,0 \times 10^{7} \mathrm{~V} / \mathrm{m}$ e BB.GAMMA $=2,0(48)$.

Para aplicações com semicondutores com transição indireta, como silício e germânio, pode ser utilizado o modelo de Klaassen (BBT.KL), que adota como valores iniciais BB. $A=4,00 \times 10^{14}, B B \cdot B=1,9 \times 10^{7} \mathrm{~V} / \mathrm{m}$ e BB.GAMMA $=2,5$ (49).

$A$ aplicação destes dois modelos, portanto, basicamente simplifica o modelo geral de Kane, omitindo a influência da temperatura.

Entretanto, como uma das análises previstas para este trabalho inclui o impacto deste parâmetro, foi adotado um modelo de Kane mais completo (BBT.KANE) (50). Ao invés de considerar uma constante na componente exponencial como nos modelos anteriores, a equação de Kane inclui a largura da faixa proibida $E_{g}$, que apresenta um ligeiro estreitamento com o aumento da temperatura, como ilustrado pela Figura 17. A relação completa é indicada pela equação (4).

$$
\left.G_{B B T}=\frac{(\text { BBT.A_KANE) }}{\sqrt{E_{g}}} F^{\text {BBT.GAMmA }} \operatorname{exp[-(BBT.B\_ KANE)} \frac{E_{g}^{\frac{3}{2}}}{F}\right]
$$

onde $E_{g}$ é a largura da faixa proibida dependente da temperatura, $F$ é a magnitude do campo elétrico e BBT.A_KANE, BBT.B_KANE e BBT.GAMMA são parâmetros definidos pelo usuário.

Os valores padrão destes parâmetros são BBT.A_KANE $=3,5 \times 10^{21}$, BBT.B_KANE $=2,25 \times 10^{7}$ e BBT.GAMMA $=2,5$. 
Figura 17 - Largura da faixa proibida do silício em função da temperatura.

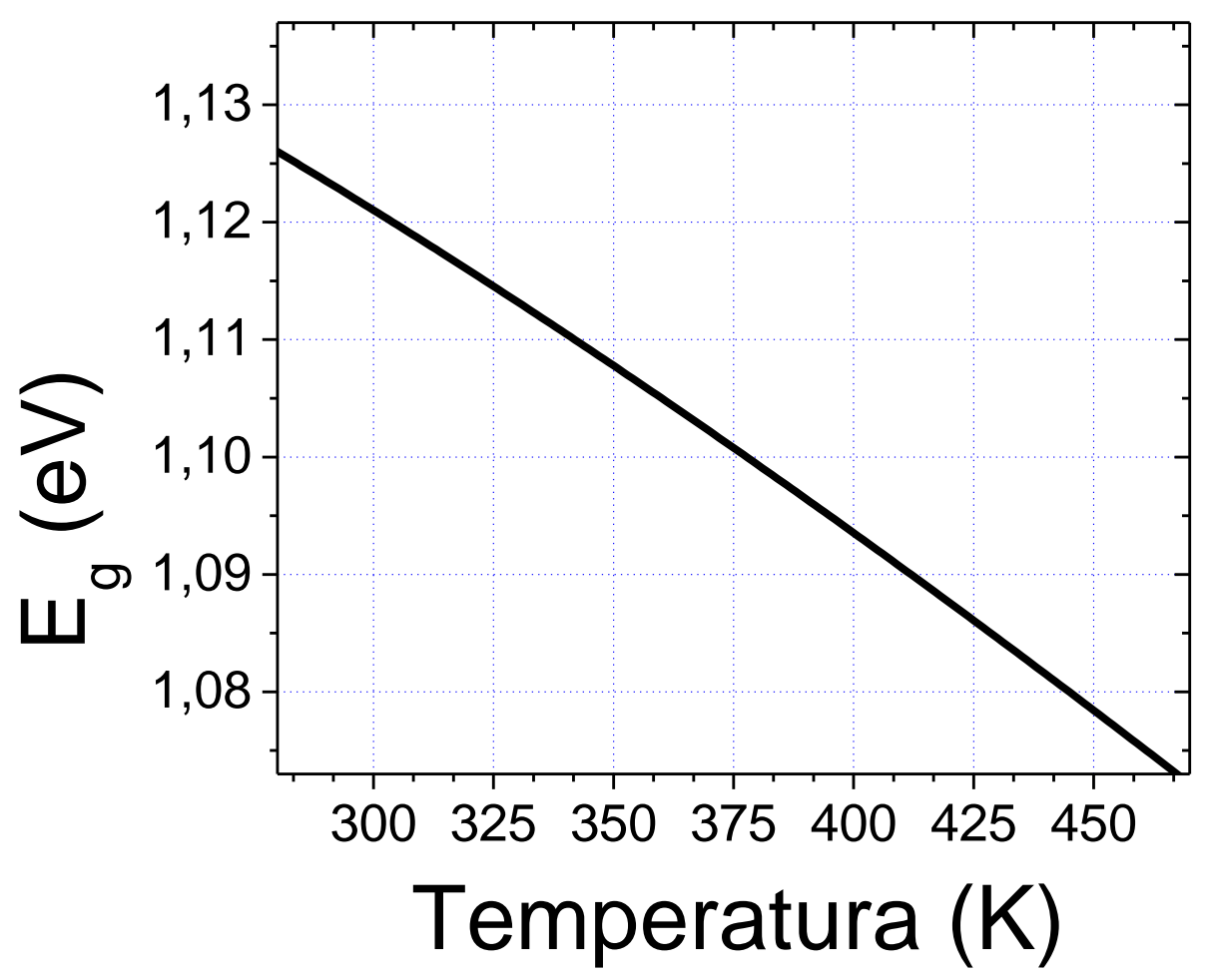

Fonte: Martino (2017)

Enquanto isso, a corrente de recombinação prevista por Schockley-Read-Hall (SRH), também explicada teoricamente em 2.2, é modelada conforme a equação (5).

$$
R_{S R H}=\frac{p n-n_{i}^{2}}{\operatorname{TAUP} 0\left[n+n_{i} \exp \left(\frac{\mathrm{ETRAP}}{k T_{L}}\right)\right]+\operatorname{TAUN} 0\left[p+n_{i} \exp \left(\frac{-\mathrm{ETRAP}}{k T_{L}}\right)\right]}
$$

onde ETRAP é a diferença entre o nível de energia da armadilha e o nível de Fermi intrínseco, TL é a temperatura da estrutura em Kelvin e TAUNO e TAUPO são os tempos de vida dos elétrons e das lacunas, respectivamente.

Optando pela implementação do modelo $\mathrm{SRH}$, os parâmetros TAUNO e TAUP0 são definidos pelo usuário e tratados como constantes. Para estruturas de silício, são adotados como padrão os valores ETRAP $=0 \mathrm{eV}$, TAUNO $=1 \times 10^{-7} \mathrm{~s}$ e TAUP0 $=1 \times 10^{-7} \mathrm{~s}$.

Por fim, o modelamento da corrente de tunelamento induzido por armadilhas (TRAP.TUNNEL) é implementado matematicamente por uma correção do modelo $\mathrm{SRH}$, conforme a equação (6). 


$$
R_{S R H}=\frac{p n-n_{i}^{2}}{\frac{\text { TAUP0 }}{1+\Gamma_{p}^{D I R A C}}\left[n+n_{i} \exp \left(\frac{\mathrm{ETRAP}}{k T_{L}}\right)\right]+\frac{\text { TAUN0 }}{1+\Gamma_{n}^{D I R A C}}\left[p+n_{i} \exp \left(\frac{-\mathrm{ETRAP}}{k T_{L}}\right)\right]}
$$

onde $\Gamma_{\mathrm{n}} \mathrm{DIRAC}$ é o termo de incremento do campo dos elétrons para poços de Dirac e $\Gamma_{\mathrm{p}}$ DIRAC é o de aumento do campo das lacunas para poços de Dirac, definidos conforme as equações (7) e (8) (51).

$$
\begin{aligned}
& \Gamma_{n}^{\text {DIRAC }}=\frac{\Delta E_{n}}{k T_{L}} \int_{0}^{1} \exp \left(\frac{\Delta E_{n}}{k T_{L}} u-K_{n} u^{\frac{3}{2}}\right) d u \\
& \Gamma_{p}^{\text {DIRAC }}=\frac{\Delta E_{p}}{k T_{L}} \int_{0}^{1} \exp \left(\frac{\Delta E_{n}}{k T_{L}} u-K_{p} u^{\frac{3}{2}}\right) d u
\end{aligned}
$$

onde u é a variável de integração, $\Delta \mathrm{E}_{n}$ é a faixa de energia para a qual há tunelamento de elétrons, $\Delta E_{p}$ é a faixa de energia para tunelamento de lacunas e $K_{n}$ e $K_{p}$ são definidos pelas equações (9) e (10).

$$
\begin{gathered}
K_{n}=\frac{4}{3} \frac{\sqrt{2 m_{0} \mathrm{MASS} . \mathrm{TUNNEL} \Delta E_{n}^{3}}}{3 q \hbar|E|} \\
K_{p}=\frac{4}{3} \frac{\sqrt{2 m_{0} \mathrm{MASS} . \mathrm{TUNNEL} \Delta E_{p}^{3}}}{3 q \hbar|E|}
\end{gathered}
$$

onde $\hbar$ é a constante de Planck reduzida ( $h / 2 \pi)$, mo é a massa do elétron em repouso e MASS.TUNNEL é a sua massa efetiva.

Desta maneira, basta comparar as equações (5) e (6) para notar que o efeito de TAT é implementado matematicamente através de uma correção na equação da corrente de recombinação de $\mathrm{SRH}$. Este ajuste leva em consideração os incrementos dos campos para elétrons e lacunas, baseado em faixas de energia onde ocorre tunelamento.

Em outras palavras, para que o efeito do tunelamento induzido por armadilhas tenha de fato efeito na simulação é necessário não apenas utilizar o modelo 
TRAP.TUNNEL, mas também garantir que a corrente de Schockley-Read-Hall utilize o modelo denominado no Atlas por SRH. Há outros modelos disponíveis para simular a corrente de Schockley-Read-Hall com equacionamento similar a (5), como o CONSRH e o KLASRH. Entretanto, estes foram preteridos justamente porque não seriam devidamente alterados na implementação de (6).

Outros fenômenos, tais quais a ionização incompleta em baixas temperaturas, a concentração de portadores e outros, também tiveram seus modelos escolhidos de modo a permitir maior compatibilização com a literatura.

Por exemplo, os cálculos referentes às correntes de difusão e deriva foram baseados no modelo DRIFT.DIFF, derivado de desenvolvimento teórico de Boltzmann (52). Para determinar estas correntes, a abordagem estatística da concentração de portadores utiliza o modelo FERMI, adequada para estruturas com regiões fortemente dopadas (53).

Também foi levado em consideração o modelo de recombinação de KlaassenAuger (KLAAUG), com coeficientes dependentes de variações na temperatura (54). Por fim, o modelo INCOMPLETE foi utilizado para deixar as simulações compatíveis também para casos de baixas temperaturas, por considerar os efeitos da ionização incompleta nesta condição (INCOMPLETE) (55).

Um resumo dos modelos adotados é apresentado na Tabela 1, mostrando que foram considerados tanto os fenômenos específicos de tunelamento quanto os relativos ao comportamento geral da estrutura submetida a ampla faixa de variação de temperatura. 
Tabela 1 - Modelos adotados para simulações dos dispositivos TFETs.

\begin{tabular}{|c|c|}
\hline Fenômeno físico & Modelo adotado \\
\hline Tunelamento de banda para banda & BBT.KANE \\
\hline Recombinação de Schockley-Read-Hall & SRH \\
\hline Tunelamento induzido por armadilhas & TRAP.TUNNEL \\
\hline Correntes de difusão e deriva & DRIFT.DIFF \\
\hline Estatística da concentração de portadores & FERMI \\
\hline Recombinação de Klaassen-Auger & KLAAUG \\
\hline lonização incompleta sob baixas temperaturas & INCOMPLETE \\
\hline
\end{tabular}

\subsection{COMPARAÇÃO DO IMPACTO DA TEMPERATURA EM CADA MECANISMO DE TRANSPORTE}

Nos capítulos 4, 5 e 6 a seguir, um dos mais importantes fatores a ser analisado é o impacto da temperatura no comportamento de dispositivos TFETs, seja quanto às características individuais, seja quanto à performance global do circuito no qual estão inseridos.

Para justificar a diferença de comportamento decorrente de cada condição de polarização e de cada tipo de estrutura, é importante destacar como os modelos dos mecanismos de transporte são susceptíveis à variação de temperatura.

Com este objetivo, devem ser comparadas as equações (4), referente ao BTBT, (5), relativa ao SRH, e (6), corresponde ao TAT. As condições para domínio de cada uma destas componentes foram detalhadas em 2.2.

Nota-se, inicialmente, que o tunelamento de banda para banda apresenta apenas uma ligeira dependência da temperatura. Apesar de não explícita na equação (4), o aumento da temperatura causa uma ligeira redução na largura da 
faixa proibida (Figura 17), o que resulta em um pequeno incremento na corrente de tunelamento.

Por outro lado, as equações (5) e (6) indicam claramente uma dependência exponencial da corrente com a temperatura. Nas condições de polarização em que estas componentes predominarem, espera-se, portanto, um aumento significativo na corrente total quando o dispositivo estiver submetido a altas temperaturas.

Esta assimetria de dependência da temperatura proporcionará diferenças em diversos parâmetros, desde a inclinação de sublimiar mínima obtida até parâmetros analógicos, como o ganho intrínseco de tensão. 


\section{PERFORMANCE DE DISPOSITIVOS TFETS IMPLEMENTADOS EM ESTRUTURA DE NANOFIOS}

Neste capítulo será estudado o comportamento de transistores de tunelamento induzido por efeito de campo em estruturas de nanofios verticais.

Inicialmente será destacada a influência de uma alta tensão de dreno em dispositivos de canal curto, em condições em que há um estreitamente da barreira de tunelamento. Este fenômeno indesejado de influência da tensão de dreno no controle da corrente pode ser avaliado quantitativamente através do parâmetro denominado DIBT (do inglês Drain Induced Barrier Thinning), que indica a susceptibilidade da tensão de limiar de um dispositivo às suas condições de polarização.

A seguir, será estudada a performance analógica deste tipo de dispositivo e a susceptibilidade à variação de temperatura e a diferentes mecanismos de transporte dominantes. Para avaliar o desempenho analógico, pode-se partir do ganho intrínseco de tensão, calculado em função de parâmetros como tensão de Early, eficiência, transcondutância e condutância de saída. Desta maneira, será destacado como as tendências dos parâmetros analógicos dependem da composição da fonte e do mecanismo de transporte predominante.

\subsection{CARACTERISTICAS DOS DISPOSITIVOS}

Os TFETs deste estudo representam a seção transversal de um nanofio vertical. Deste modo, o diâmetro $D$ do nanofio corresponde à distância entre as duas interfaces com o óxido. Neste capítulo, a denominação TFET refere-se à estrutura Point TFET descrita em 2.1.

Para a análise do DIBT, foram realizadas simulações de pTFETs com dopagem de fonte de $10^{20} \mathrm{~cm}^{-3}$ do tipo $\mathrm{n}+$, dopagem de fonte de $10^{20} \mathrm{~cm}^{-3}$ do tipo $\mathrm{p}+$ e uma região de canal com baixa dopagem $\left(10^{15} \mathrm{~cm}^{-3}\right)$. A estrutura de porta contava ainda com material de função trabalho de $4,7 \mathrm{eV}$ e óxido de porta de $2 \mathrm{~nm}$ de espessura. Já o diâmetro $D$ foi fixado em $40 \mathrm{~nm}$.

Conforme explicado em 2.1, a escolha de pTFETs faz com que as polarizações de porta e dreno tenham que ser negativas para ligá-lo. 
Foram realizadas simulações numéricas bidimensionais com variações no comprimento de canal (de 20 a 100nm) e no perfil de dopagem nas junções canal/fonte e canal/dreno (abrupto ou gaussiano). Além disso, enquanto foi mantido autoalinhamento da porta em relação à junção canal/fonte, o comprimento de porta foi variado para simular uma subposição em relação à junção canal/dreno de $10 \mathrm{a}$ $20 \mathrm{~nm}$, correspondente à diferença $L_{c h}-L G$.

A estrutura completa é ilustrada na Figura 18.

Figura 18 - Estrutura esquemática de um pTFET com alinhamento entre porta e fonte $e$ subposição entre porta e dreno. A concentração de dopagem $\mathrm{N}+$ e $\mathrm{P}+$ é de $10^{20} \mathrm{~cm}^{-3}$.

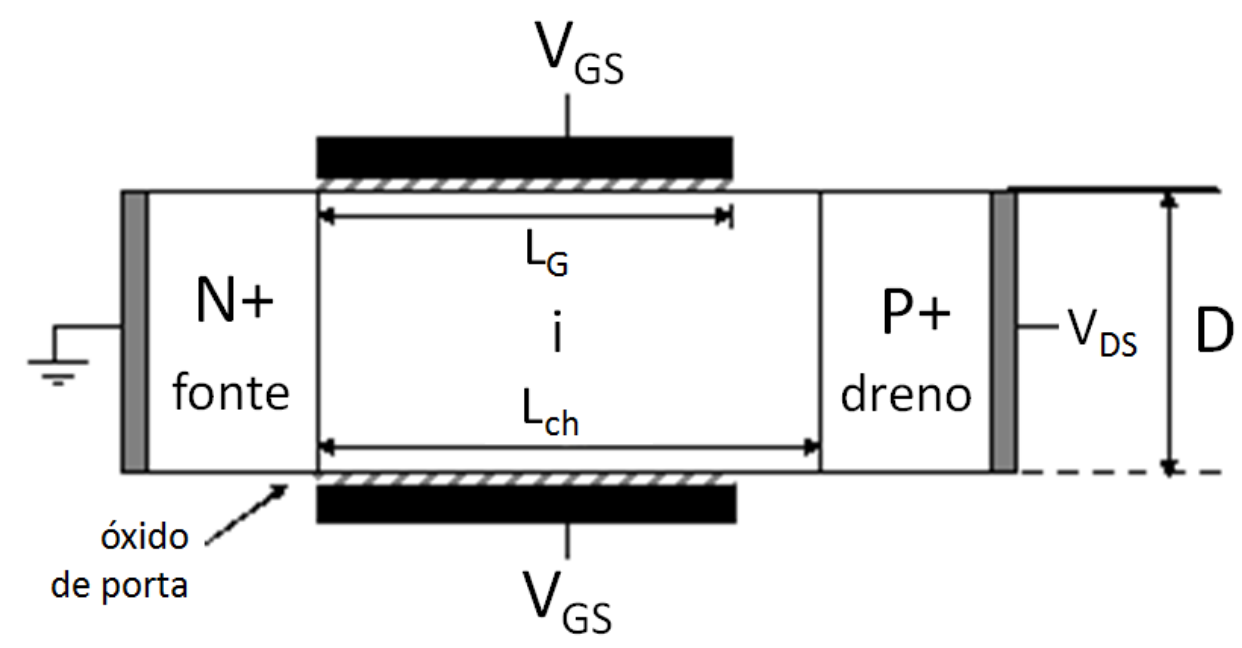

Fonte: Martino (2014)

Enquanto isso, a análise da performance analógica dos TFETs foi realizada a partir de dados experimentais obtidos em estruturas fabricados no imec/Bélgica. Foram utilizados dispositivos do tipo N, com 100 nanofios em paralelo ( $N W=100$ ), dielétrico de porta composto por $3 \mathrm{~nm}$ de $\mathrm{HfO}_{2}$ e $1 \mathrm{~nm}$ de $\mathrm{SiO}_{2}$ na interface. As demais dimensões incluem o comprimento de canal ( $\left.L_{c h}\right)$ de $220 \mathrm{~nm}$, o comprimento de porta $\left(L_{G}\right)$ de $150 \mathrm{~nm}$, a sobreposição de porta em relação à junção canal/fonte (LGS) de 30nm, a subposição em relação à junção canal/dreno (LGD) de 100nm e o diâmetro (D) de 200nm.

Foram comparados quatro dispositivos, sendo dois com fonte $\mathrm{Si}_{1-x} \mathrm{Ge}_{x}$ ( $\mathrm{Si}_{0,73} \mathrm{Ge}_{0,27}$ e $\mathrm{Si}_{0,56} \mathrm{Ge}_{0,44}$ ) e dois com fonte $100 \% \mathrm{Si}$ (junção de perfil abrupto e não abrupto). Mais detalhes sobre as estruturas utilizadas podem ser encontrados em (56). 
Figura 19 - Seção transversal de um NW-TFET obtida com microscopia eletrônica de transmissão.

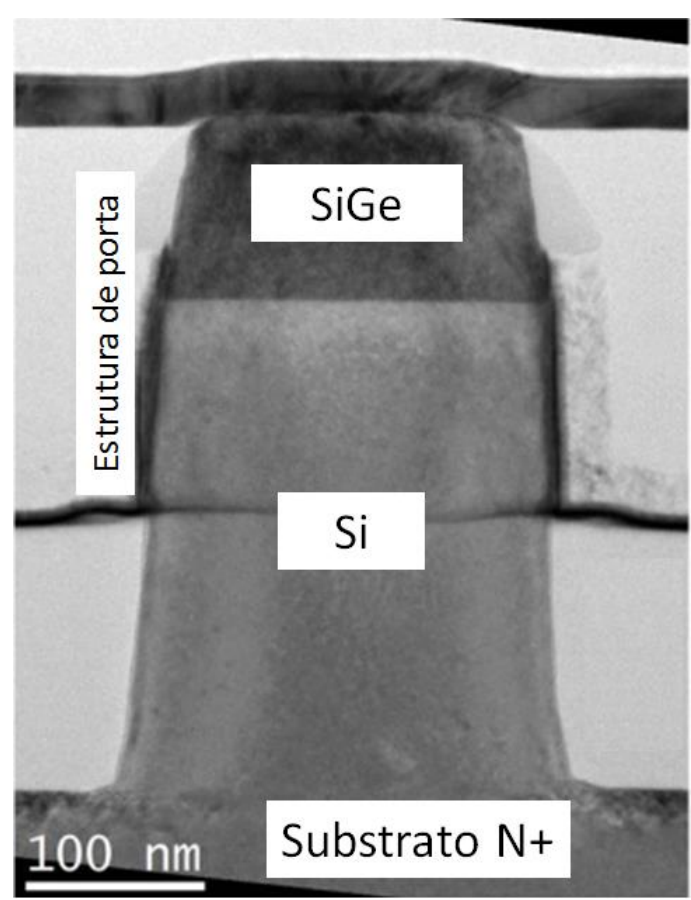

Fonte: Martino (2014)

Figura 20 - Estrutura esquemática de um NW-TFET.

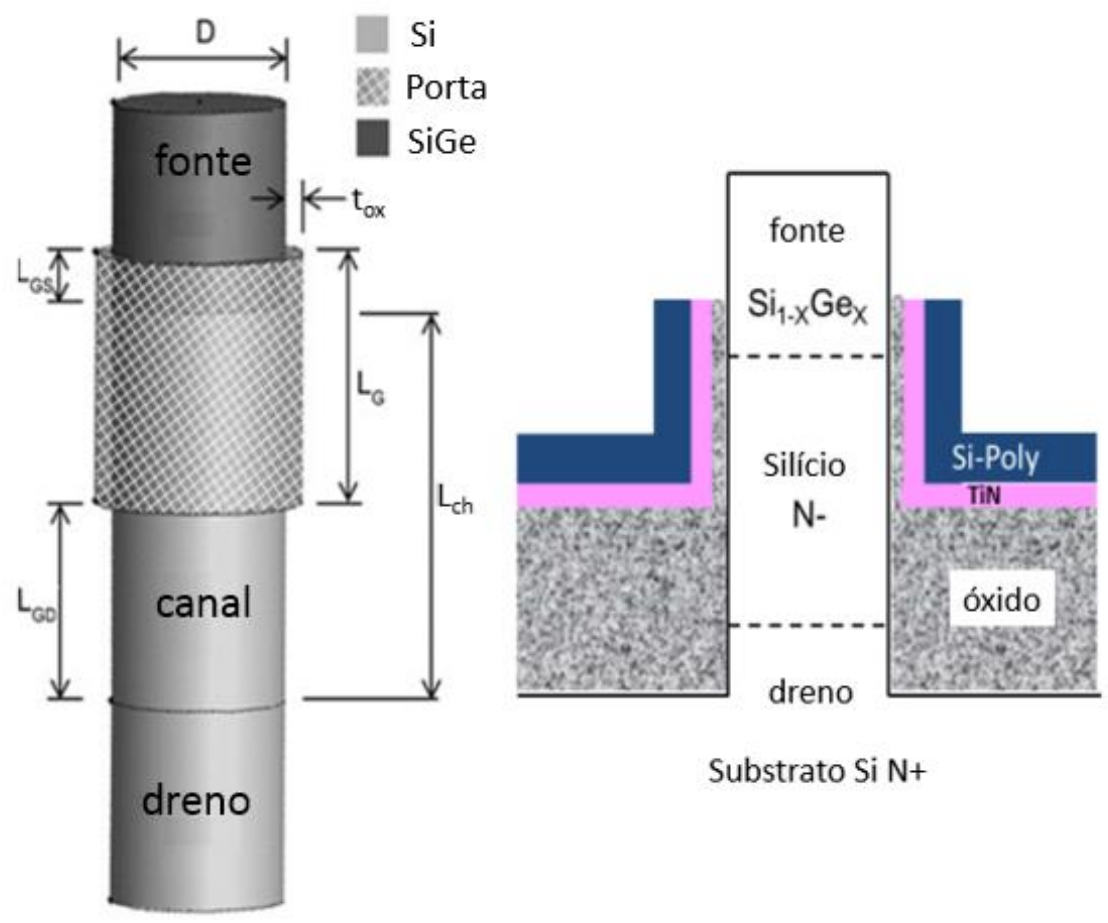

Fonte: Martino (2014) 


\subsection{IMPACTO DA ESTRUTURA NO ESTREITAMENTO DA BARREIRA DE TUNELAMENTO INDUZIDO PELA TENSÃO DE DRENO}

Como previamente comentado, nesta etapa será destacado o impacto de uma alta tensão de dreno em transistores de canal curto, com base no parâmetro do DIBT, que quantifica a variação da tensão de limiar em função das suas condições de polarização.

Será comparado o impacto de estruturas diferentes quanto ao comprimento de canal, à subposição de porta em relação à junção canal/dreno e ao perfil de dopagem nas junções canal/fonte e canal/dreno.

Reforçando a explicação teórica detalhada em 2.1, espera-se que um dispositivo TFET apresente baixa susceptibilidade ao comprimento de canal, visto que o tunelamento de banda para banda acontece muito próximo à junção canal/fonte.

Com base nisso, a Figura 21 apresenta a corrente de dreno em função da tensão de porta para comprimento de canal variando de 20 a 100nm, com tensão de dreno fixa em $-1,5 \mathrm{~V}$, suposição de porta fixa em $10 \mathrm{~nm}$ e perfis de dopagem abruptos.

Os resultados mostram que quando o comprimento de canal é reduzido até $60 \mathrm{~nm}$, a corrente de dreno praticamente não é afetada pela polarização de dreno. Entretanto, valores menores de $L_{c h}$ permitem que a alta tensão no dreno influencie nas bandas próximas à junção canal/fonte. Este efeito é extremamente importante quando o comprimento de canal atinge $20 \mathrm{~nm}$, aumentando a corrente em estado desligado, deslocando a tensão de limiar e piorando a mínima inclinação de sublimiar que pode ser obtida. 
Figura 21 - Corrente de dreno em função da tensão de porta para perfil de dopagem abrupto, com $V_{D S}=-1,5 \mathrm{~V}, \mathrm{~L}_{\mathrm{ch}}-\mathrm{L}_{\mathrm{G}}=10 \mathrm{~nm}$ e $\mathrm{L}_{\mathrm{ch}}$ variando de 20 a $100 \mathrm{~nm}$.

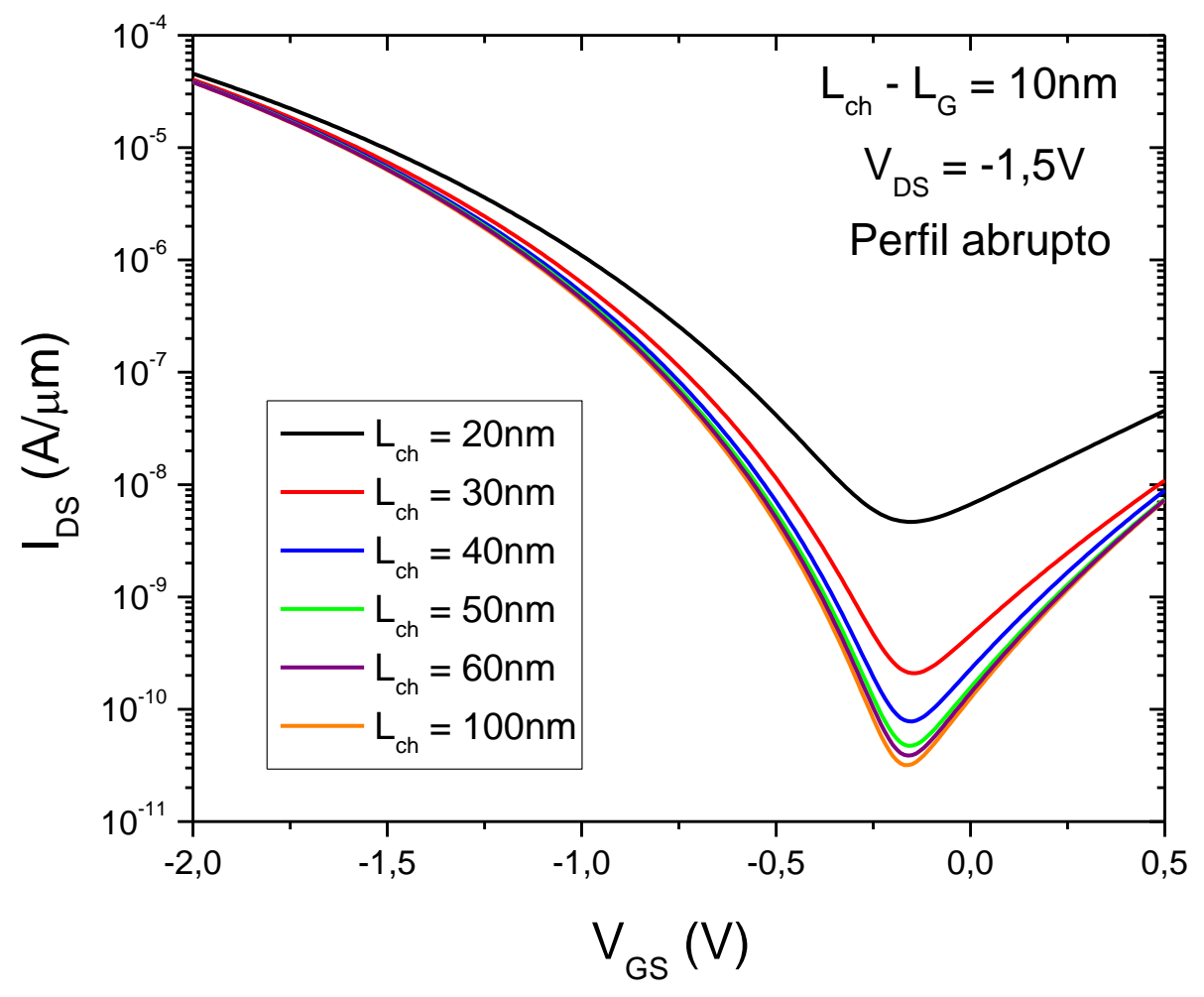

Fonte: Martino (2014)

A seguir, foram selecionados os dispositivos com comprimento de canal de $60 \mathrm{~nm}$, quando o fenômeno começa a ocorrer para $\mathrm{V}_{D S}=-1,5 \mathrm{~V}$, e de $20 \mathrm{~nm}$, quando o fenômeno é máximo entre os casos simulados. A Figura 22 mostra a corrente de dreno em função da tensão de porta para estes dois valores de comprimento de canal e para duas diferentes condições de polarização de dreno $\left(V_{D S}=-1,5 \mathrm{~V}\right.$ e $\bigvee_{D S}=$ $-0,05 \mathrm{~V})$.

Os resultados mostram que, mantendo a tensão de dreno próxima de zero, o transistor efetivamente apresenta a esperada baixa susceptibilidade ao comprimento de canal, mesmo para $L_{c h}$ de apenas $20 \mathrm{~nm}$. Além disso, fica claro que a influência da tensão de dreno é muito maior na região em que o transistor está desligado, com um elevado efeito ambipolar para polarizações de dreno mais significativas. Também pode-se notar que a tensão de limiar se desloca para a direita (isto é, aumenta em valor absoluto) à medida que o comprimento de canal é reduzido. 
Figura 22 - Corrente de dreno em função da tensão de porta para perfil de dopagem abrupto, $L_{c h}-L_{G}=10 \mathrm{~nm}, V_{D S}$ de $-1,5 \mathrm{~V}$ e $-0,05 \mathrm{~V}$ e $L_{c h}$ de $20 \mathrm{~nm}$ e $60 \mathrm{~nm}$.

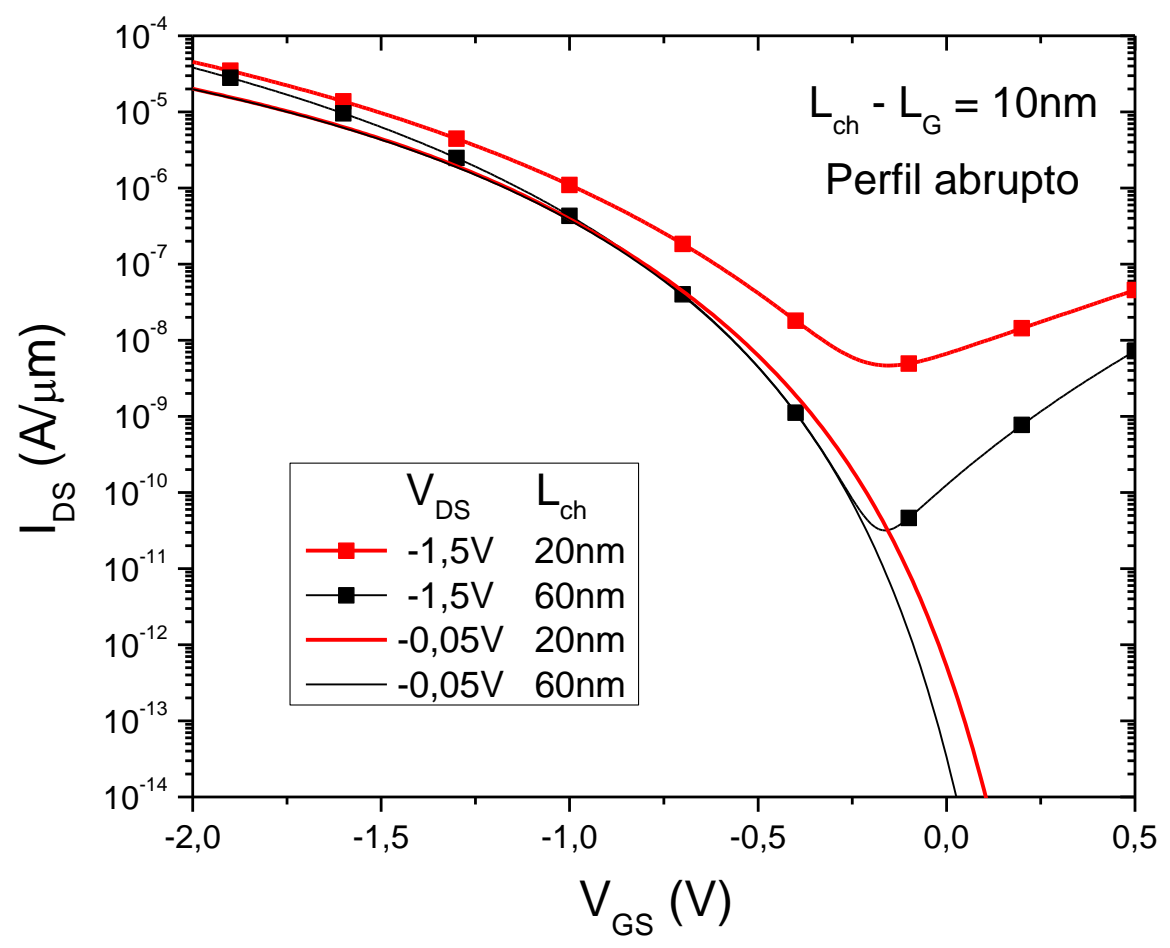

Fonte: Martino (2014)

Para esclarecer o fenômeno, a Figura 23 mostra o diagrama de bandas de energia nas quatro combinações selecionadas anteriormente. $O$ diagrama apresenta as bandas sob a condição em que a corrente de dreno é de $10^{-7} \mathrm{~A} / \mu \mathrm{m}$. Esta condição foi definida como o caso correspondente à tensão de limiar para os subsequentes cálculos do DIBT (57).

É possível observar que, quando o canal é muito curto e a tensão tem módulo elevado, há um estreitamento da barreira de tunelamento próximo à junção canal/fonte, causando um aumento na corrente de dreno, exatamente como comentado nas tanto na Figura 21 quanto na Figura 22. Este efeito seria ainda mais relevante para a condição de tensão de porta na região de sublimiar, visto que seria esperada uma largura de banda proibida grande o suficiente para manter uma baixa corrente no estado de transistor desligado.

Se qualquer uma destas condições (canal curto e alto módulo de tensão de dreno) não for satisfeita, o deslocamento da tensão de limiar se torna desprezível. Estas observações correspondem à fundamentação do fenômeno de estreitamento da barreira de tunelamento induzido pela tensão de dreno. 
Destacando o transistor com $\mathrm{L}_{c h}=60 \mathrm{~nm}$, é mais fácil notar a influência da subposição de porta em relação à junção fonte/dreno $\left(L_{c h}-L_{G}=10 \mathrm{~nm}\right)$ no formato do diagrama de bandas de energia. Maiores valores de subposição resultariam numa maior influência da tensão de dreno no canal. Com base nesta observação, o efeito da subposição de porta no DIBT também será calculado nesta seção.

Figura 23 - Diagrama de bandas de energia para perfil de dopagem abrupto, $L_{c h}-L_{G}=10 \mathrm{~nm}$, $V_{D S}$ de $-1,5 \mathrm{~V}$ e $-0,05 \mathrm{~V}$ e $\mathrm{L}_{\text {ch }}$ de $20 \mathrm{~nm}$ e $60 \mathrm{~nm}$ e $\mathrm{IDS}_{D S}=10^{-7} \mathrm{~A} / \mu \mathrm{m}$.

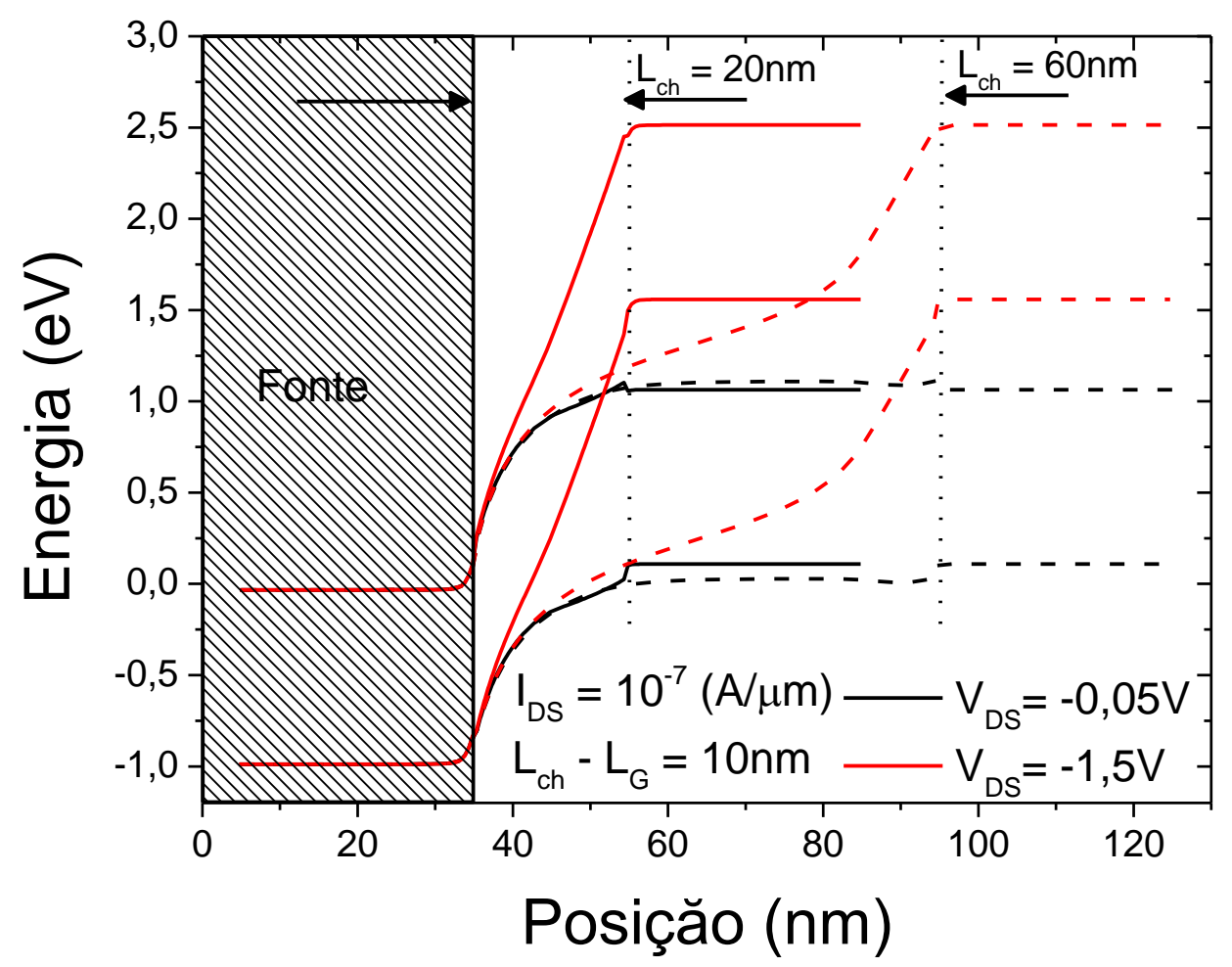

Fonte: Martino (2014)

Completando as curvas características de transferência, a Figura 24 apresenta a corrente de dreno em função da tensão de porta para dois perfis de dopagem diferentes (abrupto e gaussiano) nas junções canal/fonte e canal/dreno. $O$ comprimento de canal foi mantido constante em $30 \mathrm{~nm}$ e a subposição de porta ficou fixa em $10 \mathrm{~nm}$.

Nota-se que dispositivos com perfil de dopagem abrupto apresentam maior corrente lon, menor inclinação de sublimiar e menor corrente ambipolar. Logo, considerando os objetivos fundamentais da tecnologia TFET mencionados no capítulo 1, apresentam um melhor desempenho à primeira vista. 
Figura 24 - Corrente de dreno em função da tensão de porta para $L_{c h}-L_{G}=10 \mathrm{~nm}$, $L_{c h}=30 n m, V_{D S}$ de $-1,5 \mathrm{~V}$ e $-0,05 \mathrm{~V}$ e perfis de dopagem abrupto e gaussiano.

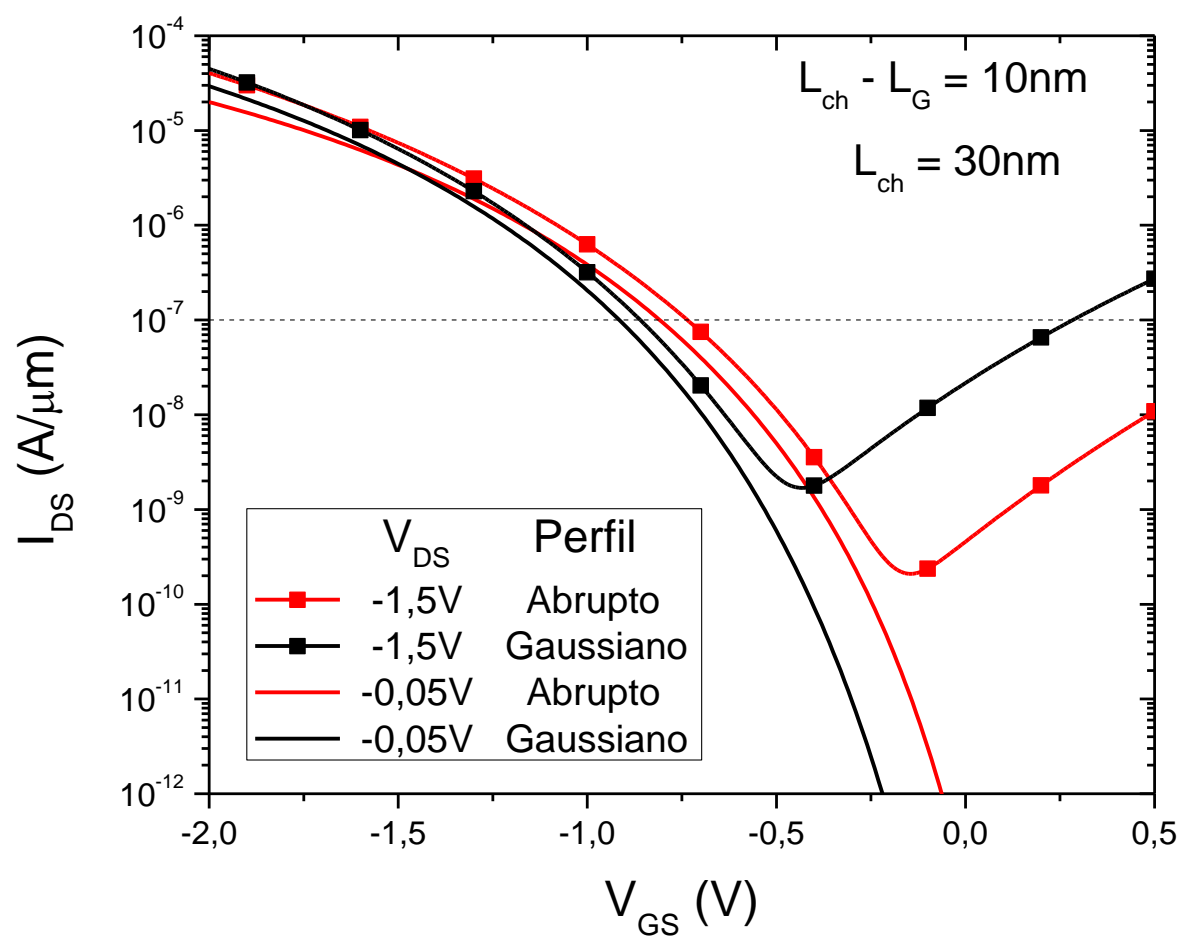

Fonte: Martino (2014)

Entretanto, deve-se também analisar o impacto do DIBT para estabelecer uma comparação em termos de imunidade aos efeitos de canal curto.

Este parâmetro será avaliado quantitativamente pela razão entre a variação de tensão de limiar para duas diferentes polarizações de dreno e a respectiva diferença de tensão de dreno, vide equação (11). Seguindo a metodologia utilizada ao longo desta seção 4.2 , foram selecionados os valores de $V_{D S 1}=-0,05 \mathrm{~V}$ e $V_{D S 2}=$ $-1,5 \mathrm{~V}$. Como já explicado, a tensão de limiar foi definida como a tensão de porta para a qual a corrente de dreno é de $10^{-7} \mathrm{~A} / \mu \mathrm{m}$, isto é, $V_{t h}=V_{G S}\left(I_{D S}=10^{-7} \mathrm{~A} / \mu \mathrm{m}\right)$.

$$
D I B T=\frac{\left|V_{t h}\left(V_{D S 2}\right)-V_{t h}\left(V_{D S 1}\right)\right|}{\left|V_{D S 2}-V_{D S 1}\right|}
$$

Com base nesta proposta matemática, a Figura 25 mostra o DIBT em função do comprimento de canal para dispositivos com perfis de dopagem abrupto e gaussiano. Pode-se concluir que o perfil abrupto resulta em uma indesejada maior influência do estreitamento da barreira de tunelamento para toda a faixa avaliada. A 
diferença entre os valores obtido gira entre $30 \%$ e $50 \%$. Vale salientar que, para $\mathrm{L}_{\mathrm{ch}}=20 \mathrm{~nm}$, o transistor com perfil de dopagem gaussiano sequer atinge o valor de IDS $=10^{-7} \mathrm{~A} / \mu \mathrm{m}$, de modo que não é possível calcular o valor de DIBT seguindo esta metodologia.

Dessa forma, é interessante concluir que, apesar da melhor corrente lon para dispositivos com perfil de dopagem abrupto, se a aplicação requer valores baixos de DIBT, o uso de junções com perfil gaussiano pode ser considerado mais apropriado.

Figura 25 - DIBT em função do comprimento de canal para $L_{c h}-L_{G}=10 \mathrm{~nm}$, $\mathrm{L}_{\mathrm{ch}}$ variando de 20 a 100 $\mathrm{nm}$ e perfis de dopagem abrupto e gaussiano.

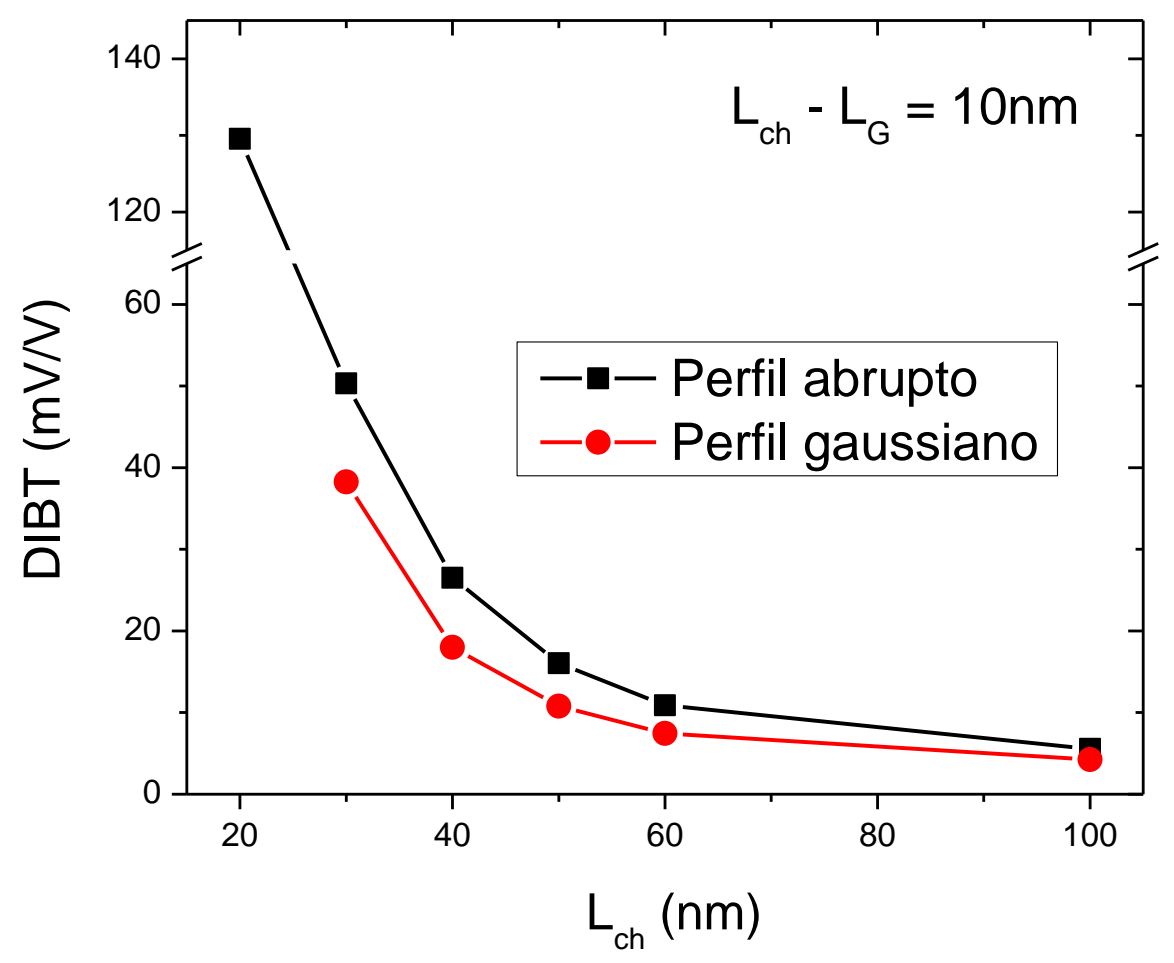

Fonte: Martino (2014)

Finalmente, este procedimento foi repetido para dispositivos com dois diferentes valores de subposição de porta em relação à junção canal/dreno (10 e $20 \mathrm{~nm})$. Estruturas autoalinhadas também foram simuladas, porém não atingiram a condição de corrente de dreno de $10^{-7} \mathrm{~A} / \mu \mathrm{m}$. A Figura 26 mostra os resultados obtidos para comprimento de canal variando de 30 a $100 \mathrm{~nm}$. 
Figura 26 - DIBT em função do comprimento de canal para perfil de dopagem abrupto, $L_{c h}-L_{G}$ de $10 \mathrm{~nm}$ e $20 \mathrm{~nm}$ e $L_{c h}$ variando de 30 a $100 \mathrm{~nm}$.

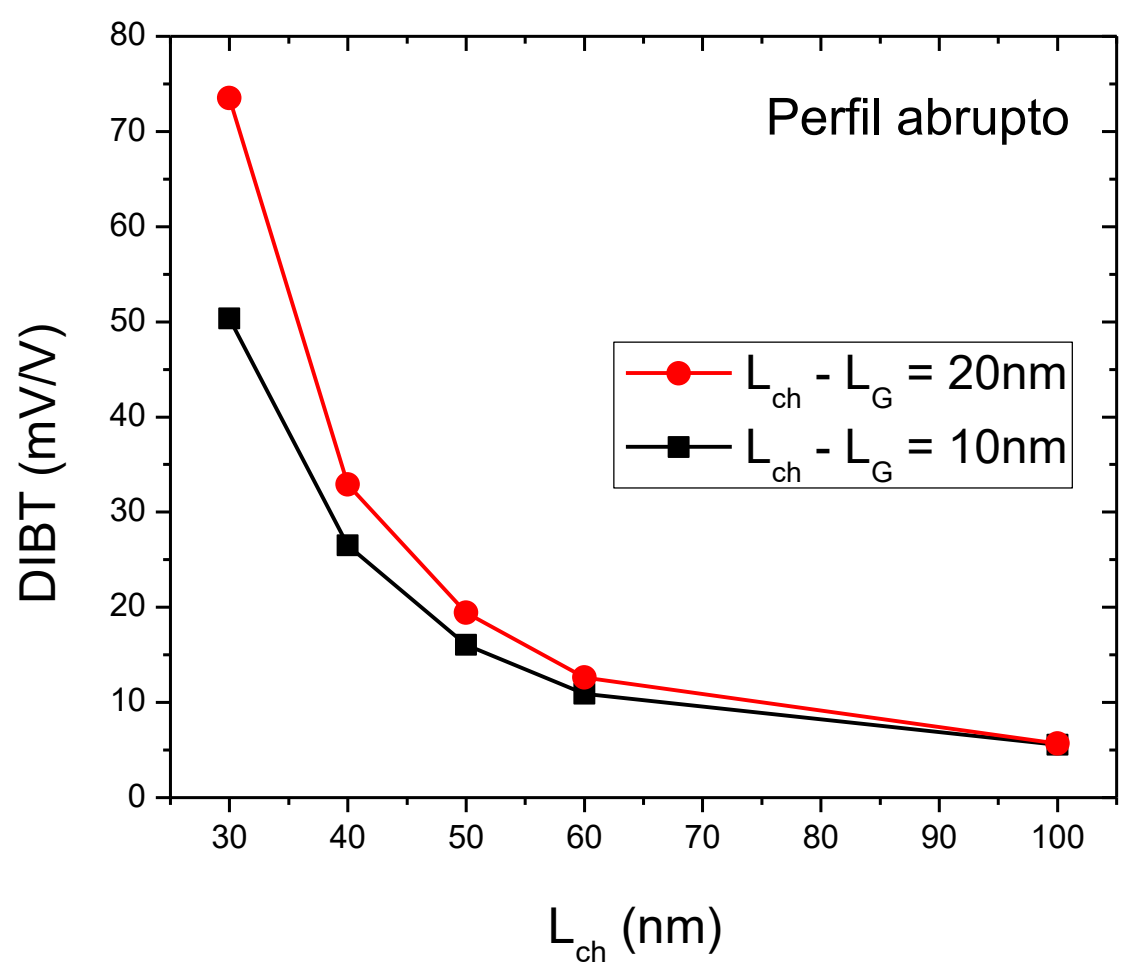

Fonte: Martino (2014)

As curvas mostram que, dado um valor fixo de comprimento de canal, o estreitamento da barreira de tunelamento piora à medida que a subposição de porta aumenta. A diferença diminui para canais mais longos, visto que a diferença relativa entre os comprimentos de porta também diminui, de modo que a influência do dreno na junção canal/fonte se torna desprezível.

Em uma comparação quantitativa, há uma diferença de $45 \%$ para o caso de $L_{c h}=30 \mathrm{~nm}\left(L_{G}\right.$ de 10 e $\left.20 \mathrm{~nm}\right)$, de $21 \%$ para $L_{c h}=50 \mathrm{~nm}$ ( $L_{G}$ de 30 e $40 \mathrm{~nm}$ ) e de apenas $2 \%$ para $L_{c h}=100 \mathrm{~nm}$ ( $L_{G}$ de 80 e $90 \mathrm{~nm}$ ). Em outras palavras, mantendo o comprimento de canal fixo, o aumento na subposição de porta torna a polarização do dreno mais relevante no diagrama de bandas próximo à junção canal/fonte, agravando o efeito do estreitamento da barreira de tunelamento.

Esta conclusão também é notável, visto que a subposição vem sendo largamente utilizada para reduzir o efeito ambipolar e melhorar o comportamento na região de sublimiar (58). Como consequência, deve-se buscar uma solução de compromisso dependendo da aplicação, para satisfazer os requerimentos relacionados à inclinação de sublimiar e ao DIBT. 
Combinando as observações desta seção, nota-se que projeto de dispositivos com junções de perfil de dopagem abrupto e com significativa subposição de porta em relação à junção canal/dreno resultam em correntes de dreno mais elevadas em estado acionado, enquanto a tendência oposta é mais adequada para aplicações que requeiram uma minimização do fenômeno de estreitamento de barreira de tunelamento induzido pela tensão de dreno.

\subsection{IMPACTO DA TEMPERATURA E DOS MECANISMOS DE TRANSPORTE NO COMPORTAMENTO ANALÓGICO}

Neste item será destacada a performance analógica de dispositivos TFETs e o impacto da variação da temperatura e do mecanismo de transporte dominante. A análise foi baseada nos resultados experimentais de transistores com diferentes composições de fonte (100\% Si e Si $\left.1_{-x} \mathrm{Ge}_{\mathrm{x}}\right)$ e na obtenção da Energia de Ativação para cada condição de polarização. Dessa forma, foi possível relacionar os resultados aos respectivos mecanismos de transporte predominantes em cada caso, notadamente o tunelamento de banda para banda e o tunelamento induzido por armadilhas, além de verificar o impacto dos mesmos nos mais importantes parâmetros analógicos.

Inicialmente, a Figura 27 mostra os resultados experimentais da corrente de dreno em função da tensão de porta para $V_{D S}=1,5 \mathrm{~V}$ e temperatura ambiente. Notase que a maior presença de germânio na composição da fonte resulta em maiores valores de lon, sem prejudicar os valores de loff, o que é justificável pela menor largura de banda proibida deste material. Com isso, são obtidos melhores valores de inclinação de sublimiar do que com os transistores $100 \%$ Si. Em termos de perfil de dopagem, junções abruptas contribuíram para maiores valores de corrente, o que está alinhado com as observações descritas em 4.2. 
Figura 27 - Corrente de dreno em função da tensão de porta para fontes com diferentes composições.

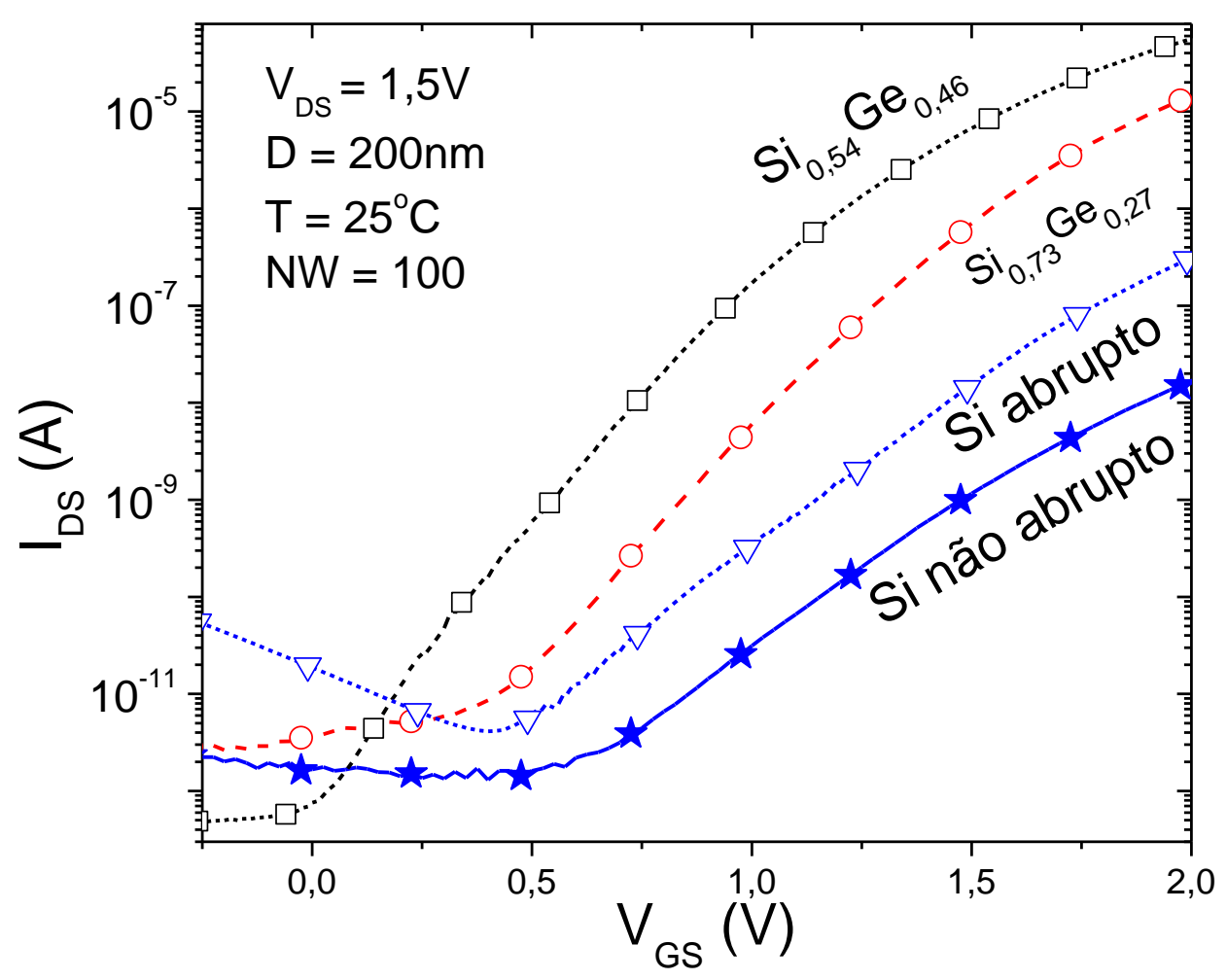

Fonte: Martino (2014)

Para investigar o impacto da temperatura, a Figura 28 e a Figura 29 apresentam as curvas de transferência para dispositivos SiGe e $100 \% \mathrm{Si}$, respectivamente, sob as mesmas polarizações e características estruturais da Figura 27 , mas com variação de temperatura de 25 a $150^{\circ} \mathrm{C}$. 
Figura 28 - Corrente de dreno experimental para temperatura variando de 25 a $150^{\circ} \mathrm{C}$. Duas diferentes estruturas de fonte foram analisadas: $\mathrm{Si}_{0,73} \mathrm{Ge}_{0,27}$ e $\mathrm{Si}_{0,54} \mathrm{Ge}_{0,46}$.

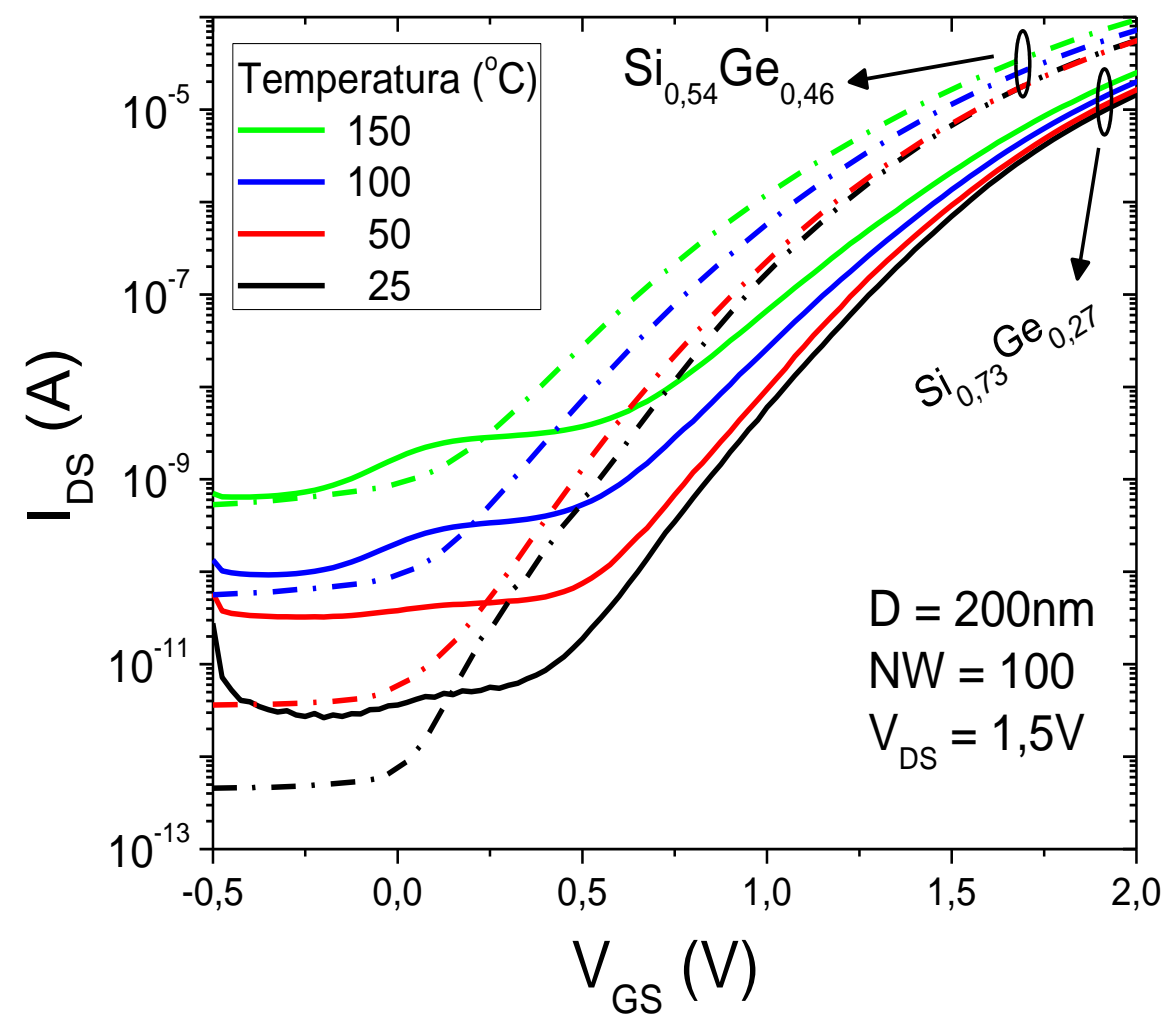

Fonte: Martino (2014)

Figura 29 - Corrente de dreno experimental para temperatura variando de 25 a $150^{\circ} \mathrm{C}$. Duas diferentes técnicas de dopagem foram analisadas.

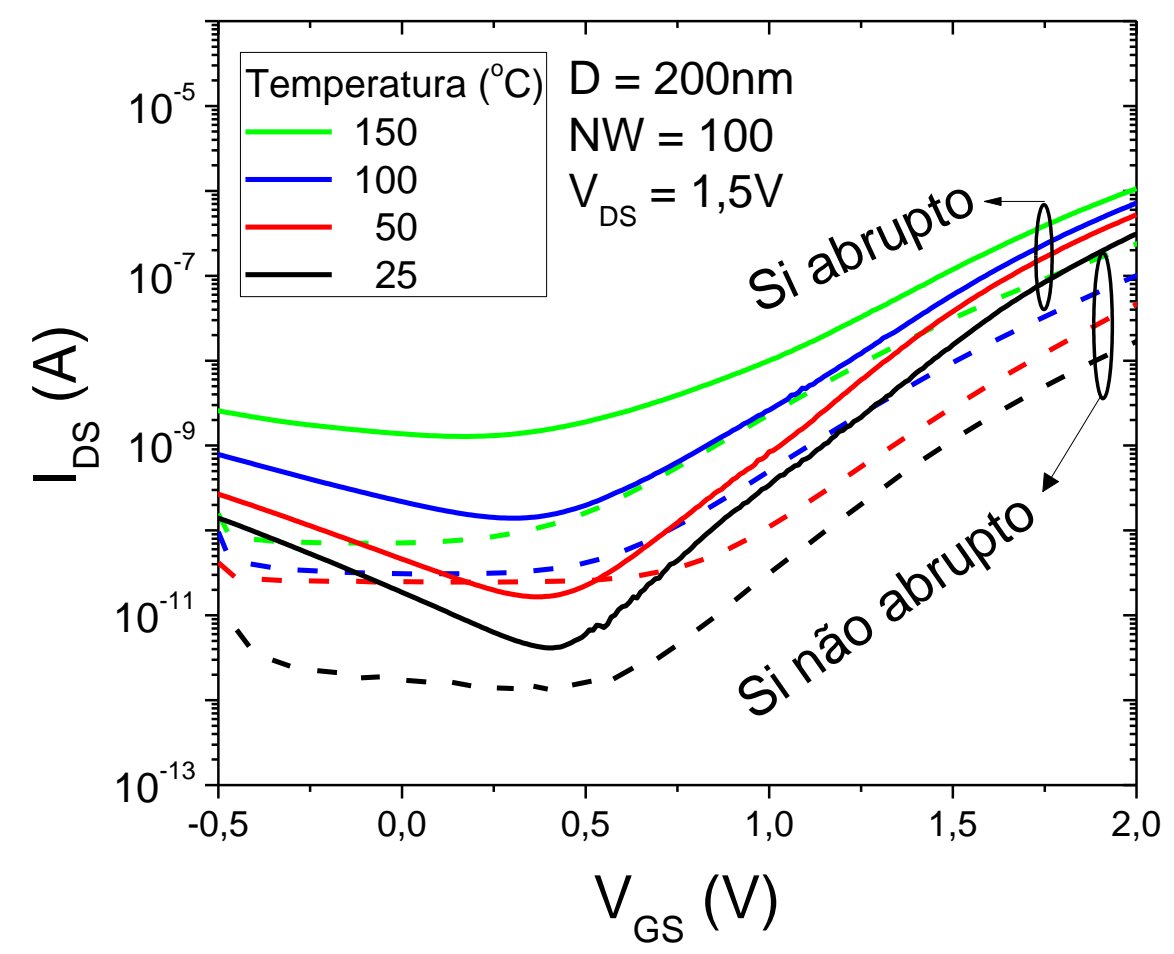

Fonte: Martino (2014) 
Conforme previamente estudado em (59), dispositivos SiGe apresentam corrente lon menos susceptível à temperatura do que transistores $100 \% \mathrm{Si}$, o que pode ser explicado pelo mecanismo de transporte dominante em cada caso. Enquanto para dispositivos com germânio na fonte tem componente principal resultante de tunelamento de banda para banda (BTBT), cuja dependência com a temperatura é apenas pelo pequeno estreitamento de banda proibida, transistores $100 \%$ Si são dominados por tunelamento induzido por armadilhas, com dependência da temperatura exponencial. Vale salientar que os detalhes sobre cada tipo de mecanismo de transporte e seus fatores determinantes estão descritos em 2.2.

Tendo em mente a importância de identificar o mecanismo de transporte dominante em cada caso, a Figura 30 mostra a Energia de Ativação $\left(E_{A}\right)$ em função da tensão de porta. Sabe-se que $E_{A}$ deve estar entre $\sim E_{g} / 2$ e $E_{g} / 2-\Delta E$ para mecanismos ativados termicamente, como SRH e TAT, e que $E_{A}$ deve apresentar valores menores do que $0,1 \mathrm{eV}$ para BTBT (58).

Figura 30 - Energia de ativação para diferentes composições de fonte.

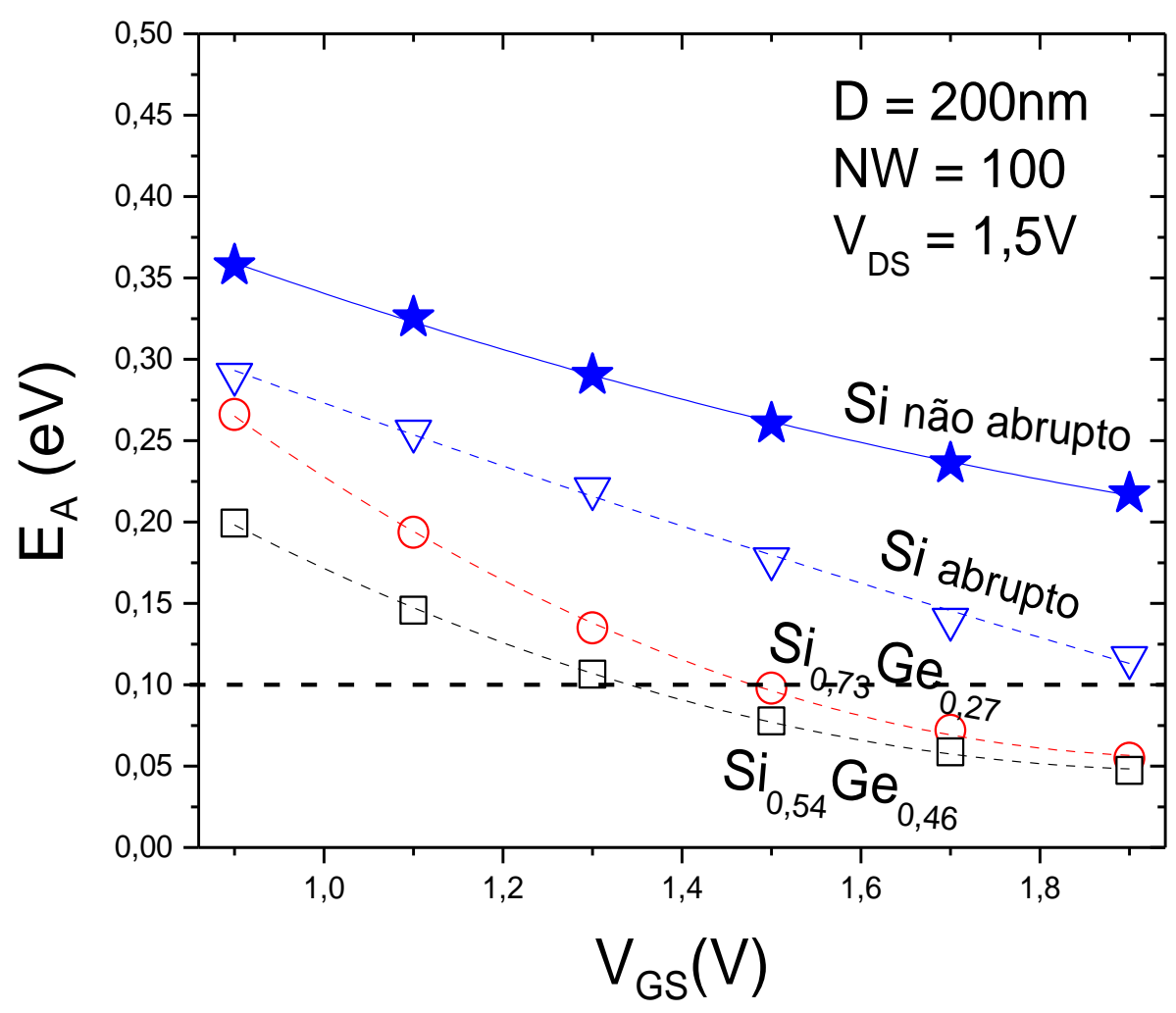

Fonte: Martino (2014) 
Desta forma, os resultados experimentais reafirmam que, para $\mathrm{V}_{\mathrm{GS}}>1,5 \mathrm{~V}$, dispositivos com SiGe são dominados por BTBT. Transistores com fonte de silício e junção abrupta atingem uma região de transição de mecanismo dominante próximo a $V_{G S}=2 \mathrm{~V}$, enquanto transistores com junção não abrupta permanecem sob forte domínio de TAT para toda a faixa de tensão de porta estudada.

Após a análise das curvas características de entrada, a Figura 31 ilustra os resultados obtidos para as curvas de saída a temperatura ambiente. O gráfico mostra um claro plateau para $\mathrm{V}_{D S}>1 \mathrm{~V}$, principalmente para dispositivos com fonte de SiGe. Este comportamento torna os TFETs promissores também para aplicações analógicas, uma vez que isto indicaria alta tensão de Early, baixa condutância de saída e alto ganho intrínseco de tensão.

Figura 31 - Corrente de dreno em função da tensão de dreno para diferentes composições de fonte.

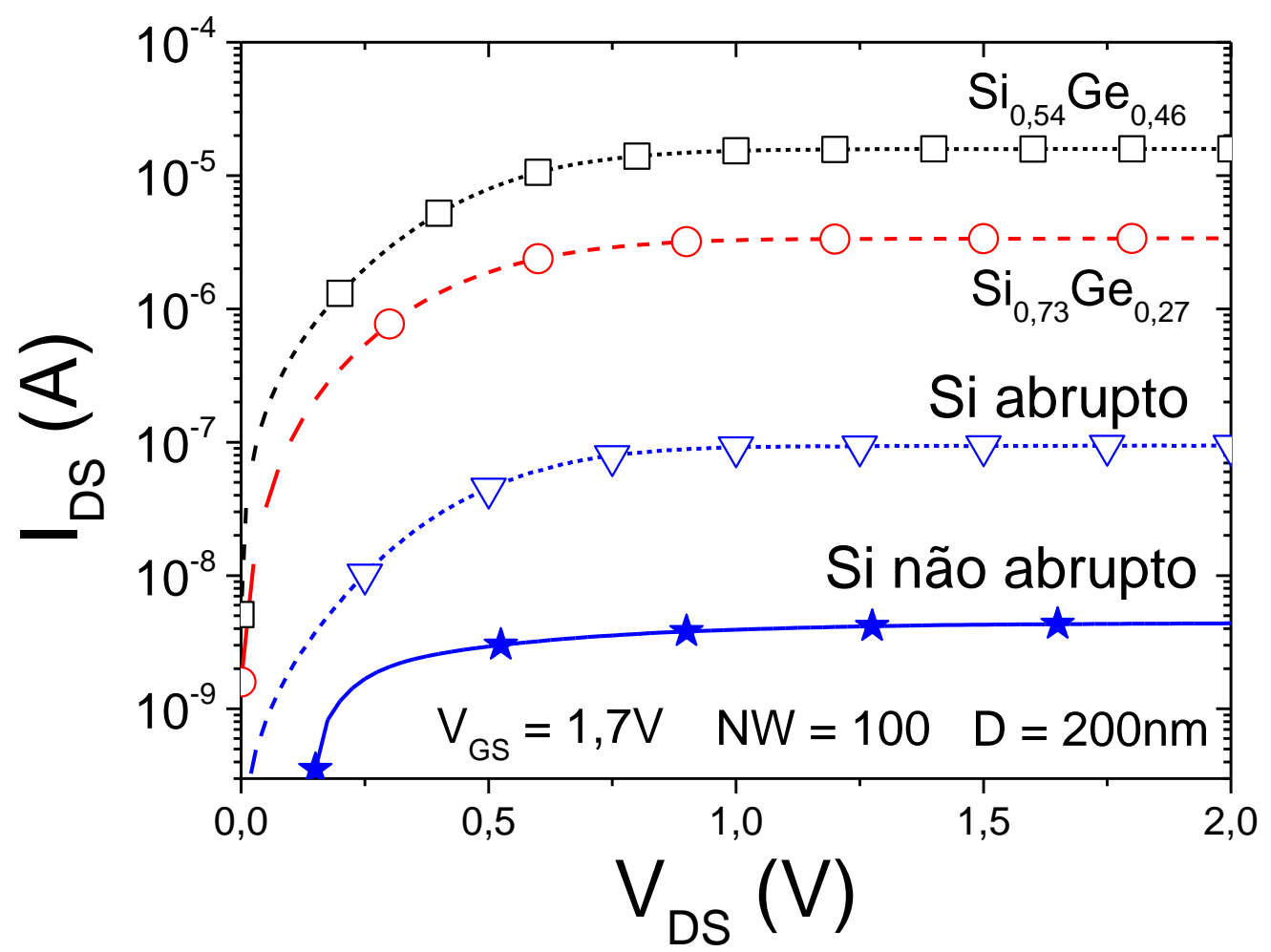

Fonte: Martino (2014)

Para estudar em detalhes a performance analógica de TFETs, a próxima parte deste estudo destaca parâmetros relacionados ao ganho intrínseco de tensão (Av). Vale ressaltar que este parâmetro pode ser calculado pela razão entre a transcondutância e a condutância de saída $\left(A v=g_{m} / g_{D}\right)$ ou pela multiplicação da 
eficiência do transistor pela sua tensão de Early $\left(A v=\left(g_{m} / l_{D S}\right) \times V_{E A}\right)$. Desta forma, os gráficos a seguir representarão cada um destes parâmetros separadamente, sempre incluindo os mesmos quatro dispositivos sob temperatura variando de 25 a $150^{\circ} \mathrm{C}$.

A Figura 32 ilustra a eficiência do transistor em função da temperatura. Os valores foram obtidos fixando uma condição de polarização $\left(V_{G S}=1,7 \mathrm{~V} e\right.$ $\left.V_{D S}=1,5 \mathrm{~V}\right)$, extraindo a corrente de dreno e, finalmente, calculando $\mathrm{g}_{\mathrm{m}} / \mathrm{lDS}_{\mathrm{DS}}$. $\mathrm{O}$ gráfico inserido na Figura 32 mostra um exemplo de impacto da temperatura na eficiência

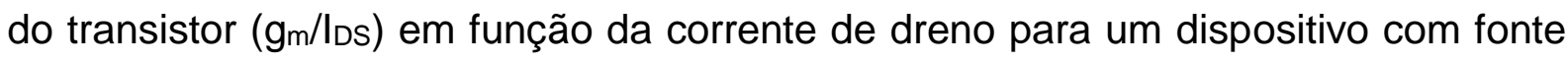
de SiGe. Nota-se uma diminuição no valor máximo com o aumento da temperatura e uma influência desprezível para valores mais altos de corrente de dreno. Uma vez mais pode-se justificar este comportamento pelo mecanismo de transporte

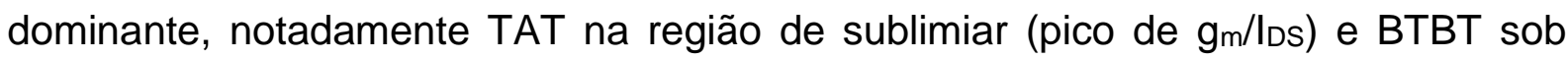
forte inversão (alto lDs).

Figura 32 - Eficiência do transistor ( $\mathrm{g}_{\mathrm{m}} / \mathrm{l}_{\mathrm{DS}}$ ) experimental em função da temperatura para diferentes composições de fonte. Gráfico inserido: Eficiência do transistor em função da corrente de dreno.

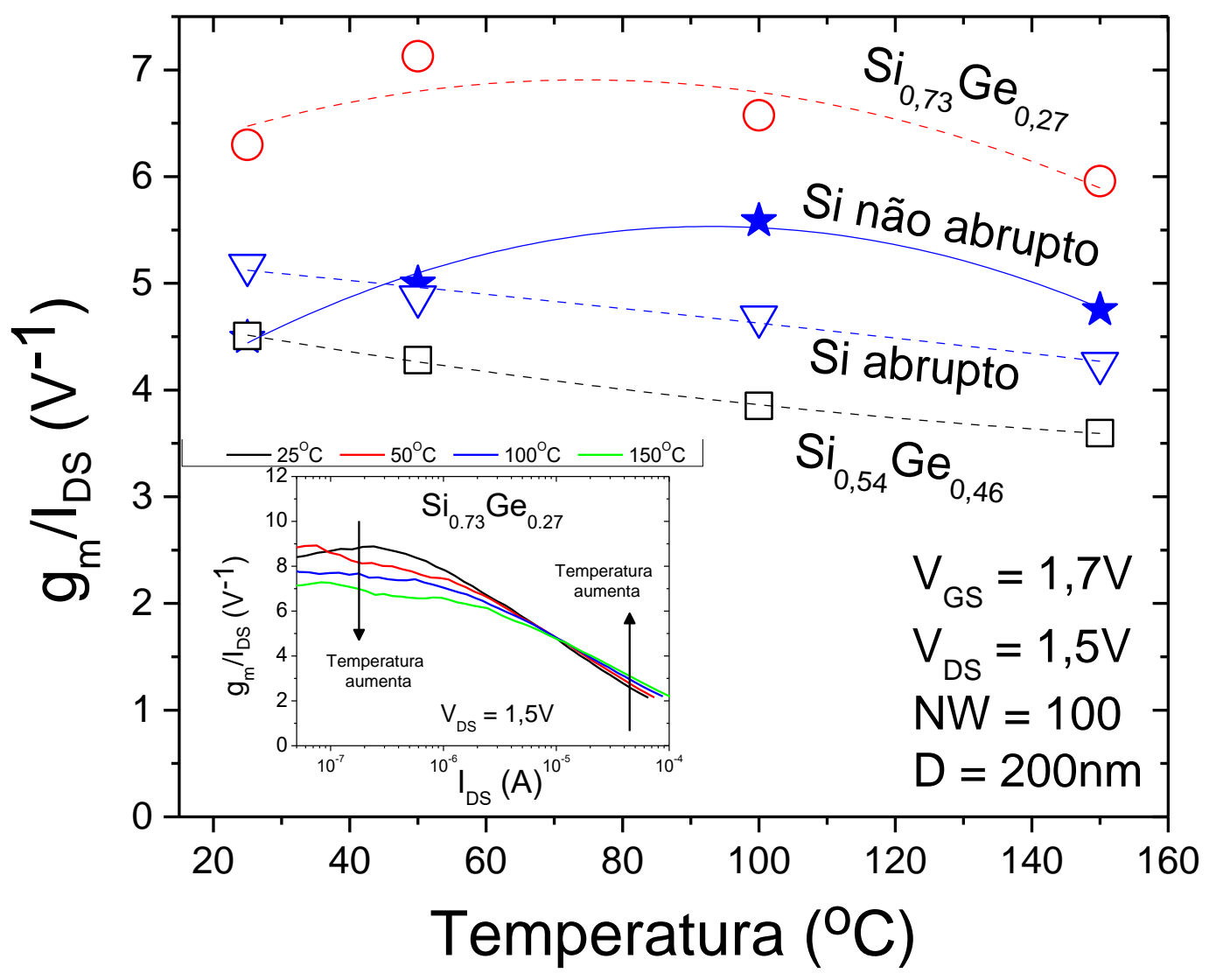

Fonte: Martino (2014) 
Inicialmente é possível notar uma interessante diferença na tendência para dispositivos $100 \%$ Si com junção não abrupta. A respeito da variação relativa, podese calcular que a maior diferença de eficiência para um mesmo transistor é de cerca de $30 \%$, um valor baixo quando comparado à variação dos parâmetros exibidos nos gráficos seguintes.

A susceptibilidade da tensão de Early à variação de temperatura é exibida pela Figura 33. Novamente há uma curva com tendência invertida em relação às demais, notadamente a de fonte de silício com junção não abrupta, que apresenta um fortíssimo aumento de 7 vezes ao longo da faixa de temperatura estudada. Entre as outras três curvas, tanto a de silício com junção abrupta quanto a de $\mathrm{Si}_{0,54} \mathrm{Ge}_{0,46}$ apresentam diminuição de mais de 3 vezes em relação ao valor obtido à temperatura ambiente.

Figura 33 - Tensão de Early em função da temperatura para diferentes composições de fonte.

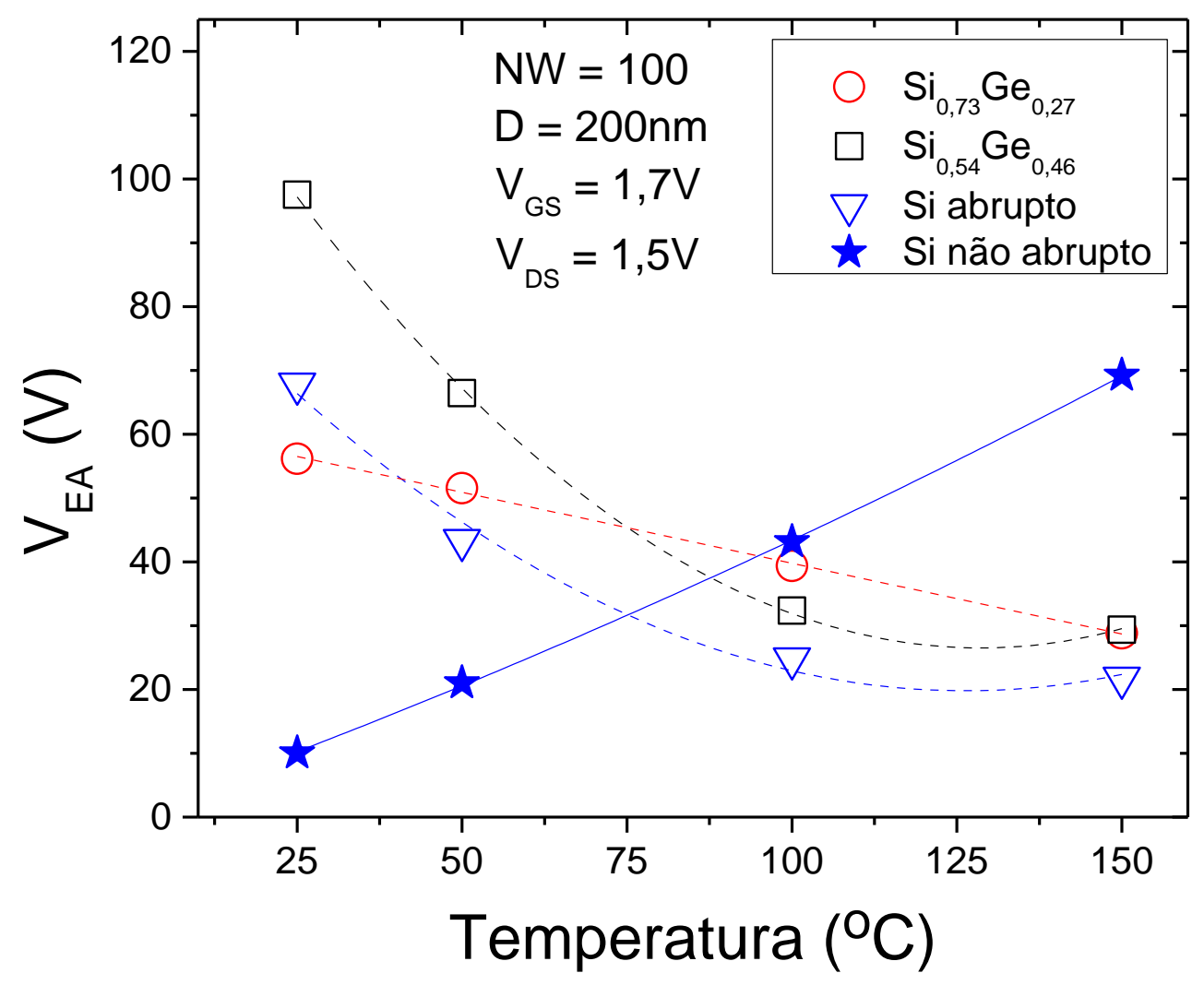

Fonte: Martino (2014) 
Outro parâmetro importante é a transcondutância, apresentado na Figura 34 para os mesmos quatro casos de dispositivos destacados neste capítulo. Nota-se um ligeiro aumento da transcondutância com a temperatura, exceto pelo caso de $\mathrm{Si}$ com junção não abrupta, para o qual a diferença é de um pouco mais de uma ordem de grandeza. Isto está intimamente relacionado à forte dependência do tunelamento induzido por armadilha com a temperatura, componente que domina este dispositivo, em contrapartida ao BTBT que prevalece nas demais três configurações.

Figura 34 - Transcondutância para diferentes composições de fonte.

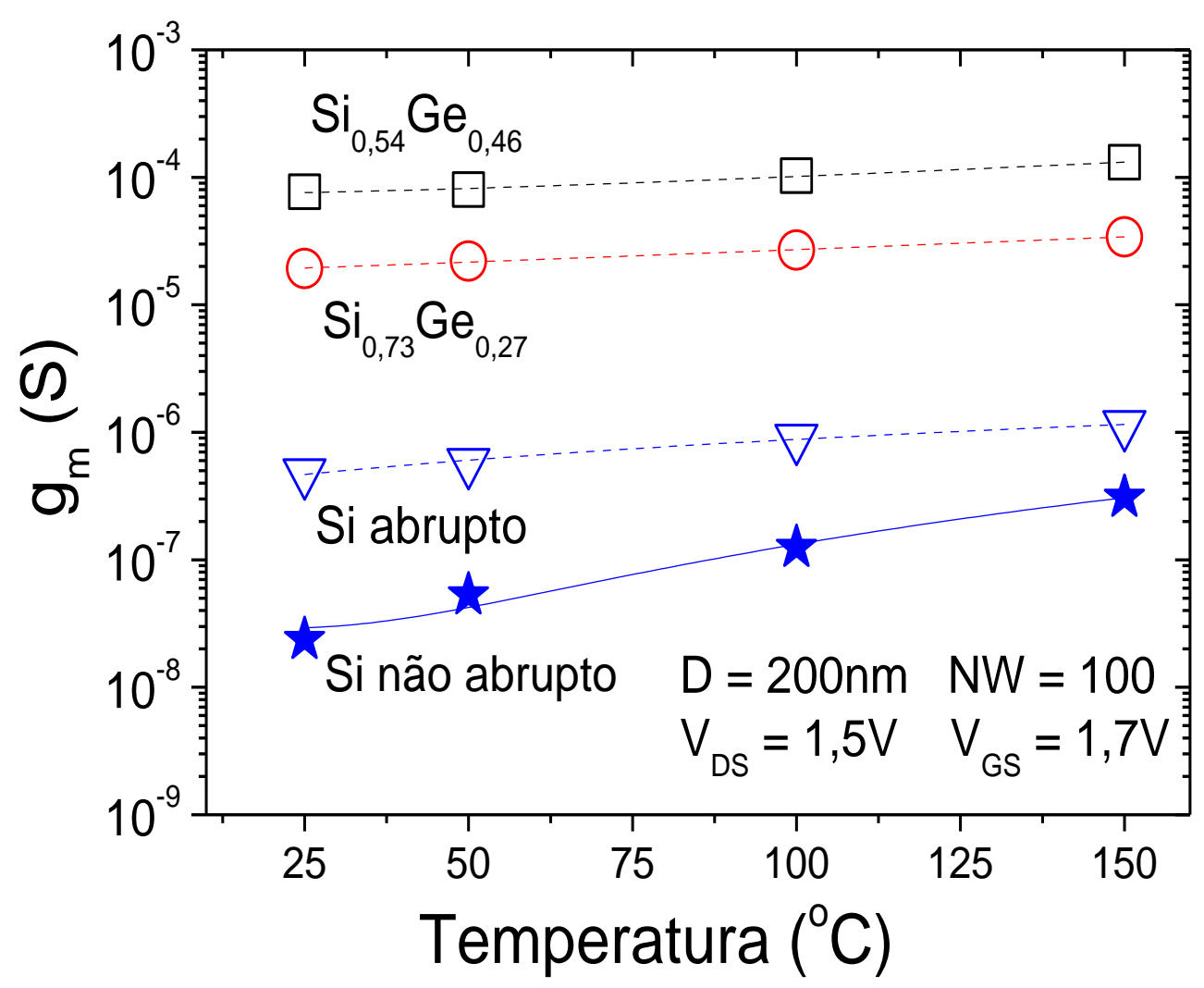

Fonte: Martino (2014)

Já a Figura 35 representa a condutância de saída em função da temperatura. Os maiores valores absolutos são obtidos para as estruturas dominadas por BTBT, em consonância com Figura 30, visto que há uma maior influência da tensão de dreno. Em termos de variação relativa, neste caso há uma tendência ligeiramente positiva para todos os casos. 
Figura 35 - Condutância de saída para diferentes composições de fonte.

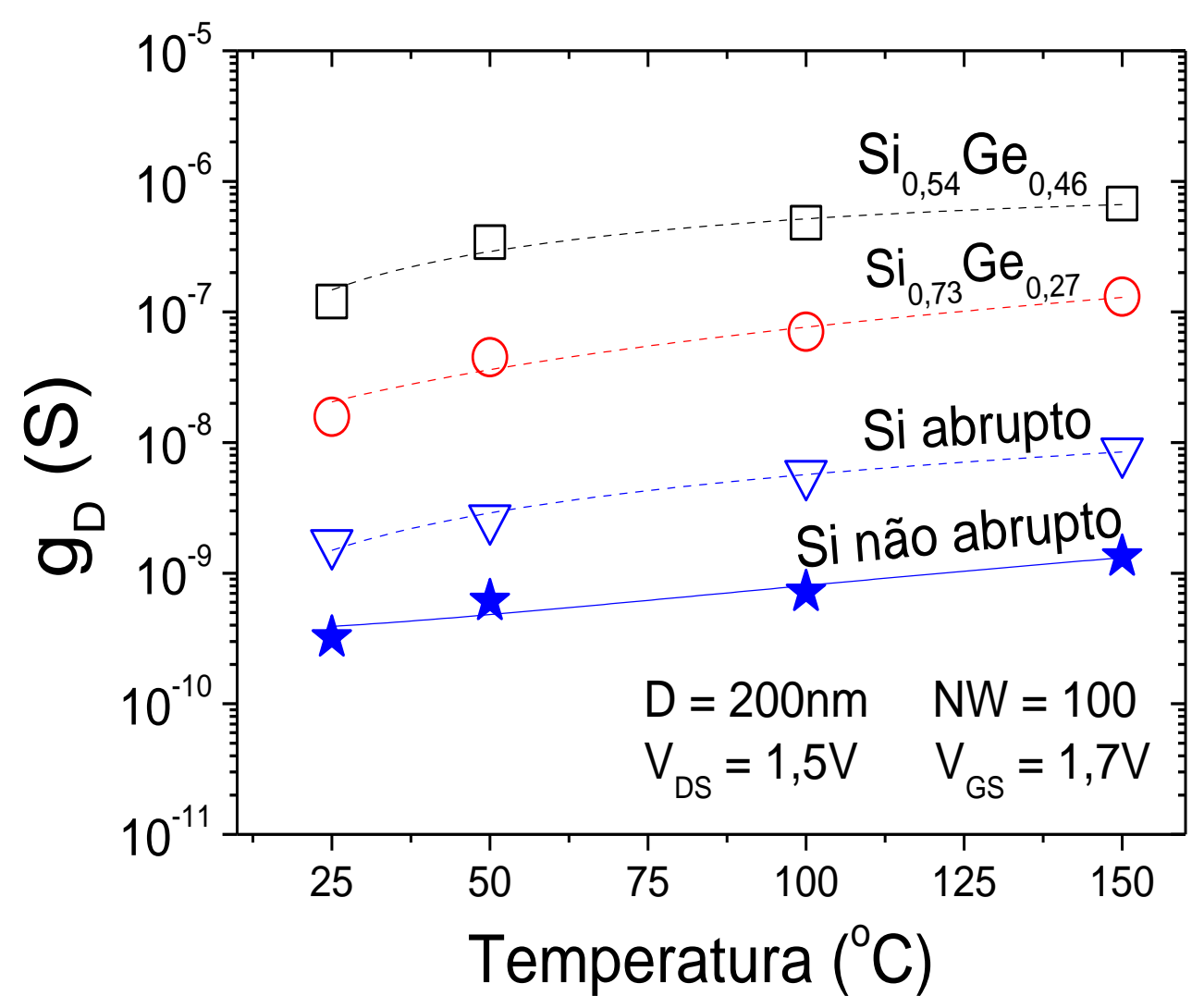

Fonte: Martino (2014)

Finalmente, considerando todos os parâmetros exibidos de eficiência, tensão de Early, transcondutância e condutância, é possível calcular o ganho intrínseco de tensão, mostrado na Figura 36. Como resultado das diferenças nas tendências e nos valores absolutos apontadas ao longo deste capítulo, dispositivos com fonte $100 \% \mathrm{Si}$ e junção não abrupta são os únicos com aumento de $A v$ para temperaturas crescentes. Outros dispositivos, com maior impacto do BTBT, apresentaram tendência negativa em relação à temperatura, revelando uma degradação na performance para aplicações sob altas temperaturas. 
Figura 36 - Ganho intrínseco de tensão em função da temperatura para diferentes composições de fonte.

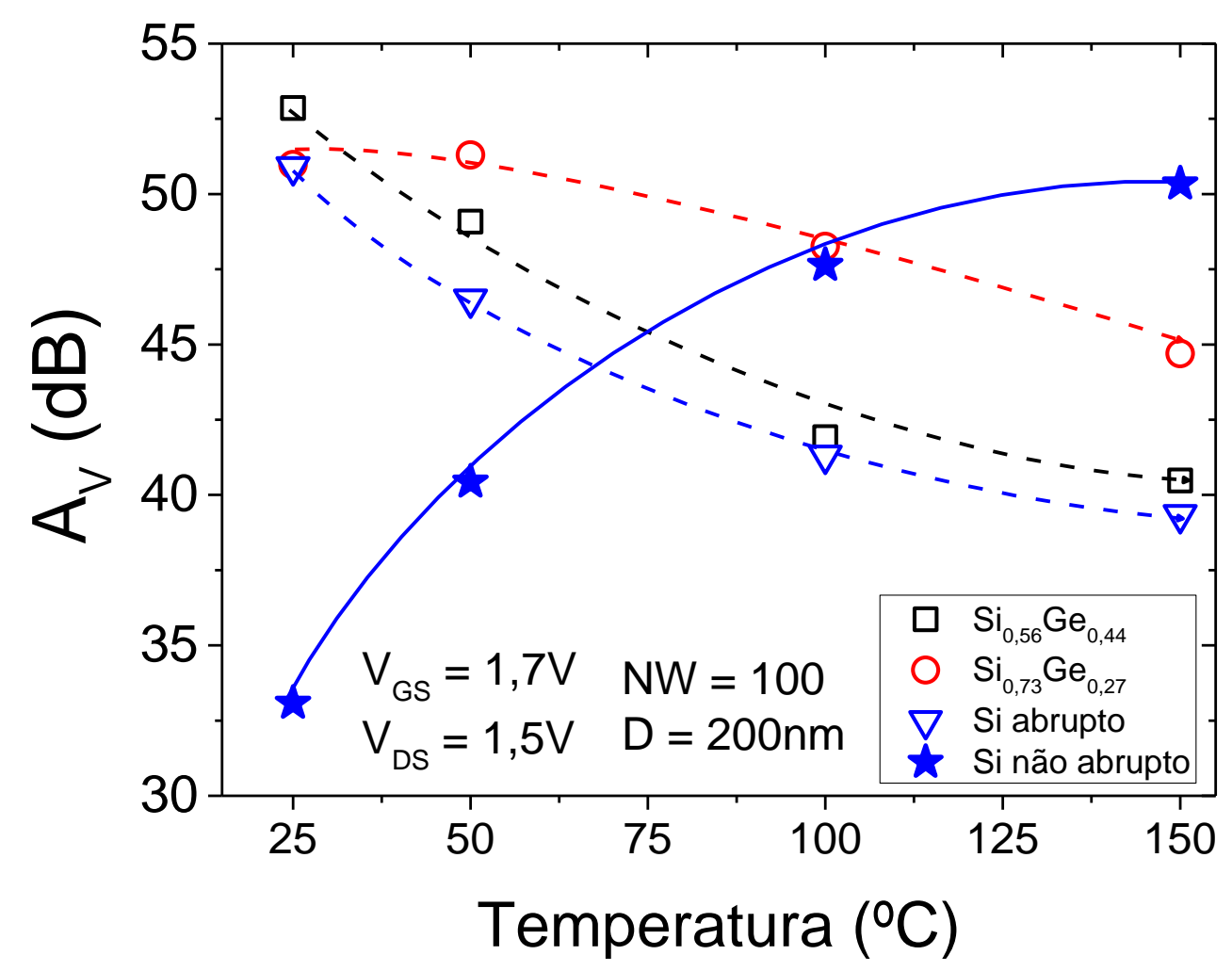

Fonte: Martino (2014)

A conclusão global desta análise focada no comportamento analógico de TFETs é que dispositivos com maior quantidade de germânio em sua composição parecem mais adequados em termos de Av para aplicações por volta da temperatura ambiente. Por outro lado, há uma significativa redução no ganho para maiores temperaturas, de modo que, para operações analógicas acima de $100^{\circ} \mathrm{C}$, dispositivos de $100 \% \mathrm{Si}$, mais simples sob o ponto de vista de fabricação, ainda podem apresentar performances bastante adequadas. 


\section{ANÁLISE DE CIRCUITOS DE ESPELHOS DE CORRENTE}

Este capítulo refere-se ao começo do estudo dos dispositivos de tunelamento sob o ponto de vista da influência que eles podem exercer nos circuitos em que são utilizados, ao invés de restringir-se à análise individual dos mesmos. Para esta análise inicial, foi montado o circuito de um espelho de corrente básico.

Neste caso, transistores Point TFETs foram implementados seguindo o mesmo processo de fabricação de um FinFET, apenas alterando a dopagem da fonte, conforme detalhado em 5.1.1. Deste modo, a performance do espelho de corrente com TFETs pôde ser comparada à do circuito montado com FinFETs, utilizado como referência.

Também foram realizadas medidas experimentais para analisar a performance de espelho de corrente projetados com a tecnologia Line TFET. Os dispositivos, detalhados em 5.1.2, também foram submetidos a diferentes condições de polarização e temperatura, com o objetivo de permitir uma comparação mais abrangente das vantagens e desvantagens de cada uma destas 3 tecnologias em aplicações que utilizem o bloco do espelho de corrente.

\subsection{CARACTERÍSTICAS DOS DISPOSITIVOS}

\subsubsection{Especificação dos dispositivos com estrutura FinFET}

As medidas experimentais foram realizadas com dispositivos de porta tripla fabricados no imec/Bélgica, processados em substratos SOI (100) com espessura de óxido enterrado de $150 \mathrm{~nm}$. TFETs e FinFETs foram fabricados seguindo os mesmos procedimentos e foram escolhidos de uma mesma lâmina. A estrutura de porta consiste de uma camada de $100 \mathrm{~nm}$ de silício policristalino sobre $5 \mathrm{~nm}$ de TiN, enquanto que o seu dielétrico é composto de $2 \mathrm{~nm}$ de $\mathrm{HfO}_{2}$ sobre $1 \mathrm{~nm}$ de $\mathrm{SiO}_{2}$. Todos os transistores apresentam canal com a dopagem natural da lâmina de $10^{15} \mathrm{~cm}^{-3}, 5$ aletas em paralelo, cada qual com altura de $65 \mathrm{~nm}$.

A diferença entre os dispositivos de tecnologias diferentes foi estabelecida pela implantação na fonte, que corresponde ao tipo $\mathrm{N}$ para TFETs e $\mathrm{P}$ para FinFETs. Podem ser encontrados mais detalhes sobre a implementação da tecnologia dos 
FinFETs em (60) e sobre a estrutura física dos componentes utilizados nesta etapa do trabalho em (23) e (61).

A Figura 37 representa a estrutura descrita, enquanto Figura 38 mostra uma imagem destacando as dopagens para o caso de implementação de Point TFETs.

Figura 37 - Representação da estrutura dos dispositivos medidos Point TFETs e FinFETs.

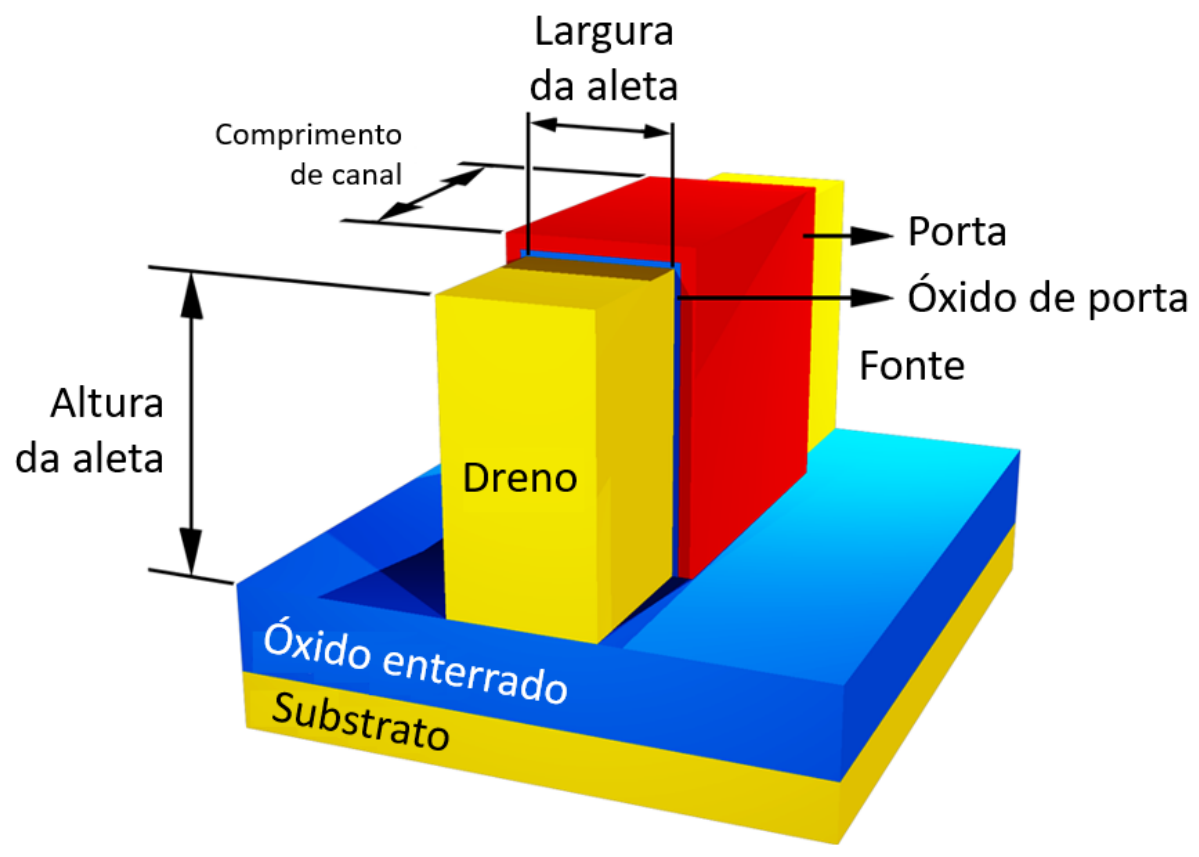

Fonte: Agopian (2015)

Figura 38 - Vista superior da estrutura, com destaque às dopagens para o caso de Point TFETs.

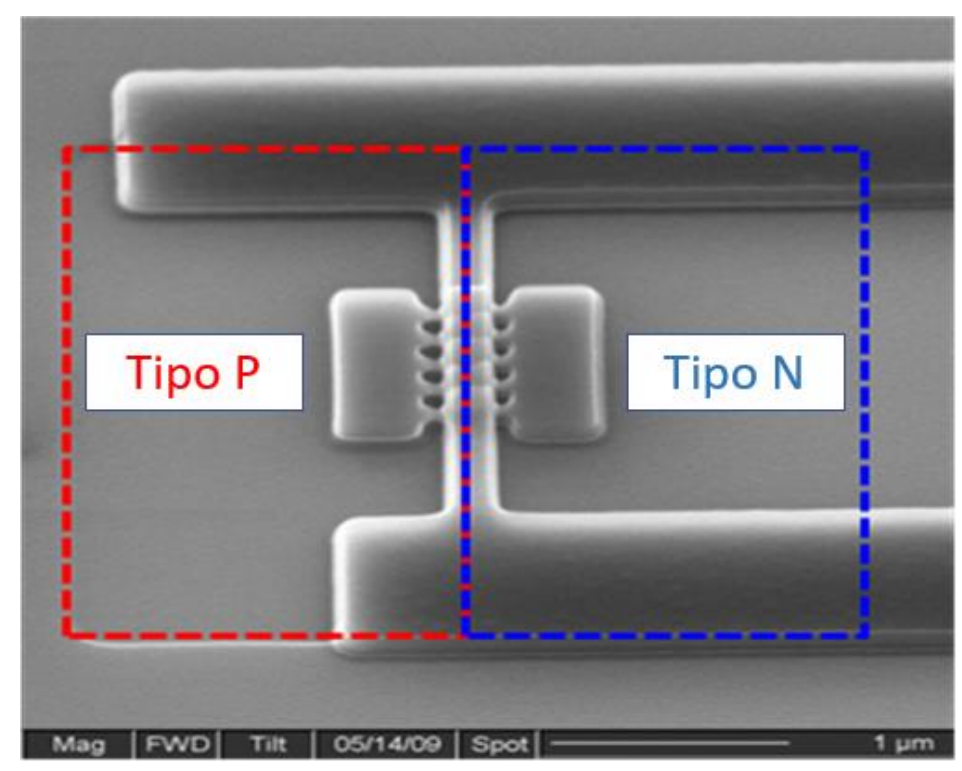

Fonte: Agopian (2015) 


\subsubsection{Especificação dos dispositivos com estrutura Line TFET}

As medidas experimentais de Line TFETs também foram realizadas a partir de 300nm fabricadas no imec/Bélgica, processados em substratos SOI (100). Os transistores foram projetados com heterojunção Si/SiGe, uma vez que é performance é melhorada com uma menor largura de faixa proibida (33). Foram utilizados Line TFETs do tipo N, com uma fina camada de silício intrínseco do canal sobre $30 \mathrm{~nm}$ de espessura de $\mathrm{Si}_{0,55} \mathrm{Ge}_{0,45}$ de fonte, que se prolonga ao longo de todo o comprimento da porta.

Em relação à estrutura de porta, há $1 \mathrm{~nm}$ de $\mathrm{SiO}_{2}$ na interface com o canal, seguido por camadas de 1,8nm de $\mathrm{HfO}_{2}$ e $2 \mathrm{~nm}$ de TiN. Quanto às dimensões de canal, neste capítulo de espelhos de corrente foram utilizados transistores com L variando de 130 a $1000 \mathrm{~nm}$ e W variando de 60 a $105 \mathrm{~nm}$.

A Figura 39 mostra a estrutura dos Line TFETs utilizados para as medidas experimentais, enquanto a Figura 40 mostra uma vista lateral do dispositivo.

Figura 39 - Representação da estrutura dos dispositivos medidos Line TFETs.

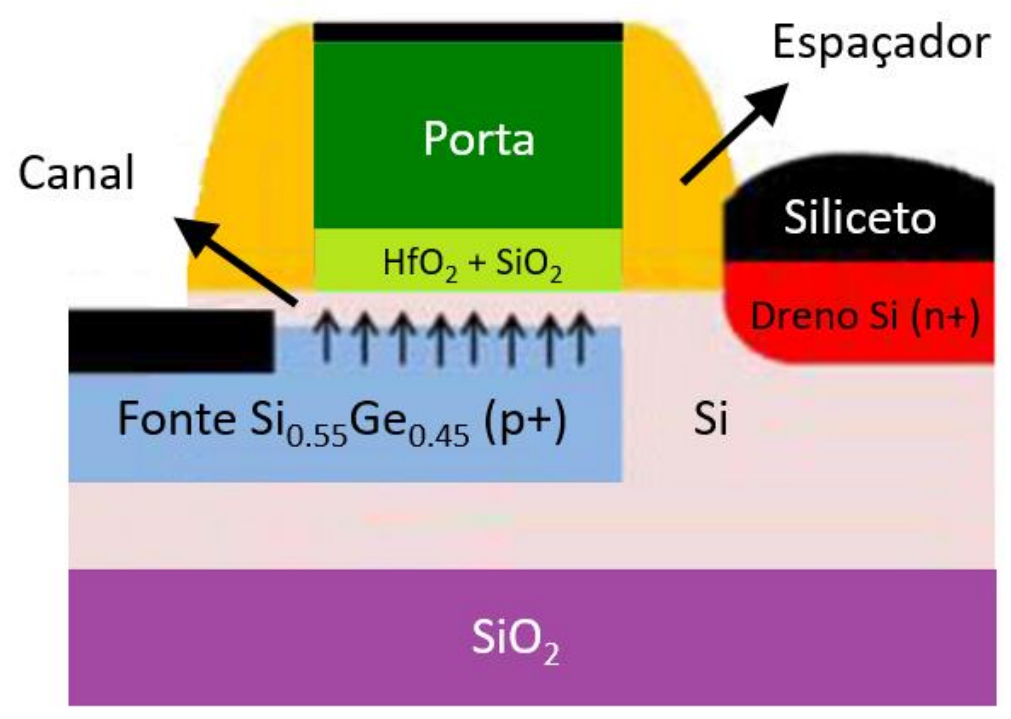

Fonte: Martino (2017) 
Figura 40 - Vista lateral da estrutura Line TFET.

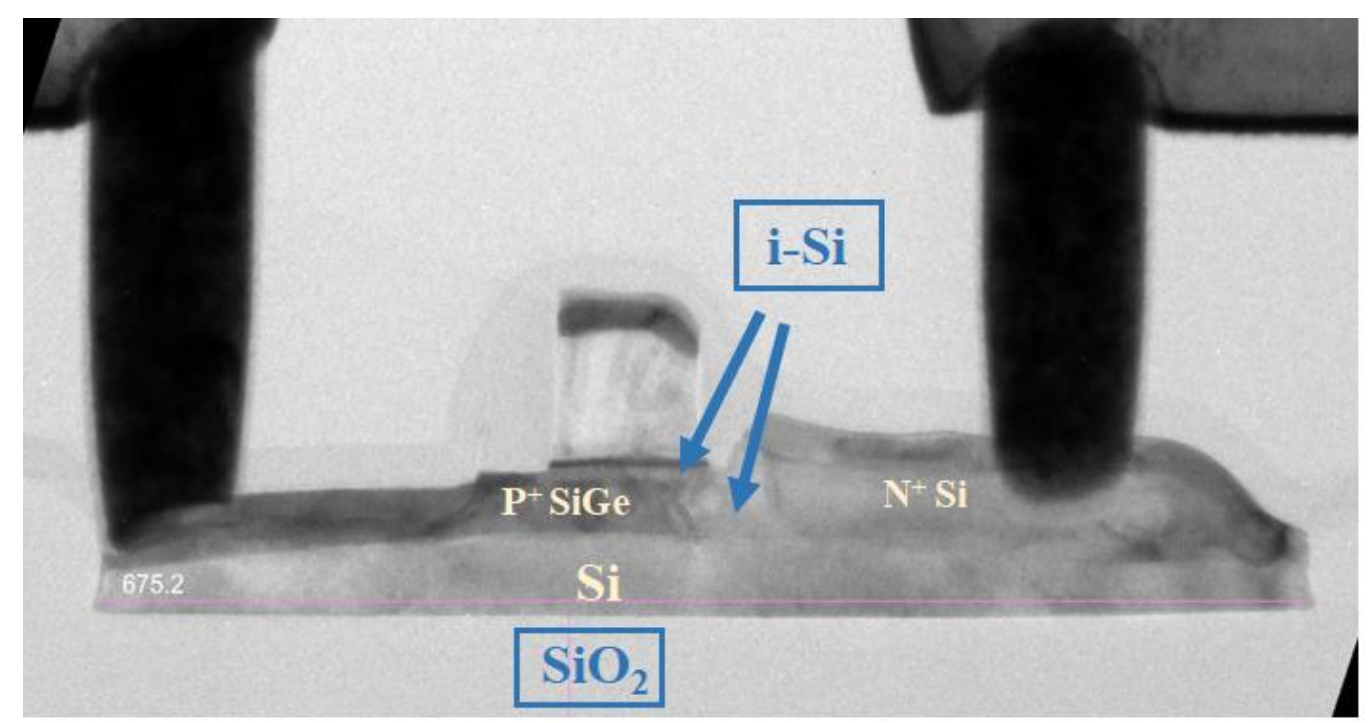

Fonte: Martino (2017)

\subsection{CARACTERÍSTICAS DO CIRCUITO DE ESPELHO DE CORRENTE}

Os esquemas fundamentais dos circuitos de espelho de corrente implementados para as medidas experimentais e para as simulações são ilustrados na Figura 41, incluindo as ligeiras diferenças entre circuitos com dispositivos do tipo $P(a)$ e do tipo $N(b)$.

Logo no início das seções 5.3 e 5.4, são definidos os valores fixos e variáveis de polarização utilizados para as medidas experimentais e para as simulações. Com base nessas condições, as correntes IDS1 e IDS2 foram avaliadas para comparação entre a performance de diferentes tecnologias.

Buscou-se analisar os desempenhos dos espelhos de corrente montados com base em parâmetros como a tensão de conformidade (isto é, a variação na polarização que ainda gera espelhamento adequado), a dependência em relação ao casamento perfeito entre os transistores, a magnitude das correntes obtidas e susceptibilidade à variação de temperatura. 
Figura 41 - Circuitos básicos de espelho de corrente

(a) com transistores do tipo $\mathrm{P} \mathrm{e}$ (b) com transistores do tipo $\mathrm{N}$.
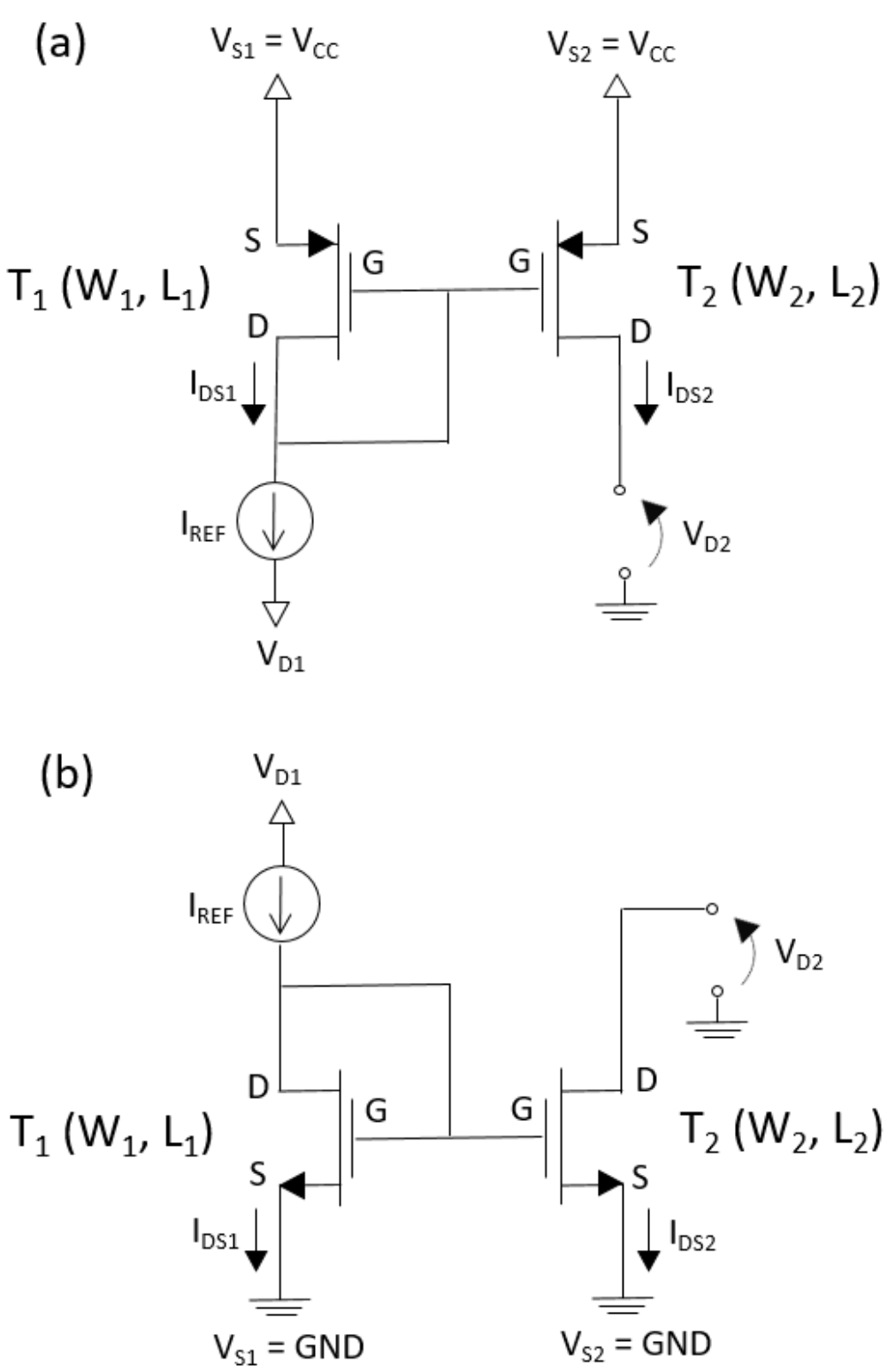

Fonte: Autor

\subsection{RESULTADOS E ANÁLISES DE CIRCUITOS COM ESTRUTURAS FINFETS}

Conforme descrito em 5.1.1, foram utilizadas estruturas típicas de FinFETs para comparação da performance de espelhos de corrente com tecnologias Point TFET e FinFET. Como foram usados dispositivos do tipo P, o circuito corresponde ao da Figura 41(a). Foi aplicada uma polarização fixa ao transistor $T_{1}$, fixando $\mathrm{V}_{\mathrm{D} 1}=\mathrm{OV}$ (o que implica $\mathrm{V}_{\mathrm{G} 1}=\mathrm{V}_{\mathrm{G} 2}=\mathrm{OV}$ ), e uma polarização variável a $T_{2}$, implementada através da tensão de dreno $V_{D 2}$ operando na faixa de $-0,5 \mathrm{~V}$ a 1,0V. 
Foi adotado o valor de tensão de alimentação $\mathrm{V}_{\mathrm{CC}}=\mathrm{V}_{\mathrm{S} 1}=\mathrm{V}_{\mathrm{S} 2}=1,7 \mathrm{~V}$. Desta forma, $\mathrm{a}$ tensão entre fonte e dreno para $T_{1}$ permaneceu constante em $V_{D S 1}=-1,7 \mathrm{~V}$, enquanto que para o transistor $\mathrm{T}_{2}$ obteve-se $\mathrm{V}_{\mathrm{DS} 2}$ entre -2,2V e -0,7V.

\subsubsection{Impacto das dimensões e da polarização}

As medidas experimentais foram realizadas com Point TFETs e FinFETs de

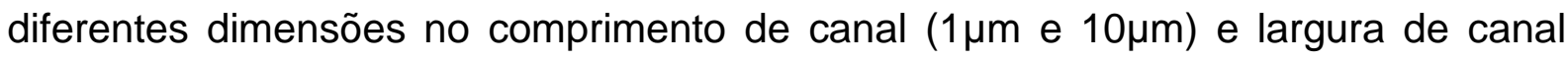
$(1 \mu \mathrm{m}$ e $0,25 \mu \mathrm{m})$. Para ilustrar a curva de transferência dos dispositivos fabricados conforme seção 5.1.1, a Figura 42 mostra a corrente de dreno em função da tensão de porta para dois transistores de cada tecnologia. A condição de $V_{G S}=1.7 \mathrm{~V}$ está destacada, uma vez que se trata da condição de polarização do transistor $T_{1} \mathrm{e}$, quando $V_{D 2}=0 \mathrm{~V}$, também da polarização de $T_{2}$. A Figura 42 revela as previstas menor corrente de dreno para Point TFETs e menor susceptibilidade de Point TFETs à variação de comprimento de canal. Estas propriedades individuais afetam diretamente o desempenho dos circuitos de espelho de corrente, como será mostrado a seguir.

Figura 42 - Corrente de dreno em função da tensão de porta para Point TFETs e FinFETs com diferentes valores de comprimento de canal.

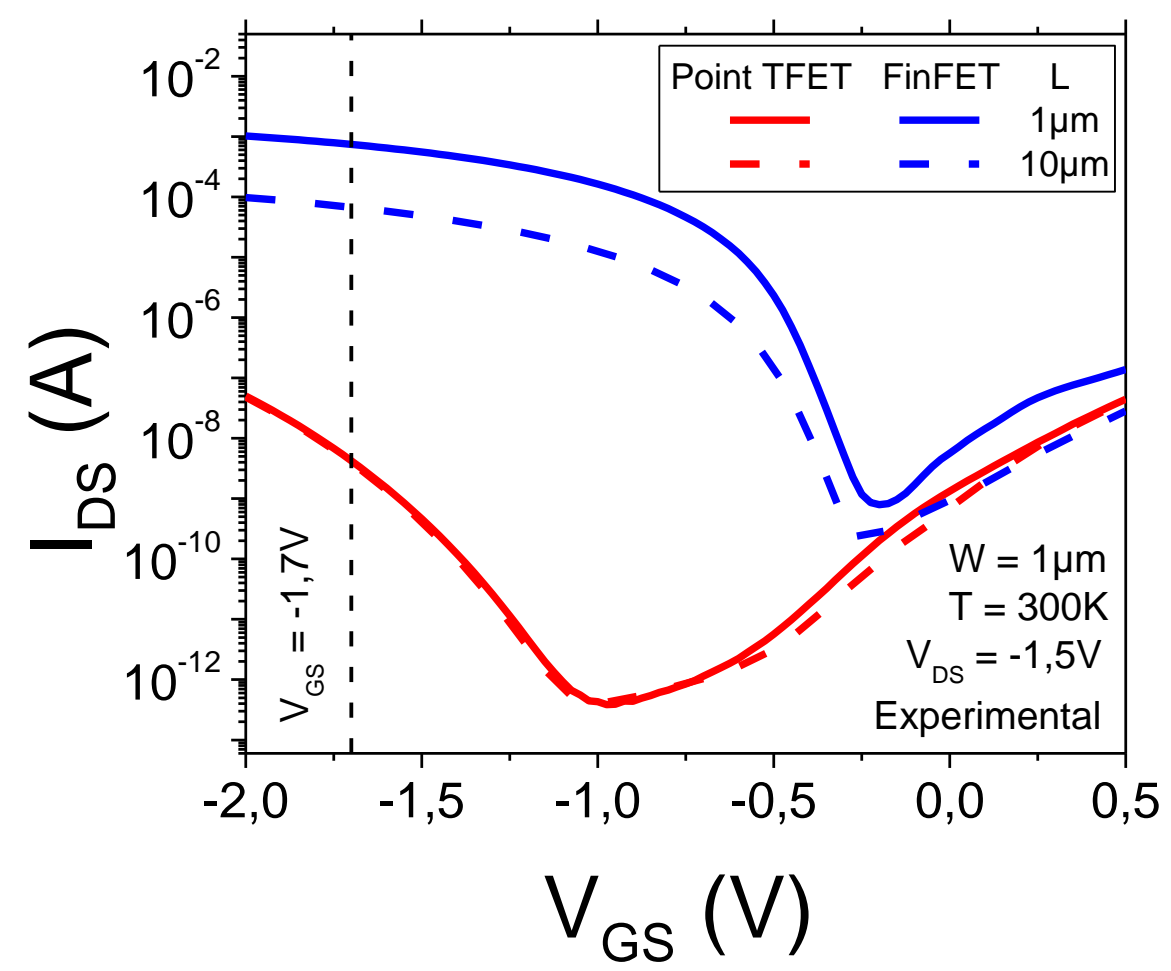

Fonte: Martino (2016) 
A Figura 43 apresenta os resultados para espelhos de corrente com Point TFETs. Uma vez que o transistor $\mathrm{T}_{1}$ está sob polarização fixa, sua corrente de dreno é basicamente constante. Enquanto isso, a corrente de dreno do dispositivo $\mathrm{T}_{2}$ diminui quando $V_{D 2}$ se aproxima de $1,0 \mathrm{~V}$, uma vez que o transistor deixa a região equivalente à saturação.

Figura 43 - Corrente de dreno em função de $V_{D 2}$ para Point TFETs com diferentes larguras e comprimentos de canal.

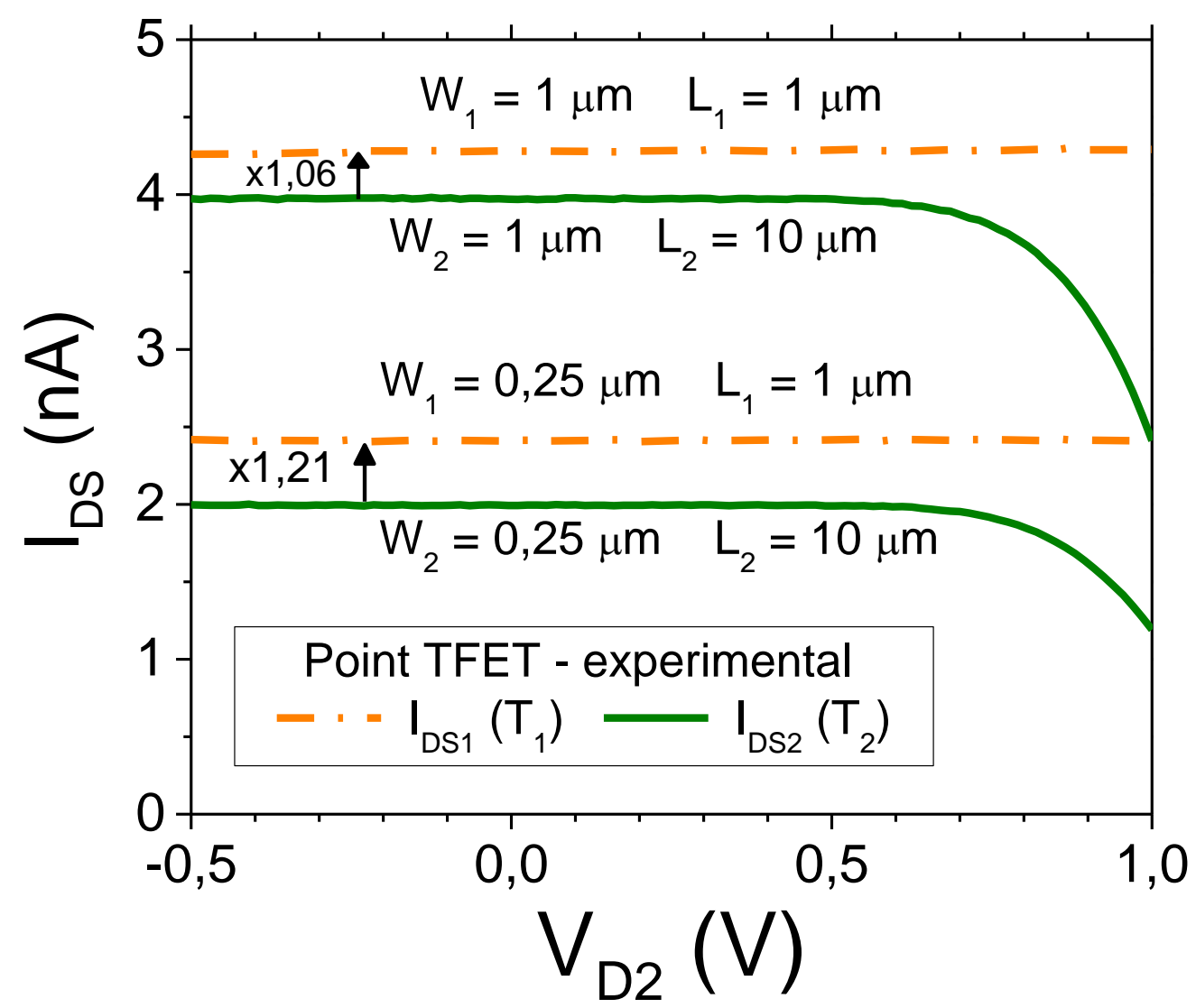

Fonte: Martino (2016)

A Figura 44 exibe as curvas para circuitos com FinFETs com as mesmas dimensões e sob as mesmas condições de polarização que na figura anterior. Comparando os resultados mostrados na Figura $43 \mathrm{com}$ os exibidos na Figura 44, nota-se que Point TFETs e FinFETs apresentam a mesma susceptibilidade à variação da largura de canal. Por outro lado, é interessante notar a diferença em termos de dependência do comprimento de canal. Comparando IDs quando o canal é reduzido de 10 vezes, FinFETs apresentam aumento bem próximo das 10 vezes esperadas, mas Point TFETs apresentam aumento de apenas $6 \%$ para $\mathrm{W}=1 \mu \mathrm{m} \mathrm{e}$ 
$21 \%$ para $W=0,25 \mu \mathrm{m}$. Esta menor dependência do espelho de corrente é consequência direta do já explicado princípio de funcionamento dos dispositivos Point TFETs, baseado no tunelamento de banda para band na região da junção entre fonte e canal.

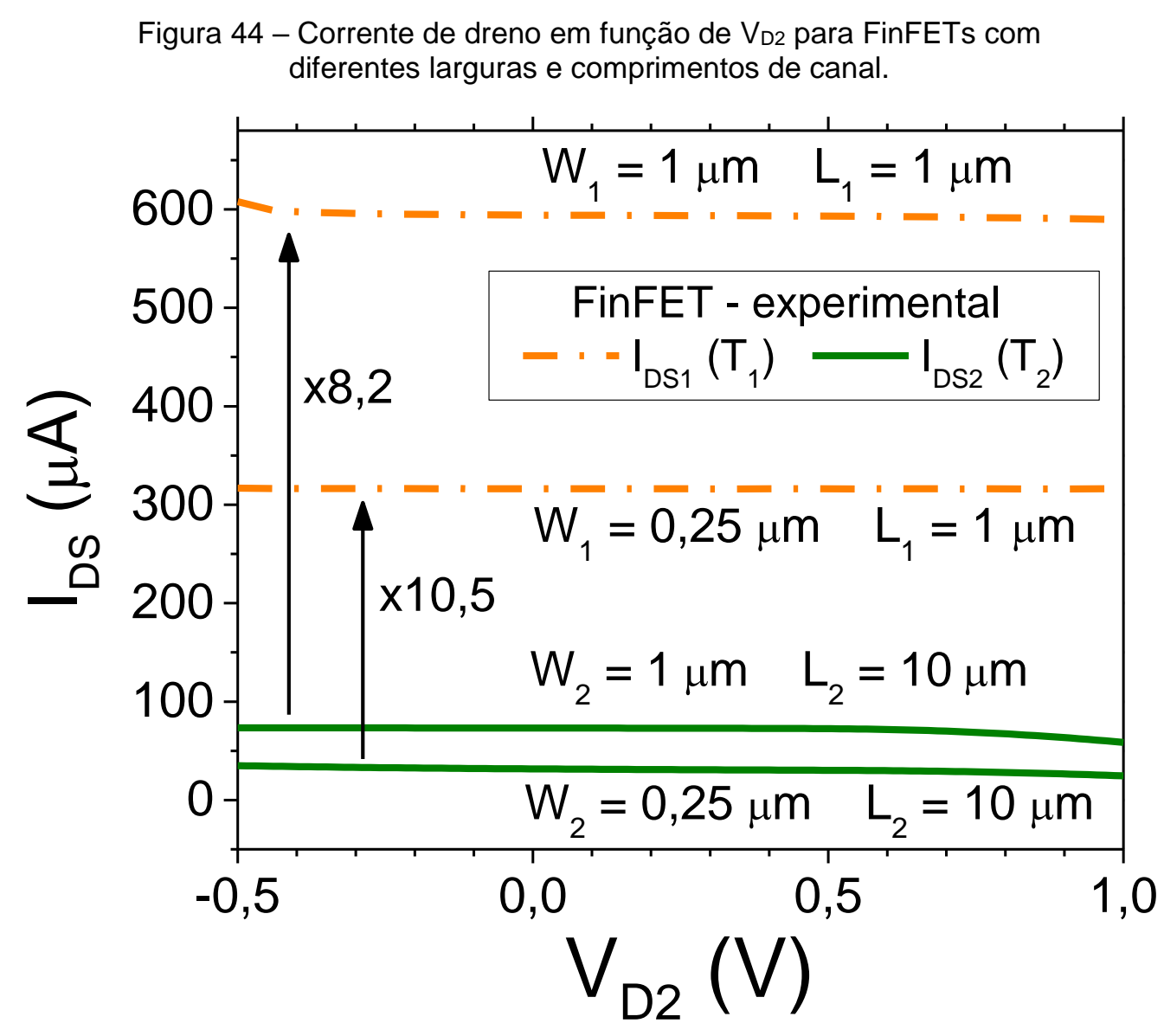

Fonte: Martino (2016)

Outro parâmetro interessante de comparação da performance de espelhos de corrente é a tensão de conformidade, que está ligada à máxima variação de polarização que ainda resulta em valores aceitáveis de corrente de saída. A Figura 45 exibe a razão IDS2/IDS1 em função da tensão de dreno no transistor $T_{2}$ para circuitos com FinFETs e com Point TFETs. Em ambos os casos, os transistores $\mathrm{T}_{1} \mathrm{e}$ $\mathrm{T}_{2}$ estão casados. Como mostrado tanto na Figura 43 quanto na Figura 44, a corrente IDS1 permanece constante, uma vez que a respectiva polarização é inalterada. Por outro lado, a corrente de dreno em $\mathrm{T}_{2}$ cai, degradando o comportamento esperado de espelhamento. 
Os resultados apresentados na Figura 45 revelam que o circuito com Point TFETs apresenta melhor comportamento de espelhamento para uma faixa de $V_{D 2}$ mais larga, notadamente até $0,82 \mathrm{~V}$. Em outras palavras, a performance do Point TFET na região análoga à saturação torna-o mais adequado para uma larga faixa de polarização de carga, porém, caso este limite seja ultrapassado, seu desempenho piora mais do que o do FinFET.

Figura 45 - Razão entre lDS2 e lDS1 em função de $V_{D 2}$ para espelhos de corrente de Point TFETS e FinFETs com largura de canal de $1 \mu \mathrm{m}$ e comprimento de canal de $10 \mu \mathrm{m}$.

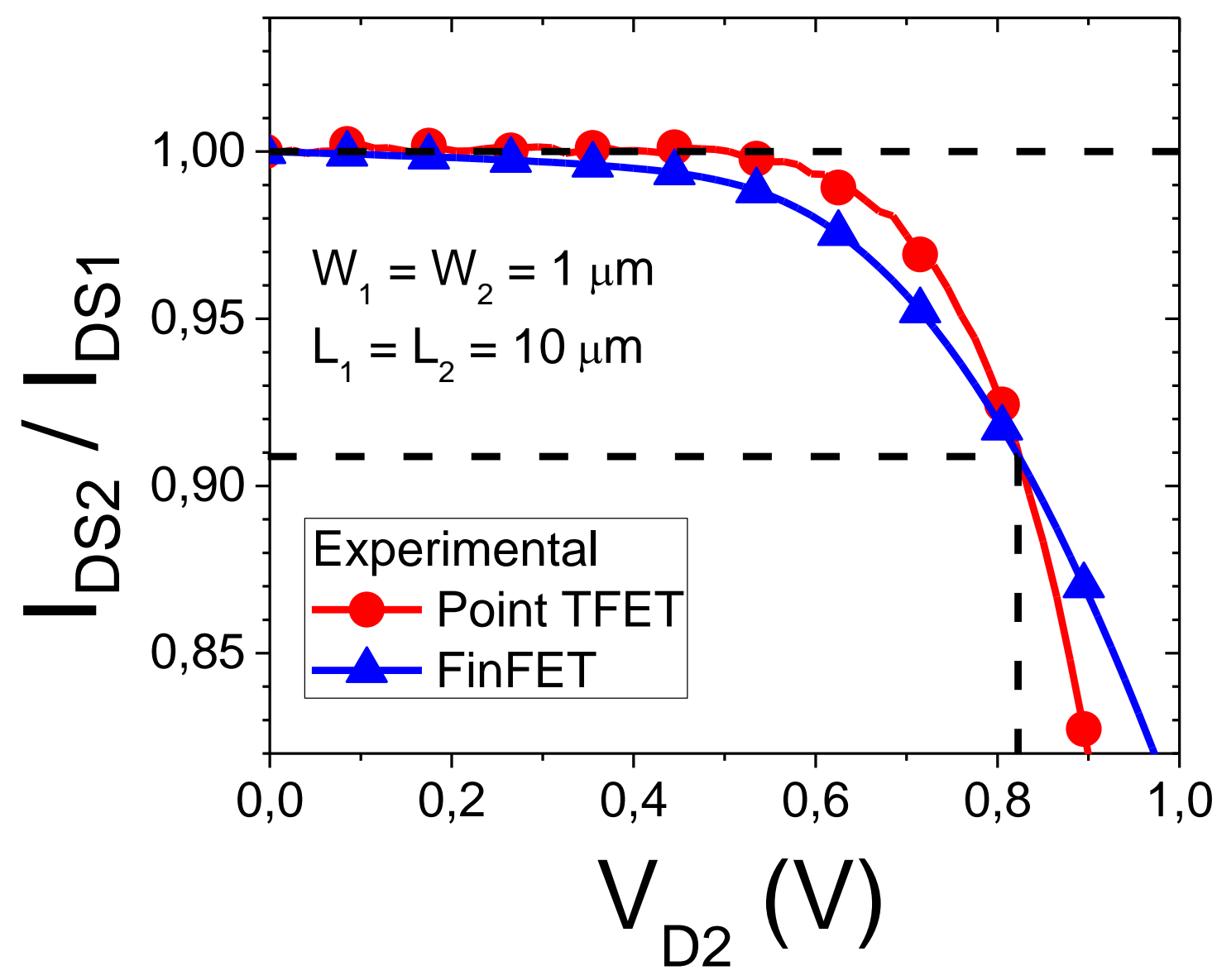

Fonte: Martino (2016)

Com base nestas observações, foram realizadas simulações para avaliar em mais detalhes o impacto do comprimento de canal na aplicabilidade de Point TFETs e FinFETs em circuitos de espelho de corrente. Vale a pena salientar que as simulações foram calibradas com base nos dados experimentais, conforme descrito em (61). A Figura 46 mostra um bom ajuste, principalmente para $\mathrm{V}_{\mathrm{GS}}=-1,7 \mathrm{~V}$, polarização tipicamente utilizada nesta análise. 
Figura 46 - Resultados experimental e simulado da corrente de dreno em função da tensão de porta para Point TFET tipo P.

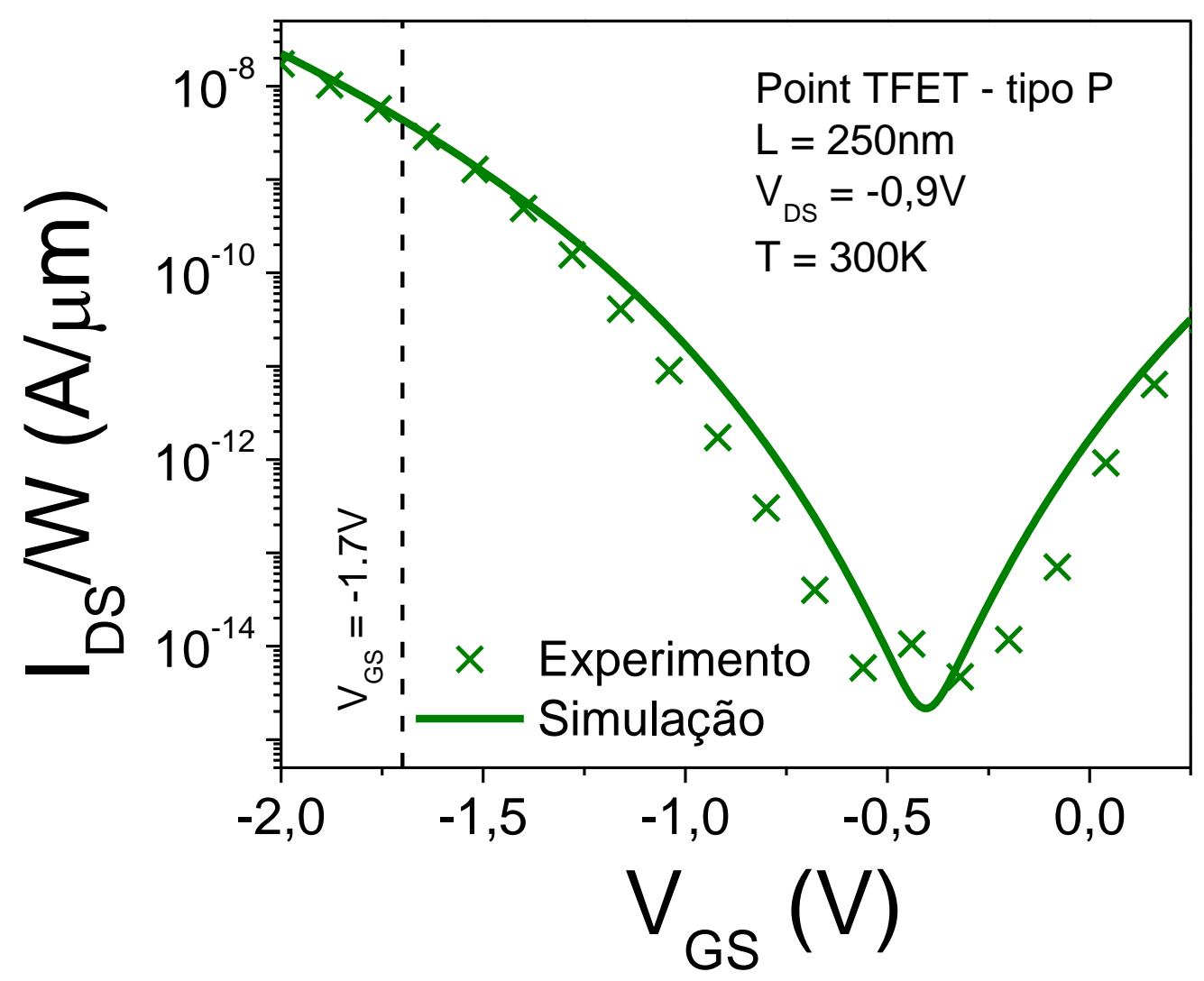

Fonte: Martino (2016)

O conjunto inicial de simulações foi realizado para 0 caso em que 0 comprimento de canal do transistor $T_{1}$ permaneceu fixo em $L_{1}=60 \mathrm{~nm}$, enquanto $T_{2}$ teve $L_{2}$ variando de 20 a 100nm. A Figura 47 (Point TFETs) e a Figura 48 (FinFETs) mostram os valores da razão IDS2/lDS1 em função de $V_{D 2}$. A situação de casamento perfeito seria então representada pelas condições $L_{2}=L_{1}=60 \mathrm{~nm}$ e $V_{D 2}=V_{D 1}=0 \mathrm{~V}$, que efetivamente geram razão unitária quando são atendidas simultaneamente. As linhas tracejadas delimitam a variação de $10 \%$ na razão entre as correntes, que poderia ser admitida como limiar de aceite para efeitos de comparação. 
Figura 47 - Razão entre lDS2 e IDS1 em função de $V_{D 2}$ para espelhos de corrente de Point TFETS com comprimento de canal do transistor $\mathrm{T}_{2}$ variando de 20 a $100 \mathrm{~nm}$.

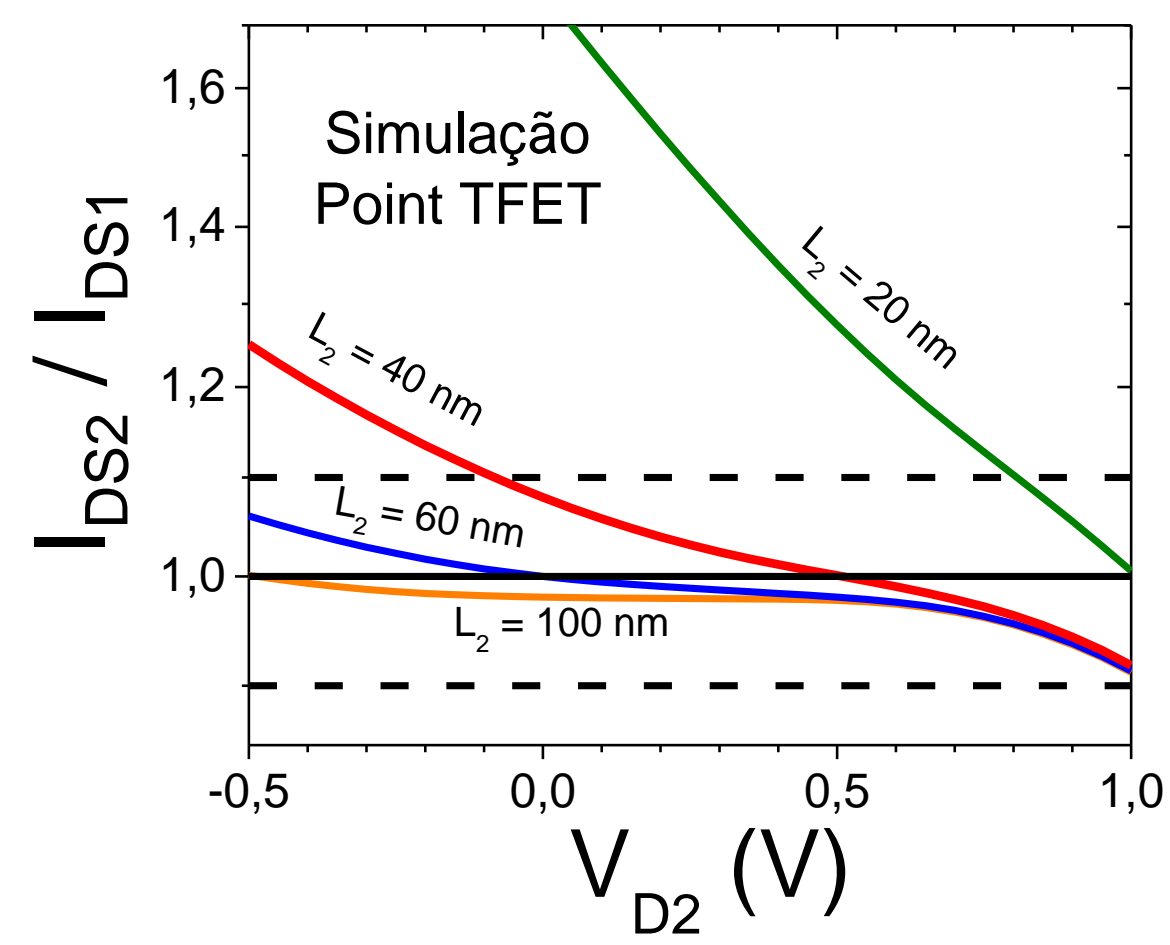

Fonte: Martino (2016)

Figura 48 - Razão entre lDs2 e lDS1 em função de $V_{D 2}$ para espelhos de corrente de FinFETs com comprimento de canal do transistor $\mathrm{T}_{2}$ variando de 20 a $100 \mathrm{~nm}$.

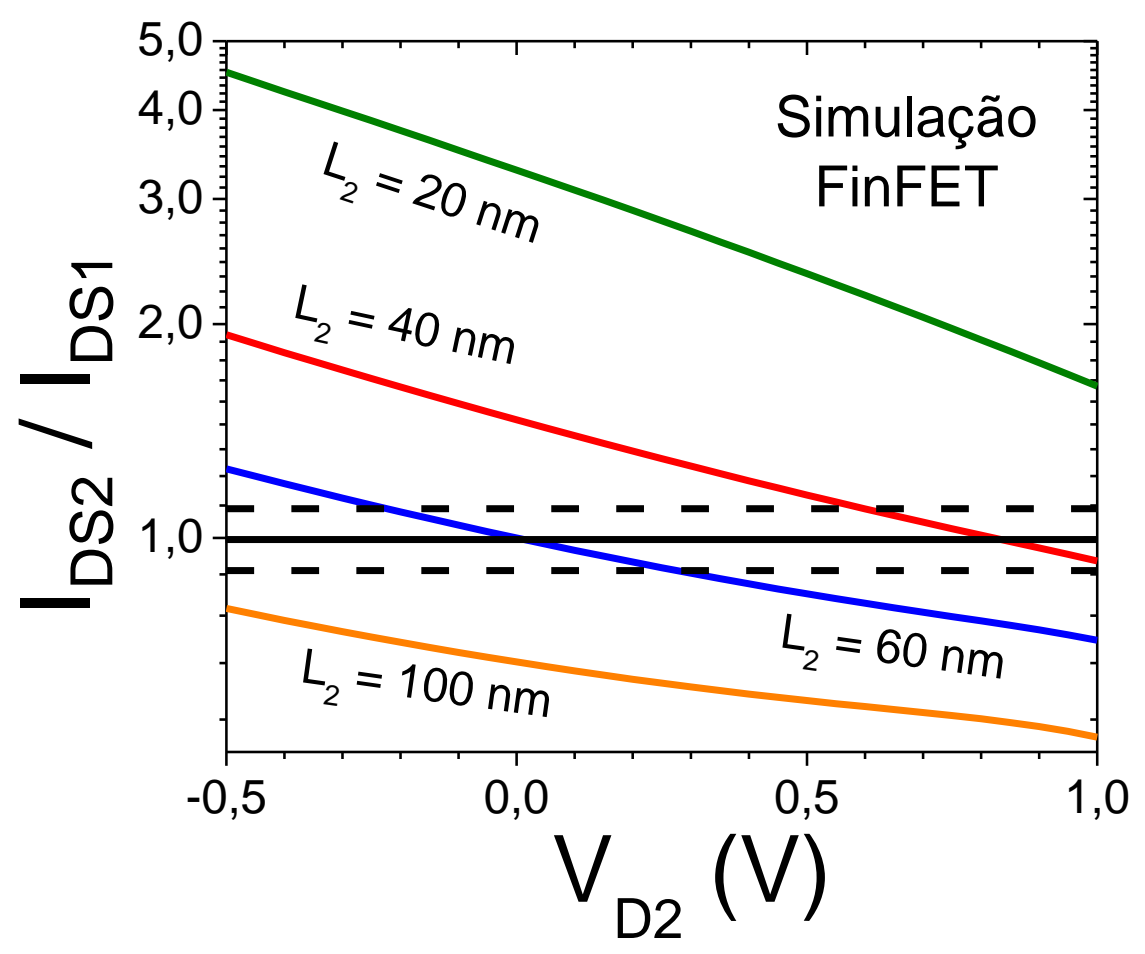

Fonte: Martino (2016) 
Desta forma, é possível avaliar a combinação dos efeitos de descasamento entre os transistores e de variações na polarização na razão IDS2/IDS1. Usando as linhas tracejadas como referência, é patente que circuitos com FinFETs são muito mais influenciados por ambos os parâmetros. Para $V_{D 2}=0 \mathrm{~V}$, a razão entre as correntes permanece dentro da margem de $10 \%$ para $L_{2}$ na faixa de 40 a $100 \mathrm{~nm}$ no caso de Point TFETs. Além disso, os resultados são aceitáveis para larga faixa de variação de $V_{D 2}$, exceto para $L_{2}=20 \mathrm{~nm}$. Por outro lado, uma análise similar para FinFETs revela que apenas uma estreita faixa de $V_{D 2}$ e uma ligeira variação em $L_{2}$ são capazes de resultar em performance aceitável em termos de espelhamento de corrente. Dispositivos com comprimento de canal de $T_{2}$ de 20 ou 100nm não geraram resultados satisfatórios para nenhum valor de $V_{D 2}$ na faixa analisada.

A Figura 49 resume estas observações, exibindo IDs2/lDs1 em função de L2. As linhas sólidas representam 0 caso de $\mathrm{V}_{\mathrm{D} 2}=0 \mathrm{~V}$, enquanto as linhas tracejadas correspondem a variações de $0,5 \mathrm{~V}$ na condição de polarização. Vale ressaltar que o caso de casamento perfeito refere-se a $L_{2}=L_{1}=60 \mathrm{~nm}$ e $V_{D 2}=V_{D 1}=0 \mathrm{~V}$, que efetivamente resulta em razão de correntes unitária.

Figura 49 - Razão entre IDS2 e IDS1 em função de $L_{2}$ para circuitos de espelho de corrente com Point TFETs e com FinFETs para $\mathrm{V}_{\mathrm{D} 2}$ variando de $-0,5 \mathrm{~V} \mathrm{a}+0,5 \mathrm{~V}$.

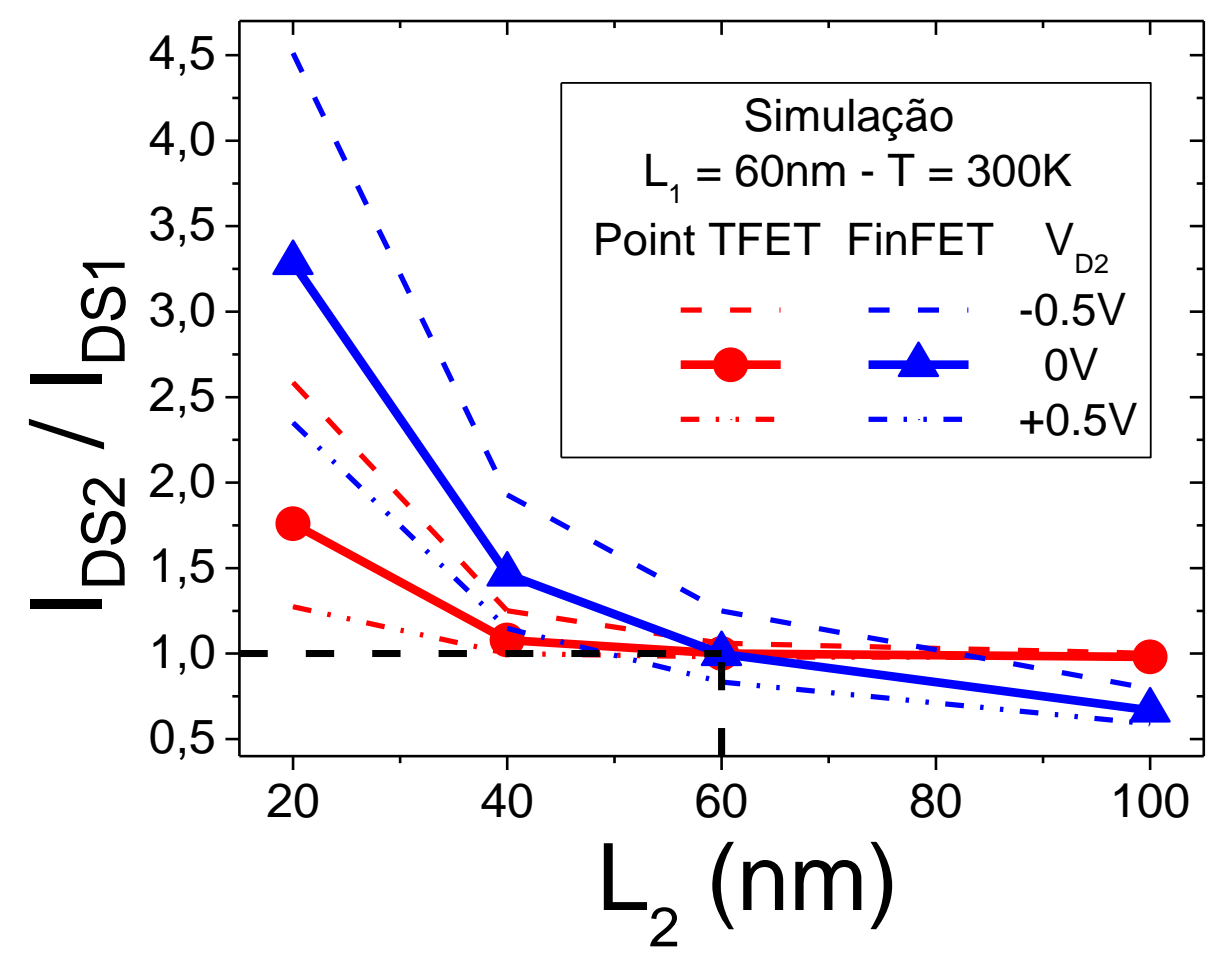

Fonte: Martino (2016) 
Destacando inicialmente as curvas sólidas, os resultados mostram que o circuito com Point TFETs sofreu uma influência muito menor da variação de $L_{2}$ do que o circuito com FinFETs. Desta forma, é interessante observar que o circuito exibe um comportamento de espelhamento muito bom mesmo para casos em que os transistores não apresentem comprimento de canal perfeitamente casados. Esta é uma consequência direta do já comentado princípio de funcionamento da tecnologia TFET, com tunelamento acontecendo próximo à junção canal/fonte. $A$ corrente de dreno é afetada por $L_{2}$ apenas para valores menores de $40 \mathrm{~nm}$, o que é justificável pelo impacto do DIBT (estreitamento de barreira de tunelamento induzido pela tensão de dreno), detalhado no capítulo 4 (62).

Enquanto isso, circuitos com FinFETs perdem a capacidade de espelhar a corrente de entrada quando $L_{2}$ muda. Por exemplo, quando $L_{2}$ varia de 40 a $100 \mathrm{~nm}$, a variação na corrente de saída chega a 50\%, enquanto que, para Point TFETs, não passa de $10 \%$. No cenário de pior caso para ambos os casos $\left(\mathrm{L}_{2}=20 \mathrm{~nm}\right)$, o desvio na corrente de dreno de saída quando comparada ao caso de casamento perfeito chega a $80 \%$ para TFETs e $230 \%$ para FinFETs.

Em relação à influência de $V_{D 2}$, também fica evidenciado que espelhos de corrente com Point TFETs são muito menos susceptíveis, desde que o DIBT possa ser desprezado. Como previsto pela Figura 47 (Point TFETs) e pela Figura 48 (FinFETs), as linhas tracejadas para Point TFETs ficam bastante próximas da linha sólida para $L_{2}$ maior que $40 \mathrm{~nm}$, o que está ligado à maior tensão de conformidade observada para esta tecnologia em relação a circuitos com FinFETs.

\subsubsection{Impacto da temperatura}

Finalmente, simulações foram utilizadas para expandir a análise do impacto da temperatura. As correntes de dreno dos transistores $T_{1}$ e $T_{2}$ são exibidas na Figura 50 (Point TFETs) e na Figura 51 (FinFETs) para temperaturas variando de 300 a $500 K$. 
Figura 50 - Corrente de dreno em função de $V_{D 2}$ para Point TFETS com temperatura variando de 300 a $500 \mathrm{~K}$.

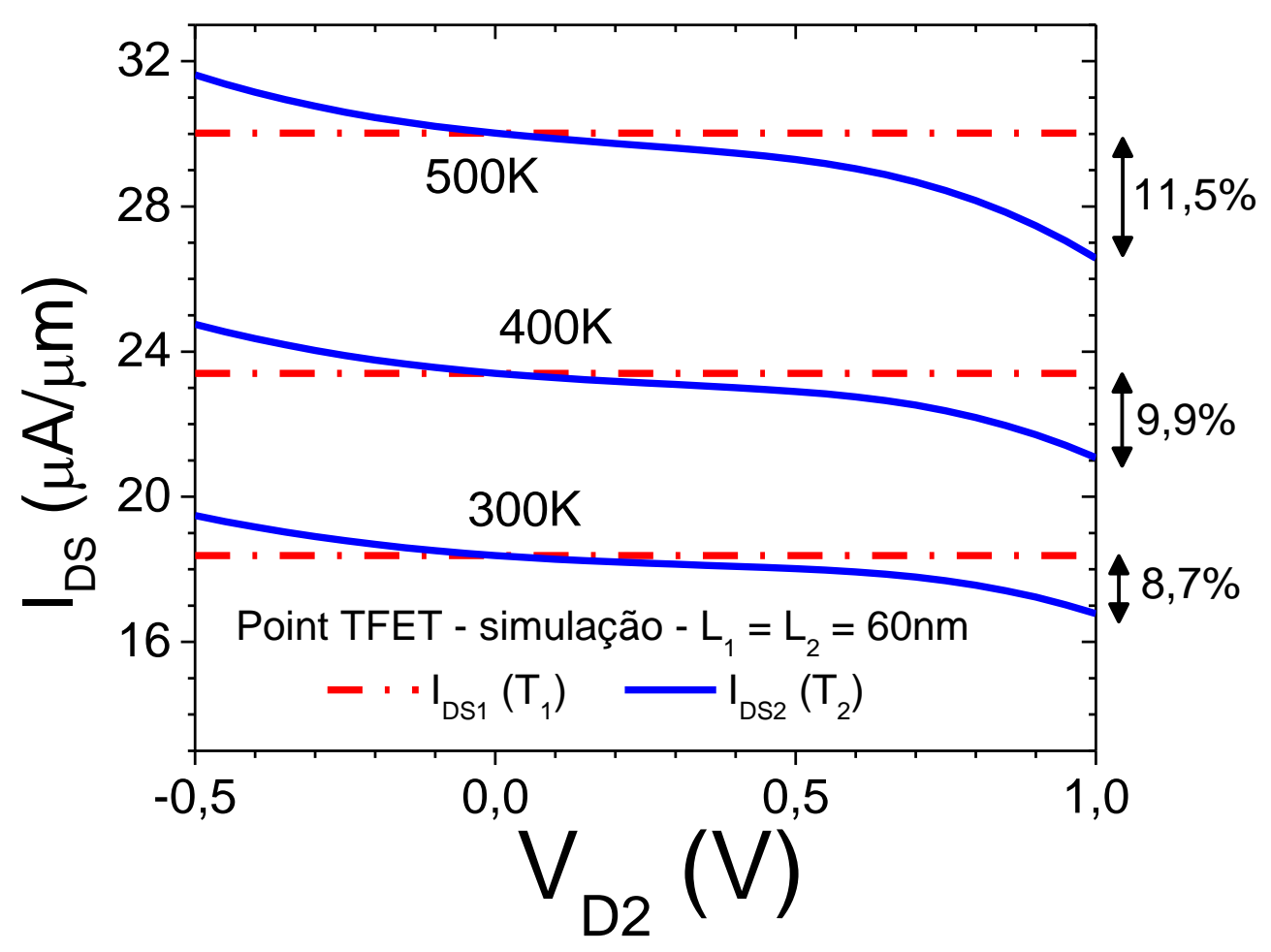

Fonte: Martino (2016)

Figura 51 - Corrente de dreno em função de $\mathrm{V}_{\mathrm{D} 2}$ para FinFETs com temperatura variando de 300 a $500 \mathrm{~K}$.

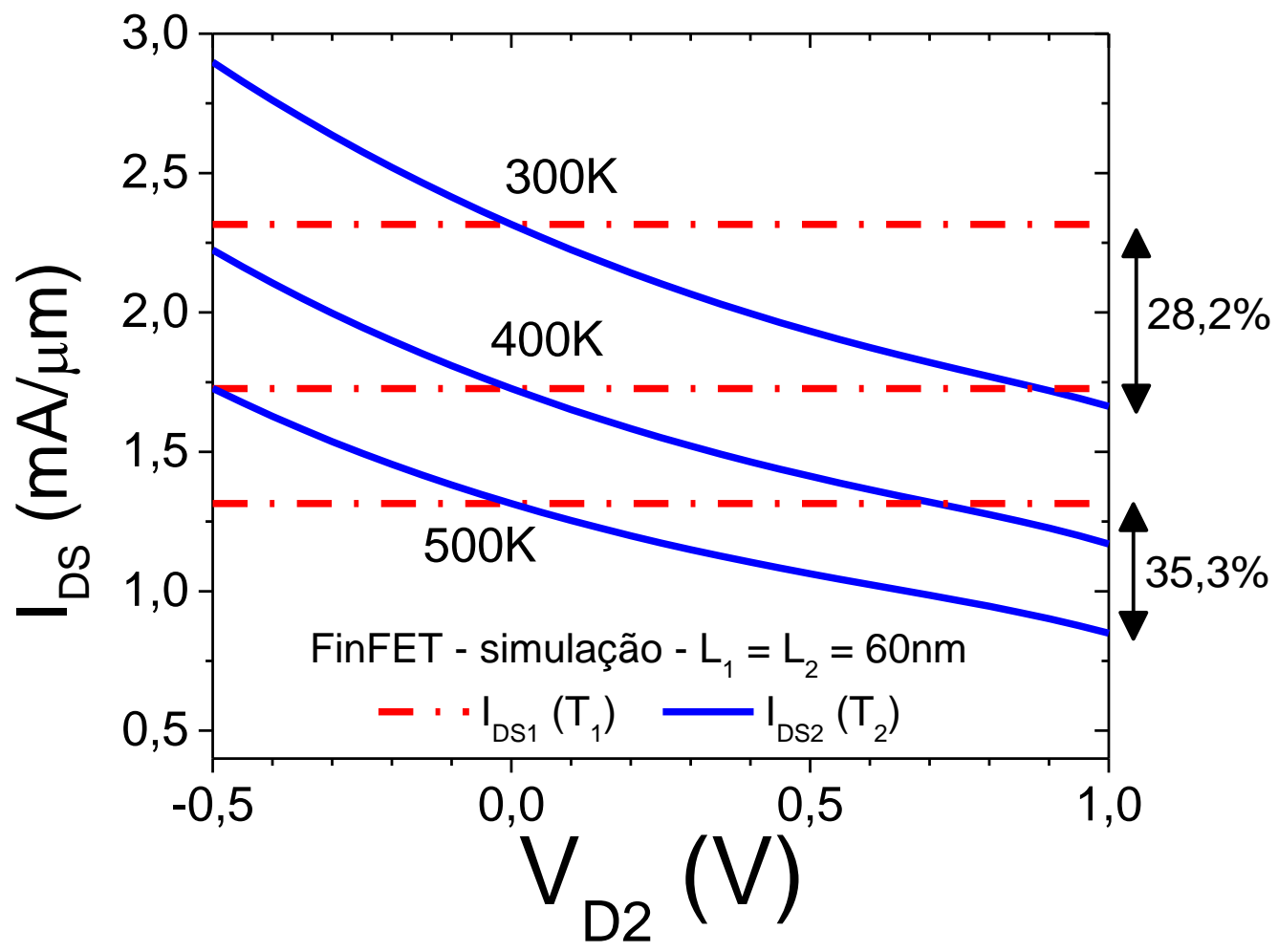

Fonte: Martino (2016) 
As curvas plotadas revelam 3 diferenças significativas que devem ser esperadas entre circuitos com Point TFETs e com FinFETs. A primeira é a tendência oposta de variação com o aumento da temperatura, ascendente apenas para o circuito com Point TFETs. Este comportamento pode ser explicado pela diferença no mecanismo de transporte predominante em cada caso. Para dispositivos Point TFETs, verificou-se que o tunelamento de banda para banda (BTBT) prevalece em relação ao tunelamento induzido por armadilhas (TAT) e à corrente de SchockleyRead-Hall (SRH) para valores altos de $\left|V_{G S}\right|$ (61). Com isso, o impacto da temperatura será positivo, uma vez que a largura de faixa proibida diminui com o aumento da temperatura, potencializando a componente de BTBT $(19,61)$. Enquanto isso, no caso dos FinFETs, dominados pelos mecanismos de difusão e deriva, o maior impacto de altas temperaturas é no sentido de degradar a mobilidade por causa do maior espalhamento de fônons. O efeito prático desse fenômeno é a redução da corrente de dreno quase pela metade na faixa de temperatura estudada.

Além disso, comparando as inclinações nas curvas de los2, pode-se inferir sobre a susceptibilidade de espelhos de correntes com cada tecnologia à variação de $\mathrm{V}_{\mathrm{D} 2}$. O cenário de pior caso ocorre para $\mathrm{V}_{\mathrm{D} 2}=1,0 \mathrm{~V}$ e temperatura de $500 \mathrm{~K}$, para o qual pode-se extrair o desvio máximo de $11,5 \%$ para Point TFETs e $35,3 \%$ para FinFETs. Comparando a Figura 50 (Point TFETs) e a Figura 51 (FinFETs) pode-se notar uma diminuição na tensão de conformidade sob altas temperaturas para ambos os casos, mas com melhores resultados para espelhos de correntes com Point TFETs ao longo de toda a faixa de temperatura considerada.

A terceira diferença é a ordem de grandeza das correntes de dreno envolvidas em cada circuito, cuja explicação novamente passa pela diferença no mecanismo de transporte predominante em cada caso. As menores correntes oriundas de BTBT compõem um fator a ser levado em consideração com base na aplicação específica em que o espelho de corrente será utilizado.

Para resumir o impacto da temperatura em espelhos de corrente, a Figura 52 e a Figura 53 plotam a razão IDs2(T) / IDs2(300K) para temperatura variando de 300 a $500 \mathrm{~K}$. Em ambos os casos, as linhas sólidas representam o caso de casamento perfeito, isto é, com $L_{2}=L_{1}=60 \mathrm{~nm}$ e $V_{D 2}=V_{D 1}=0 \mathrm{~V}$. Já as linhas tracejadas são aplicadas para sacramentar o impacto da condição de polarização $V_{D 2}$ (Figura 52, com variação de $0,5 \mathrm{~V}$ para mais e para menos) e do descasamento do comprimento 
de canal do transistor $T_{2}$ (Figura 53 , com variação de $40 \mathrm{~nm}$ para mais e para menos).

Figura 52 - IDS2 $(T) / \operatorname{lDS}_{1}(300 \mathrm{~K})$ em função da temperatura para espelhos de corrente de Point TFETs e de FinFETs com $V_{D 2}$ variando de $-0,5 \mathrm{~V}$ a $+0,5 \mathrm{~V}$

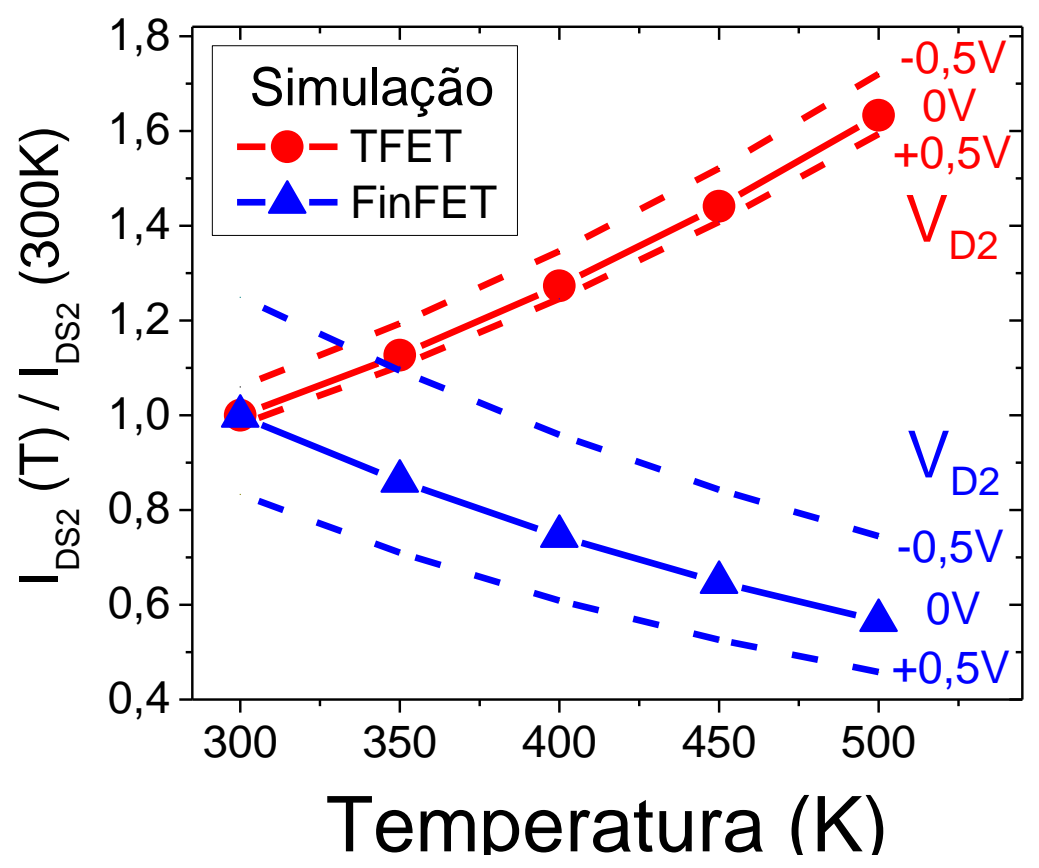

Fonte: Martino (2015)

Figura 53 - IDs2 $(T) / \operatorname{lDS}_{1}(300 \mathrm{~K})$ em função da temperatura para espelhos de corrente de Point TFETs e de FinFETs com L2 variando de $20 \mathrm{~nm}$ a $100 \mathrm{~nm}$.

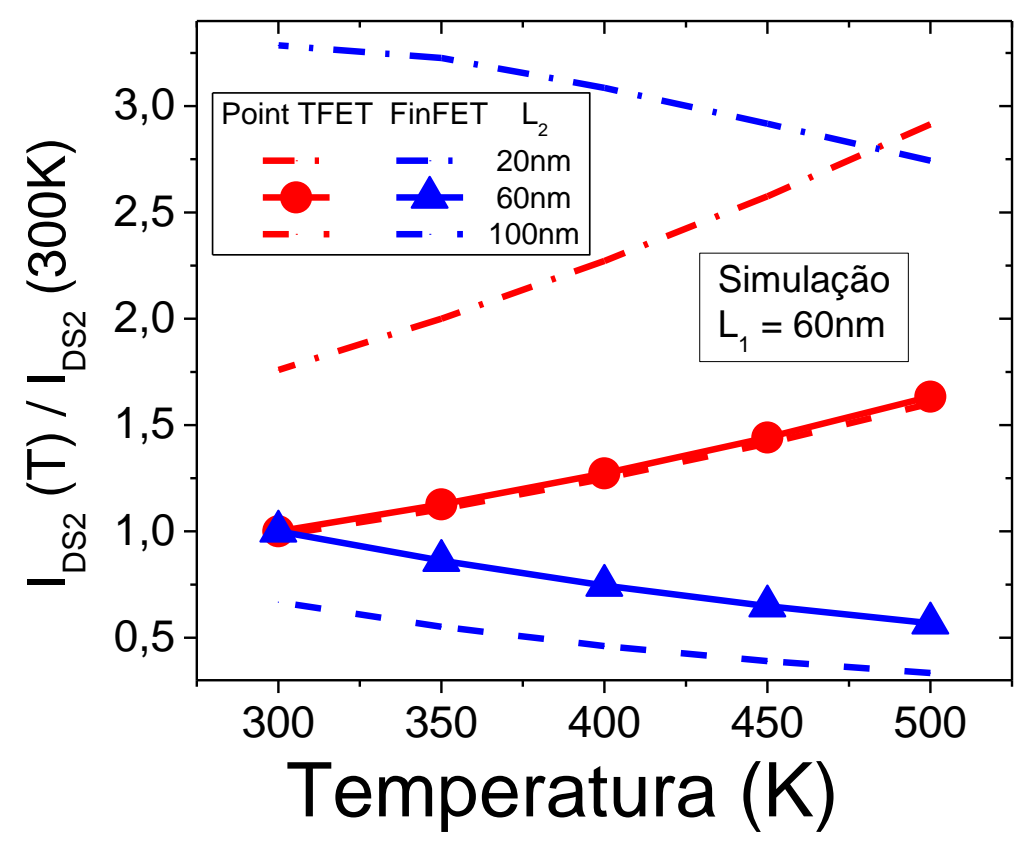

Fonte: Martino (2016) 
As linhas sólidas permitem a comparação quantitativa mais direta do efeito do mecanismos de transporte predominante para cada tecnologia. Enquanto isso, as linhas tracejadas na Figura 52 mostram uma variação de apenas 6\% na razão entre as correntes para as condições de polarização avaliadas, enquanto nota-se um desvio de até $30 \%$ para circuito análogo com a tecnologia FinFET. Em relação ao impacto do comprimento de canal, verifica-se que o cenário de pior caso ocorre para $\mathrm{L}_{2}=20 \mathrm{~nm}$ para ambas as tecnologias, porém com clara diferença quanto à magnitude e à estabilidade do efeito. Enquanto o máximo desvio observado para Point TFETs é de cerca de $75 \%$ para toda a faixa de temperatura, para FinFETs a diferença varia de $230 \%$ à temperatura ambiente até $390 \%$ a $500 \mathrm{~K}$, revelando-se não apenas mais significativa, mas também mais variável com a temperatura.

Resumidamente, pode-se afirmar que circuitos de espelho de corrente implementados com dispositivos TFETs apresentaram menor susceptibilidade a diversos parâmetros, tais quais descasamento de dimensões, variação de temperatura e flutuações na polarização de saída. Isso significa que esta tecnologia apresenta maior habilidade de espelhar corrente, tornando-se, desta forma, mais adequada para aplicações digitais e analógicas que requeiram este tipo de estágio, desde que a magnitude da corrente de dreno não seja um fator essencial.

\subsection{RESULTADOS E ANÁLISES DE CIRCUITOS COM ESTRUTURAS LINE TFETS}

Com base nas vantagens promissoras da estrutura Line TFET explicadas em 2.4, também foi analisado o desempenho de circuitos de espelhos de correntes com dispositivos desta tecnologia. Para isso, foram utilizados transistores do tipo N, cujas características individuais foram especificadas em 5.1.2, montados conforme esquema apresentado na Figura 41(b). A polarização adotada para as medidas experimentais foi tal que os transistores $T_{1}$ e $T_{2}$ tinham $V_{G S 1}=V_{G S 2}$ variando na faixa de $1,2 \mathrm{~V}$ a 1,8V. A diferença fundamental é que, enquanto para $\mathrm{T}_{1}$ era fixa a relação $V_{D S 1}=V_{G S 1}$, para $T_{2}$ a tensão de dreno foi variada independentemente na faixa de OV a $1,5 \mathrm{~V}$. 


\subsubsection{Impacto das dimensões e da polarização}

Para as medidas experimentais, foram utilizados transistores Line TFETs com largura de canal entre 60 e 105nm e comprimento de canal entre 130 e 1000nm. Para a caracterização individual, que posteriormente será utilizada para embasar os desempenhos dos respectivos circuitos, a Figura 54 mostra a corrente de dreno em função da tensão de porta para duas polarizações de dreno, enquanto a Figura 55 exibe a corrente de dreno em função da tensão de dreno para duas polarizações de porta.

Figura 54 - Corrente de dreno em função da tensão de porta para Line TFETs com diferentes valores de tensão de dreno e de comprimento e largura de canal.

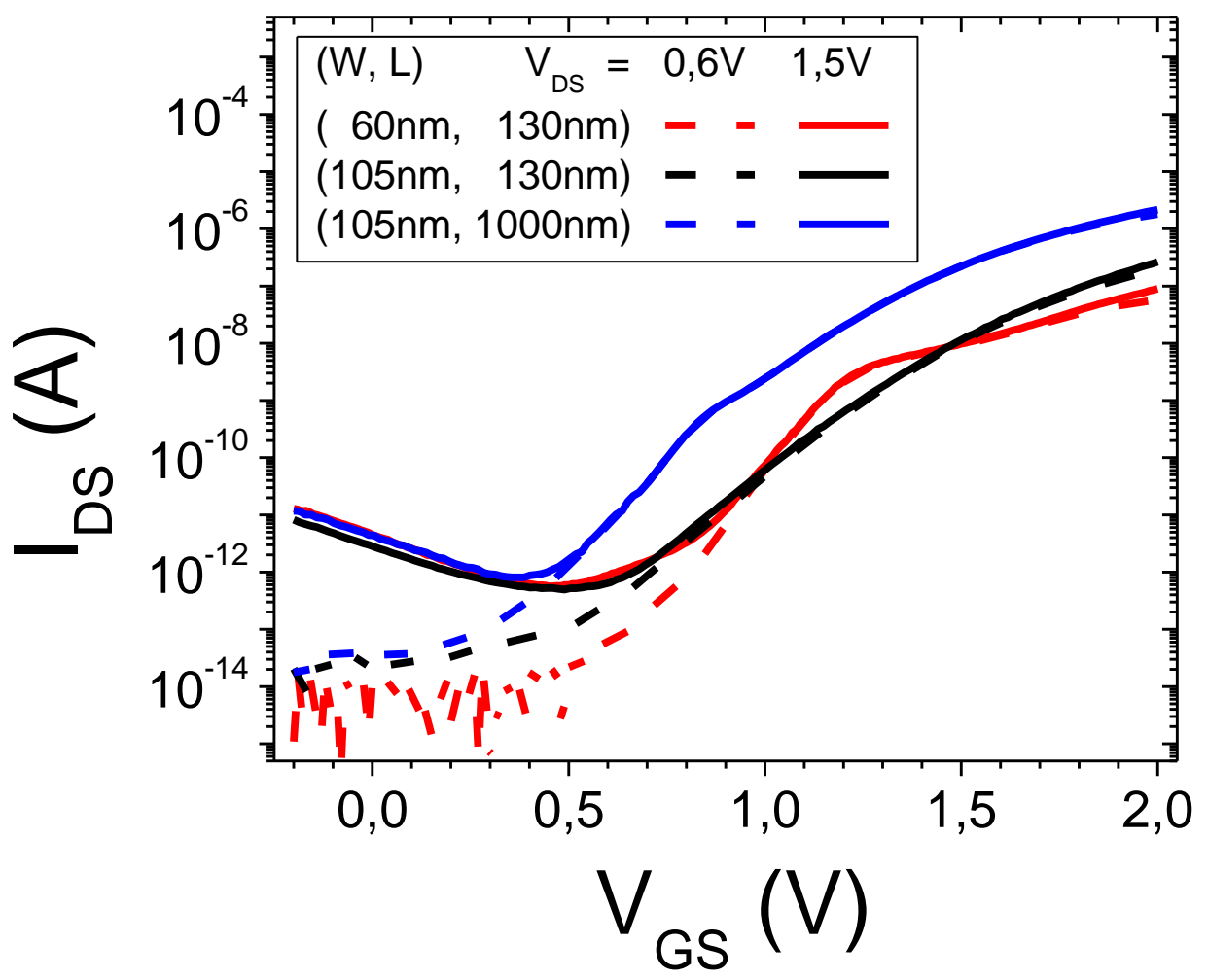

Fonte: Martino (2017) 
Figura 55 - Corrente de dreno em função da tensão de dreno para Line TFETs com diferentes valores de tensão de porta e de comprimento e largura de canal.

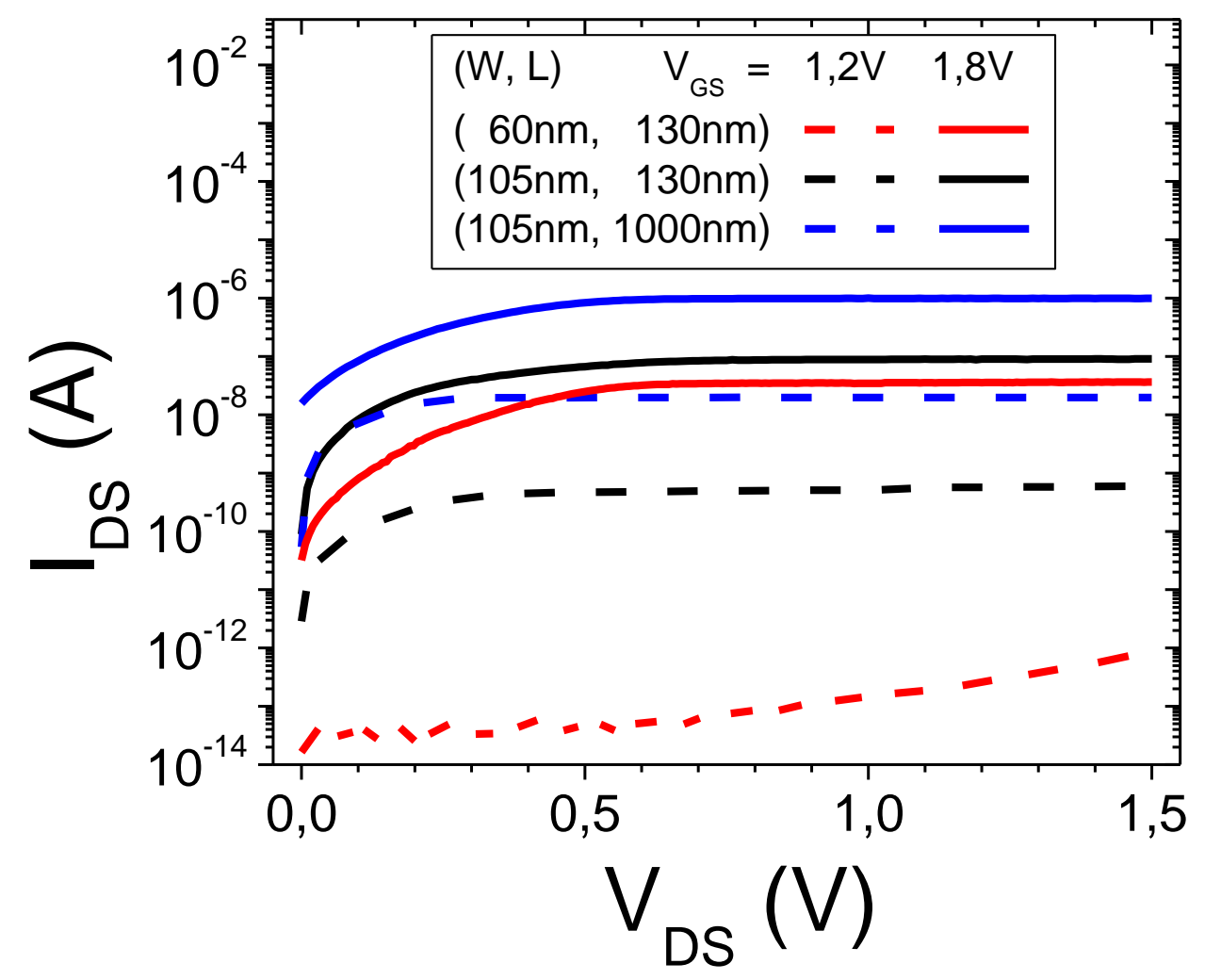

Fonte: Martino (2017)

Coerentemente com o princípio de funcionamento dos Line TFETs detalhado em 2.4, nota-se que a corrente de dreno varia proporcionalmente com a área do canal, diferindo fundamentalmente das duas tecnologias avaliadas em 5.3. No caso dos Point TFETs, tem-se tunelamento local perpendicular ao campo elétrico de porta, tornando-os muito pouco dependentes do comprimento de canal $(12,33,62)$. Já para transistores FinFETs, o dominante mecanismo de difusão e deriva gera um decréscimo na corrente em caso de canais mais longos. Neste ponto, vale a pena ressaltar que comprimentos e larguras de canais listados correspondem aos respectivos valores de máscara.

Outro comportamento digno de nota refere-se ao formato das curvas relativas ao transistor de $W=60 \mathrm{~nm}$ e $\mathrm{L}=130 \mathrm{~nm}$ na Figura 54 . Pode-se relacionar este tipo de formato indesejável a um tipo efetivo de estrutura ilustrado na Figura 56. Como detalhado em (33), uma variação abrupta na inclinação da corrente de dreno pode ser decorrente do desalinhamento entre fonte e porta. Quando a extremidade da fonte ultrapassa o limite do comprimento de canal, a região do canal com baixo 
acoplamento em relação à porta apresenta uma elevada tensão de limiar, diminuindo a corrente de dreno. É importante considerar a inclinação da corrente de dreno para dispositivos selecionados para uso em espelhos de corrente, uma vez que isso afetará criticamente a razão de espelhamento de corrente lDS2/lDs1.

Figura 56 - Estrutura básica de um Line TFET com subposição da porta em relação ao canal.

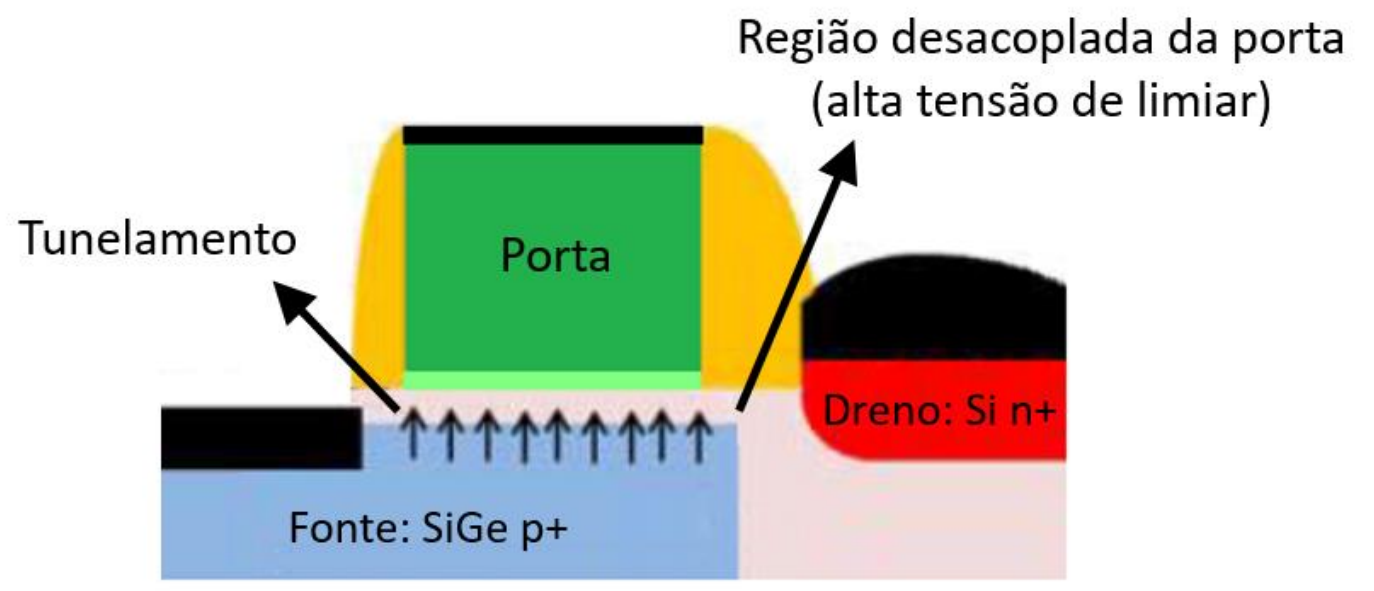

Fonte: Martino (2017)

A Figura 57 mostra os resultados obtidos para a razão de espelhamento de corrente quando a tensão $V_{D 2}$ é $0 \mathrm{~V}$ a $1,5 \mathrm{~V}$. A polarização com a corrente de referência IREF ocorre de modo que as tensões variem na faixa de 1,2V a 1,8V.

Como esperado pelos resultados individuais mostrados na Figura 54 (IDs vs. $V_{G S}$ ) e na Figura 55 (IDS vs. $V_{D S}$ ) um aumento na corrente de referência (e o consequente aumento em VGS) resulta em menor patamar de IDS2/lDS1. Enquanto isso, maiores valores de tensão de porta exigiram $V_{D 2}$ mais alto para causar saturação em $T_{2}$, estreitando a região de operação e diminuindo a tensão de conformidade. É possível inclusive comparar a Figura $57 \mathrm{com}$ a Figura 45 para verificar que, sob condições de polarizações similares, o dispositivo Line TFET permite maior excursão de $V_{D 2}$ sem degradar o espelhamento (delimitando $V_{D 2}$ entre a condição limiar para saturação de $T_{2}$ e sua respectiva tensão de porta $V_{G 2}$ ), sugerindo também uma tensão de conformidade mais elevada. 
Figura 57 - Razão de espelhamento de corrente em função de $V_{D 2}$ para diferentes valores de tensão de porta.

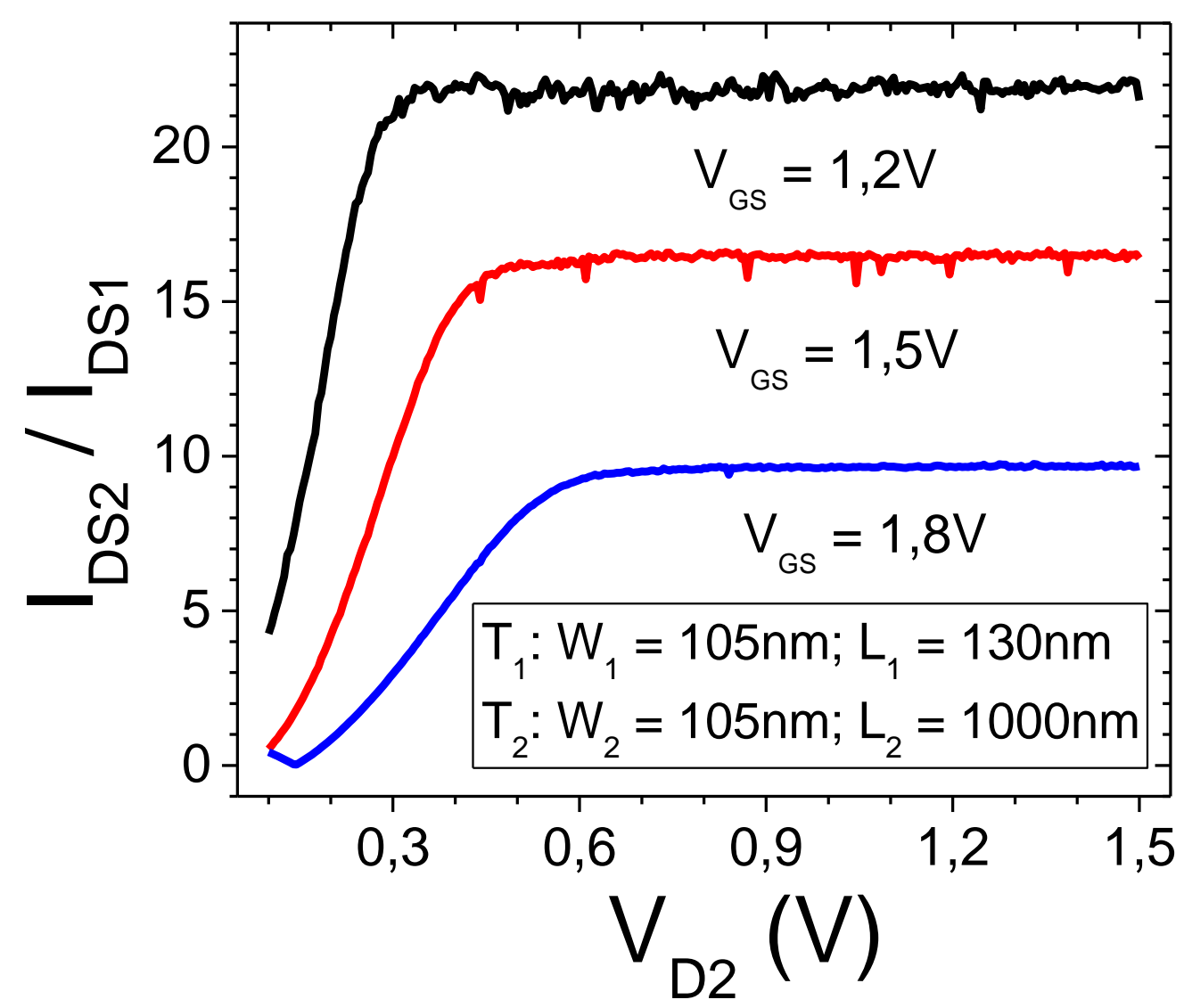

Fonte: Martino (2017)

\subsubsection{Impacto da temperatura}

Para avaliar o impacto da temperatura em espelhos de corrente com Line TFETs, inicialmente são apresentadas curvas características dos transistores individuais para temperatura variando de $300 \mathrm{~K}$ a $450 \mathrm{~K}$. A Figura 58 mostra a corrente de dreno em função da tensão de porta, enquanto a Figura 59 exibe a corrente de dreno em função da tensão de dreno. Em ambos os casos, foram apresentados os dados dos mesmos transistores que compunham o espelho de corrente das curvas plotadas na Figura 57. 
Figura 58 - Corrente de dreno em função da tensão de porta para Line TFETs com diferentes temperaturas e dimensões.

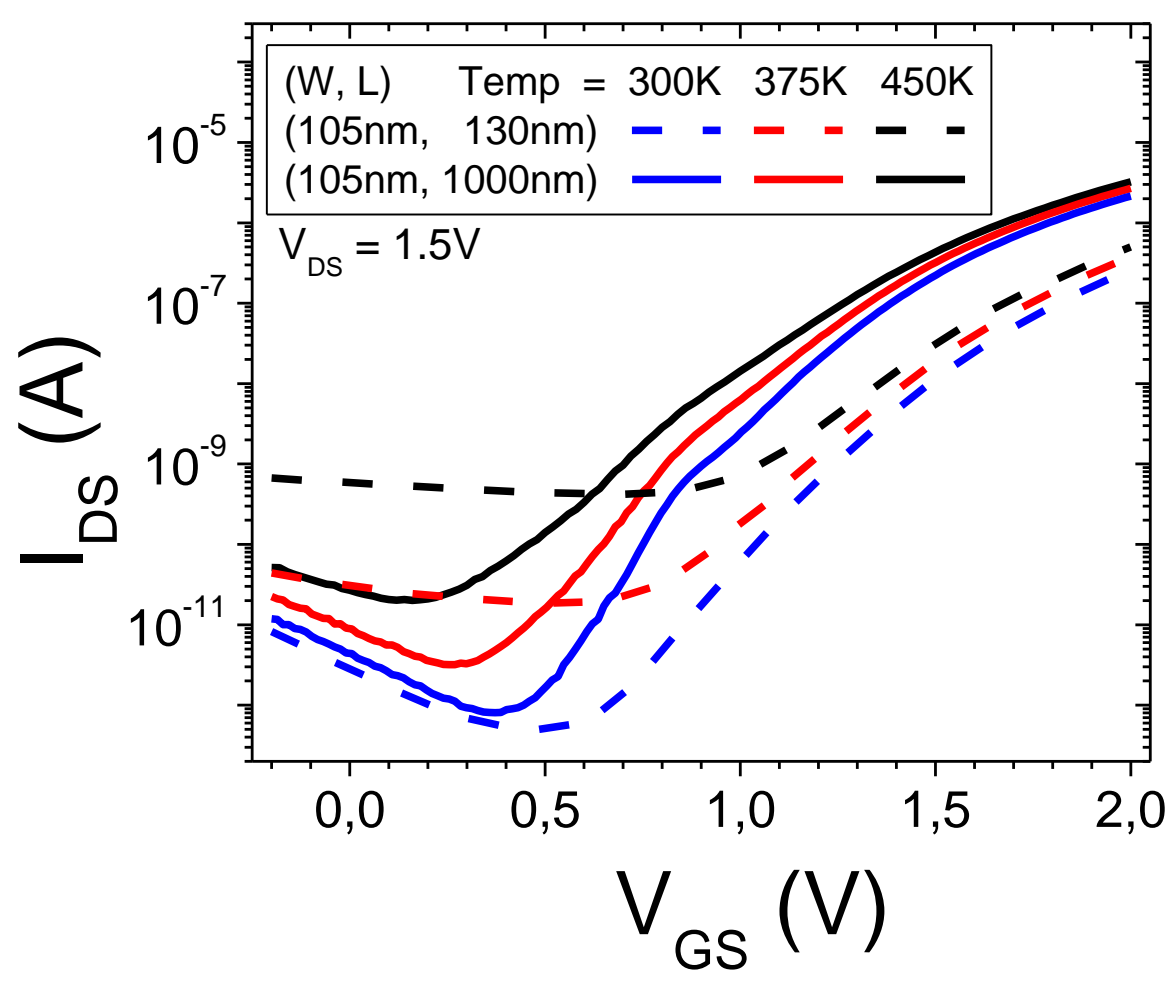

Fonte: Martino (2017)

Figura 59 - Corrente de dreno em função da tensão de dreno para Line TFETs com diferentes temperaturas e dimensões.

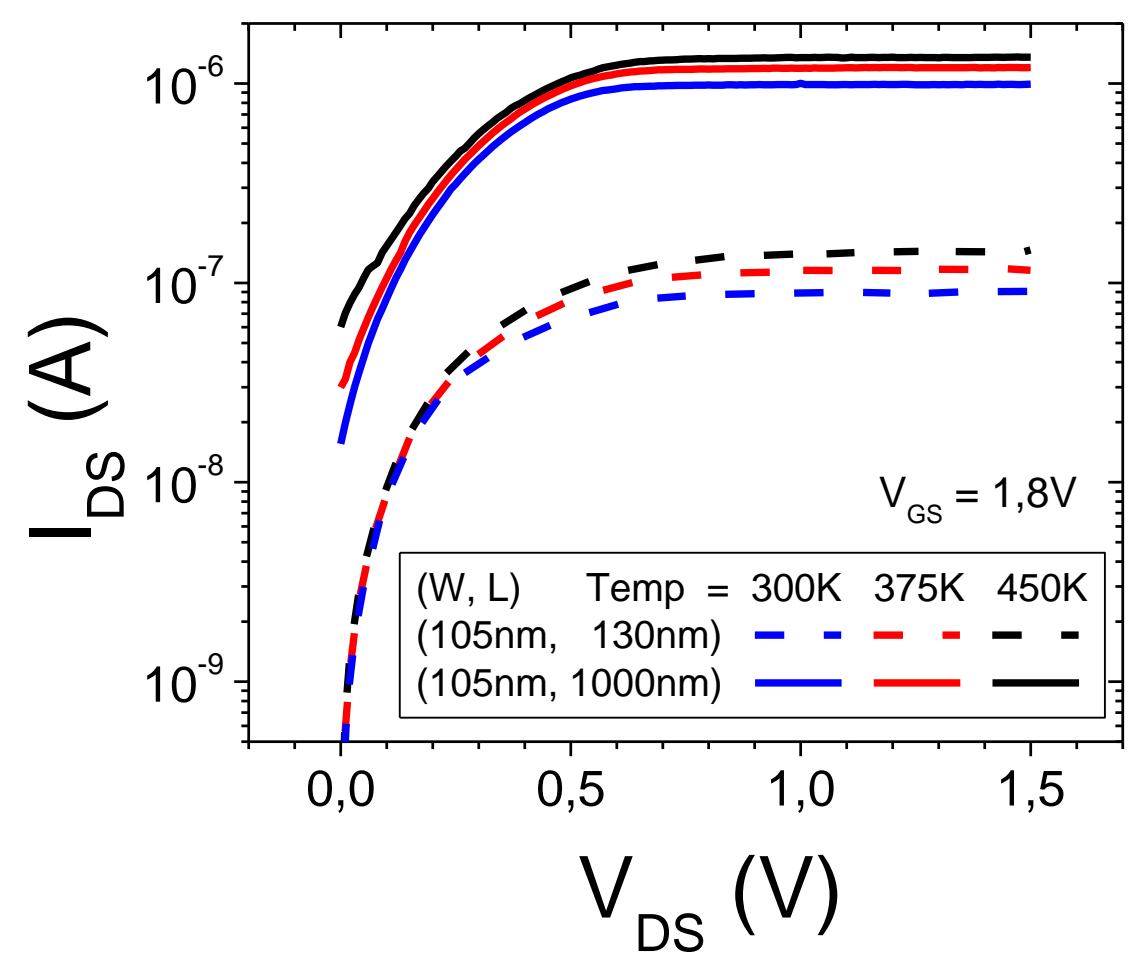

Fonte: Martino (2017) 
A seguir, extraiu-se a energia de ativação para cada um dos transistores estudados, de modo a investigar o mecanismo de transporte dominante em função da condição de polarização. Os valores da energia de ativação para tensão de porta entre $0,6 \mathrm{~V}$ e $1,8 \mathrm{~V}$ são mostrados na Figura 60.

Figura 60 - Energia de ativação em função da tensão de porta para Line TFETs com diferentes dimensões.

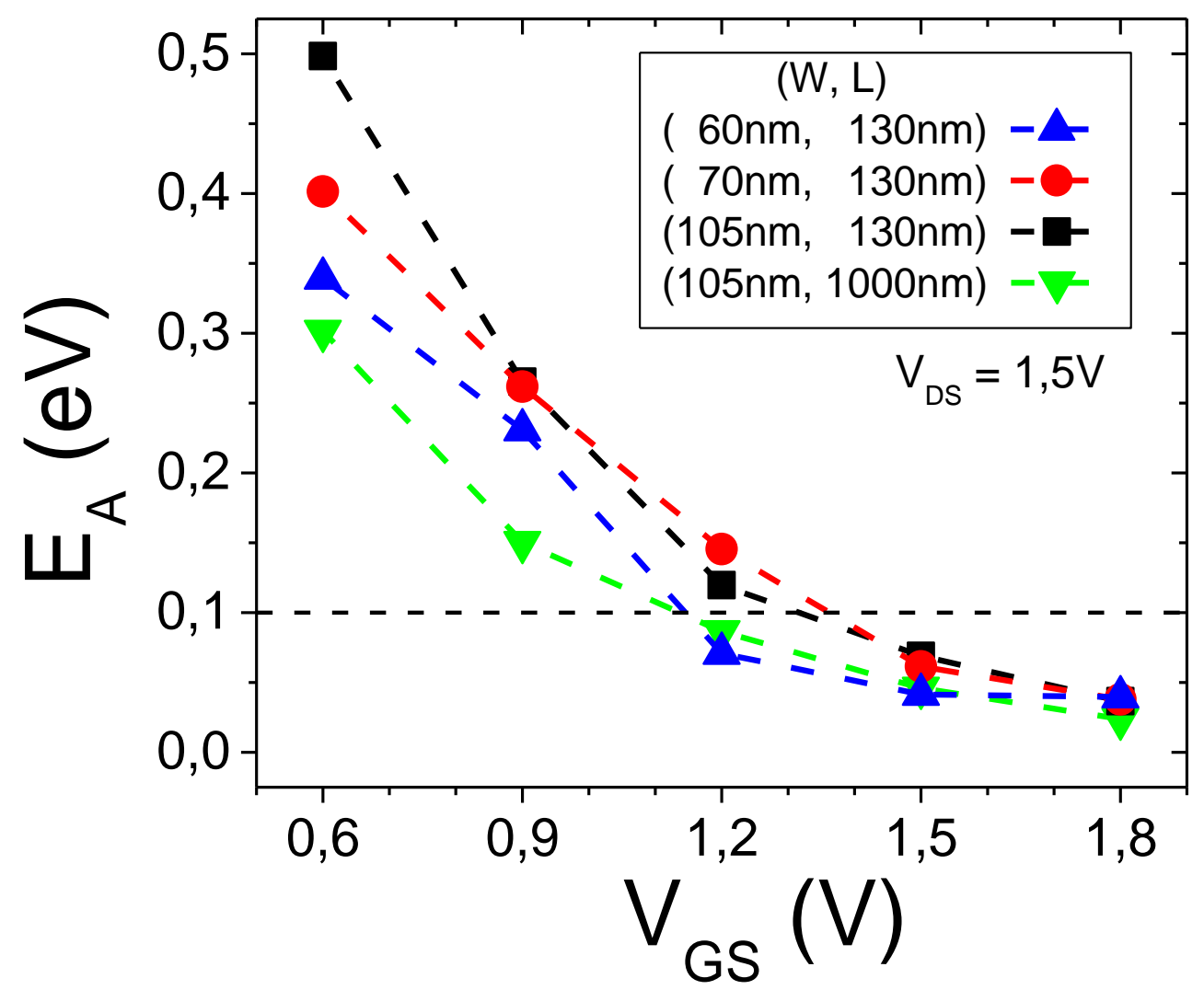

Fonte: Martino (2017)

Conforme já levantado em 4.3, o tunelamento de banda para banda pode ser considerado dominante para $E_{A}<0,1 \mathrm{eV}$, enquanto o tunelamento induzido por armadilhas prevalece caso contrário (58). Dessa forma, para garantir que todos os dispositivos estudados estejam sob forte domínio de BTBT, foi adotada a condição de polarização de $V_{G S}=1,8 \mathrm{~V}$ para a sequência da análise.

A Figura 61 exibe os resultados obtidos para o mesmo par de transistores do circuito reportado na Figura 57. Nota-se que um aumento na temperatura ocasionou uma diminuição no nível do plateau da razão de espelhamento de corrente, o que pode ser explicado pela energia de ativação de $T_{1}$ ser ligeiramente maior do que a 
$E_{A}$ do transistor $T_{2}$. Observa-se ainda que a faixa de operação em relação a $V_{D 2}$ não é afetada pela temperatura, o que sugere a constância também da tensão de conformidade.

Figura 61 - Razão de espelhamento de corrente em função de $V_{D 2}$ para diferentes temperaturas.

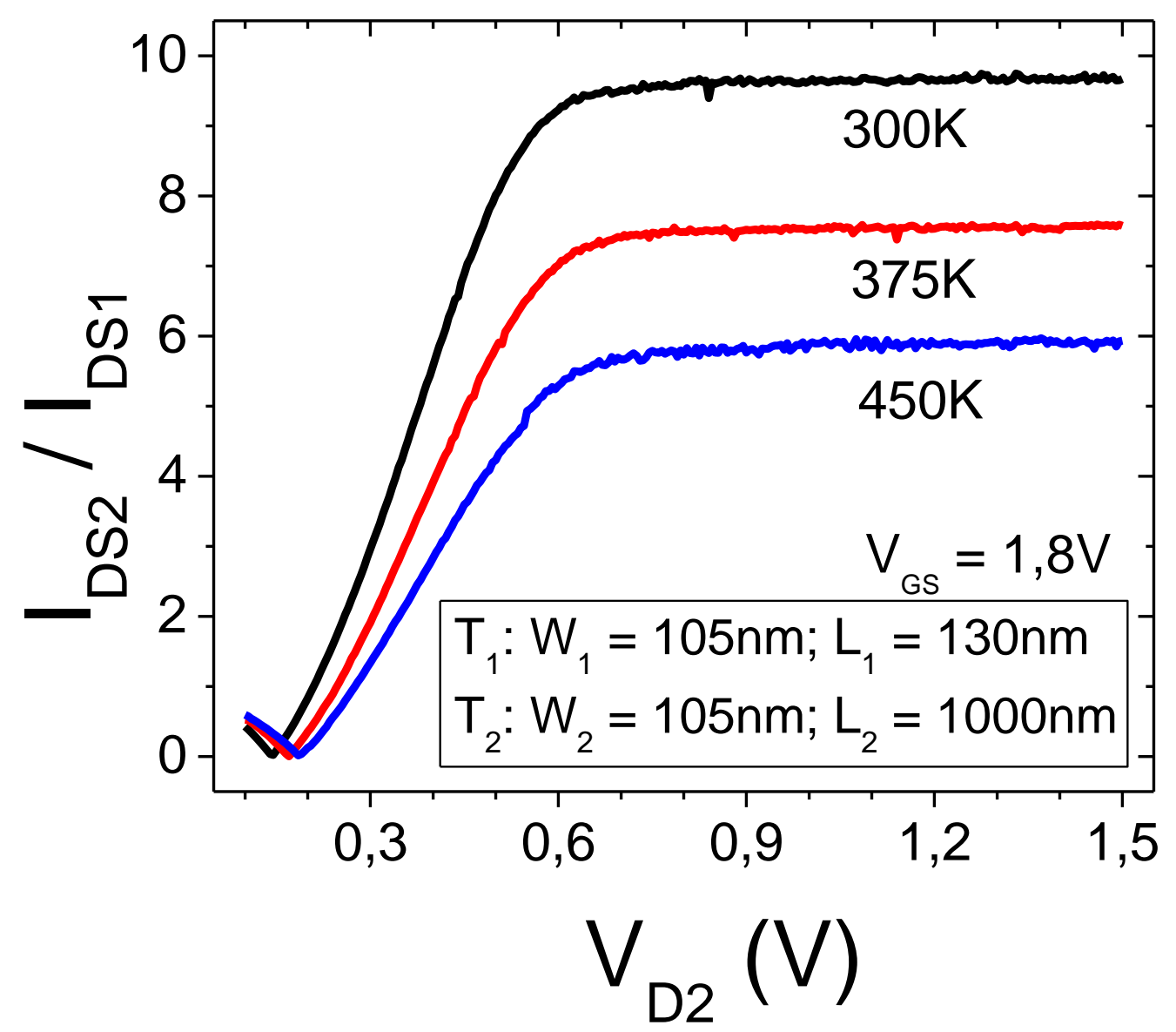

Fonte: Martino (2017)

Finalmente, são extraídos os valores do patamar de IDS2/LDS1 para circuitos compostos por transistores de diferentes dimensões e submetidos a diferentes temperaturas. Os dados obtidos são consolidados na Figura 62, em função da temperatura, e na Figura 63, em função da área de canal. 
Figura 62 - Razão de espelhamento de corrente em função da temperatura para diferentes dimensões do transistor $\mathrm{T}_{1}$.

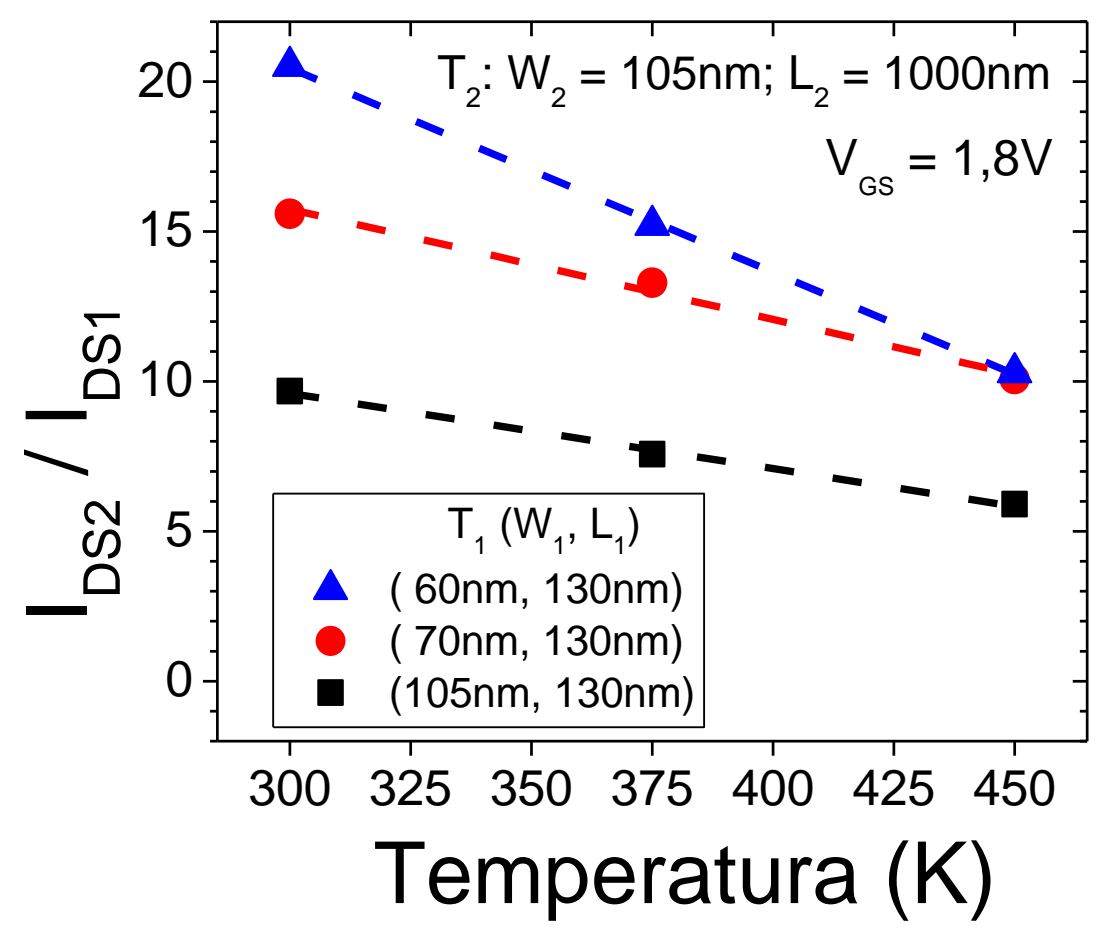

Fonte: Martino (2017)

Figura 63 - Razão de espelhamento de corrente em função da razão entre as áreas de canal dos transistores $T_{2}$ e $T_{1}$ para diferentes temperaturas.

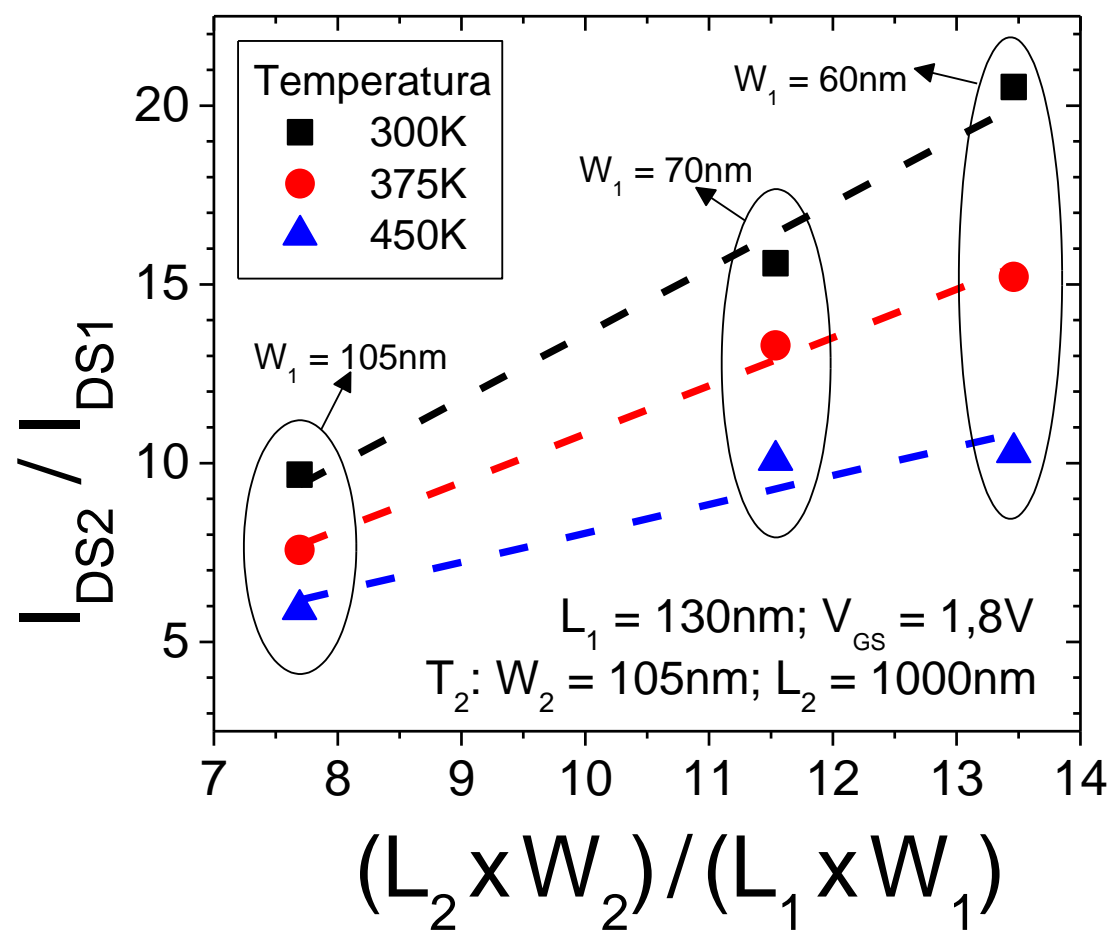

Fonte: Martino (2017) 
Para todos os circuitos estudados, observa-se uma tendência da razão de espelhamento de corrente negativa aproximadamente linear em relação à temperatura. A tendência negativa pode ser explicada com base na diferença de entre as energias de ativação, conforme Figura 60. Para $\mathrm{V}_{\mathrm{GS}}=1,8 \mathrm{~V}$, o dispositivo com comprimento de canal de $1000 \mathrm{~nm}$ e largura de canal de $105 \mathrm{~nm}$ é precisamente o que apresenta menor $E_{A}$. Como ele aparece como $T_{2}$ nos três circuitos estudados, um aumento de temperatura gera uma elevação mais forte em IDS1 do que em IDs2, reduzindo a razão IDS2/IDS1. A inclinação nesta análise aumenta para maiores diferenças de energia de ativação.

Enquanto isso, o comportamento aproximadamente linear deriva do mecanismo de transporte predominante. Uma vez que o tunelamento de banda para banda prevalece tanto para $T_{1}$ quanto para $T_{2}$, as variações são decorrentes basicamente do estreitamento da banda proibida com altas temperaturas. A equação (12) resume a susceptibilidade de BTBT em relação a $E_{g}(19)$, que leva à variação sutil e aproximadamente linear com a temperatura conforme havia sido representado graficamente na Figura 17.

$$
I_{B T B T} \propto e^{\left(-k \cdot E_{g}{ }^{3 / 2}\right)}
$$

Em relação ao impacto da área de canal, a Figura 63 reforça a previamente explicada dependência dos Line TFETs às suas dimensões, como tendência positiva aproximadamente linear de los2/lDS1 em relação à razão das áreas de $T_{2}$ e $T_{1}$. Vale a pena lembrar que desvios em relação à curva prevista podem ocorrer em virtude das diferenças entre as dimensões de máscara e efetivas ou por estruturas não ideais, como exemplificado na Figura 56.

Dessa forma, foi possível caracterizar espelhos de corrente com dispositivos Line TFETs, que apresentam níveis de corrente muito superiores aos dos Point TFETs, mas mantém um mecanismo de transporte predominante cuja dependência com a temperatura é muito menor do que a dos FinFETs. 


\subsection{COMPARAÇÃO DE DESEMPENHO DE CIRCUITOS COM TRANSISTORES FINFETS, POINT TFETS E LINE TFETS}

Considerando o princípio de funcionamento das 3 tecnologias analisadas, a comparação pode partir da equação (13), que generaliza a corrente de dreno em função das dimensões efetivas de comprimento e largura de canal. Como descrito em (14), o parâmetro $m$ da equação (13) assumiria valores entre -1 e +1 para cada tecnologia, para indicar as respectivas dependências em relação ao comprimento de canal. Ressalte-se que esta generalização despreza o Efeito Early, o DIBT e outros efeitos de canal curto.

$$
\begin{gathered}
I_{D S} \propto \frac{W_{e f}}{L_{e f}^{m}} \\
m_{\text {Line } T F E T}=-1 ; m_{\text {Point } T F E T}=0 ; m_{\text {FinFET }}=1
\end{gathered}
$$

Considerando esta generalização das correntes de dreno para cada tecnologia e o impacto da temperatura dependente da energia de ativação dos transistores envolvidos, é proposta a equação (15) para resumir a determinação da razão de espelhamento de correntes em circuitos desta natureza. Foi incluído um fator de ajuste $p$, justamente para expressar o impacto da temperatura com base na diferença entre a energia de ativação de $T_{1}$ e $T_{2}$, e mantido o parâmetro $m$ da dependência do comprimento de canal, que segue os valores propostos em (14).

$$
\frac{I_{D S 2}}{I_{D S 1}}=p\left(E_{A 1}, E_{A 2}\right) \cdot \frac{W_{e f 2} / L_{e f 2}^{m}}{W_{e f 1} / L_{e f 1}^{m}}
$$

A respeito da adequação de cada tecnologia para uso em circuitos espelhos de corrente, a Tabela 2 resume as vantagens de cada uma em termos da magnitude das correntes envolvidas e das dependências em relação a temperatura, descasamento de dimensões e polarização.

Como conclusão, pode-se resumir que os dispositivos Point TFETs podem ser considerados boas alternativas, exceto para aplicações com forte requerimento 
quanto às correntes exigidas. Para estes casos, a melhor opção seria a tecnologia Line TFET, que, apesar de dependente do comprimento de canal, consegue aliar uma elevada corrente de dreno, similar às observadas em FinFETs, a uma baixa dependência de temperatura e polarização, típica de dispositivos de tunelamento.

Tabela 2 - Comparação das características de espelhos de corrente projetados com dispositivos FinFETs, Point TFETs e Line TFETs.

\begin{tabular}{|c|c|c|c|}
\hline & FinFET & Point TFET & Line TFET \\
\hline Alta magnitude de corrente de referência & $\checkmark$ & & $\checkmark$ \\
\hline $\begin{array}{c}\text { Corrente de referência pouco dependente } \\
\text { da temperatura }\end{array}$ & & $\checkmark$ & $\checkmark$ \\
\hline $\begin{array}{c}\text { Baixa susceptibilidade ao descasamento } \\
\text { do comprimento de canal }\end{array}$ & & $\checkmark$ & \\
\hline $\begin{array}{c}\text { Baixa susceptibilidade à variação da } \\
\text { polarização (alta tensão de conformidade) }\end{array}$ & & $\checkmark$ & $\checkmark$ \\
\hline
\end{tabular}




\section{ANÁLISE DE CIRCUITOS DE PARES DIFERENCIAIS}

Este capítulo refere-se à análise da viabilidade de dispositivos de tunelamento em outro importante circuito analógico, notadamente os pares diferenciais.

Analogamente ao capítulo anterior, este estudo também começou com a comparação entre circuitos projetados com FinFETs e Point TFETs, explorando inclusive as diferenças entre pares com carga ativa e passiva. Esta comparação é facilitada pela possível similaridade estrutural, que permite a comparação direta entre transistores com mesmas dimensões, detalhadas em 6.1.1.

Posteriormente, a tecnologia Line TFET também foi estudada, como especificado em 6.1.2. Estes resultados adicionais permitiram comparações entre as vantagens e desvantagens das 3 tecnologias quanto a importantes parâmetros de pares diferenciais, como o ganho de tensão diferencial, a tensão de conformidade e a susceptibilidade a variações nas dimensões e na temperatura.

\subsection{CARACTERÍSTICAS DOS DISPOSITIVOS}

\subsubsection{Especificação dos dispositivos com estrutura FinFET}

Para a comparação entre as tecnologias FinFET e Point TFET, foram utilizados dispositivos representativos da seção transversal de uma estrutura de nanofio vertical, conforme ilustrado na Figura 64.

Estes transistores apresentam porta autoalinhada com as junções do canal tanto com o dreno quanto com a fonte, com distância de $40 \mathrm{~nm}$ entre as interfaces de óxido de porta. A estrutura de porta conta com um material de função trabalho $4,7 \mathrm{eV}$ e óxido de porta com $2 \mathrm{~nm}$ de espessura. Os dispositivos Point TFET do tipo $\mathrm{N}$ apresentam canal com baixa dopagem $\left(5 \times 10^{15} \mathrm{~cm}^{-3}\right)$, dreno com dopagem $\mathrm{n}+$ $\left(10^{20} \mathrm{~cm}^{-3}\right)$ e fonte com dopagem $\mathrm{p}+\left(10^{20} \mathrm{~cm}^{-3}\right)$. FinFETs foram simulados com a mesma estrutura, porém invertendo a dopagem de fonte. Transistores do tipo $\mathrm{P}$ foram obtidos analogamente, conforme esquema da Figura 65. 
Figura 64 - Plano de corte de uma estrutura de nanofio vertical.

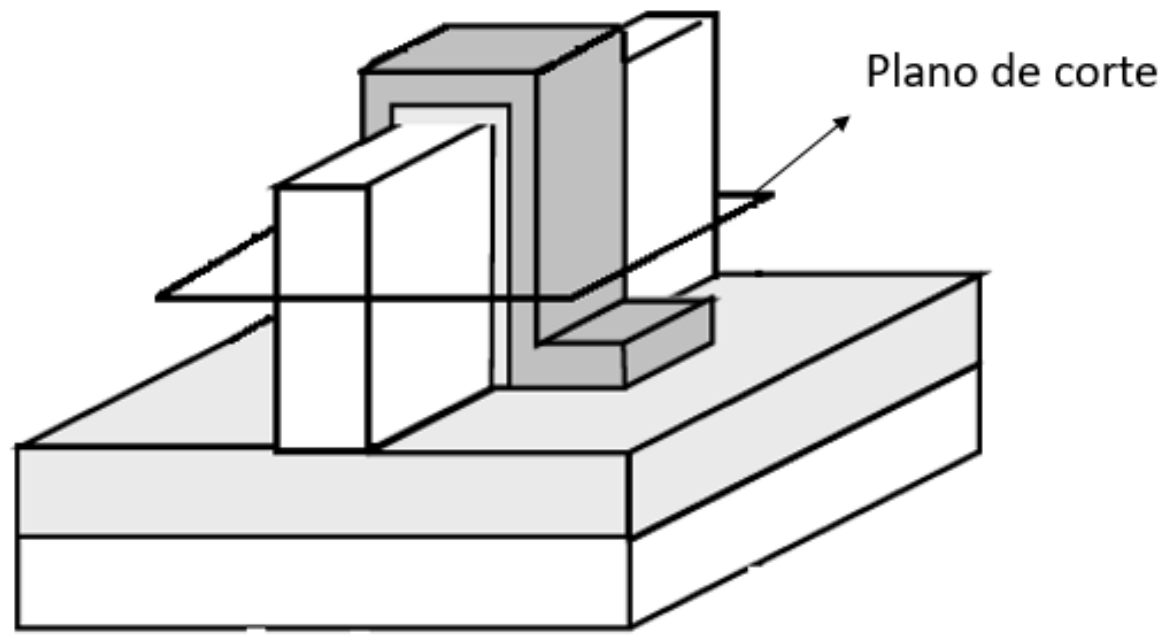

Fonte: Martino (2016)

Figura 65 - Representação esquemática da estrutura de um Point TFET e um FinFET do tipo P.
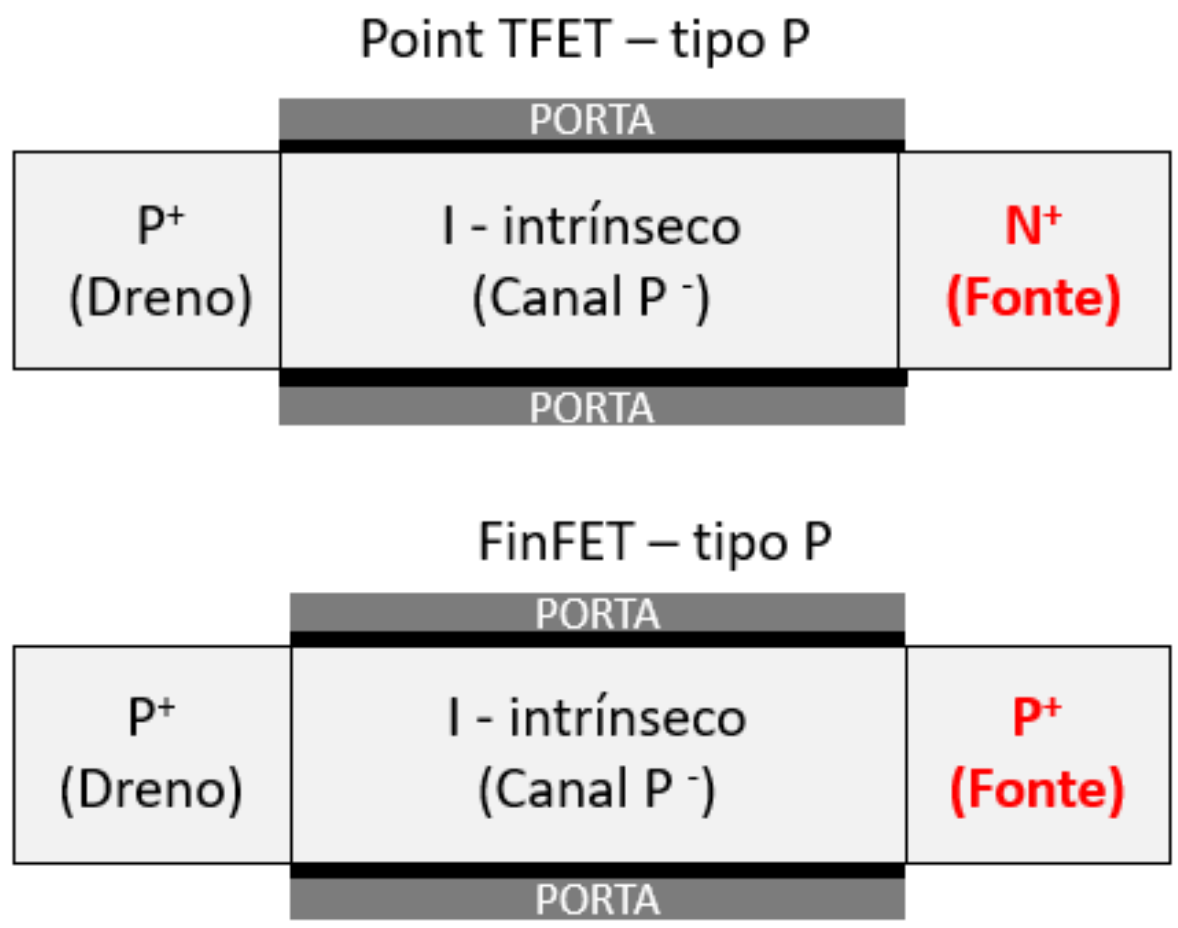

Fonte: Martino (2016) 


\subsubsection{Especificação dos dispositivos com estrutura Line TFET}

As medidas experimentais dos pares diferenciais com Line TFETs foram realizadas com transistores cujas características de fabricação são também as descritas em 5.1.2.

A principal diferença refere-se a quais dispositivos foram selecionados para os circuitos medidas neste capítulo. Objetivou-se escolher os que apresentavam correntes de dreno mais próximas para as condições de polarização aplicadas. Por isso, foram selecionados 3 transistores com menor variação de dimensão, com comprimento de canal entre 70 e $150 \mathrm{~nm}$ e largura de canal entre 70 e $130 \mathrm{~nm}$.

\subsection{CARACTERÍSTICAS DO CIRCUITO DE PAR DIFERENCIAL}

O esquema geral de par diferencial está representado na Figura 66, tanto com a configuração clássica para o par com carga passiva (a) quanto com a configuração do circuito com carga ativa (b). O esquema está desenhado com a simbologia de transistores de tunelamento, porém o circuito para FinFETs seria análogo. Foram utilizados transistores do tipo $\mathrm{N}$ como $\mathrm{T}_{1}$ e $\mathrm{T}_{2} \mathrm{e}$, nos casos em que foi avaliado o circuito com carga ativa, foram adotados transistores do tipo $P$ como carga $\left(T_{3}\right.$ e $\left.T_{4}\right)$.

No início das seções 6.3 e 6.4, são definidas as condições de polarização para as medidas experimentais e para as simulações, bem como a medida de $V_{\text {out, }}$ que será utilizada para o cálculo do ganho de tensão diferencial ( $A_{d}$, conforme equação (16)), do ganho de tensão de modo comum $\left(A_{c m}\right.$, definido pela equação (17)) e da taxa de rejeição de modo comum (CMRR, de acordo com a expressão (18)).

$$
\begin{gathered}
A_{d}=\frac{\left|\Delta V_{\text {out }}\right|}{\left|\Delta v_{\text {id }}\right|} \quad v_{i d}=v_{\text {in } 1}-v_{\text {in } 2} \\
A_{c m}=\frac{\left|\Delta v_{\text {out }}\right|}{\left|\Delta v_{\text {icm }}\right|} \quad v_{\text {icm }}=v_{\text {in } 1}=v_{\text {in } 2} \\
\operatorname{CMRR}(d B)=10 \log _{10}\left(\frac{\left|A_{d}\right|}{\left|A_{c m}\right|}\right)^{2}=20 \log _{10}\left(\frac{\left|A_{d}\right|}{\left|A_{c m}\right|}\right)
\end{gathered}
$$


Figura 66 - Circuitos básicos de pares diferenciais

(a) com carga passiva e (b) com carga ativa.

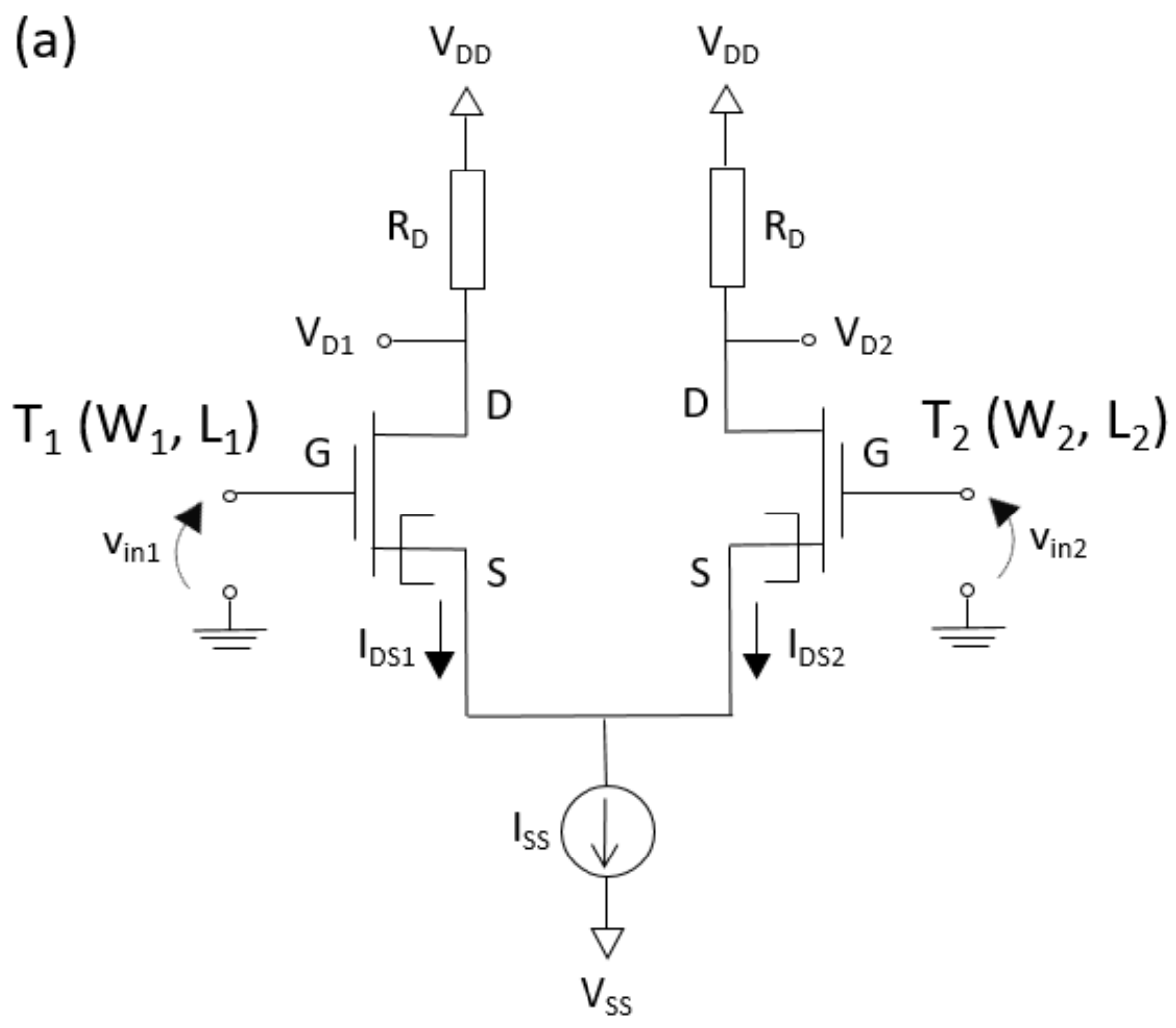

(b)

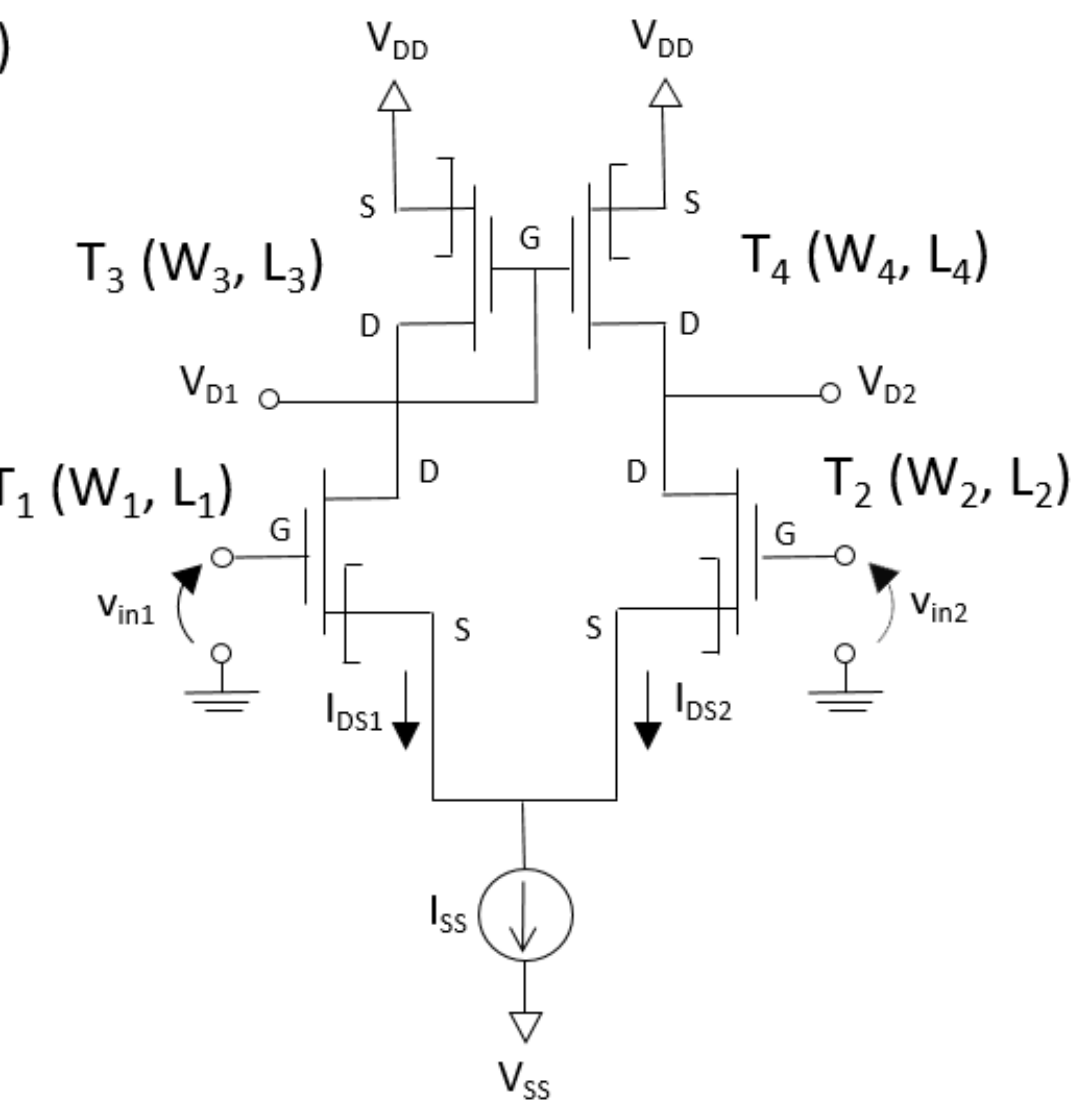

Fonte: Autor 
Após a avaliação de pares diferenciais com dispositivos FinFETs, Point TFETS e Line TFETs, foram determinadas as melhores escolhas com base em critérios como tensão de conformidade, ganho de tensão diferencial, susceptibilidade ao descasamento entre os transistores e susceptibilidade à variação de temperatura.

\subsection{RESULTADOS E ANÁLISES DE CIRCUITOS COM ESTRUTURAS FINFETS}

Como especificado em 6.1.1, estruturas similares, porém com diferenças em dopagens, foram utilizadas para o estudo de pares diferenciais com as tecnologias FinFET e Point TFET.

Inicialmente, um circuito com carga passiva (usando esquema da Figura 66(a)) comparou o ganho de tensão diferencial e o ganho de tensão de modo comum extraídos com $T_{1}$ e $T_{2}$ perfeitamente casados. Então, verificou-se como $A_{d}$, $A_{c m}$ e CMRR mudam quando o transistor $T_{2}$ tem comprimento de canal variado de 20 a $100 \mathrm{~nm}$, mantendo-se $\mathrm{L}_{1}=60 \mathrm{~nm}$.

Posteriormente, foi avaliado um circuito com carga ativa (usando esquema da Figura 66(b)) e, após caracterização à temperatura ambiente, estudou-se como os mesmos 3 parâmetros fundamentais $A_{d}$, $A_{c m}$ e CMRR mudam com o aumento da temperatura.

Para ambos os casos, adotou-se polarização com $\mathrm{V}_{\mathrm{DD}}=+1,7 \mathrm{~V}$ e $\mathrm{V}_{S S}=-1,7 \mathrm{~V}$. Também nos dois circuitos, o cálculo do ganho de tensão diferencial foi realizado com a polarização $V_{\text {in2 }}=-V_{\text {in1 }}$, implicando $V_{\text {id }}=V_{\text {in1 }}-V_{\text {in2 }}=2$. $v_{\text {in1 }}$. Já 0 ganho de tensão de modo comum, conforme equação (17), é obtido quando Vin1 = Vin2.

\subsubsection{Impacto das dimensões e da polarização}

Para avaliar o impacto da polarização, primeiramente foi aplicada tensão diferencial no par projetado com dispositivos Point TFETs e FinFETs, medindo-se a corrente que passa por $\mathrm{T}_{1}$ e por $\mathrm{T}_{2}$. Os valores destas correntes, normalizados em relação à corrente total Iss, são exibidos na Figura 67 em função da tensão de entrada diferencial.

Conforme esperado para a situação de casamento perfeito entre os transistores, quando a tensão de entrada diferencial é nula, temos a corrente total Iss sendo igualmente dividida entre $T_{1}$ e $T_{2}$. Valores positivos de vid indicam maior $V_{G S}$ 
em $T_{1}$, cuja corrente de dreno aumento, e menor $V_{G S}$ em $T_{2}$, cuja corrente diminui. Naturalmente, o oposto ocorre para excursão negativa de vid.

Pode-se notar duas diferenças fundamentais entre os circuitos com FinFETs e Point TFETs. A primeira é que, em termos proporcionais, a corrente nos transistores de tunelamento variou mais com a variação da polarização do que nos FinFETs. Para vid muito pequeno, a diferença de inclinação da curva da corrente normalizada é quase 12 vezes maior do que a inclinação para o par com FinFETs.

Por outro lado, enquanto a variação das correntes em $T_{1}$ e $T_{2}$ é linear para toda a faixa de vid no caso de FinFETs, para os Point TFETs a linearidade é obtida apenas para uma estreita faixa de $V_{\text {id, }}$ notadamente para $\left|\mathrm{V}_{\text {id }}\right|<0,2 \mathrm{~V}$. Numericamente, é possível calcular que a inclinação da curva da corrente normalizada para circuito com FinFETs varia menos de $2 \%$ ao longo de toda a faixa exibida de vid. Para Point TFETs, porém, a inclinação cai 38\% nos extremos das condições de polarização estudadas.

Figura 67 - IDs1/Iss e IDS2/Iss em função da tensão de entrada diferencial Vid para um par diferencial balanceado com Point TFETs ou FinFETs.

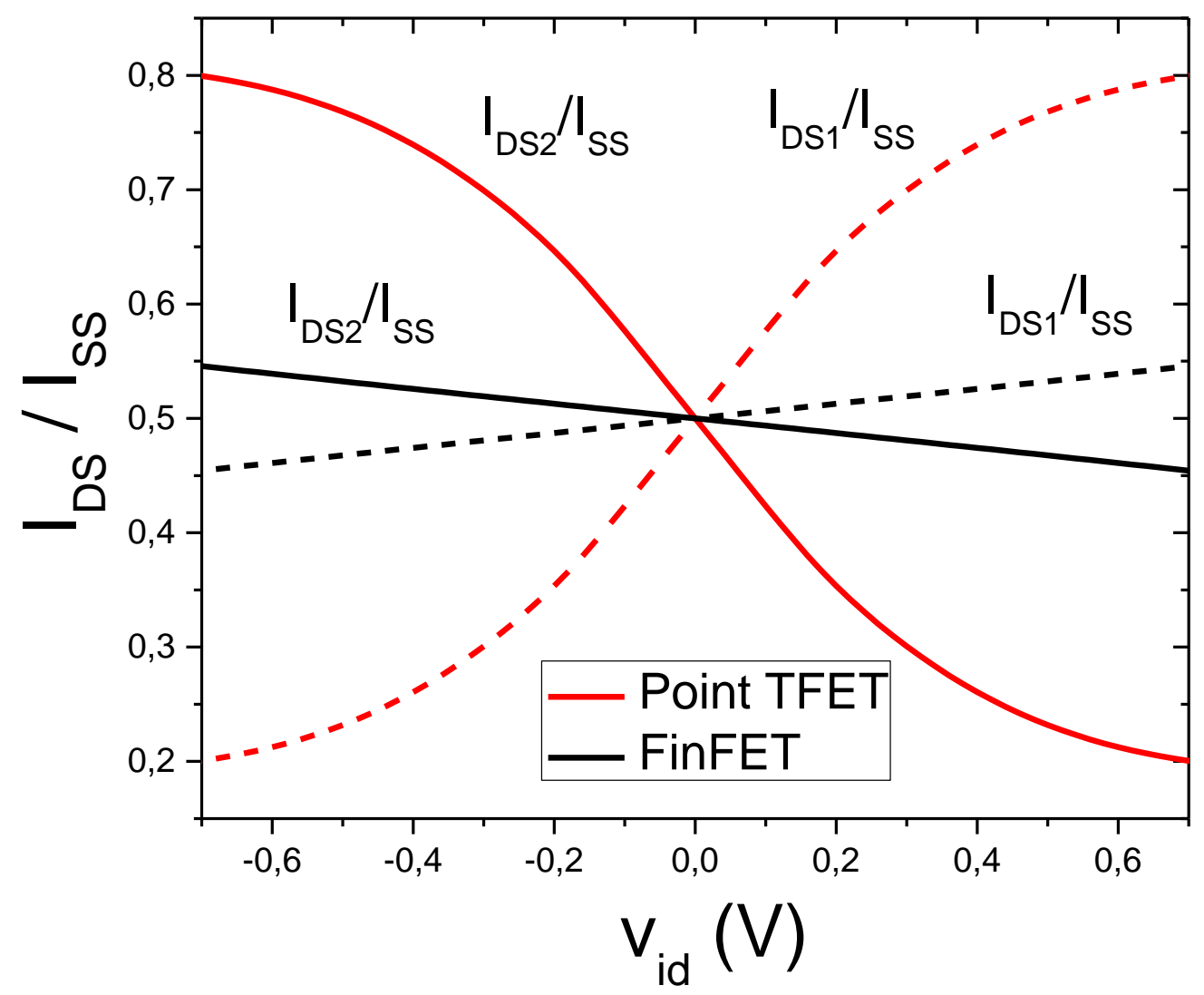

Fonte: Martino (2015) 
Em termos práticos da viabilidade de aplicação de dispositivos de cada tecnologia em pares diferenciais, pode-se inferir que a tensão de conformidade de circuitos com FinFETs é maior, isto é, seria necessário alterar mais bruscamente a polarização para que o circuito tenha seu ganho degradado significativamente.

Em relação ao valor absoluto de $A_{d}$, caso fossem comparados circuitos com idêntico $R_{D}$, a variação em $V_{D 1}$ e $V_{D 2}$ dependeria não apenas da inclinação da corrente normalizada da Figura 67, mas também dos valores absolutos das correntes de dreno envolvidas. De acordo com a Figura 42, como a diferença de magnitude da corrente seria de mais de uma ordem de grandeza, o valor resultante do ganho de tensão diferencial ainda seria maior para circuitos com FinFETs.

Procedimento análogo foi seguido para avaliação do ganho de tensão de modo comum para circuitos com as duas tecnologias. Também foram parecidas as comparações em termos de magnitude e sensibilidade dos valores obtidos em função de variações na polarização da entrada. Para a faixa de variação de vicm de $-0,5 \mathrm{~V}$ a $+0,5 \mathrm{~V}$, obteve-se variação de cerca de $15 \%$ para FinFETs e de até $60 \%$ para Point TFETs, sempre em relação à condição de vicm próximo de zero.

Essas bruscas alterações observadas em pares diferenciais com Point TFETs podem ser relacionadas à forte variação de parâmetros como transcondutância e resistência de saída associada a mecanismos de transporte dominantes nestes dispositivos. Na faixa de operação em que BTBT domina, há um significativo decréscimo em ro quando aumenta a tensão de porta. Já quando há redução na polarização, o mecanismo de TAT, que passa a dominar, sofre forte redução em $\mathrm{gm}_{\mathrm{m}}$ com sucessivas reduções de tensão de porta.

A partir destas extrações realizadas para os casos de casamento perfeito entre as dimensões de $T_{1}$ e $T_{2}$, foi estudado como os parâmetros fundamentais de pares diferenciais seriam afetados pelo descasamento, considerado a partir da variação de $L_{2}$ de 20 a $100 \mathrm{~nm}$, mantendo $L_{1}$ fixo em $60 \mathrm{~nm}$. A Figura 68 ilustra a variação do ganho de tensão diferencial em função do comprimento de canal do transistor $\mathrm{T}_{2}$. 
Figura 68 - Variação do ganho diferencial $\left(A_{d}\left(L_{2}\right) / A_{d}(60 n m)\right)$ em função do comprimento de canal $\left(\mathrm{L}_{2}\right)$ do transistor $\mathrm{T}_{2}$.

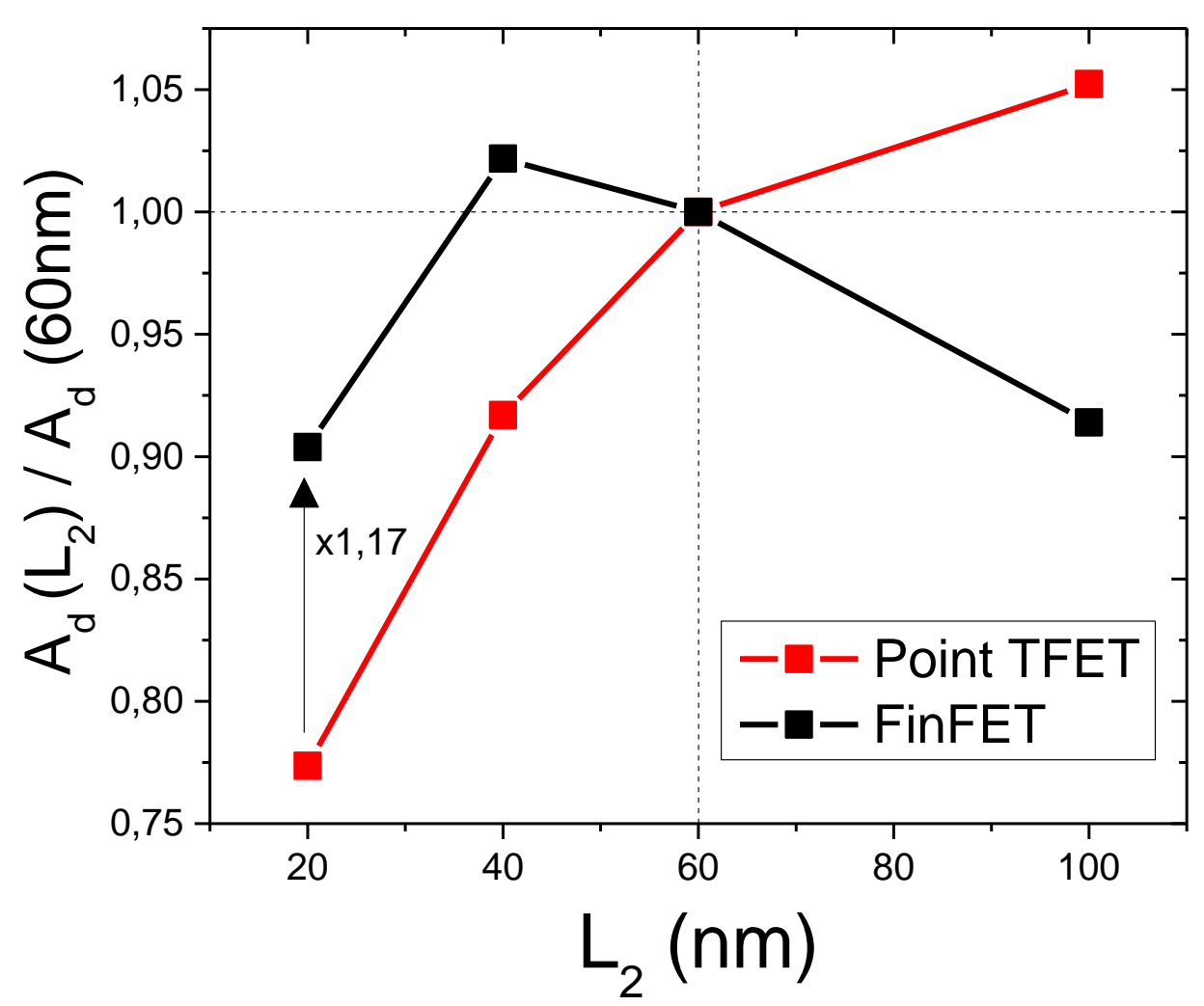

Fonte: Martino (2015)

Partindo da condição de casamento perfeito $\left(L_{1}=L_{2}=60 \mathrm{~nm}\right)$ e aumentando o valor de $L_{2}$ até $100 \mathrm{~nm}$, observa-se uma variação no ganho do par com Point TFETs de $4 \%$, enquanto no caso de FinFETs a variação chega a $9 \%$. Essa menor sensibilidade de Point TFETs de canais longos com $L$ está diretamente relacionada ao princípio de funcionamento desta tecnologia, com tunelamento acontecendo basicamente na junção do canal com a fonte. Por outro lado, valores muito pequenos de comprimento de canal ainda podem tornar importante o fenômeno do DIBT, coerentemente com o que foi detalhadamente explicado em 4.2.

É interessante observar que também está destacado na Figura 68 que a máxima diferença relativa é de $17 \%$. Lembrando que na situação de casamento perfeito a diferença de inclinação nas correntes normalizadas era de quase 12 vezes, com degradação de até $38 \%$ em função da polarização, pode-se inferir que os comentários previamente realizados quanto às comparações entre ganho de modo diferencial seguem inalterados por este tipo de descasamento entre $T_{1}$ e $T_{2}$. 
A Figura 69 apresenta o mesmo tipo de estudo, porém agora considerando os valores obtidos para o ganho de tensão de modo comum.

Figura 69 - Variação do ganho de modo comum $\left(A_{C M}\left(L_{2}\right) / A_{C M}(60 n m)\right)$ em função do comprimento de canal $\left(\mathrm{L}_{2}\right)$ do transistor $\mathrm{T}_{2}$.

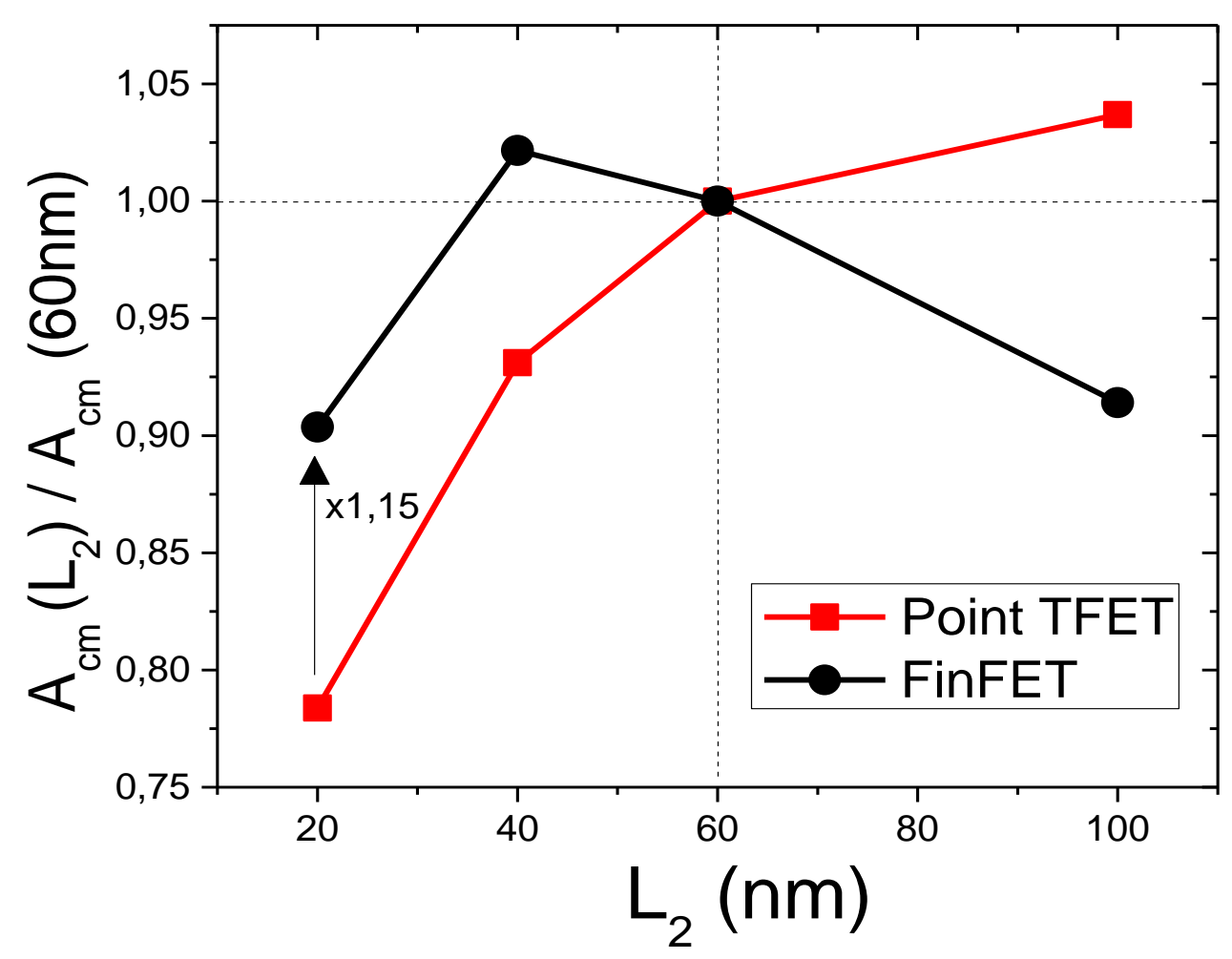

Fonte: Martino (2015)

Nota-se que a tendência de impacto do descasamento em $A_{c m}$ segue padrão bastante parecido com o observado no caso de $A_{d}$, isto é, com maior susceptibilidade ao aumento de canal no caso do par projetado com FinFETs. A diferença observada no pior caso de DIBT na faixa analisada, de $15 \%$ quando $\mathrm{L}_{2}=20 \mathrm{~nm}$, novamente não altera 0 maior impacto do sinal em modo comum na oscilação do sinal de saída.

Finalmente, a Figura 70 exibe os resultados para o CMRR, calculado com base na equação (18). Neste caso, relembrando que tratamos de valores absolutos e variações menores de ganho no caso da tecnologia FinFET, observamos também flutuação muito menor na taxa de rejeição de modo comum, abaixo de $10 \%$, enquanto a diferença entre os valores extremos extraídos para Point TFETs é de mais de 5 vezes. 
Figura 70 - Variação da taxa de rejeição de modo comum (CMRR $\left(\mathrm{L}_{2}\right)$ / $\left.\mathrm{CMRR}(60 \mathrm{~nm})\right)$ em função do comprimento de canal $\left(\mathrm{L}_{2}\right)$ do transistor $\mathrm{T}_{2}$.

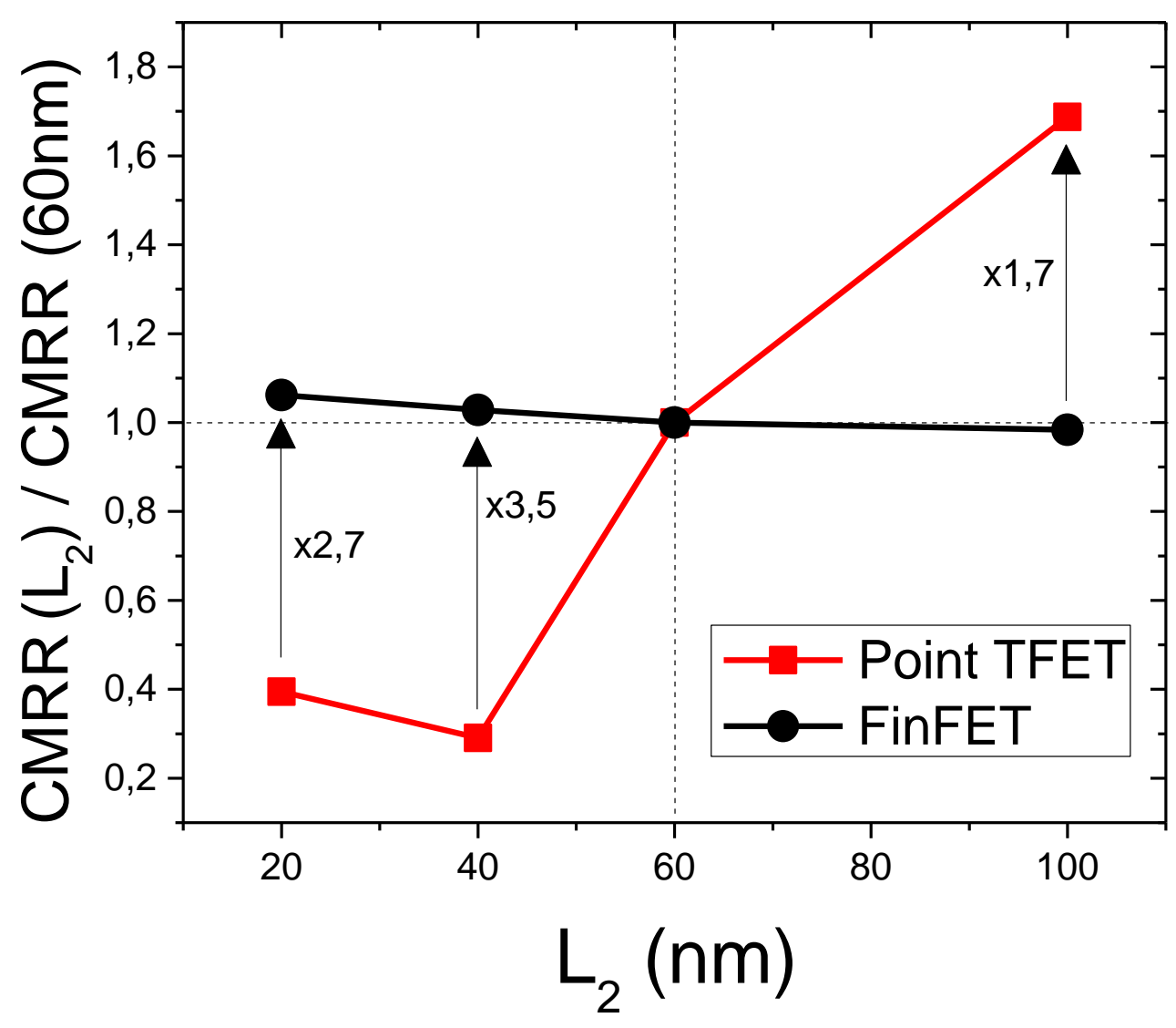

Fonte: Martino (2015)

Outra forma de comparar a viabilidade de uso de transistores Point TFETs e FinFETs em blocos de circuitos como o par diferencial é através do esquema proposto na Figura 66(b), isto é, através de um par diferencial com carga ativa. Após a avaliação do comportamento com entrada diferencial e de modo comum à temperatura ambiente, também foi estudado como um aumento na temperatura influencia os parâmetros principais.

Aplicando entrada diferencial nos transistores $T_{1}$ e $T_{2}$, com $v_{i d}$ na faixa de $-0,5 \mathrm{~V}$ a $+0,5 \mathrm{~V}$, a Figura 71 mostra os valores obtidos para as tensões de dreno $\mathrm{V}_{\mathrm{D} 1} \mathrm{e}$ $\mathrm{V}_{\mathrm{D} 2 .}$ 
Figura 71 - Tensões de dreno em função da tensão de entrada diferencial Vid para um par diferencial balanceado com Point TFETs ou FinFETs.

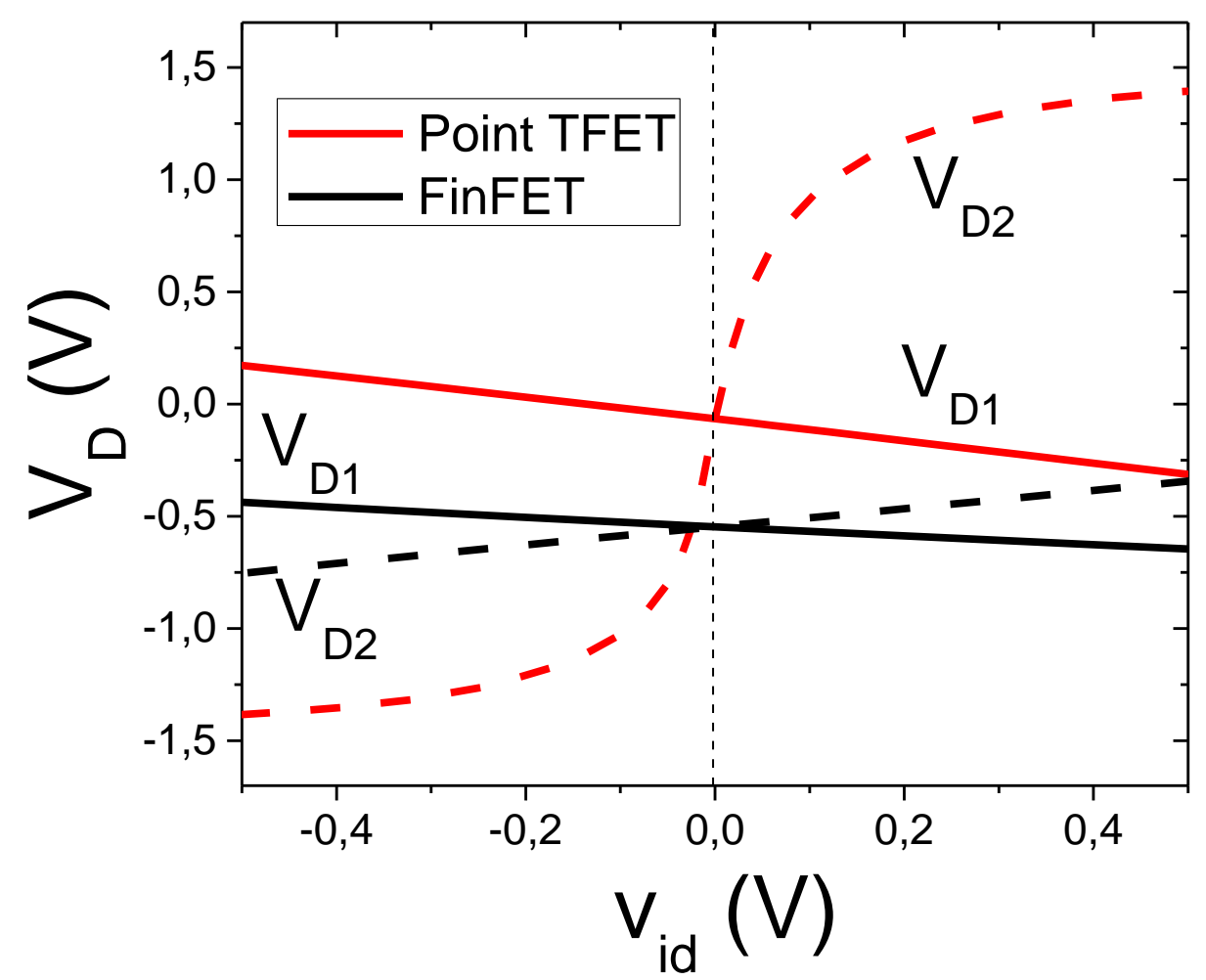

Fonte: Martino (2016)

É interessante observar duas diferenças flagrantes entre os circuitos analisados, notadamente as tensões de saída para entrada diferencial nula e o formato não linear de $V_{D 2}$. Para FinFETs, a diferença de mobilidade entre os portadores deve ser compensada pela assimetria entre as condições de polarização dos pFinFETs na carga ativa e dos nFinFETs no par diferencial. Dessa forma, as tensões de saída $V_{D 1}$ e $V_{D 2}$ ficam em -0,55V para FinFETs e praticamente nulas para TFETs, nos quais a corrente principal de BTBT ocorre próximo à junção entre fonte e canal, dependendo principalmente da largura de faixa proibida.

Em relação ao formato de $V_{D 2}$ para o circuito com TFETs, é importante notar o consequente aumento abrupto na inclinação para entradas perto de $0 \mathrm{~V}$ e a distorção pela saturação para $\mid \mathrm{V}$ id $\mid>0,05 \mathrm{~V}$, com clara analogia ao observado no circuito com carga passiva. Em comparação com o circuito de carga passiva, a razão entre os valores obtidos para Point TFET e para FinFETs com vid próximo de zero é até maior, chegando a 50 vezes. Entretanto, a faixa linear é mais estreita, de modo que a degradação desta inclinação é de mais de $80 \%$ para a faixa estudada. Sob o ponto 
de vista de viabilidade do bloco, isso representa novamente uma menor tensão de conformidade para pares projetados com Point TFETs.

A justificativa física para esta inclinação novamente poderia ser baseada na susceptibilidade dos mecanismos de transporte que atuam nos transistores de tunelamento, notadamente o tunelamento de banda para banda e o tunelamento induzido por armadilhas, à polarização, isto é, à significativa variação de ro e gm com variações da polarização quando BTBT e TAT prevalecem, respectivamente. A assimetria entre $V_{D 1}$ e $V_{D 2}$ também pode ser avaliada, sob o ponto de vista de circuitos, a partir da diferença que reside no curto circuito entre as portas dos transistores $T_{3}$ e $T_{4}$ com $V_{D 1}$. Isto é, para $Q_{3}$ fixa a relação $V_{G S}=V_{D S}$, o que não ocorre com $\mathrm{T}_{4}$.

A assimetria do circuito da carga ativa também é ilustrada pelos resultados na Figura 72, com as correntes normalizadas em função da entrada diferencial sob mesma excursão.

Figura 72 - IDS1/Iss e IDS2/Iss em função da tensão de entrada diferencial Vid para um par diferencial balanceado com Point TFETs ou FinFETs.

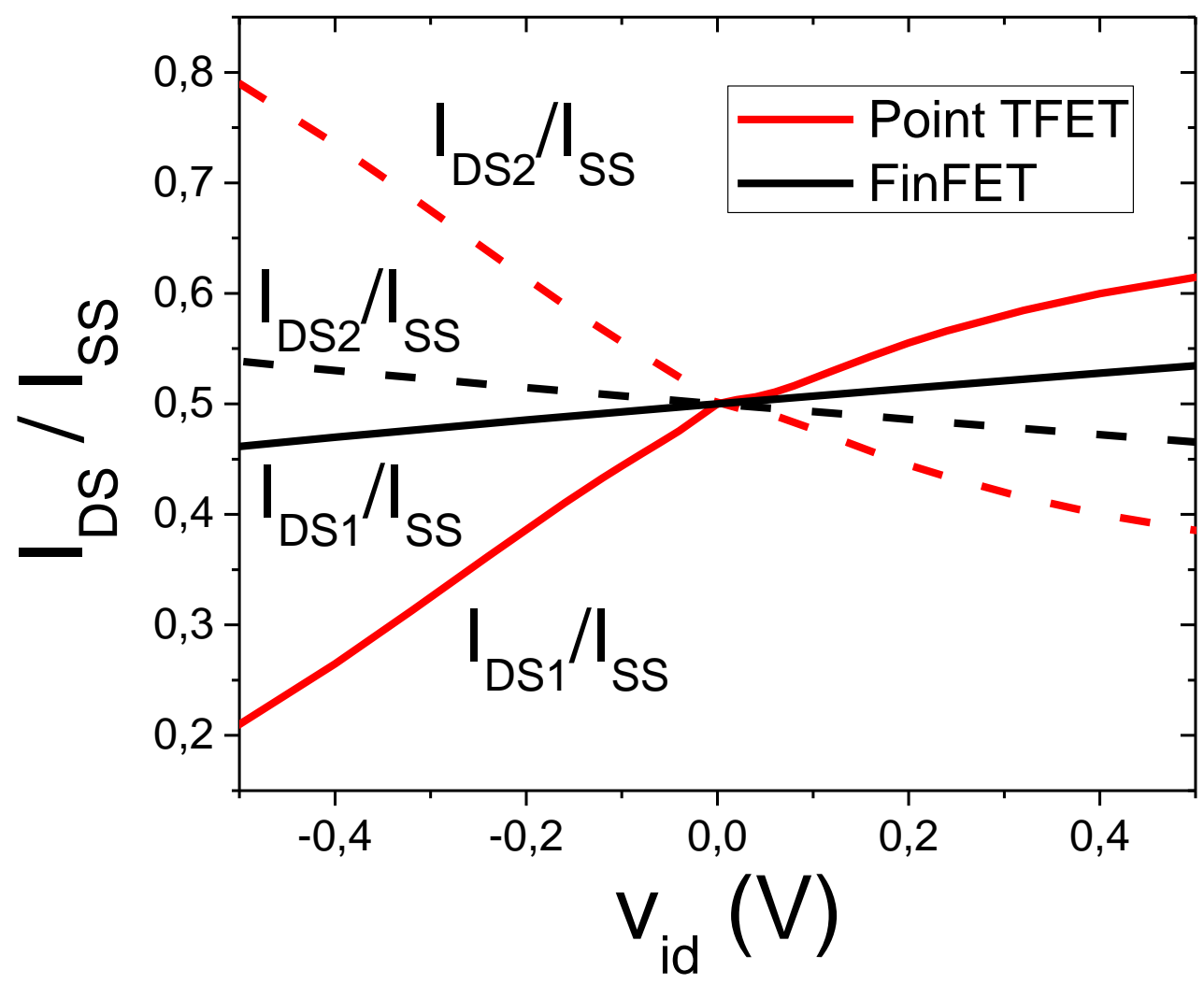

Fonte: Martino (2016) 
Vale a pena destacar o impacto da carga ativa nas curvas das correntes normalizadas, comparando com a Figura 67, que usa par diferencial projetado com as mesmas tecnologias. $O$ curto circuito entre dreno e porta de $T_{3}$ o mantém na região de saturação para uma faixa de tensões de entrada mais larga do que $T_{4}$. Além disso, a variação nas resistências de saída de $T_{3}$ e $T_{4}$ deixam o formato das curvas na Figura 71 diferente das formas das curvas na Figura 72, ao contrário do que ocorreria com as resistências fixas do circuito com carga passiva.

Em relação ao caso de polarização do circuito em modo comum, por outro lado, notou-se que o circuito de Point TFETs com carga ativa não apresentava sensibilidade em relação à entrada muito superior à dos FinFETs nem grandes degradações ao longo da faixa de variação de vicm. Em outras palavras, o parâmetro do CMRR dos circuitos com FinFETs varia muito pouco com a polarização, enquanto que para Point TFETs fica dependente basicamente do formato do ganho de tensão diferencial.

\subsubsection{Impacto da temperatura}

Para avaliar o impacto da temperatura em pares diferenciais com as tecnologias FinFET e Point TFET, foi utilizado o mesmo circuito de carga ativa já caracterizado à temperatura ambiente, porém agora simulado sob temperaturas de até $450 \mathrm{~K}$.

A Figura 73 mostra a variação do valor de tensão diferencial para cada tecnologia, em relação aos respectivos valores a 300K. Já a Figura 74 mostra curvas análogas, porém para o caso de entrada em modo comum. 
Figura 73 - Ganho de tensão diferencial para temperaturas de 300 a 450K.

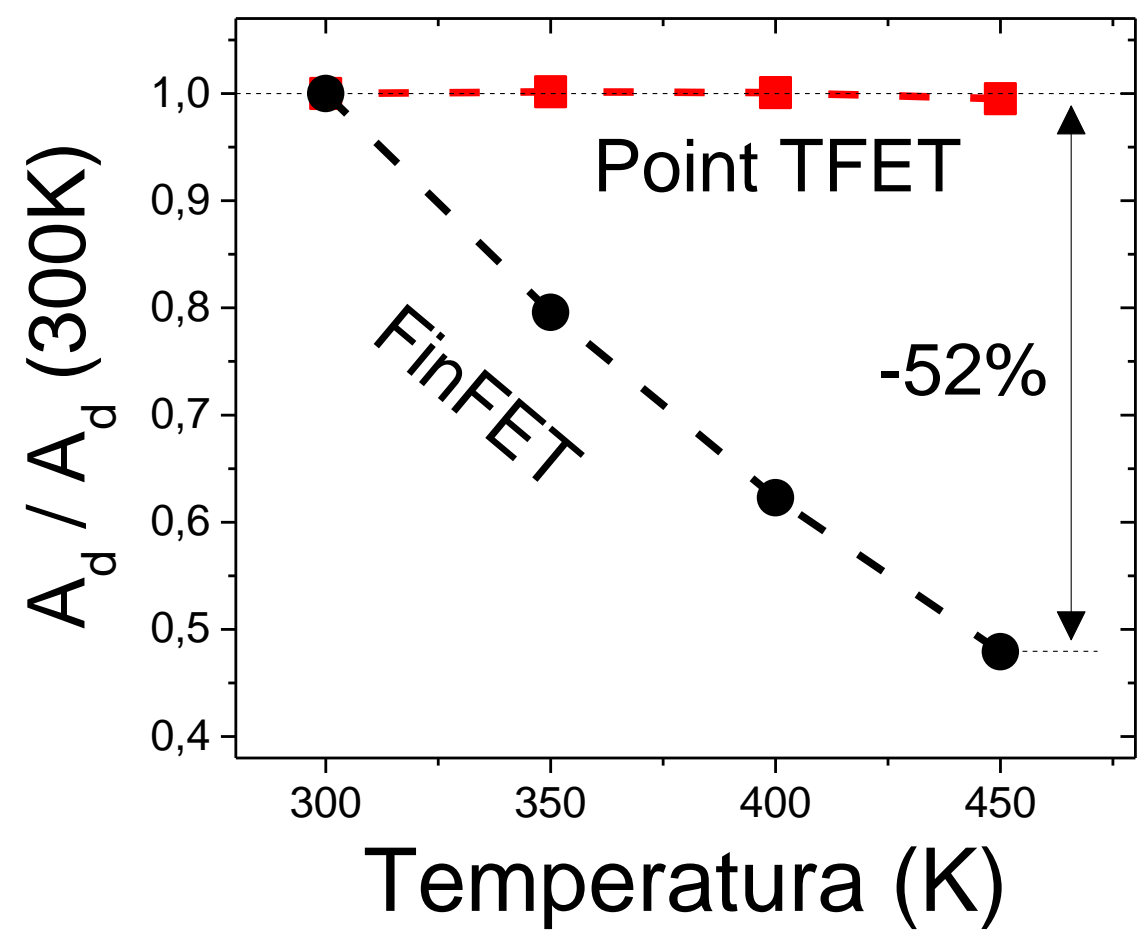

Fonte: Martino (2016)

Figura 74 - Ganho de tensão de modo comum para temperaturas de 300 a $450 \mathrm{~K}$.

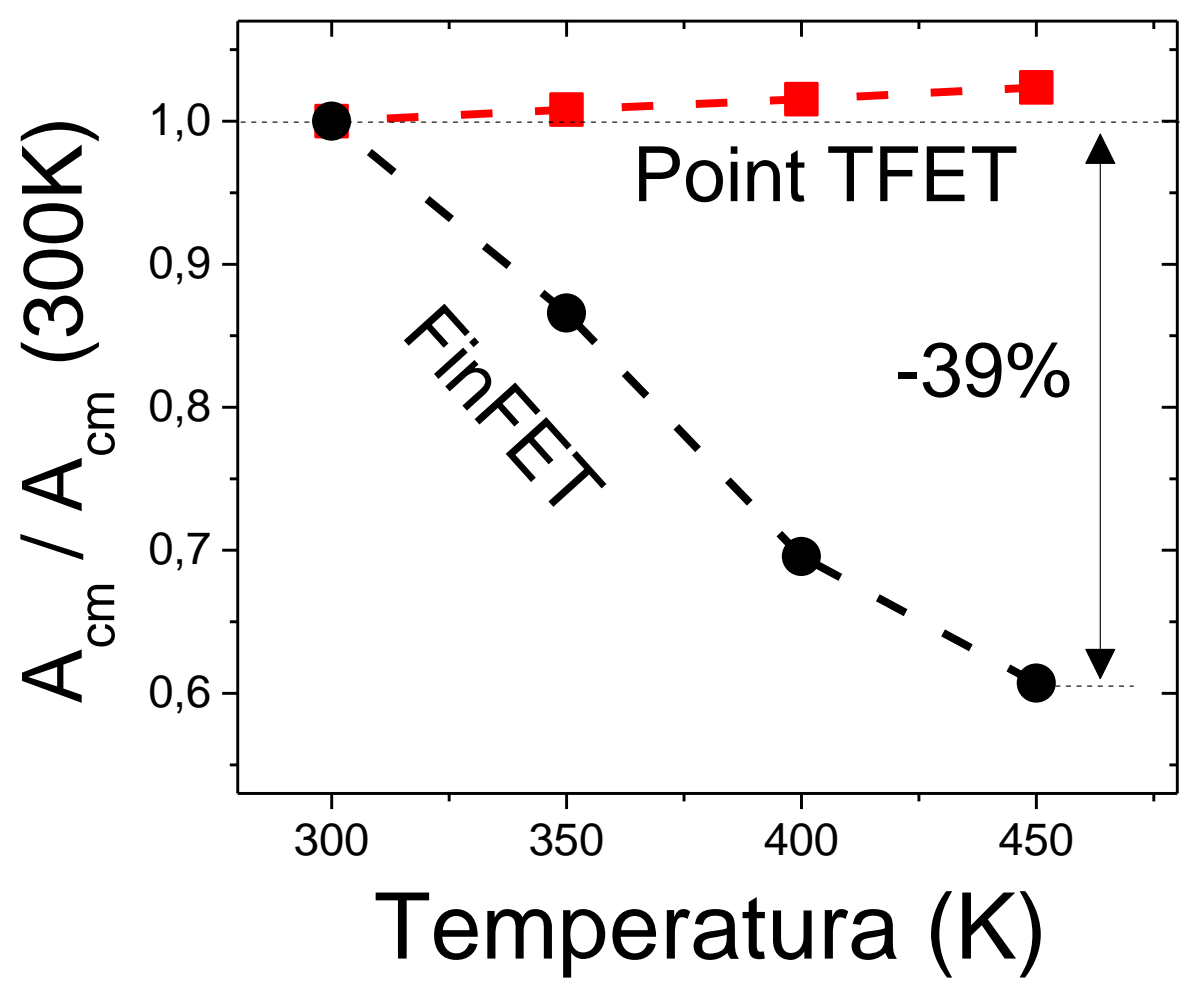

Fonte: Martino (2016) 
É possível notar uma significativa redução no ganho de modo diferencial para o circuito com FinFETs, ultrapassando 50\%, enquanto o par com Point TFETs ficou praticamente inalterado. A grande diferença no caso dos FinFETs remete à degradação de mobilidade para altas temperaturas, enquanto que, para os Point TFETs, o estreitamente da banda proibida foi basicamente compensado pelo ligeiro aumento da condutância de saída. Ainda ecoando a menor sensibilidade das correntes de tunelamento com a temperatura, observa-se na Figura 74 um ligeiro aumento para o caso de Point TFETs, enquanto o par com FinFETs apresenta forte redução quando submetido a $450 \mathrm{~K}$.

Notando que a redução de $A_{c m}$ é menor do que a redução de $A_{d}$ para FinFETs, decorrem os resultados mostrados na Figura 75 , que mostra a variação de CMRR para as duas tecnologias. A razão entre $A_{d}$ e $A_{c m}$ leva a uma diminuição de $21 \%$ para o circuito com FinFETs, enquanto o com Point TFETs apresenta variação máxima de $3 \%$, reforçando a viabilidade para aplicações que exijam parâmetros de desempenho estáveis sob ampla variação de temperatura.

Figura 75 - Taxa de rejeição de modo comum para temperaturas de 300 a $450 \mathrm{~K}$.

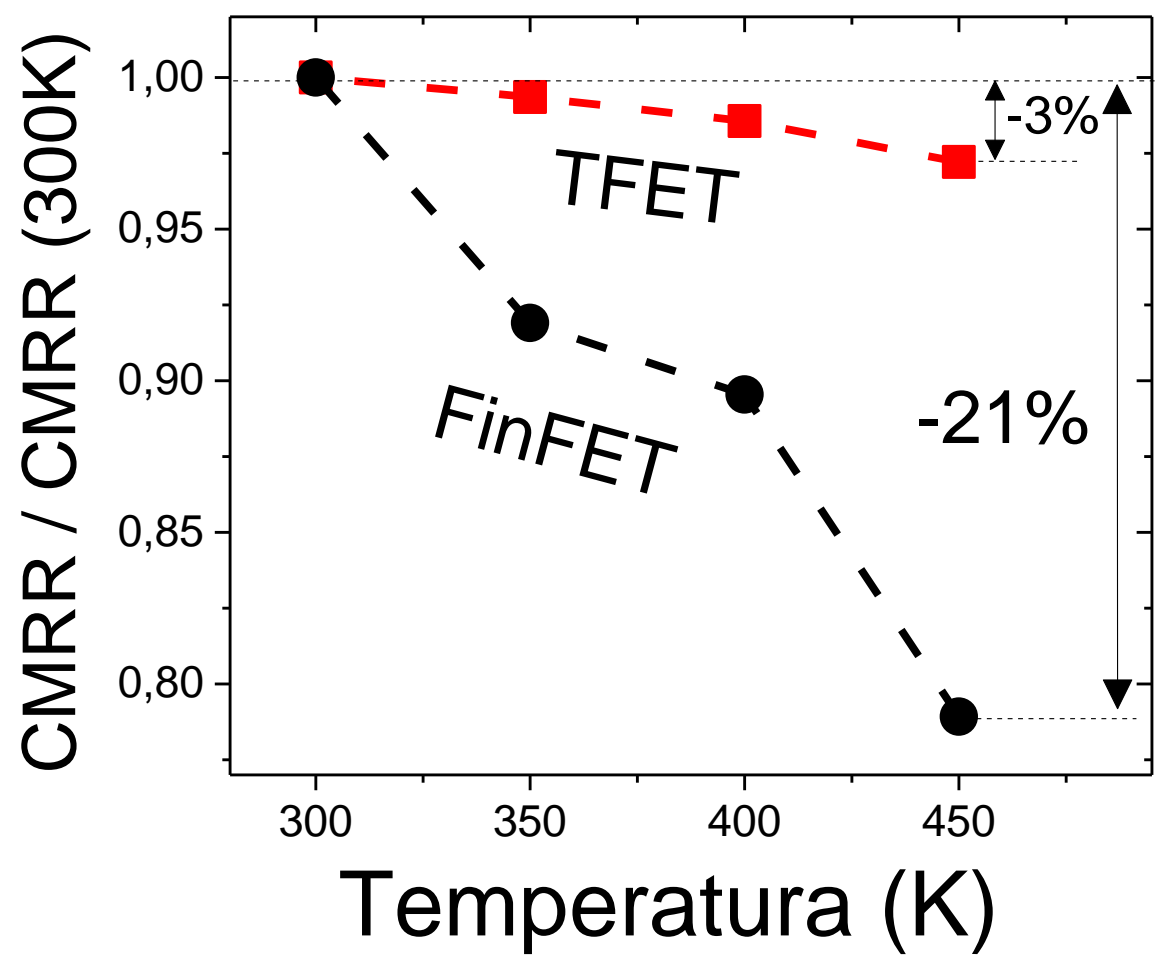

Fonte: Martino (2016) 


\subsection{RESULTADOS E ANÁLISES DE CIRCUITOS COM ESTRUTURAS LINE TFETS}

Assim como realizado em relação ao circuito de espelho de corrente analisado no capítulo 5, também foi estudada a possibilidade de utilizar transistores Line TFETs para circuitos de pares diferenciais.

Para extrair o ganho de tensão diferencial experimentalmente, foi utilizada a configuração de par com carga passiva (Figura 66(a)) aterrando a porta do transistor $T_{2}$, de modo que a tensão diferencial vid equivale a Vin1. Os ganhos foram comparados com base na saída do mesmo transistor em que foi aplicada a tensão diferencial (isto é, considerando $V_{\text {out }}=V_{D 1}$ ).

Foram avaliadas diferentes condições de polarização, com 1,3V $\leq|\mathrm{V} s \mathrm{ss}| \leq 1,5 \mathrm{~V}$ e $-0,4 \mathrm{~V} \leq \mathrm{v}_{\text {id }} \leq+0,4 \mathrm{~V}$. Foram realizadas medidas experimentais à temperatura ambiente e sob altas temperaturas (até 450K).

\subsubsection{Impacto das dimensões e da polarização}

A parte inicial da investigação sobre o desempenho de pares diferenciais com Line TFETs consistiu na obtenção das curvas características à temperatura ambiente dos 3 transistores selecionados.

Com este objetivo, a Figura 76 mostra a corrente de dreno em função da tensão de porta para duas tensões de dreno distintas. Enquanto isso, a Figura 77 exibe a corrente de dreno em função da tensão de dreno para dois valores de tensão de porta. Já na Figura 78 são plotadas as curvas da transcondutância em função da tensão de porta para duas tensões de dreno. No caso da Figura 76 e da Figura 78 , os gráficos inseridos ajudam a verificar a ordenação das curvas para elevadas tensões de porta. 
Figura 76 - Corrente de dreno em função da tensão de porta para Line TFETs com diferentes dimensões.

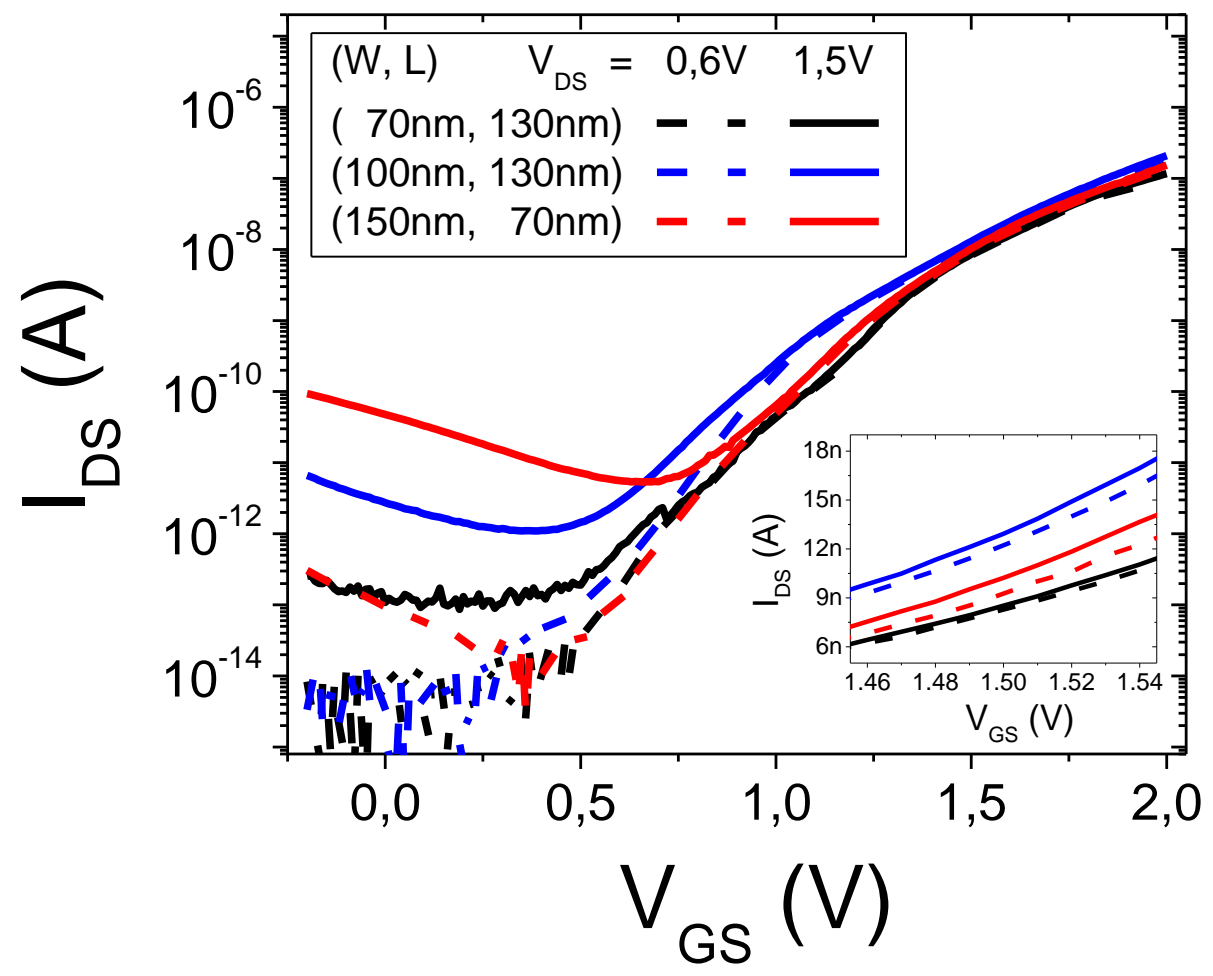

Fonte: Martino (2017)

Figura 77 - Corrente de dreno em função da tensão de dreno para Line TFETs com diferentes dimensões.

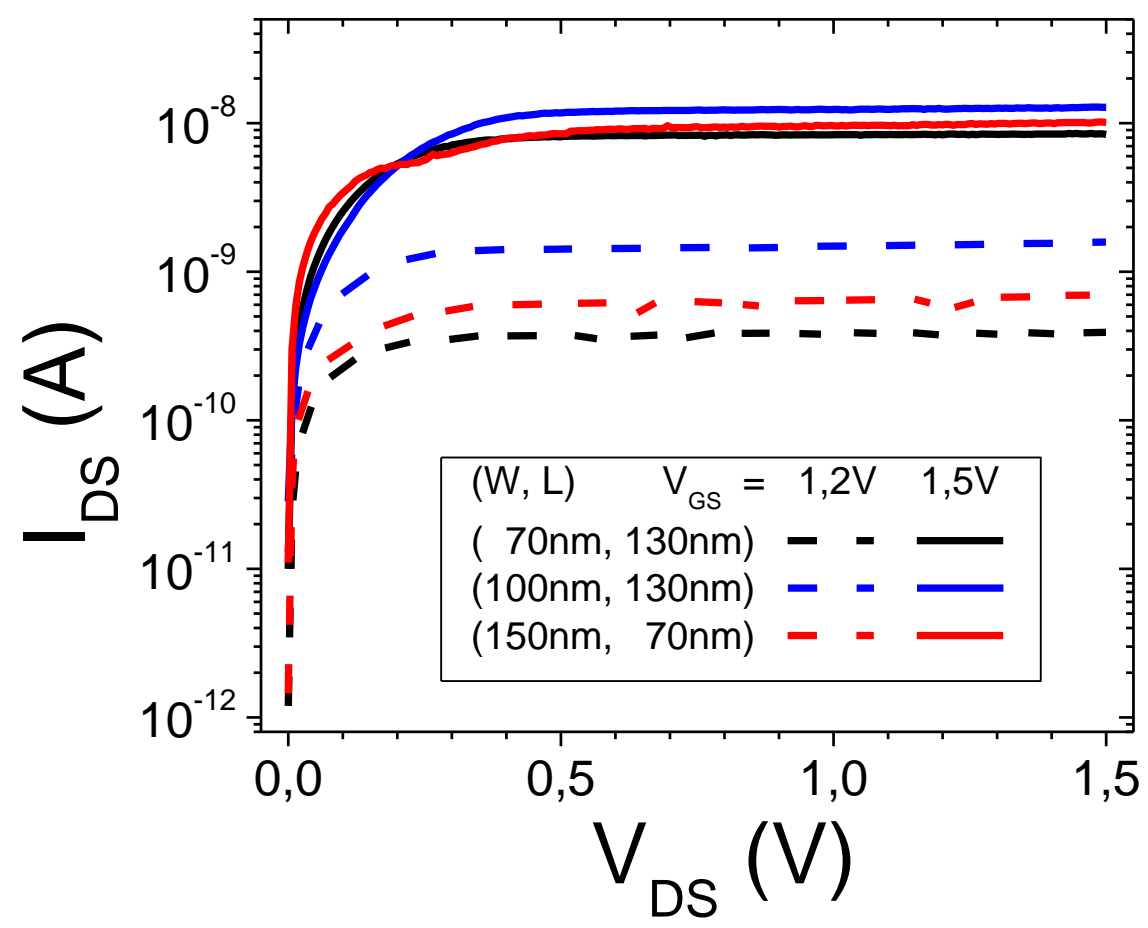

Fonte: Martino (2017) 
Figura 78 - Transcondutância em função da tensão de porta para Line TFETs com diferentes dimensões.

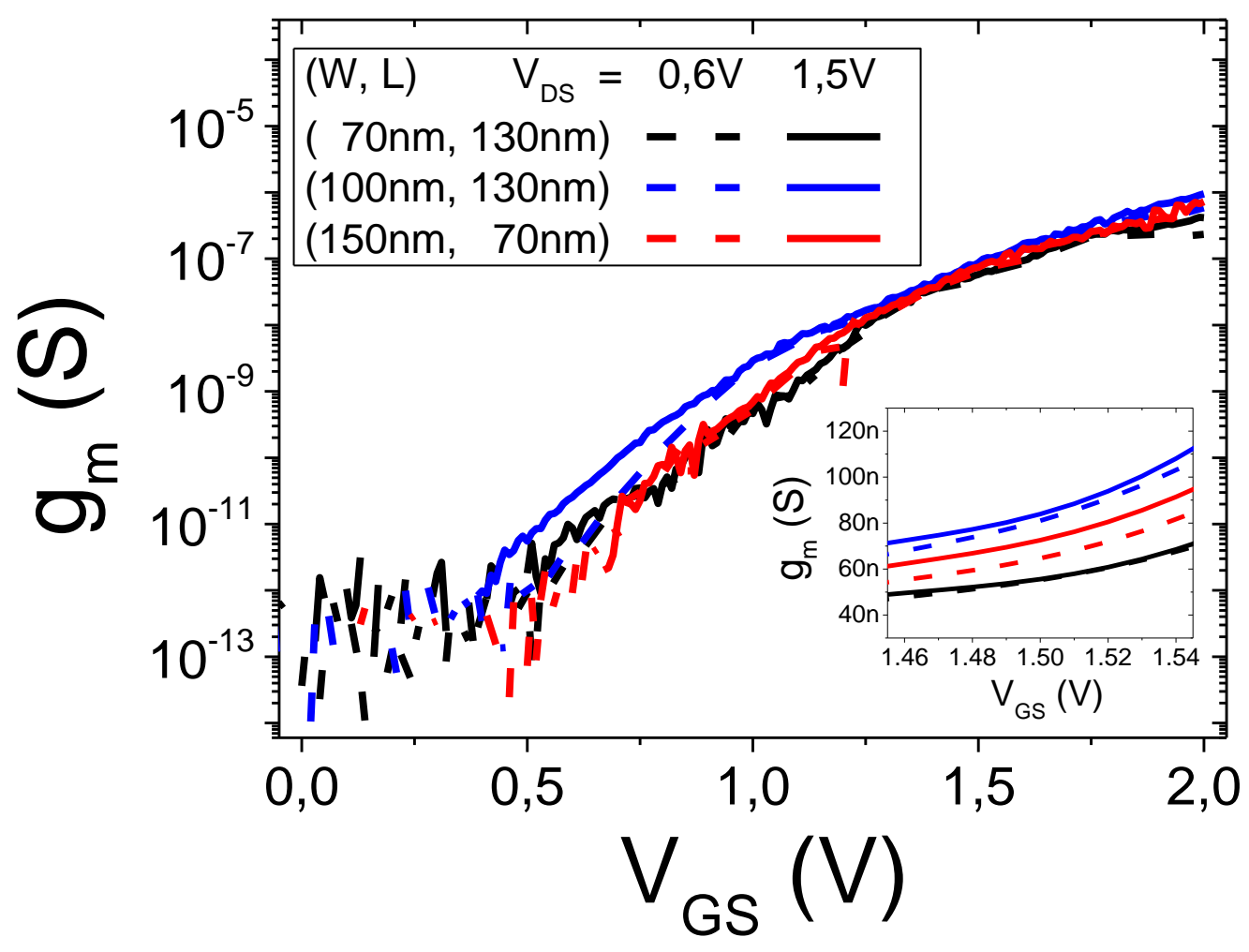

Fonte: Martino (2017)

Inicialmente, em comparação com a Figura 42, pode-se reforçar a vantagem de nível de corrente de dreno dos Line TFETs em relação aos Point TFETs, com base na observação dos valores medidos experimentalmente e das dimensões de cada caso. Em contrapartida, as curvas características também reforçam as já comentadas diferenças quanto à susceptibilidade à variação do comprimento de canal.

Também é possível comparar outros parâmetros importantes, como a transcondutância e a condutância e resistência de saída. Em relação a $\mathrm{gm}_{\mathrm{m}}$ a ordem de magnitude observada para Line TFETs na Figura $78\left(\mathrm{~g}_{\mathrm{m}} \sim 10^{-7} \mathrm{~S}\right)$ é similar à de FinFETs e melhor do que os relativamente baixos valores obtidos para Point TFETs. Já da Figura 77 pode-se extrair os valores da condutância e resistência de saída de Line TFETs (gD $\sim 10^{-9} \mathrm{~S}, \mathrm{r}_{0} \sim 10^{9} \Omega$ ), que são piores do que os para Point TFETs e melhores do que os de FinFETs. Estes parâmetros impactam diretamente no desempenho dos pares diferenciais projetados com cada tecnologia. É interessante 
observar que as dependências de $g_{m}$ e g com as dimensões também podem ser derivadas a partir da equação generalizada (13).

Após a caracterização individual, estes 3 dispositivos foram utilizados para as medidas experimentais de pares diferenciais sob diferentes condições de polarização. A Figura 79 mostra as correntes de dreno normalizadas, IDs1/lss e IDs2/Iss, em função da tensão diferencial Vid. Pode-se notar um aumento na sobretensão de condução para valores maiores de Iss (e Vss), devido ao aumento da tensão entre porta e fonte. Isso proporciona uma região de operação mais alta, isto é, uma tensão de conformidade maior, com tendência em linha ao observado para Point TFETs e FinFETs. Enquanto isso, a magnitude da tensão de conformidade pode ser comparada com base na Figura 67, que sugere valores similares para Line TFETs e Point TFETs, porém claramente menores do que para FinFETs.

Figura 79 - Corrente de dreno normalizada em função da tensão de entrada diferencial para Line TFETs com diferentes dimensões.

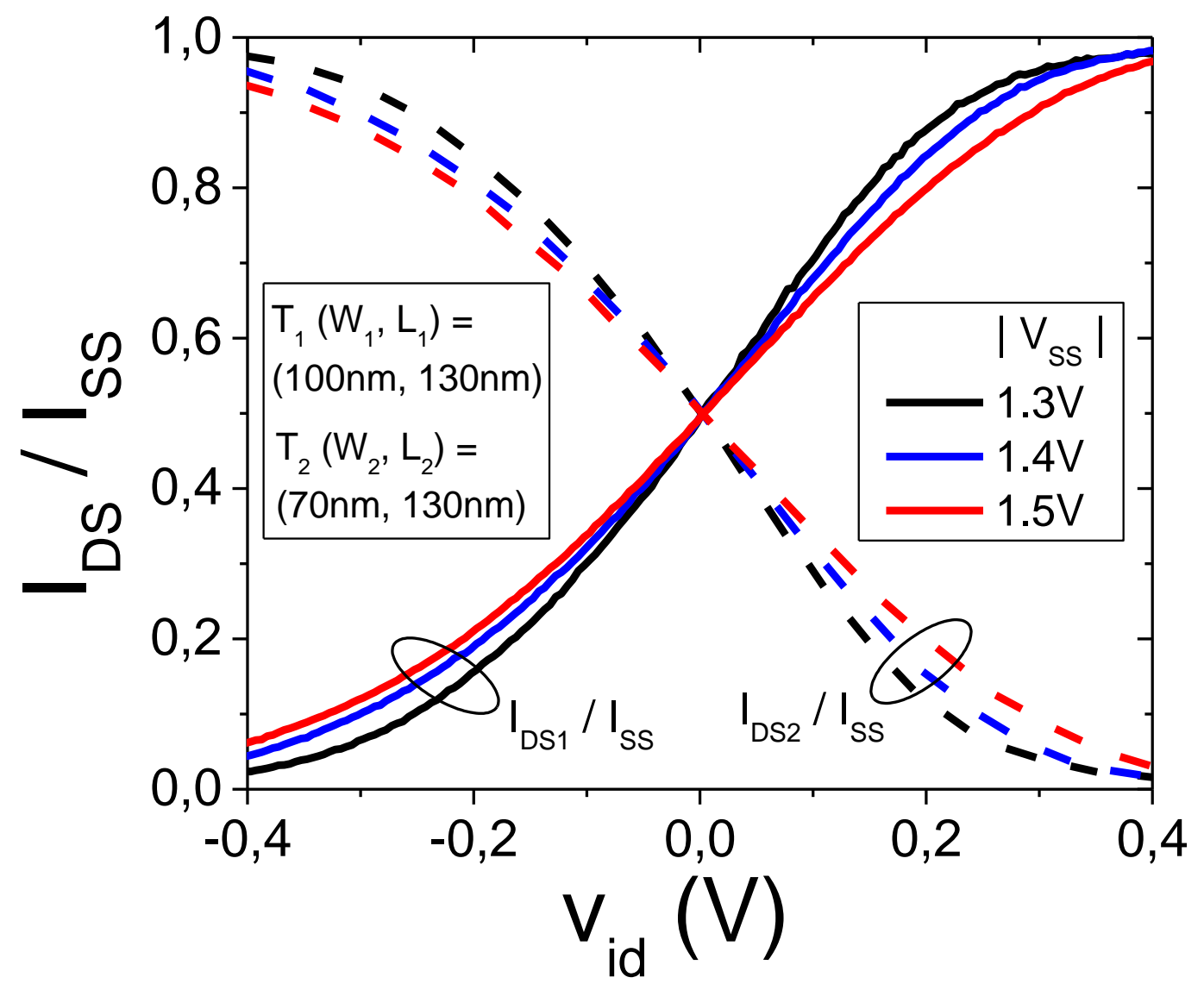

Fonte: Martino (2017) 
A inclinação das curvas da Figura 79 e os valores absolutos da Figura 76 podem ser utilizados para extrair o ganho de tensão diferencial para cada condição de polarização. Dessa forma, como um maior valor de $V_{S S}$ causa aumento de corrente mais significativo do que a diminuição na inclinação da corrente normalizada, o valor global Ad resultante também cresce com Vss.

Nesse sentido, a Figura 80 resume o impacto em três diferentes configurações de circuitos de pares diferenciais. Para todos os pares, nota-se a mesma tendência de crescimento de $A_{d}$ com $V_{s s}$, porém com valores absolutos maiores para circuitos projetados com transistores com as maiores áreas de canal. Apesar das inclinações das correntes normalizadas serem similares nos três casos, a diferença novamente recai sobre o aumento em IDs para Line TFETs com maior área de canal.

Figura 80 - Ganho de tensão diferencial em função de Vss para pares de Line TFETs com diferentes dimensões.

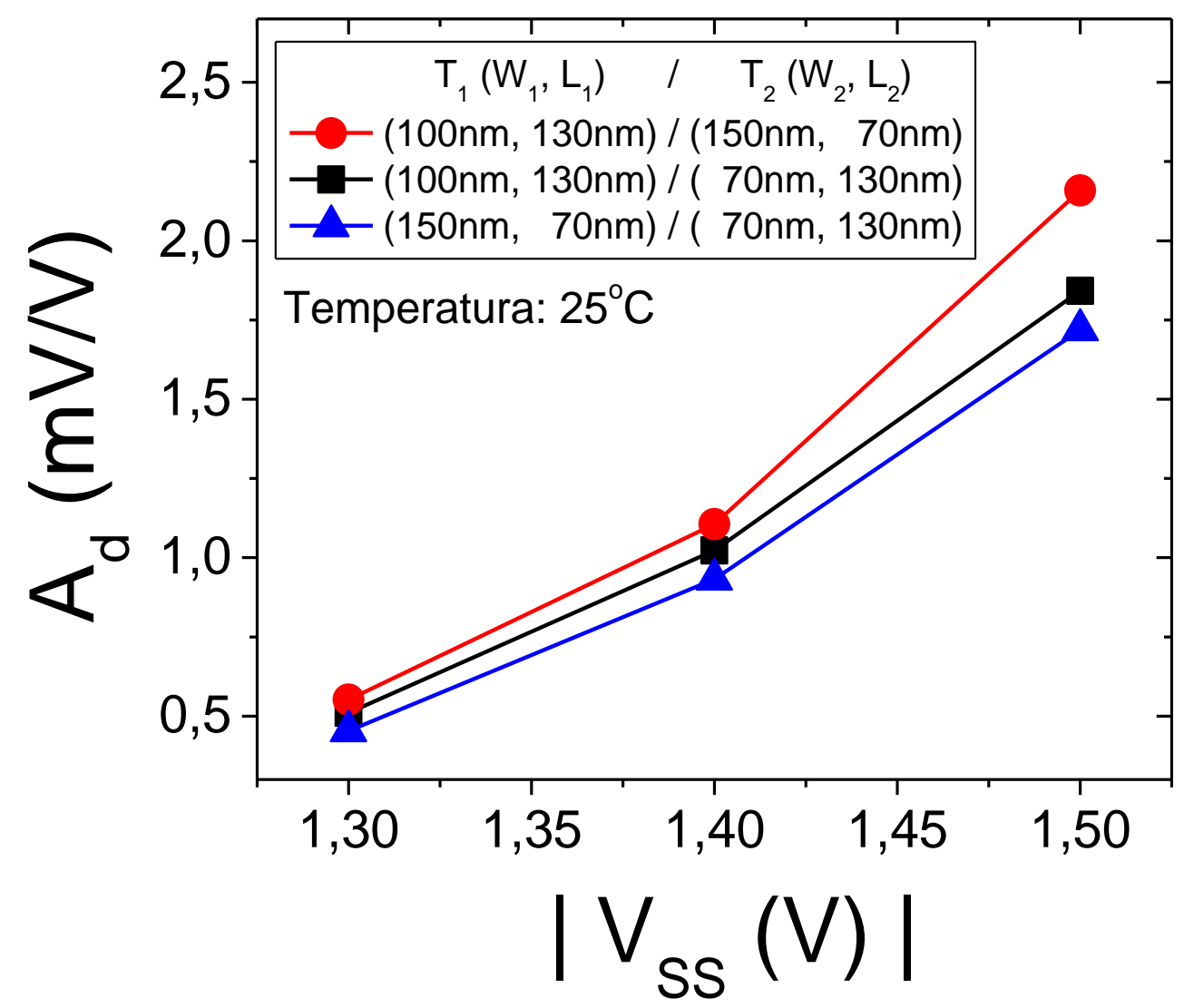

Fonte: Martino (2017) 
Com isso, pode-se estabelecer uma comparação preliminar com o desempenho previamente analisado de circuitos com Point TFETs e FinFETs. FinFETs. Pela menor inclinação na corrente normalizada, FinFETs tenderiam a apresentar a maior tensão de conformidade, enquanto Point TFETs manteriam a vantagem da não susceptibilidade ao descasamento de comprimentos de canal. Enquanto isso, Line TFETs proporcionariam o maior valor de ganho de tensão diferencial, superando os FinFETs (devido a uma inclinação de corrente normalizada muito superior e uma corrente ligeiramente inferior) e os Point TFETs (devido à similar inclinação de corrente normalizada, mas corrente claramente superior).

\subsubsection{Impacto da temperatura}

Para avaliar a influência da temperatura em pares diferenciais com Line TFETs, inicialmente são exibidas as caracterizações individuais de $300 \mathrm{~K}$ a $450 \mathrm{~K}$. A Figura 81 mostra a corrente de dreno em função da tensão de porta, a Figura 82 exibe a corrente de dreno em função da tensão de dreno e a Figura 83 plota a transcondutância em função da tensão de porta.

Em comparação com a Figura 58 (IDs vs. VGS) e com a Figura 59 (IDS vs. VDS), agora são exibidos dispositivos diferindo entre si pela largura do canal e também são mostradas curvas para duas diferentes polarizações à temperatura ambiente, permitindo comparação direta entre a magnitude da influência da variação da temperatura e da tensão aplicada. Nota-se que a influência da tensão de dreno é muito superior à da temperatura apenas na Figura 82, que está diretamente ligada aos valores anteriormente extraídos de condutância e resistência de saída. 
Figura 81 - Corrente de dreno em função da tensão de porta para Line TFETs com diferentes dimensões, tensões de dreno e temperaturas.

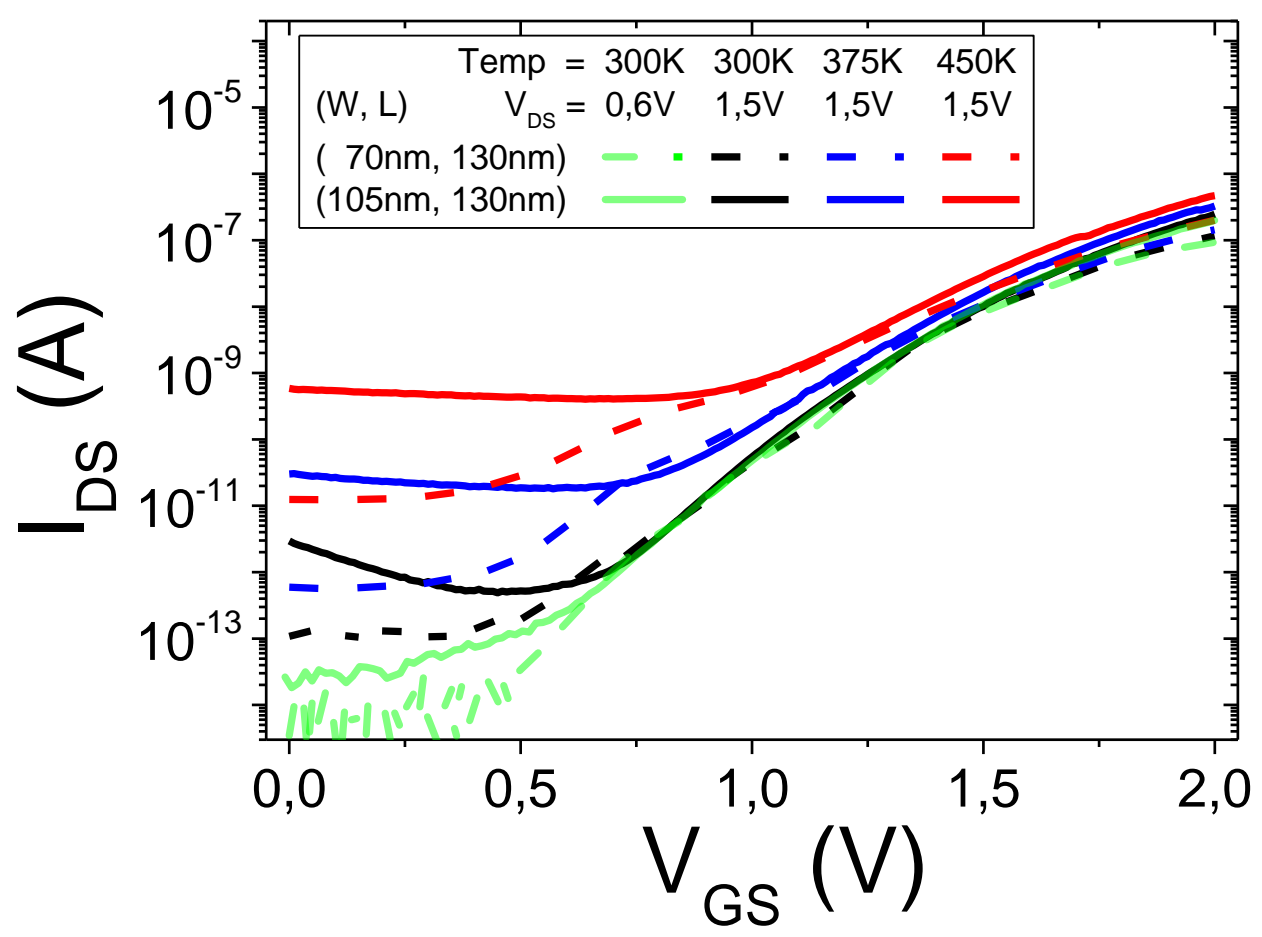

Fonte: Martino (2017)

Figura 82 - Corrente de dreno em função da tensão de dreno para Line TFETs com diferentes dimensões, tensões de porta e temperaturas.

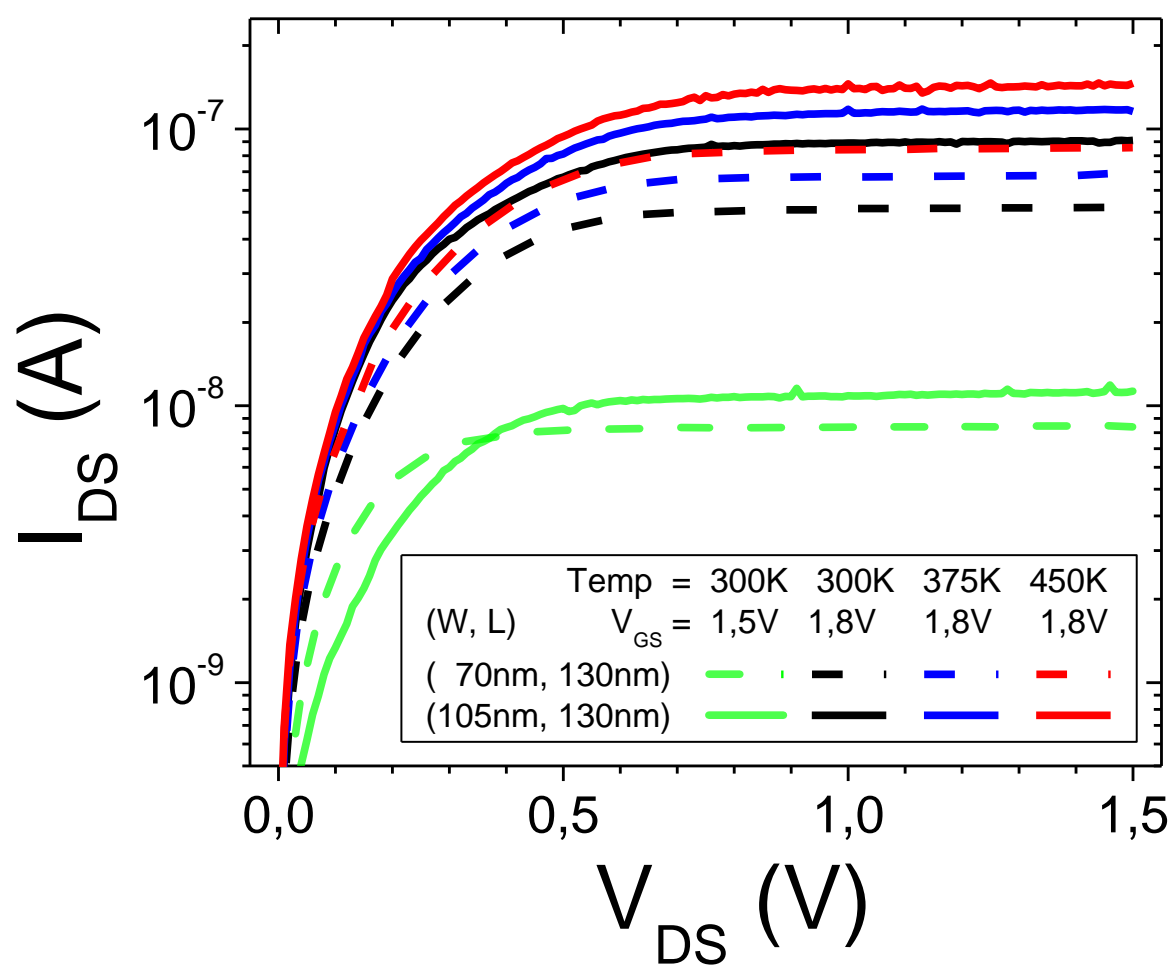

Fonte: Martino (2017) 
Figura 83 - Transcondutância em função da tensão de porta para Line TFETs com diferentes dimensões, tensões de dreno e temperaturas.

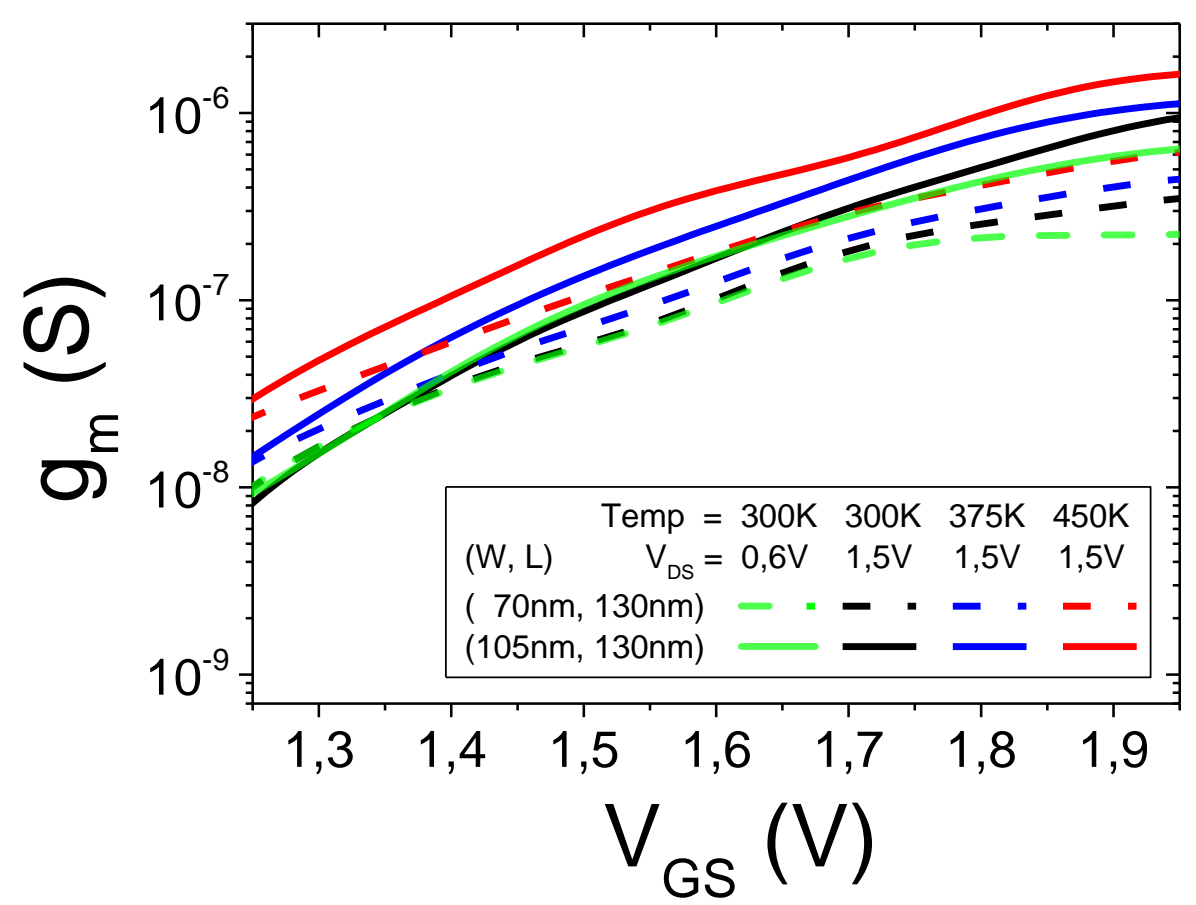

Fonte: Martino (2017)

Neste ponto, é importante relembrar ainda a variação da energia de ativação de Line TFETs em função da polarização previamente exibida na Figura 60. Como explicado em 5.4.2, o tunelamento de banda para banda predomina quando a energia de ativação fica abaixo de $0,1 \mathrm{eV}$, enquanto o tunelamento induzido por armadilhas prevalece em caso contrário. Isso significa que, ao setar |Iss| para gerar $\left|V_{s S}\right|=1,5 \mathrm{~V}$ quando $v_{i d}=0 \mathrm{~V}$ e então variar vid de $-0,4 \mathrm{~V}$ a $+0,4 \mathrm{~V}$, haverá uma transição no mecanismo de transporte dominante.

A Figura 84 mostra, em função de vid, as correntes de dreno normalizadas para o mesmo par estudado na Figura 79, porém agora incluindo os dados para 3 diferentes temperaturas. Pode-se observar uma ligeira diminuição na inclinação para temperaturas mais elevadas. Entretanto, como esta variação é inferior ao aumento no Iss observado para $375 \mathrm{~K}$ e $450 \mathrm{~K}$ (Figura 81 ), o efeito resultante no ganho de tensão diferencial é de aumento com a temperatura. Este impacto global da temperatura em $A_{d}$ é ilustrado na Figura 85 , que engloba os mesmos pares previamente estudados à temperatura ambiente (Figura 80 ). 
Figura 84 - Corrente de dreno normalizada em função da tensão de entrada diferencial para pares de Line TFETs com diferentes temperaturas.

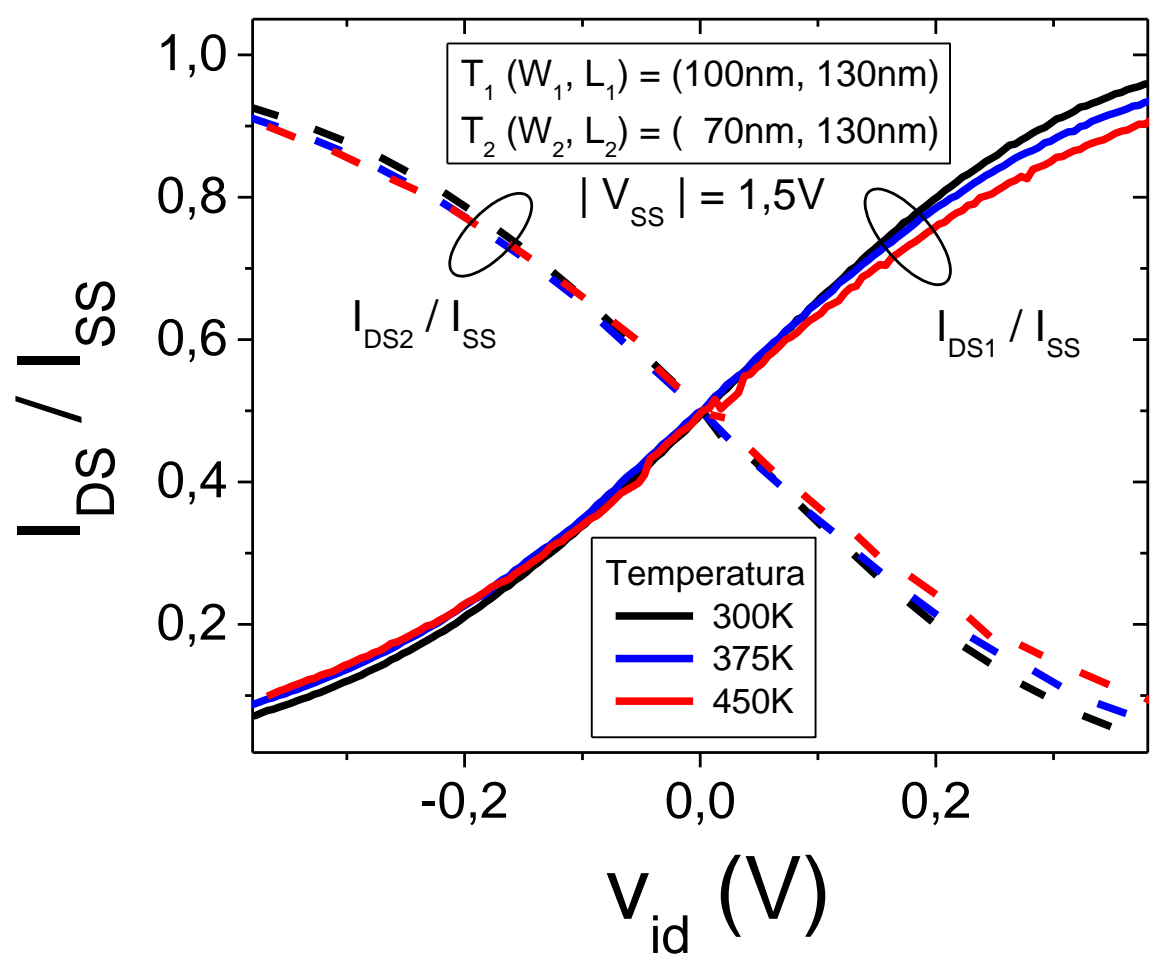

Fonte: Martino (2017)

Figura 85 - Ganho de tensão diferencial em função da temperatura para pares de Line TFETs com diferentes dimensões.

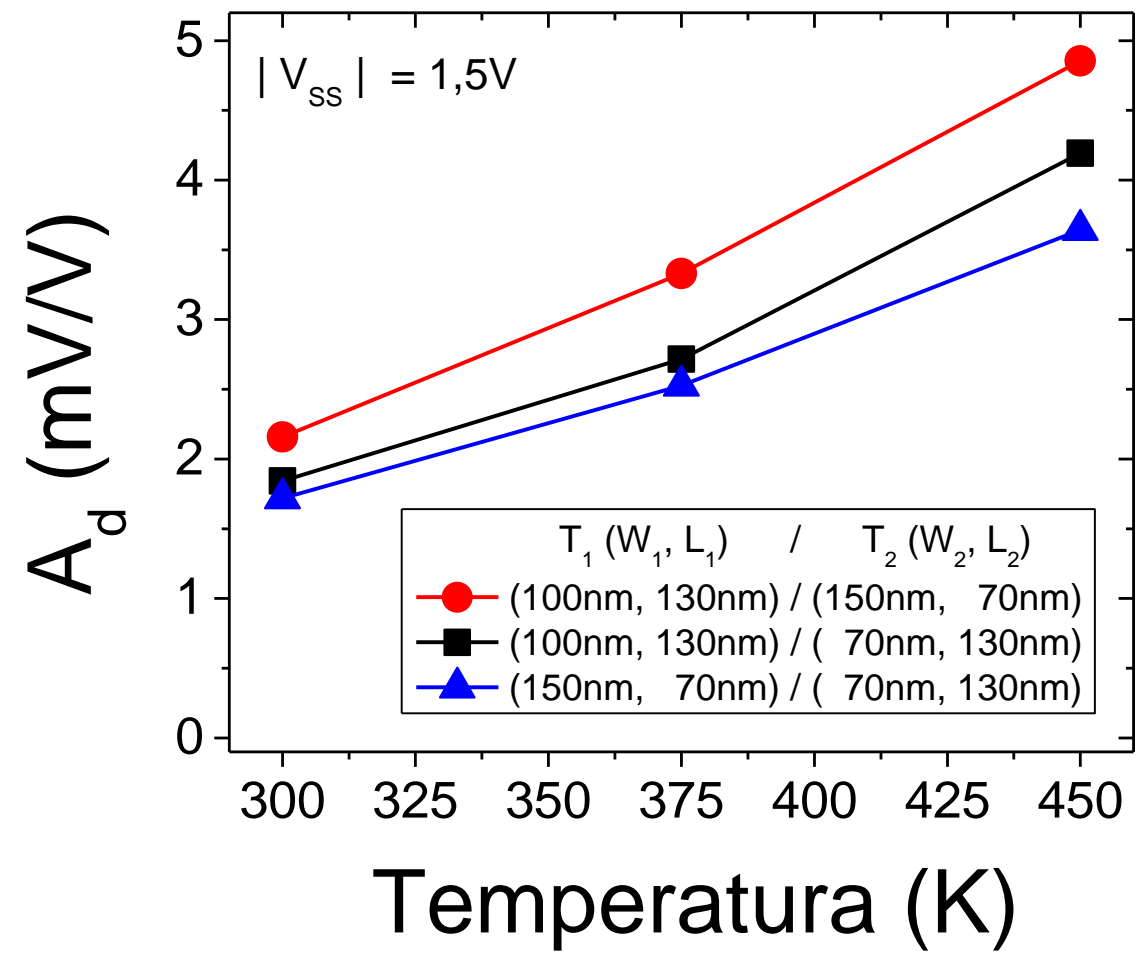

Fonte: Martino (2017) 
Vale lembrar que os valores do ganho de tensão diferencial extraídos foram determinados com base na inclinação da corrente normalizada para o caso em que $\left|V_{s s}\right|=1,5 \mathrm{~V}$ e $V_{\text {id }}=0 \mathrm{~V}$, condição em que tanto $T_{1}$ quanto $T_{2}$ apresentam BTBT como mecanismo de transporte dominante. Dessa forma, a dependência da temperatura exibida na Figura 85 deve ser interpretada como consequência direta do estreitamento da banda proibida sob altas temperaturas. Um modelo desta dependência foi previamente descrito pela equação (12) e o gráfico com a variação de Eg em função da temperatura foi apresentado na Figura 17.

A tendência positiva de $A_{d}$ com a temperatura, decorrente deste aumento no tunelamento, é uma é diferença importante em relação aos pares diferenciais projetados com FinFETs, nos quais há tendência invertida pela degradação da mobilidade sob altas temperaturas. Conforme visto em 6.3.2, o ganho chega a cair mais de $50 \%$ para circuito com FinFETs exposto à mesma variação de temperatura que a apresentada na Figura 85.

Com isso, foi possível demonstrar a viabilidade de projetos de pares diferenciais com LineTFETs, obtendo alto ganho de tensão diferencial e sem degradação deste ganho sob altas temperaturas.

\subsection{COMPARAÇÃO DE DESEMPENHO DE CIRCUITOS COM TRANSISTORES FINFETS, POINT TFETS E LINE TFETS}

Com base nos resultados apresentados em 6.3 e 6.4, pode-se propor uma equação geral para representar o ganho de tensão diferencial para os pares projetados com FinFETs, Point TFETs e Line TFETs. Além disso, pode-se comparar a viabilidade de aplicação de cada uma destas três tecnologias dependendo do grau de restrição da aplicação quanto à magnitude do ganho de tensão diferencial e de sua susceptibilidade à temperatura, à polarização e ao descasamento entre os transistores.

Pode-se partir das equações (13) e (14), que representam a corrente de dreno dos dispositivos em função das dimensões efetivas de comprimento e largura de canal, com um parâmetro m que diferencia a dependência para cada tecnologia.

Então, a partir dos resultados dos gráficos de 6.3.1 e 6.4.1, discutiu-se que o ganho de tensão diferencial vai ser uma combinação principalmente de três fatores: a tecnologia (que resulta numa ordem de grandeza de corrente e da inclinação da 
corrente normalizada), a polarização (que ajusta eventual redução da inclinação do corrente normalizada por causa da saturação) e as dimensões efetivas (que ajustam nível corrente conforme dependência da tecnologia específica com $W_{\text {ef }}$ e Lef, além de incorporar possível descasamento). Combinando estes fatores, pode-se resumir o modelo na equação (19).

$$
A_{d}=q(\text { technology, bias }) \times f\left(\frac{W_{e f 1}}{L_{e f 1}^{m}}, \frac{W_{e f 2}}{L_{e f 2}^{m}}\right)
$$

Finalmente, com base nas análises descritas em 6.3 .2 e 6.4.2, pode-se incorporar o efeito da temperatura nos dispositivos. Uma forma de representar este impacto é pela energia de ativação de cada transistor, que já engloba os efeitos dos respectivos mecanismos de transporte dominantes na condição de polarização analisada. Portanto, analogamente ao apresentado na equação (15) dos espelhos de correntes, inclui-se para os pares diferenciais um derradeiro parâmetro de ajuste $p$, vide equação (20).

$$
A_{d}=p\left(E_{A 1}, E_{A 2}\right) \times q(\text { technology, bias }) \times f\left(\frac{W_{e f 1}}{L_{e f 1}^{m}}, \frac{W_{e f 2}}{L_{e f 2}^{m}}\right)
$$

Finalmente, pode-se resumir as vantagens e desvantagens da aplicação de cada uma das três tecnologias em pares diferenciais na Tabela 3.

A tensão de conformidade é decorrência direta das curvas de correntes normalizadas, sugerindo melhor desempenho para FinFETs. Já a susceptibilidade ao descasamento do comprimento de canal é uma vantagem dos circuitos com Point TFETs, devido à já explicada consequência do tunelamento ocorrendo basicamente na junção entre canal e fonte. Quanto ao ganho diferencial, foi explicado que ele depende da combinação entre a inclinação da corrente normalizada e a magnitude das correntes envolvidas. Dessa forma, os Line TFETs ficam em vantagem, pois apresentam alta inclinação, como os Point TFETs, e alto nível de corrente, como os FinFETs. O último quesito, que se refere ao impacto da temperatura, pode ser compreendido com base nas dependências dos mecanismos de transporte dominantes em cada caso. Nesse caso, a vantagem seria dos transistores de 
tunelamento, nos quais há um ligeiro aumento na corrente pelo estreitamento da banda proibida, ao contrário da degradação da mobilidade observada nos FinFETs.

Tabela 3 - Comparação das características de pares diferenciais projetados com dispositivos FinfETs, Point TFETs e Line TFETs.

\begin{tabular}{|c|c|c|c|}
\hline & FinFET & Point TFET & Line TFET \\
\hline $\begin{array}{c}\text { Alto ganho de tensão diferencial } \\
\text { temperatura }\end{array}$ & $\checkmark$ & & $\checkmark \checkmark$ \\
\hline $\begin{array}{c}\text { Ganho não degrada com aumento da } \\
\text { polarização (alta tensãa de conformidade) }\end{array}$ & & $\checkmark$ & $\checkmark$ \\
\hline $\begin{array}{c}\text { Baixa susceptibilidade ao descasamento } \\
\text { do comprimento de canal }\end{array}$ & & $\checkmark$ & \\
\hline
\end{tabular}

Resumidamente, observa-se que pares diferenciais com FinFETs são os mais adequados para aplicações que exijam alto ganho de tensão diferencial e alta tensão de conformidade. Circuitos com Point TFETs são os melhores caso seja requerida estabilidade do ganho para altas temperaturas e para descasamento entre os transistores. Finalmente, a tecnologia Line TFET é a mais adequada para aplicações que necessitem de alto ganho de tensão diferencial e que não permitam perda deste ganho quando expostas a altas temperaturas. 


\section{CONCLUSÕES}

Este trabalhou analisou o desempenho de transistores de tunelamento controlados por efeito de campo tanto sob o ponto de vista individual quanto como componente de circuitos básicos. Foram estudados impactos em relação a parâmetros como dimensionamento, temperatura, materiais da estrutura, perfil de dopagem e polarização dos dispositivos.

Inicialmente foi contextualizada a importância do estudo de TFETs, bem como seus principais potenciais de impacto tecnológico e desafios atuais. Foram descritas as duas estruturas de transistores de tunelamento destacadas, notadamente os Point TFETs e os Line TFETs. Também foram detalhadas as definições de modelos utilizados na execução das simulações deste tipo de dispositivo.

Já durante a análise dos resultados individuais, foi destacado o efeito de estreitamento da barreira de tunelamento induzido pela tensão de dreno. Foi verificado que este fenômeno foi minimizado com menor subposição de porta em relação à junção canal/dreno e perfil de dopagem gaussiano, apesar das correntes de dreno mais elevadas obtidas seguindo a tendência oposta. Quantitativamente, a diferença entre os valores de DIBT extraídos para estruturas com perfil abrupto ou gaussiano girava entre $30 \%$ e 50\%. Quanto à subposição de porta, a diferença era irrelevante para canais longos, mas chegava a até $45 \%$ para o caso de transistor com canal de $30 \mathrm{~nm}$ de comprimento.

Também foi estudado como a performance analógica de dispositivos TFET varia com a temperatura e com condições que resultem em diferentes mecanismos de transporte predominantes. Foram observadas diferenças marcantes de tendências, por exemplo, na extração da tensão de Early. Aumentando a temperatura de 25 para $150^{\circ} \mathrm{C}$, o valor de VEA para estrutura de silício e perfil de dopagem não abrupto aumentou cerca de 7 vezes ao mesmo tempo em que houve queda significativa para os demais tipos de transistores estudados. Avaliando a influência global de parâmetros analógicos, conclui-se que transistores com maior quantidade de germânio em sua composição apresentaram os mais adequados valores de ganho intrínseco de tensão à temperatura ambiente, por causa do predomínio do BTBT. Por outro lado, para maiores temperaturas, apenas dispositivos $100 \% \mathrm{Si}$ e perfil não abrupto, dominados por TAT, apresentaram 
melhoria de desempenho, tornando-se o tipo mais adequado para operações acima de $100^{\circ} \mathrm{C}$.

Após todas estas verificações sobre possibilidades de otimização de estruturas de TFETs individuais, o foco passou ao uso desta tecnologia em circuitos analógicos fundamentais, como o espelho de corrente e o par diferencial. Para efeito comparativo, utilizou-se como referência um circuito com transistores FinFETs de mesmas dimensões e fabricados seguindo o mesmo fluxo adotado para os Point TFETs. A tecnologia Line TFET também foi estudada e comparada para ambos os circuitos.

A avaliação experimental dos espelhos de corrente destacou a diferença de susceptibilidade de cada tecnologia em relação ao comprimento de canal. Aumentando este valor em 10 vezes, mediu-se uma variação na corrente de saída de 10 vezes para FinFETs, mas de não mais do que 20\% para Point TFETs. Simulações foram realizadas para também comparar quantitativamente o impacto do descasamento entre as dimensões dos transistores e da variação de temperatura. No cenário de pior caso de alteração de comprimento de canal, uma variação de 80\% para Point TFETs ocorria na mesma condição que resultava num desvio de 230\% para FinFETs. Em relação à temperatura, observou-se dependência oposta ao comparar os dois circuitos, com susceptibilidade relativa à tensão de polarização 5 vezes maior dos FinFETs em relação ao circuito com Point TFETs.

Ao adicionar o estudo dos espelhos de corrente com Line TFET, verificou-se experimentalmente como a diferente dependência da corrente de dreno em relação ao comprimento de canal afeta a razão de espelhamento do respectivo circuito. Verificou-se ainda como um aumento na polarização teve como consequência positiva o aumento na magnitude das correntes envolvidas, porém degradou tanto a razão de espelhamento quanto a tensão de conformidade. Também foi mostrado como o aumento da temperatura afetou a razão de espelhamento com sentido dependente da relação entre as energias de ativação. No caso dos circuitos medidos neste trabalho, uma variação de temperatura de $300 \mathrm{~K}$ a $450 \mathrm{~K}$ degradou a razão de espelhamento de correntes entre $30 \%$ e 50\%. Em termos comparativos, observou-se que a tecnologia Point TFET seria a mais adequada para aplicações que exijam baixa susceptibilidade à temperatura, ao descasamento de dimensões e à polarização. Entretanto, se for exigida alta corrente de referência, a tecnologia Line 
TFET consegue aliar nível de corrente quase tão alto quanto os FinFETs e os comportamentos benéficos das correntes de tunelamento.

Finalmente, foram estudados circuitos de pares diferenciais, tanto em configuração de carga passiva quanto de carga ativa. Seguindo metodologia análoga de comparar FinFETs, Point TFETs e Line TFETs, estudou-se como as dimensões, a polarização e a temperatura afetam parâmetros como o ganho de tensão diferencial e a tensão de conformidade. Ao contrário do observado em espelhos de corrente, em pares diferenciais a maior tensão de conformidade foi obtida para FinFETs. Na faixa de polarização analisada, por exemplo, a inclinação na curva de correntes normalizadas variava menos de $2 \%$, em comparação a $38 \%$ do circuito com Point TFETs, em tendências similares às observadas em relação ao ganho de modo comum. Já em relação ao descasamento entre as dimensões dos transistores, os pares com Point TFET apresentaram variações menores do que a metade do observado para FinFETs com canais longos. O decorrente CMRR flutuou menos de $10 \%$ para FinFETs, porém mais de 5 vezes para Point TFETs. O impacto da temperatura, por outro lado, foi flagrantemente maior para circuitos com FinFETs, cujos parâmetros principais variaram na faixa de $20 \%$ a $50 \%$, contra um máximo de $3 \%$ de flutuação para Point TFETs.

No caso de Line TFETs, observou-se comportamento com inclinação de correntes normalizadas similar à dos Point TFETs, porém magnitude de corrente mais próxima dos FinFETs. Em termos práticos, isso resulta em ganho de tensão diferencial superior às outras duas tecnologias, porém ainda com baixa tensão de conformidade. $O$ aumento da polarização permitiu importantes benefícios simultaneamente, com aumento tanto no valor absoluto do ganho quanto na tensão de conformidade. $\mathrm{O}$ impacto da temperatura aumentou os ganhos medidos em mais de $100 \%$, em contraposição à forte degradação observada em FinFETs, de modo que os Line TFETs permitiram a obtenção de um par aliando o ganho relativamente alto dos FinFETs com o bom comportamento sob variação de temperatura, típico de transistores de tunelamento.

Como futuros trabalhos, poderia ser aprofundado o modelo matemático das equações gerais apresentadas para os parâmetros principais dos circuitos estudados, particularmente detalhando os valores numéricos dos parâmetros de ajuste. No caso de pares diferenciais com carga ativa, seria interessante complementar a análise com o estudo da opção de mesclar dispositivos de 
tecnologias diferentes. Também seria possível expandir a análise para circuitos mais complexos, que utilizem entre seus estágios blocos similares às configurações de espelhos de corrente e pares diferenciais analisadas.

Dessa forma, conclui-se o trabalho com a avaliação da promissora tecnologia de transistores de tunelamento induzido por efeito de campo, a qual permite que os dispositivos continuem a ser escalados e otimizados de modo a se obter adequados parâmetros de desempenho individual e favoráveis atributos para integrar blocos de circuitos analógicos e digitais. 


\section{PUBLICAÇÕES GERADAS}

\section{- Artigos publicados em revistas:}

Agopian, P. G. D.; Martino, M. D. V.; Santos, S. D.; Neves, F.; Martino, J. A.; Rooyackers, R.; Vandooren, A.; Simoen, E.; Thean, A.; Claeys, C. "Influence of the Source Composition on the Analog Performance Parameters of Vertical Nanowire-TFETs", IEEE Transactions on Electron Devices, v. 62, p. 16-22, 2015.

Martino, M. D. V.; Neves, F.; Agopian, P. G. D.; Martino, J. A.; Vandooren, A.; Rooyackers, R.; Simoen, E.; Thean, A.; Claeys, C. "Analog Performance of Vertical Nanowire TFETs as a Function of Temperature and Transport Mechanism", Solid-State Electronics, v. 112, p. 51-55, 2015.

Martino, M. D. V.; Martino, J. A.; Agopian, P. G. D.; Vandooren, A.; Rooyackers, R.; Simoen, E.; Thean, A.; Claeys, C. "Performance of TFET and FinfET devices applied to current mirrors for different dimensions and temperatures", Semiconductor Science and Technology, v. 31, n. 5, 055001, 2016.

Martino, M. D. V.; Martino, J. A.; Agopian, P. G. D.; Vandooren, A.; Rooyackers, R.; Simoen, E.; Claeys, C. "Analysis of current mirror circuits designed with line tunnel FET devices at different temperatures", Semiconductor Science and Technology, v. 32, n. 5, 055015, 2017.

\section{- Artigos publicados em anais de congressos:}

Martino, M. D. V.; Martino, J. A.; Agopian, P. G. D.; "Drain induced barrier thinning on TFETs with different source/drain engineering", 29th Symposium on Microelectronics Technology and Devices (SBMicro), p. 1-4, 2014. 
Martino, M. D. V.; Neves, F.; Agopian, P. G. D.; Martino, J. A.; Vandooren, A.; Rooyackers, R.; Simoen, E.; Thean, A.; Claeys, C. "Early Voltage and Intrinsic Voltage Gain in Vertical Nanowire-TFETs as a function of Temperature", Proceedings of the IX ICCDCS Conference, v. 1. p. 78-81, 2014.

Martino, M. D. V.; Neves, F.; Agopian, P. G. D.; Martino, J. A.; Vandooren, A.; Rooyackers, R.; Simoen, E.; Thean, A.; Claeys, C. "Transport mechanism influence on Vertical Nanowire-TFET analog performance as a function of temperature", Proceedings of 10th Workshop of the Thematic Network on Silicon on Insulator Technology, Devices and Circuits, v. 1, p. 1-2, 2014.

Martino, M. D. V.; Martino, J. A.; Agopian, P. G. D.; Vandooren, A.; Rooyackers, R.; Simoen, E.; Thean, A.; Claeys, C. "Comparison of Current Mirrors Designed with TFET or FinFET Devices for Different Dimensions and Temperatures", 227th ECS Meeting, v. 66, p. 303-308, 2015.

Martino, M. D. V.; Martino, J. A.; Agopian, P. G. D.; "Performance Comparison Between TFET and FinFET Differential Pair", 30th Symposium on Microelectronics Technology and Devices (SBMicro), p.1-2, 2015.

Martino, M. D. V.; Martino, J. A.; Agopian, P. G. D.; "Analysis of TFET and FinFET differential pairs with active load from $300 \mathrm{~K}$ to $450 \mathrm{~K}$ ", EUROSOI Workshop and International Conference on Ultimate Integration on Silicon (EUROSOI-ULIS), p. 246-249, 2016.

Martino, M. D. V.; Martino, J. A.; Agopian, P. G. D.; Rooyackers, R.; Simoen, E.; Collaert, N.; Claeys, C. "Experimental analysis of differential pairs designed with Line Tunnel FET devices", IEEE SOI-3D-Substhreshold Microelectronics Technology Unified Conference (S3S), 2017.

- Artigo submetido para revista: 
Martino, M. D. V.; Martino, J. A.; Agopian, P. G. D.; Rooyackers, R.; Simoen, E.; Collaert, N.; Claeys, C. "Performance of differential pair circuits designed with Line Tunnel FET devices at different temperatures", IEEE Transactions on Electron Devices, 2017. 


\section{REFERÊNCIAS BIBLIOGRÁFICAS}

(1) CHANG, L.; CHOI, Y. K.; KEDZIERSKI, J.; LINDERT, N.; XUAN, P.; BOKOR, J.; HU, C.; KING, T. J. K.; Moores's law lives on [CMOS transistor], Circuits and Devices Magazine, IEEE, v. 19, n. 1, 2003.

(2) MOORE, G. E.; Cramming more components onto integrated circuits, Electronics Magazine, n. 4, 1965.

(3) HISAMOTO, D.; KAGA, T.; TAKEDA, E.; Impact of the vertical SOI DELTA structure on planar device technology, IEEE Transaction on Electron Devices, v. 38, n.1, p.1419, 1991.

(4) HISAMOTO, D.; et al.; A folded-channel MOSFET for deep-sub-tenth micron era, Technical Digest International Electron Devices Meeting, IEDM, p. 1032, 1998.

(5) CLAEYS, C.; LEONELLI, D.; ROOYACKERS, R.; VANDOOREN, A.; VERHULST, A.; HEYNS, M.; GROESENEKEN, G.; DE GENDT, S.; Fabrication and characterization of $\mathrm{Si}$ and hetero-junction tunnel field effect transistors, G-COE PICE International Symposium, 2009.

(6) NILSSON, P.; Arithmetic reduction of the static power consumption in nanoscale CMOS, IEEE International Conference on Electronics, Circuits and Systems, $p$. 656-659, 2006.

(7) PACKAN, P.; Short Course, IEDM, 2007.

(8) COX, D.; Trends and challenges in device scaling and circuit design, IRPS Tutorials, 2004.

(9) CHEN, H. H.; LIN, J. T.; LU, K. Y.; ENG, Y. C.; LIN, P. H.; A new type of CMOS inverter with Lubistor load and TFET driver for sub-20 nm technology generation, Solid-State and Integrated Circuit Technology, ICSICT, p. 93, 2010.

(10) SEABAUGH, A.; ZHANG, Q.; Low-voltage tunnel transistors for beyond CMOS logic, Proceedings of the IEEE, v. 28, n. 12, p. 2095-2110, 2010.

(11) LEONELLI, D.; VANDOOREN, A.; ROOYACKERS, R.; VERHULST, A. S.; GENDT, S.; HEYNS,M. M.; GROESENEKEN, G.; Performance enhancement in multi gate tunneling field effect transistors by scaling the fin-width, Japanese Journal of Applied Physics, 04DC10, 2010.

(12) WU, J.; MIN, J.; TAUR, Y.; Short-channel effects in tunnel FETs, IEEE Transaction on Electron Devices, v. 62, n. 9, p. 3019-3024, 2015.

(13) GUO, P. F.; YANG, L. T.; YANG, Y.; FAN, L.; HAN, G. Q.; SAMUDRA, G. S.; YEO, Y. C.; Tunneling field-effect transistor: Effect of strain and temperature on tunneling current, IEEE Electron Device Letters, v. 30, p. 981, 2009. 
(14) KRISHNAMOHAN, T.; KIM, D.; RAGHUNATHAN, S.; SARASWAT, K.; Doublegate strained-Ge heterostructure tunneling FET (TFET) with record high drive currents and <60mV/dec subthreshold slope, IEDM Technical Digest, p. 947, 2008.

(15) COLINGE, J. P.; Silicon-on-insulator technology: Materials to VLSI, Kluwer Academics Publishers, 2003.

(16) ANGHEL, C.; VLADIMIRESCU, A.; AMARA, A.; Design of silicon double gate tunnel FETs with ultra low ambipolar currents, EUROSOI 2011 Conference Proceedings, v. 1, p. 73-74, 2011.

(17) WANG., P.-F.; HILSENBECK, K.; NIRSCHL, T.; OSWALD, M.; STEPPER, C.; WEISS, M.; SCHMITT-LANDSIEDEL, D.; HANSCH, W.; Complementary tunneling transistor for low power application, Solid-State Electronics, v. 48, n. 12, p. 2281, 2004.

(18) LEONELLI, D.; VANDOOREN, A.; ROOYACKERS, R.; VERHULST, A. S.; GENDT, S.; HEYNS, M. M.; GROESENEKEN, G.; Drive current improvement in $\mathrm{Si}$ tunnel field effect transistors by means of silicide engineering, Proceedings of the International Conference on SSDM, p. 693-694, 2010.

(19) SCHENK, A.; Rigorous theory and simplified model of the band-to-band tunneling in silicon, Solid-State Electronics, v. 36, p. 19-34, 1993.

(20) ANGHEL, C.; CHILAGANI, P.; AMARA, A.; VLADIMIRESCU, A.; Tunnel field effect transistor with increased ON current, low-k spacer and high-k dielectric, Applied Physics Letters, v. 96, 122104, 2010.

(21) WAN, J.; LE ROYER, C.; ZASLAVSKY, A.; CRISTOLOVEANU, S.; Tunneling FETs on SOI: Supressing of ambipolar leakage, low-frequency noise behavior and modeling, Solid-State Electronics, v. 65-66, p. 226, 2011.

(22) BOUCART, K.; Simulation of double-gate silicon tunnel FETs with a high-k gate dielectric, Dissertação de Doutorado, École Polytechnique Fédérale de Lausanne, 2010.

(23) LEONELLI, D.; VANDOOREN, A.; ROOYACKERS, R.; GENDT, S.; HEYNS, M. M.; GROESENEKEN, G.; Drive current enhancement in p-tunnel FETs by optimization of the process conditions, Solid-State Electronics, v. 65-66, p. 28, 2011.

(24) PATEL, N.; RAMESHA, A.; MAHAPATRA, S.; Drive current boosting of n-type tunnel FET with strained SiGe layer at source, Microelectronics Journal, v. 39, n. 12, p. 1671-1677, 2008.

(25) CLAEYS, C.; LEONELLI, D.; ROOYACKERS, R.; VANDOOREN, A.; VERHULST, A. S.; HEYNS, M. M.; GROESENEKEN, G.; DE GEND, S.; Trends and challenges in $\mathrm{Si}$ and hetero-junction tunnel field effect transistors, ECS Transactions, v. 35, n. 5, p. 15-26, 2011. 
(26) VERHULST, A. S.; VANDENBERGHE, W. G.; MAEX, K.; GROESENEKEN, G.; Boosting the on-current of a n-channel nanowire tunnel field-effect transistor by source material optimization, Journal of Applied Physics, v. 104, n. 6, 4514, 2008.

(27) VERHULST, A. S.; VANDENBERGHE, W. G.; MAEX, K.; DE GENDT, S.; HEYNS, M.; GROESENEKEN, G.; Complementary silicon-based heterostructure tunnel-FETs with high tunnel rates, Electron Device Letters, v. 29, n. 12, p. 1398, 2008.

(28) GUANGLE, G.; LI, R.; VASEN, T.; QI, M.; CHAE, S.; LU, Y.; ZHANG, Q.; ZHU, H.; KUO, J.; KOSEL, T.; WISTEY, M.; FAY, P.; SEABAUGH, A.; XING, H.; Novel gate-recessed vertical InAs/GaSb TFETs with record high lon of $180 \mu \mathrm{A} / \mu \mathrm{m}$ at $\mathrm{V}_{D S}=$ 0.5 V, Proc. IEEE Int. Electron Device Meeting (IEDM), p. 32.6.1-32.6.4, 2012.

(29) FISCHER, I.; BAKIBILLAH, A.; GOLVE, M.; HAHNEL, D.; ISEMANN, H.; KOTTANTHARAYIL, A.; OEHME, M.; SCHULZE, J.; Silicon tunneling field-effect transistors with tunneling in line with the gate field, IEEE Electron Device Letters, $v$. 34, n. 2, p. 154-156, 2013.

(30) MICHIELIS, L.; LATTANZIO, L.; PALESTRI, P.; SELMI, L.; IONESCU, A.; Tunnel-FET architecture with improved performance due to enhanced gate modulation of the tunneling barrier, 69th Device Research Conference, p. 111-112, 2011.

(31) CHANG, H.; ADAMS, B.; CHIEN P.; LI, J.; WOO, J.; Improved subthreshold and output characteristics of source-pocket $\mathrm{Si}$ tunnel FET by the application of laser annealing, IEEE Transaction on Electron Devices, v. 60, p. 92-96, 2013.

(32) MOSELUND, K.; SCHMID, H.; BESSIRE, C.; BJORK, M.; GHONEIM, H.; RIEL, H.; InAs-Si Nanowire Heterojunction Tunnel FETs, IEEE Electron Device Letters, v. 33, n. 10, p. 1453-1455, 2012.

(33) WALKE, A.; VANDOOREN, A.; ROOYACKERS, R; LEONELLI, D.; HIKAVYY, A.; LOO, R.; VERHULST, A.; KAO, K.; HUYGHEBAERT, C.; GROESENEKEN, G.; RAO, V.; BHUWALKA, K.; HEYNS, M.; COLLAERT, N.; THEAN, A.; Fabrication and analysis of a $\mathrm{Si} / \mathrm{Si}_{0.55} \mathrm{Ge}_{0.45}$ heterojunction line tunnel FET, IEEE Transaction on Electron Devices, v. 61, n. 3, p. 701-715, 2014.

(34) MOHATA D.; BIJESH R.; ZHU Y.; HUDAIT M.; SOUTHWICK R.; CHBILI Z.; GUNDLACH, D.; SUEHLE, J.; FASTENAU, J.; LOUBYCHEV, D.; LIU, A.; MAYER, T.; NARAYANAN, V.; DATTA, S.; Demonstration of improved heteroepitaxy, scaled gate stack and reduced interface states enabling heterojunction tunnel FETs with high drive current and high on-off ratio, Symposium on VLSI Technology (VLSIT), p. 53-54, 2012.

(35) HUANG, Q.; HUANG, R.; WU, C.; ZHU, H.; CHEN, C.; WANG, J.; GUO, L.; WANG, R.; YE, L.; WANG, Y.; Comprehensive performance re-assessment of TFETs with a novel design by gate and source engineering from device/circuit perspective, IEEE International Electron Devices Meeting, p. 13.3.1-13.3.4, 2014. 
(36) ALIOTO, M.; ESSENI, D.; Performance and impact of process variations in Tunnel-FET ultra-low voltage digital circuits, 27th Symposium on Integrated Circuits and Systems Design (SBCCl), p. 1-6, 2014.

(37) CHEN, C.; CHEN, Y.; FAN, M.; HU, V.; SU, P.; CHUANG, C.; Impacts of work function variation and line-edge roughness on TFET and FinFET devices and logic circuits, SOI-3D-Subthreshold Microelectronics Technology Unified Conference (S3S), p. 1-2, 2014.

(38) MORRIS, D.; AVCI, U.; RIOS, R.; YOUNG, I.; Design of low voltage tunnelingFET logic circuits considering asymmetric conduction characteristics, IEEE Journal on Emerging and Selected Topics in Circuits and Systems, v. 4, n. 4, p. 380-388, 2014.

(39) SHAIK, S.; KRISHNA, K.; VADDI, R.; Circuit and Architectural Co-design for Reliable Adder Cells with Steep Slope Tunnel Transistors for Energy Efficient Computing, International Conference on VLSI Design (VLSID), p. 306, 2016.

(40) RICHTER, S.; SCHULTE-BRAUCKS, C.; KNOLL, L.; LUONG, G.; SCHAFER, A.; TRELLENKAMP, S.; ZHAO, Q.; MANTL, S.; Experimental demonstration of inverter and NAND operation in p-TFET logic at ultra-low supply voltages down to $V_{D D}=0.15 \mathrm{~V}, 72$ nd Device Research Conference, p. 23-24, 2014.

(41) AVCI, U.; HASAN, S.; NIKONOV, D.; RIOS, R.; KUHN, K.; YOUNG, I.; Understanding the feasibility of scaled III-V TFET for logic by bridging atomistic simulations and experimental results, Symposium on VLSI Technology (VLSIT), p. 183-184, 2012.

(42) SEDIGHI, B.; HU X.; LIU, H.; NAHAS, J.; NIEMIER, M.; Analog Circuit Design Using Tunnel-FETs, IEEE Transactions on Circuits and Systems I: Regular Papers, v. 62, n. 1, p. 39-48, 2015.

(43) KAUSHAL, G.; SUBRAMANYAM, K.; RAO, S.; VIDYA, G.; RAMYA, R.; SHAIK, S.; JEONG, H.; JUNG, S.; VADDI, R.; Design and performance benchmarking of steep-slope tunnel transistors for low voltage digital and analog circuits enabling selfpowered SOCs, International SoC Design Conference (ISOCC), p. 32-33, 2014

(44) BISWAS, A.; LUONG, G.; CHOWDHURY, M.; ALPER, C.; ZHAO, Q.; UDREA, F.; MANTL, S.; IONESCU, A.; Benchmarking of Homojunction Strained-Si NW Tunnel FETs for Basic Analog Functions, IEEE Transactions on Electron Devices, v. 64, n. 4, p. 1441-1448, 2017.

(45) SETTINO, F.; LANUZZA, M.; STRANGIO, S.; CRUPI, F.; PALESTRI, P.; ESSENI, D.; SELMI, L.; Understanding the Potential and Limitations of Tunnel FETs for Low-Voltage Analog/Mixed-Signal Circuits, IEEE Transactions on Electron Devices, v. 64, n. 6, p. 2736-2743, 2017.

(46) Atlas Device Simulation, User's Manual, version 5.16.3.R, Silvaco International, 2011. 
(47) HURKX, G. A. M.; GRAAF, H. C.; KLOSTERMAN, W. J. et. al.; A novel compact model description of reverse biase diode characteristics including tunneling, ESSDERC Proceedings, p. 49-52, 1990.

(48) HURKX, G. A. M.; KLAASSEN, D. B. M.; KNUVERS, M. P. G.; A new recombination model for device simulation including tunneling, IEEE Trans. Electron Devices, v. 39, p. 331-338, 1992.

(49) KLAASSEN, D. B. M.; Physical modeling bipolar device simulation, Simulation of Semiconductor Devices and Processes, v. 4, p. 23-43, 1991.

(50) KANE, E. O.; Zener tunneling in semiconductors, Journal Phys. Chem. Solids, v. 12 , p. $181-188,1959$.

(51) HURKX, G. A. M.; KLAASSEN, D. B. M.; KNUVERS, M. P. G.; O'HARA, F. G.; A new recombination model describing heavy-doping effects and low temperature behaviour, IEDM Technical Digest, p. 307-310, 1989.

(52) SELBERHERR, S.; Analysis and simulation of semiconductor devices, Springer-Verlag, 1984.

(53) YU, Z.; DUTTON, R. W.; SEDAN III - A generalized electronic material device analysis program, Stanford Electronics Laboratory Technical Report, Stanford University, 1985.

(54) KLAASSEN, D. B. M.; SLOTBOOM, J. W.; DE GRAAFF, H. C.; Unified apparent bandgap narrowing in $n$ - and $p$ - type silicon, Solid-State Electronics, v. 35, n. 2, p. 125-129, 1992.

(55) JAEGER, R. C.; GAENSSLER, F. H.; Simulation of impurity freezeout through numerical solution of Poisson's equations and applications to MOS device behavior, IEEE Transaction on Electron Devices, v. 27, p. 914-920, 1980.

(56) VANDOOREN, V.; LEONELLI, D.; ROOYACKERS, R.; ARSTILA, K.; GROESENEKEN, G.; HUYGHEBAERT, C.; Impact of process and geometrical parameters on the electrical characteristics of vertical nanowire silicon n-TFETs, Solid-State Electronics, v. 72, p. 82-87, 2012.

(57) LIU, L.; MOHATA, D.; DATTA, S.; Scaling Length Theory of Double-Gate Interband Tunnel Field-Effect Transistors, IEEE Transactions on Electron Devices, v. 59, n. 4, p. 902-908, 2012.

(58) VANDOOREN, A.; LEONELLI, D.; ROOYACKERS, R.; HIKAVYY, A.; DEVRIENDT, K.; DEMAND, M.; LOO, R.; GROESENEKEN, G.; HUYGHEBAERT, C.; Analysis of trap-assisted tunneling in vertical Si homo-junction and SiGe heterojunction Tunnel-FETs, Solid-State Electronics, v. 83, p. 50-55, 2013.

(59) AGOPIAN, P.; MARTINO, J.; ROOYACKERS, R.; VANDOOREN, A.; SIMOEN, E.; CLAEYS, C.; Experimental Comparison Between Trigate $p$-TFET and p-FinFET Analog Performance as a Function of Temperature, IEEE Trans. Electron Devices, 
v. 60 , p. $2493-2497,2013$.

(60) COLLAERT, N.; DEMAND, M.; FERAIN, I.; LISONI, J.; SINGANAMALLA, R.; ZIMMERMAN, P.; YIM, Y.; SCHRAM, T.; MANNAERT, G.; GOODWIN, M.; HOOKER, J.; NEUILLY, F.; KIM, M.; MEYER, K.; GENDT, S.; BOULLART, W.; JURCZAK, M.; BIESEMANS, S.; Tall triple-Gate devices with $\mathrm{TiN} / \mathrm{HfO}_{2}$ gate stack, Symp. VLSI Tech. Dig., p. 108-109, 2005.

(61) AGOPIAN, P.; MARTINO, M.; SANTOS FILHO, S.; MARTINO, J.; ROOYACKERS, R.; LEONELLI, D.; CLAEYS, C.; Temperature impact on the tunnel FET off-state current components, Solid-State Electron., v. 78, p. 141-146, 2012.

(62) MARTINO, M.; MARTINO, J.; AGOPIAN, P.; Drain induced barrier thinning on TFETs with different source/drain engineering, 29th Symposium on Microelectronics Technology and Devices (SBMicro), p. 1-4, 2014. 


\section{ANEXO 1: ARQUIVO DE SIMULAÇÃO DE UM TRANSISTOR DE TUNELAMENTO INDIVIDUAL}

Arquivo de simulação da geração da estrutura e da caracterização individual de um dispositivo Point TFET do tipo P.

go atlas

mesh space. mult $=1.0$

$\mathrm{x} . \mathrm{mesh} \mathrm{loc}=-0.065 \mathrm{spac}=0.005$

$\mathrm{x} . \mathrm{mesh}$ loc $=-0.060 \mathrm{spac}=0.005$

$\mathrm{x} . \mathrm{mesh} \mathrm{loc}=-0.040 \mathrm{spac}=0.0005$

$\mathrm{x} . \mathrm{mesh} \mathrm{loc}=-0.030 \mathrm{spac}=0.0005$

$\mathrm{x} . \mathrm{mesh} \mathrm{loc}=-0.020 \mathrm{spac}=0.0005$

$\mathrm{x} . \mathrm{mesh} \mathrm{loc}=-0.015$ spac $=0.001$

x.mesh loc $=0 \quad$ spac $=0.002$

x.mesh loc $=0.015$ spac $=0.001$

$\mathrm{x} . \mathrm{mesh} \mathrm{loc}=0.020 \mathrm{spac}=0.0005$

$\mathrm{x}$.mesh loc $=0.030 \mathrm{spac}=0.0005$

$\mathrm{x}$.mesh loc $=0.040 \mathrm{spac}=0.0005$

$\mathrm{x} . \mathrm{mesh} \mathrm{loc}=0.060 \mathrm{spac}=0.005$

$\mathrm{x} . \mathrm{mesh} \mathrm{loc}=0.065 \mathrm{spac}=0.005$

$$
\begin{aligned}
& \text { y.mesh loc }=-0.025 \text { spac }=0.0005 \\
& \text { y.mesh loc }=-0.022 \text { spac }=0.0005 \\
& \text { y.mesh } l o c=-0.020 \text { spac }=0.0005 \\
& \text { y.mesh } \mathrm{loc}=-0.015 \quad \mathrm{spac}=0.001 \\
& \text { y.mesh } \mathrm{loc}=-0.01 \quad \mathrm{spac}=0.001 \\
& \text { y.mesh loc }=0 \quad \text { spac }=0.002 \\
& \text { y. mesh loc }=0.01 \quad \text { spac }=0.001 \\
& \text { y.mesh loc }=0.015 \quad \text { spac }=0.001 \\
& \text { y.mesh loc }=0.020 \text { spac }=0.0005 \\
& \text { y.mesh loc }=0.022 \text { spac }=0.0005 \\
& \text { y.mesh loc }=0.025 \text { spac }=0.0005
\end{aligned}
$$

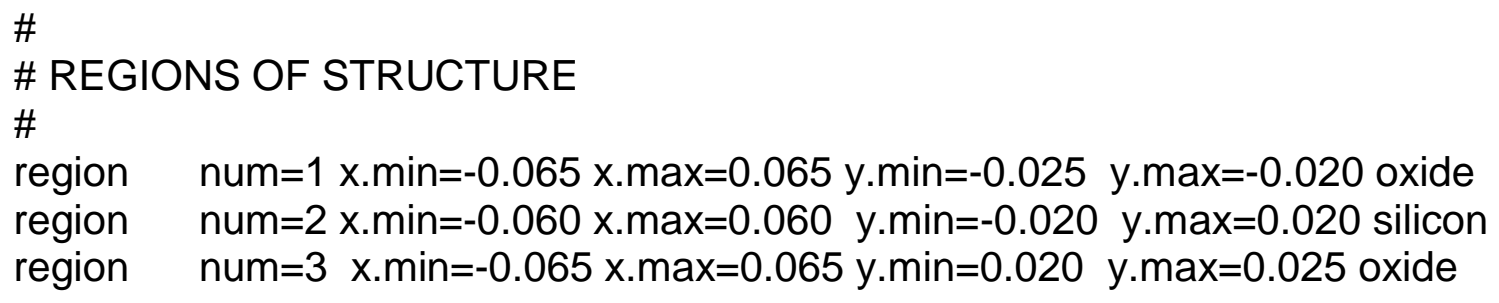




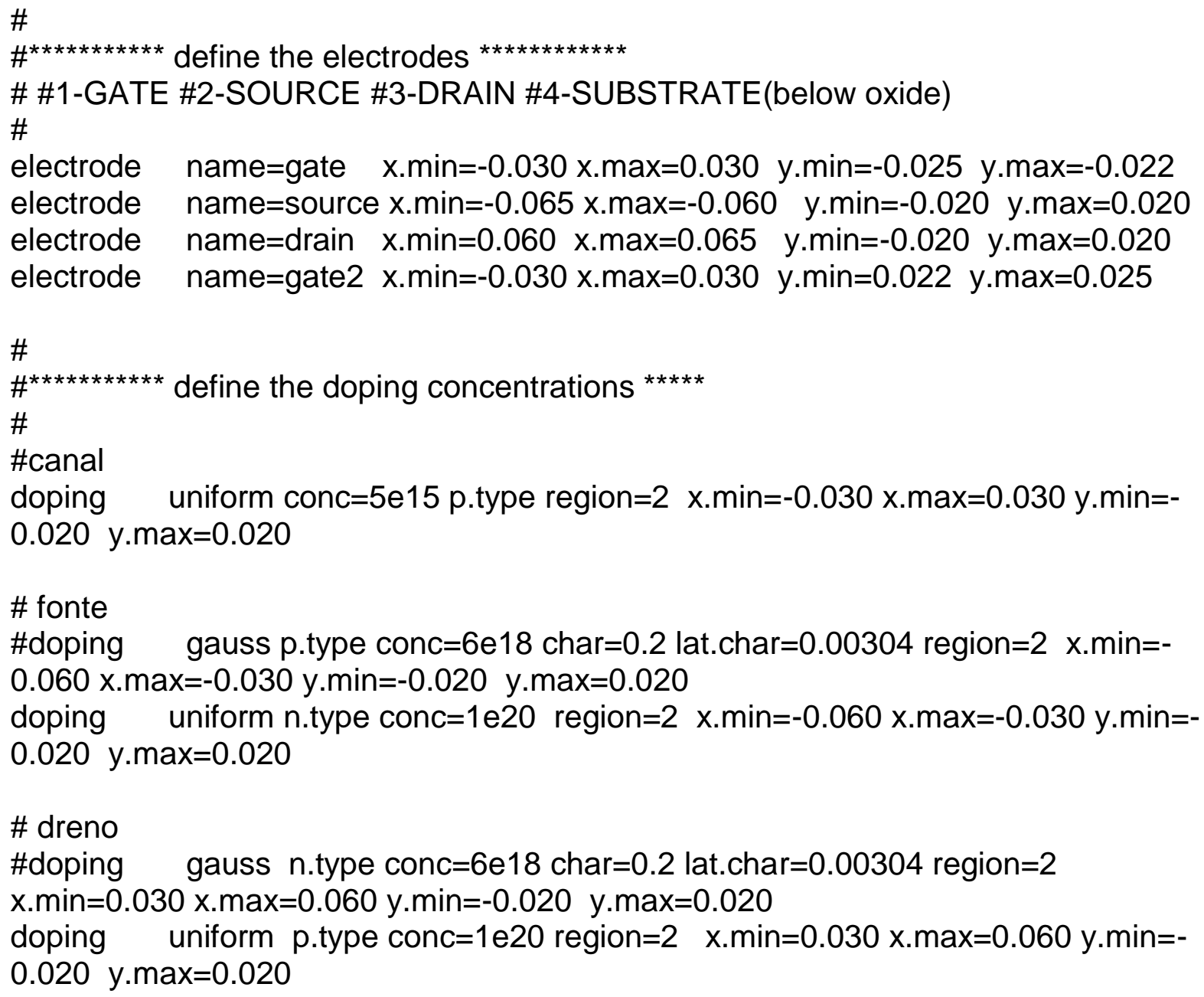

structure outf=L60_tsi40_doped_abrupto_P_self.str

\# set interface charge separately on front and back oxide interfaces

\#interf $\quad \mathrm{qf}=5 \mathrm{e} 10 \mathrm{y} \cdot \mathrm{min}=-0.020 \mathrm{y} \cdot \max =-0.015$

\#interf $\quad \mathrm{qf}=1 \mathrm{e} 11 \mathrm{y} \cdot \mathrm{min}=0.015 \mathrm{y} \cdot \max =0.020$

\# set workfunction of gate

contact name $=$ gate n.poly workfunc $=4.7$

contact name $=$ gate 2 n.poly common $=$ gate workfunc $=4.7$

\# select models

models shi bgn klaaug fldmob print temp $=300$ bbt.kane

\# srh consrh bbt.nonlocal qtunn.dir=1 BBT.A_KANE $=5 \mathrm{E} 20$ mass.tunnel $=0.3$

BBT.B_KANE $=2.3 E 7$ trap.tunnel

\#

solve init 


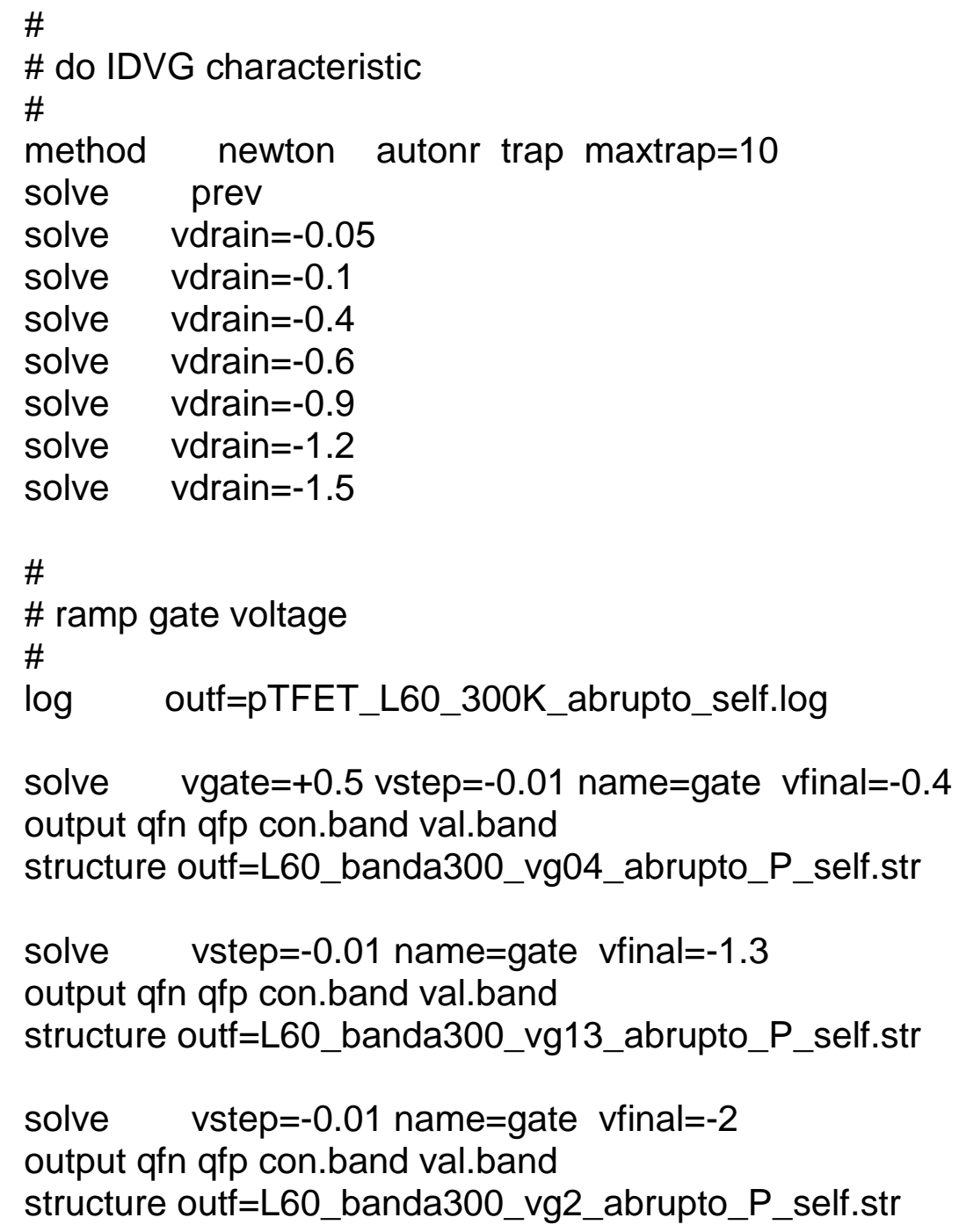

quit 


\section{ANEXO 2: ARQUIVO DE SIMULAÇÃO DE UM CIRCUITO DE ESPELHO DE CORRENTE}

Arquivo de simulação de um circuito de espelho de corrente com dispositivos Point TFET do tipo P, com descasamento entre o comprimento de canal dos transistores $\left(L_{1}=60 \mathrm{~nm}\right.$ e $\left.L_{2}=100 \mathrm{~nm}\right)$ e temperatura alta $(450 \mathrm{~K})$.

go atlas

mesh infile=L60_tsi40_doped_abrupto_P_self.str

mesh infile $=L 100 \_$tsi 40 _doped_abrupto_P_self.str

.Begin

V1 101.0

V2 200

ATFET1 $0=$ drain $0=$ gate $0=$ gate $21=$ source infile=L60_tsi40_doped_abrupto_P_self.str

ATFET2 $2=$ drain $0=$ gate $0=$ gate $21=$ source infile=L100_tsi40_doped_abrupto_P_self.str

*.NUMERIC LTE $=0.1$ TOLDC $=1 . \bar{E}-4$ VCHANGE $=5 . E 7$

.OPTIONS PRINT RELPOT WRITE $=10$

*.NODESET $\vee(1)=2.4 \mathrm{~V}(2)=1.2$

$*$.IC $V(1)=1$

.LOG OUTFILE=L60_L100_T450/Resultado_L60_L100_T450

.SAVE MASTER=L60_L100_T450/Resultado_L60_L100_T450

.DC V1 1.01 .70 .1

.DC V2 $0-0.5-0.05$

. $\mathrm{DC}$ V2 -0.51 .00 .05$

.END

contact DEVICE $=$ ATFET1

contact DEVICE $=$ ATFET1

MODELS DEVICE=ATFET1

IMPACT DEVICE=ATFET1

contact DEVICE $=$ ATFET2

contact DEVICE=ATFET2

MODELS DEVICE $=$ ATFET2

IMPACT DEVICE=ATFET2 name $=$ gate $n$. poly workfunc $=4.7$

name $=$ gate 2 n.poly common $=$ gate workfunc $=4.7$ shi bgn klaaug fldmob print temp $=450$ bbt.kane SELB

name $=$ gate $n$. poly workfunc $=4.7$

name $=$ gate 2 n.poly common $=$ gate workfunc $=4.7$ shi bgn klaaug fldmob print temp $=450$ bbt.kane SELB

QUIT 


\section{ANEXO 3: ARQUIVO DE SIMULAÇÃO DE UM CIRCUITO DE PAR DIFERENCIAL}

Arquivo de simulação de um circuito de par diferencial com carga ativa com dispositivos Point TFET, polarizado em modo diferencial, sob temperatura alta (450K).

go atlas

mesh infile=L60_tsi40_doped_abrupto_P_self.str

mesh infile=L60_tsi40_doped_abrupto_N_self.str

.Begin

V1 100.0

*V2 200.0

*V3 300.0

V4 400.0

V5 500.0

V6 600.0

*V7 700.0

V8 840.0

*V8 840.0 AC 0.1

E9 $9584-1.0$

${ }^{*}$ E6 $6010-1.0$

${ }^{*} \mathrm{R} 1671$

${ }^{*} \mathrm{R} 2201000$

${ }^{*}$ R3 301000

ATFET1 3=drain 3=gate $3=$ gate 2 1=source infile=L60_tsi40_doped_abrupto_P_self.str ATFET2 $2=$ drain $3=$ gate $3=$ gate $\overline{1} 1=$ source infile=L60_tsi40_doped_abrupto_P_self.str

ATFET3 $3=$ drain $9=$ gate $9=$ gate 2 $6=$ source infile=L60_tsi40_doped_abrupto_N_self.str ATFET4 $2=$ drain $8=$ gate $8=$ gate $26=$ source infile=L60_tsi40_doped_abrupto_N_self.str

*.NUMERIC LTE=0.1 TOLDC=1.E-4 VCHANGE=5.E7 .OPTIONS PRINT RELPOT WRITE $=10$

*.NODESET $\mathrm{V}(2)=0 \mathrm{~V}(3)=0 \mathrm{~V}(6)=-1.0$

$* . I C V(6)=-1.7$ 
.LOG OUTFILE=TEMP_TFET/TEMP_TFET_AD_T450

$. \operatorname{IC~} \mathrm{V}(2)=0.0 \mathrm{~V}(3)=0.0$

.DC V1 0.01 .70 .1

.DC V6 $0.0-1.7-0.1$

.DC V8 0.00 .010 .01

.TRAN $1 \mathrm{e}-102 \mathrm{e}-9$

END

contact $\mathrm{DEVICE}=\mathrm{ATFET} 1 \quad$ name $=$ gate $\mathrm{n}$. poly workfunc $=4.7$

contact DEVICE=ATFET1 name=gate2 n. poly common=gate workfunc $=4.7$

MODELS DEVICE=ATFET1 shi bgn klaaug fldmob print temp=450 bbt.kane IMPACT DEVICE=ATFET1 SELB

contact $\mathrm{DEVICE}=\mathrm{ATFET2} \quad$ name $=$ gate n. poly workfunc $=4.7$

contact DEVICE=ATFET2 name $=$ gate2 $n$. poly common $=$ gate workfunc $=4.7$

MODELS DEVICE=ATFET2 shi bgn klaaug fldmob print temp=450 bbt.kane

IMPACT DEVICE=ATFET2 SELB

contact $\mathrm{DEVICE}=\mathrm{ATFET3}$ name $=$ gate $\mathrm{n}$. poly workfunc $=4.7$

contact DEVICE=ATFET3 name=gate2 n.poly common $=$ gate workfunc $=4.7$

MODELS DEVICE=ATFET3 shi bgn klaaug fldmob print temp=450 bbt.kane IMPACT DEVICE=ATFET3 SELB

contact $\mathrm{DEVICE}=\mathrm{ATFET} 4 \quad$ name $=$ gate n. poly workfunc $=4.7$

contact DEVICE=ATFET4 name=gate2 n. poly common=gate workfunc $=4.7$

MODELS DEVICE=ATFET4 shi bgn klaaug fldmob print temp=450 bbt.kane IMPACT DEVICE=ATFET4 SELB

QUIT 